INSTITUTO DE PESQUISAS ENERGÉTICAS E NUCLEARES

Autarquia associada à Universidade de São Paulo

ESTUDO DA INFLUÊNCIA DO COEFICIENTE DE PARTIÇÃO DE METAIS NO SOLO DE FIGUEIRA, PARANÁ, NO CÁLCULO DO RISCO À SAÚDE HUMANA, UTILIZANDO O MODELO C-SOIL

IARA MARIA CARNEIRO DE CAMARGO

Tese apresentada como parte dos requisitos para obtenção do Grau de Doutor em Ciências na Área de Tecnologia Nuclear - Materiais

Orientador:

Dra. Marlene Flues

SÃO PAULO

2005 
Aos meus dois filhos, Felipe e

Pedro, que nasceram no início e fim do doutorado, respectivamente. 


\section{AGRADECIMENTOS}

À Dra. Marlene Flues pela orientação, carinho, compreensão, incentivo e discussão durante toda a tese de doutorado.

Ao Dr. Goro Hiromoto pela orientação, incentivo e discussão.

Ao gerente Nilo Schneider da Companhia Carbonífera Cambuí pela permissão da realização do estudo, apoio financeiro e coleta das amostras de cinza e carvão.

À Fundação de Amparo à Pesquisa do Estado de São Paulo, FAPESP, pelo apoio financeiro.

À Msc. Marycel Cotrin pelas análises instrumentais.

Aos colegas do Centro de Química e Meio Ambiente, CQMA, que de alguma forma contribuíram para o fechamento da tese de doutorado.

Aos colegas da biblioteca Terezine Arantes Ferraz, do Instituto de Pesquisas Energéticas e Nucleares, IPEN, pela aquisição de artigos e ajuda na elaboração das referências bibliográficas.

Aos amigos e familiares pelo apoio e incentivo. 


\title{
ESTUDO DA INFLUÊNCIA DO COEFICIENTE DE PARTIÇÃO DE METAIS NO SOLO DE FIGUEIRA, PARANÁ, NO CÁLCULO DO RISCO À SAÚDE HUMANA, UTILIZANDO O MODELO C-SOIL
}

\author{
lara Maria Carneiro de Camargo
}

\section{RESUMO}

Estudos de coeficiente de partição mostram que o valor de Kp do metal pode variar ordens de grandeza conforme as características físico-químicas do solo. Portanto, o Kp é um parâmetro sensível no modelo de avaliação de risco à saúde humana, e normalmente é um valor nominal adotado por agências ambientais que pode não representar adequadamente o solo em estudo e implicar erros no cálculo do risco. Este trabalho tem como objetivos: avaliar a contaminação do solo adjacente à usina termoelétrica de Figueira por metais tóxicos; determinar o $\mathrm{Kp}$ dos metais $\mathrm{As}, \mathrm{Cd}, \mathrm{Co}, \mathrm{Cr}, \mathrm{Cu}, \mathrm{Mo}, \mathrm{Ni}, \mathrm{Pb}$ e $\mathrm{Zn}$ no solo pela razão entre a concentração do metal obtida por digestão com $\mathrm{HNO}_{3}$ concentrado e a concentração do metal obtida por extração com EDTA 0,05 mol $\mathrm{L}^{-1}\left(\mathrm{Kp}_{\text {EDTA }}\right)$ ou $\mathrm{Ca}\left(\mathrm{NO}_{3}\right)_{2}$ 0,1 $\mathrm{mol} \mathrm{L}^{-1}\left(\mathrm{Kp}_{\left.\mathrm{Ca}\left(\mathrm{NO}_{3}\right)_{2}\right)}\right)$; e avaliar a influência do uso dos diferentes valores de $\mathrm{Kp}$ no modelo de avaliação de risco à saúde humana C-Soil no cálculo do risco. As principais conclusões foram: os metais contaminantes do solo de Figueira foram $\mathrm{As}, \mathrm{Cd}, \mathrm{Mo}, \mathrm{Pb}$ e $\mathrm{Zn}$, e o As foi o elemento mais crítico; tanto o valor de $\mathrm{Kp}_{\mathrm{Ca}\left(\mathrm{NO}_{3}\right)_{2}}$ quanto o de $\mathrm{Kp}_{\text {EDTA }}$ poderiam ser utilizados no cálculo do risco à saúde humana, no caso de Figueira, exceto para o $\mathrm{Pb}$, mas o Kp $\mathrm{p}_{\mathrm{EDTA}}$ seria mais recomendado, por apresentar valores com menor dispersão; os valores nominais de $\mathrm{Kp}_{\mathrm{CS} \text { oil }}$ dos metais poderiam ser utilizados para o cálculo de risco à saúde humana no caso de Figueira, ou seja, não teria necessidade de se determinar valores de $\mathrm{Kp}$ locais ( $\mathrm{Kp}_{\mathrm{EDTA}}$ e $\mathrm{Kp} \mathrm{Ca}_{\left(\mathrm{NO}_{3}\right)_{2}}$ ), exceto para o $\mathrm{Pb}$. 


\title{
STUDY OF THE INFLUENCE OF THE METAL PARTITION COEFFICIENT ON THE HUMAN HEALTH RISK EVALUATION, APPLIED TO FIGUEIRA (PR) SOIL REGION, USING C-SOIL MODEL
}

\author{
lara Maria Carneiro de Camargo
}

\begin{abstract}
Studies of partition coefficient show that $\mathrm{Kp}$ values of metals can vary orders of magnitude according to the soil physical-chemistry characteristics. Therefore, the $\mathrm{Kp}$ is a sensible parameter in human health risk assessment model. In general, a default value is adopted by environmental agencies and often it is not represent suitably the soil studied and can cause errors in the risk calculation. The objectives of this work are: evaluate the heavy metals soil contamination around the Figueira coal-fired power plant; determine the metal $\mathrm{Kp}$ of $\mathrm{As}, \mathrm{Cd}, \mathrm{Co}, \mathrm{Cr}, \mathrm{Cu}$, $\mathrm{Mo}, \mathrm{Ni}, \mathrm{Pb}$ and $\mathrm{Zn}$ in soil by the ratio between the metal concentration obtained by concentrate $\mathrm{HNO}_{3}$ digestion and the metal concentration obtained by extraction with EDTA $0,05 \mathrm{~mol} \mathrm{~L}^{-1}\left(\mathrm{Kp}_{\text {EDTA }}\right)$ or $\mathrm{Ca}\left(\mathrm{NO}_{3}\right)_{2} 0,1 \mathrm{~mol} \mathrm{~L}^{-1}\left(\mathrm{Kp}_{\left.\mathrm{Ca}\left(\mathrm{NO}_{3}\right)_{2}\right)}\right)$; and evaluate the influence of the application of different $\mathrm{Kp}$ values in human health risk assessment $\mathrm{C}$-Soil model in risk calculation. The main conclusions of the present study were: As, $\mathrm{Cd}$, Mo, Pb e Zn were the Figueira soil metal contaminants, being As the pollunt of major human health concern; either $\mathrm{Kp} \mathrm{Pa}_{\mathrm{C}\left(\mathrm{NO}_{3}\right)_{2}}$ or $\mathrm{Kp}_{\text {EDTA }}$ values could be used for human health risk calculation, in Figueira case, except for $\mathrm{Pb}$, and the $\mathrm{Kp}_{\mathrm{EDTA}}$ values were preferably recommended due to the less dispersion of their values; the $\mathrm{Kp}_{\text {CSoil }}$ metals default values could be applied for the human health risk calculation in Figueira case, in other words, it would not have necessity to determine $\mathrm{Kp}$ values of region $\left(\mathrm{Kp}_{\mathrm{EDTA}}\right.$ and $\left.\mathrm{Kp} \mathrm{Ca}_{\left(\mathrm{NO}_{3}\right)_{2}}\right)$, except to $\mathrm{Pb}$.
\end{abstract}




\section{SUMÁRIO}

Página

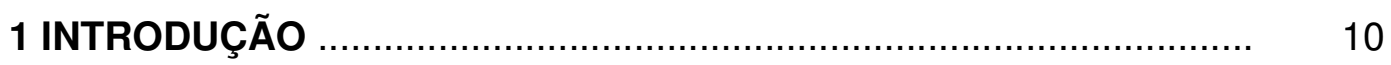

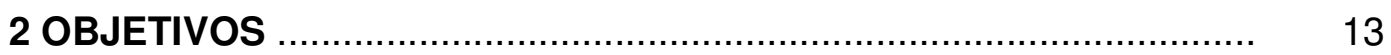

3 REVISÃO DA LITERATURA …..................................................... 14

3.1 Definição e determinação de Kp ................................................... 14

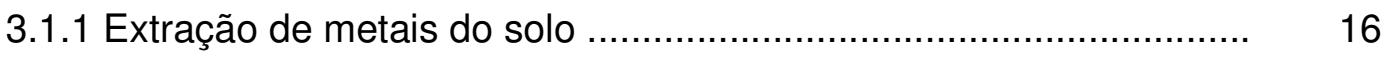

3.2 Variação de $\mathrm{Kp}$ de metais em relação às características físicoquímicas do solo, concentração e forma química do metal e metodologia

3.3 Importância de Kp de metal em solo em avaliação de risco à saúde humana

3.4 Valores de $\mathrm{Kp}$ de metais em solo apresentados por agências ambientais

4 CARACTERÍSTICAS DOS METAIS: MOBILIDADE, TOXICIDADE, CONCENTRAÇÃO EM SOLO NATURAL E TRANSFERÊNCIA SOLO/PLANTA

5 MODELO DE AVALIAÇÃO DE RISCO À SAÚDE HUMANA - CSOIL 57

5.1 Concentração na fase líquida ....................................................... 60

5.2 Acumulação em cultura ................................................................ 61

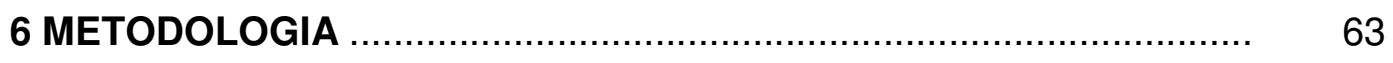

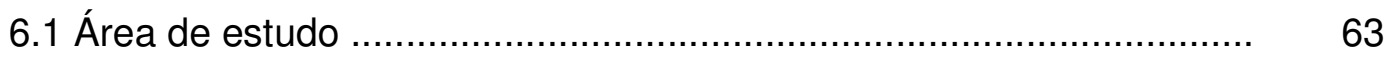

6.2 Coleta das amostras de cinzas e solo ……......................................... 64

6.3 Pré-tratamento das amostras ........................................................... 67

6.4 Caracterização das amostras de solo ............................................. 67

6.5 Preparação das amostras para determinação da concentração dos

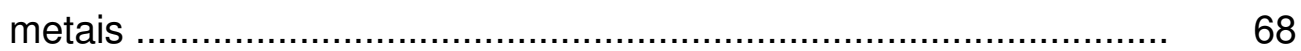

6.5.1 Pastilhas de dupla camada .................................................... 68

6.5.2 Digestão ácida em forno de microondas ……………………........ 69

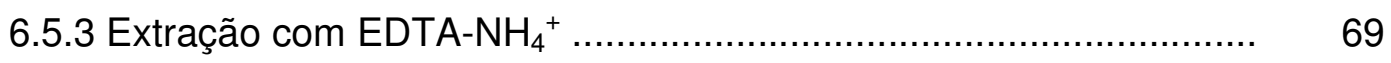

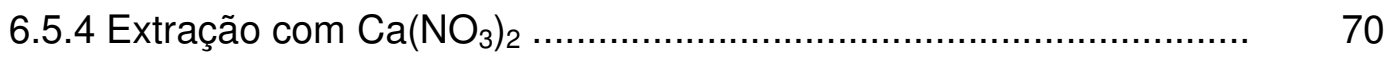


6.6 Determinação da concentração total, parcial, biodisponível e trocável

6.7 Determinação de Kp ............................................................ 71

7 RESULTADOS E DISCUSSÃO …...................................................... 72

7.1 Avaliação da contaminação do solo ................................................ 72

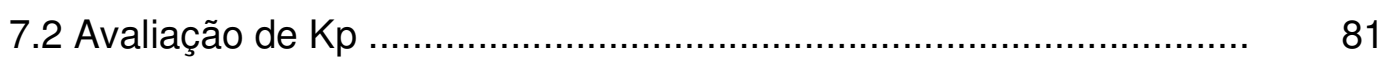

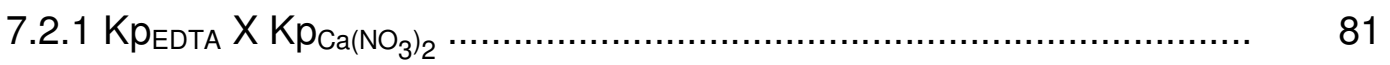

7.2.1.1 Valores de KPEDTA dos pontos 400 e 600 do transect $A$, coletados após a instalação dos filtros na usina

7.2.2 Comparação dos valores de $\mathrm{Kp}$ experimentais com os da literatura

7.2.3 Valores de Kp calculados por modelos de adsorção da literatura .. $\quad 96$

7.2.4 Kp X características do solo ....................................................... 101

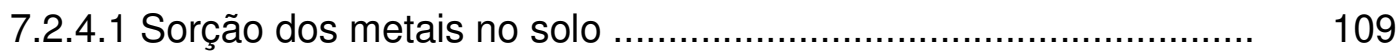

7.2.5 Kp em solo solo contaminado $x$ solo não contaminado e $\mathrm{Kp} \mathrm{x}$ profundidade do solo ............................................................... 111

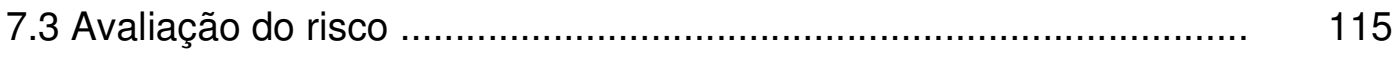

7.3.1 Influência do $\mathrm{Kp}$ no cálculo do risco utilizando o modelo de avaliação de risco à saúde humana, C-Soil .................................. 115

7.3.1.1 Avaliação da contaminação do solo .......................................... 120

7.3.1.2 Necessidade de determinar Kp de Figueira ............................... 120

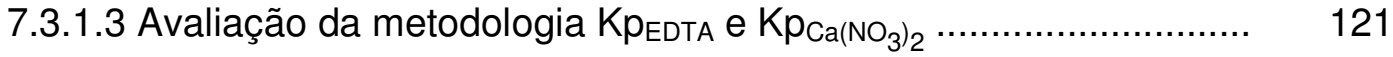

7.3.2 Influência do BCF calculado por $\mathrm{Kp}_{\mathrm{EDTA}}$ e $\mathrm{Kp}_{\mathrm{Ca}\left(\mathrm{NO}_{3}\right)_{2}}$ na determinação do risco ................................................................ 122

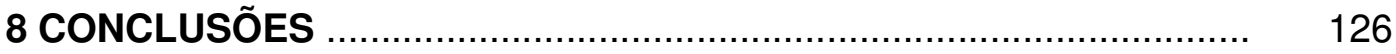

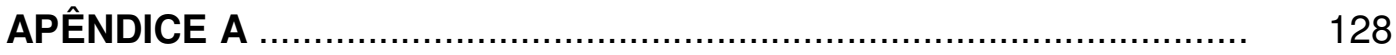

TABELA A1 - Concentração média parcial dos metais $\left(\mathrm{mg} \mathrm{kg}^{-1}\right)$ nas amostras do solo de Figueira coletadas ao redor da usina termoelétrica

TABELA A2 - Concentração parcial dos metais no solo coletado em 2001 depois da instalação dos filtros na usina. 
TABELA A3 - Concentração média biodisponível dos metais ( $\mathrm{mg} \mathrm{L}^{-1}$ ) nas amostras do solo de Figueira coletadas ao redor da usina termoelétrica

132

TABELA A4 - Concentração média trocável dos metais $\left(\mathrm{mg} \mathrm{L}^{-1}\right)$ nas amostras do solo de Figueira coletadas ao redor da usina termoelétrica

TABELA A5 - Valores de KpEDTA dos metais nas amostras do solo de Figueira coletadas ao redor da usina termoelétrica .........

TABELA A6 - Valores de $\mathrm{Kp}_{\mathrm{Ca}\left(\mathrm{NO}_{3}\right)_{2}}$ dos metais nas amostras do solo de Figueira coletadas ao redor da usina termoelétrica .........

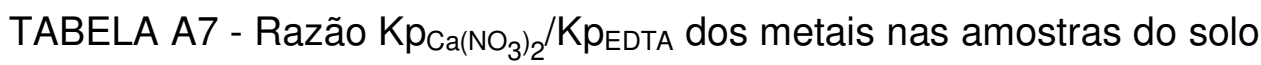
de Figueira coletadas ao redor da usina termoelétrica ...

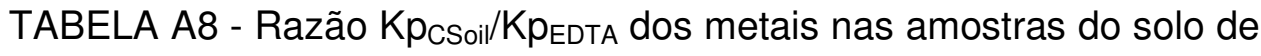
Figueira coletadas ao redor da usina termoelétrica .........

TABELA A9 - Razão $\mathrm{Kp}_{\mathrm{CSoi}} / \mathrm{Kp}_{\mathrm{Ca}\left(\mathrm{NO}_{3}\right)_{2}}$ dos metais nas amostras do solo de Figueira coletadas ao redor da usina termoelétrica ...

TABELA A10 - Valores de Kp EDTA dos metais nas amostras do solo de Figueira coletadas em 2001 depois da instalação dos filtros na usina

TABELA A11 - Características físico-químicas das amostras do solo de Figueira coletadas ao redor da usina termoelétrica ...... 142

TABELA A12 - Concentração total dos metais $\left(\mathrm{mg} \mathrm{kg}^{-1}\right)$ nas amostras do solo de Figueira coletadas ao redor da usina termoelétrica

GLOSSÁRIO 145

REFERÊNCIAS BIBLIOGRÁFICAS 


\section{LISTA DE SIGLAS}

\begin{tabular}{|c|c|}
\hline APMax & área de proteção máxima \\
\hline BCF & fator de bioconcentração \\
\hline CETESB & $\begin{array}{l}\text { Companhia de Tecnologia de Saneamento Ambiental do Estado } \\
\text { de São Paulo }\end{array}$ \\
\hline $\mathrm{CO}$ & carbono orgânico \\
\hline C-Soil & modelo de avaliação de risco à saúde humana \\
\hline CTC & capacidade de troca catiônica \\
\hline DTPA & ácido dietilenotriaminapentacetico \\
\hline EDTA & ácido etilenodiaminatetracetico \\
\hline EMBRAPA & Empresa Brasileira de Agropecuária \\
\hline EPA & Environmental Protection Agengy \\
\hline FRX & fluorescência de raios $X$ \\
\hline IPEN & Instituto de Pesquisas Energéticas e Nucleares \\
\hline $\mathrm{Kd}$ & coeficiente de distribuição \\
\hline Kp & coeficiente de partição \\
\hline $\mathrm{Kp} \mathrm{Ca}_{\left(\mathrm{NO}_{3}\right)_{2}}$ & razão entre a concentração parcial e a concentração trocável \\
\hline Kp Csoil & valor nominal de Kp \\
\hline $\mathrm{Kp}_{\text {EDTA }}$ & razão entre a concentração parcial e a concentração biodisponível \\
\hline LABO & Bund-Länder-Arbeitsgemeinschaft Bodenschutz \\
\hline MO & matéria orgânica \\
\hline RIVM & Instituto Nacional de Saúde Pública e Meio Ambiente \\
\hline USDA & United State Department of Agriculture Soil Staff \\
\hline
\end{tabular}




\section{INTRODUÇÃO}

A contaminação do solo, decorrente da deposição de poluentes atmosféricos, do uso de defensivos agrícolas e fertilizantes e da destinação de resíduos sólidos industriais, urbanos e substâncias tóxicas diversas, tem sido, nas últimas décadas, motivo de preocupação ambiental e visto como um problema de saúde pública.

A avaliação de um solo suspeito de contaminação é importante para se decidir sobre o uso e ocupação deste solo, ou a necessidade de remediação. Para identificar um solo contaminado é necessário comparar as concentrações obtidas das substâncias no diagnóstico do solo com os valores de intervenção estabelecidos (que indicam o nível de contaminação acima do qual existe risco potencial à saúde humana) e sua remediação deve ser executada com base em modelos de avaliação de risco. A avaliação de risco é um trabalho mais complexo e caro que fornece resultados mais exatos por ser específico do local analisado, que deve ser executada no momento da decisão sobre a urgência da remediação.

A tendência mundial é o estabelecimento de uma lista orientadora geral de valores de referência de qualidade que indicam o limite de qualidade para um solo considerado limpo e de valores de intervenção que indicam o limite de contaminação do solo, acima do qual, existe risco potencial à saúde humana (Dias e Casarini, 1996). Os valores de referência são obtidos por meio de análises químicas do solo e os valores de intervenção são obtidos por modelos matemáticos de avaliação de risco, com base na definição de cenários de uso e ocupação do solo, nas diferentes vias de exposição e na quantificação de variáveis toxicológicas.

No Estado de São Paulo, a Companhia de Tecnologia de Saneamento Ambiental do Estado de São Paulo (CETESB) tem a atribuição legal de proteger a qualidade dos solos e controlar a poluição de áreas contaminadas e suspeitas de contaminação. Desde 1996, a CETESB vem desenvolvendo um projeto para estabelecer valores de referência de qualidade e valores de intervenção para 
solos, com base em metodologia adotada na Holanda. Em 2001 foi publicado o "Relatório de estabelecimento de valores orientadores para solos e águas subterrâneas no Estado de São Paulo" (CETESB, 2001).

Os valores de intervenção são calculados por meio de modelos matemáticos de avaliação de risco que, tomando-se por base a concentração inicial do contaminante no solo, simula seu comportamento nos vários compartimentos de um ecossistema. Desta forma pode-se estimar a concentração resultante nas fases líquida e gasosa do solo, na água de abastecimento e água subterrânea, no ar devido a ressuspensão e na vegetação circunzivinha, que representam as respectivas vias de exposição. O risco à saúde humana é calculado pelo ingresso do contaminante no indivíduo pelas diversas vias de exposição, admitindo-se uma probabilidade de incidência de câncer para as substâncias carcinogênicas, ou pela comparação com a ingestão diária tolerável pelo organismo, para as demais substâncias.

A CETESB adotou o modelo de avaliação de risco à saúde humana denominado C-Soil para o estabelecimento de valores de intervenção para solos. O C-Soil é um modelo desenvolvido na Holanda pelo Instituto Nacional de Saúde Pública e Meio Ambiente, RIVM, (Berg, 1994), relativamente simples, equacionado em planilha Excel, bastante conhecido, aceito e seguido por diversos países (CETESB, 2001).

Vários projetos de remediação de solo atualmente em curso nos países mais desenvolvidos, em decorrência de ações poluidoras ocorridas no passado, quando a conscientização pública e governamental relativa à proteção do solo ainda era inócua, atestam a importância do estudo deste meio.

Nesses países a preocupação com a qualidade do solo e criação de programas de estudos governamentais começou depois dos anos 70. No Brasil esta tendência é mais recente e, de certa forma, ainda incipiente.

Em São Paulo, o Centro de Química e Meio Ambiente do IPEN tem desenvolvido um projeto de avaliação de elementos poluidores das cinzas e do solo decorrentes da operação da usina termoelétrica a carvão localizada em Figueira (PR). A utilização do carvão como combustível para operação de uma usina termoelétrica sem controle de emissões é um exemplo de introdução de poluentes atmosféricos $\left(\mathrm{SO}_{2}, \mathrm{NO}_{2}\right.$, cinzas volantes) e resíduos sólidos (cinzas pesadas) que podem provocar contaminação do meio ambiente, inclusive dos 
solos. Globel e Andres (1985), Sato e Sada (1992), Schulze et al. (1997), Mehra et al. (1998), Kapicka et al. (1999), Kaminski e Landsberger (2000) são alguns pesquisadores que avaliaram a contaminação de metais no solo decorrente da combustão de carvão.

Alguns trabalhos relacionados a este projeto de Figueira já têm sido publicados: 1. avaliação da contaminação de radionuclídeos em amostras de carvão, cinzas e solo (Moraes, 2000; Flues, 2002a); 2. avaliação da água de chuva da região de Figueira (Hama, 2001; Flues, 2002b); 3. suscetibilidade do solo em relação à água de chuva (Flues, 2003); 4. apresentação de resultados de concentração de metais no solo de profundidade de 0 a $25 \mathrm{~cm}$, na direção NW (Camargo, 2001).

Para dar continuidade a este projeto aproveitou-se para estimar o risco à saúde humana referente aos metais determinados no solo de Figueira coletado ao redor da usina termoelétrica, utilizando o modelo de avaliação de risco C-Soil, dando ênfase à etapa do modelo que envolve a fase líquida do solo.

O estudo da fase líquida do solo é uma etapa importante dentro do modelo de avaliação de risco à saúde humana porque está diretamente ligado ao transporte do contaminante para as águas subterrâneas e a assimilação pelos vegetais. Dentre os parâmetros relacionados nesta fase, o coeficiente de partição, $\mathrm{Kp}$, pode variar ordens de grandeza conforme as características físico-químicas do solo. A utilização do valor nominal de Kp do modelo pode implicar numa estimativa incorreta da concentração do contaminante na fase líquida do solo e, conseqüentemente, numa estimativa do risco com incerteza também.

Uma avaliação realista da contaminação de águas subterrâneas está, portanto, fortemente relacionada com a exatidão da estimativa da concentração do contaminante na fase líquida do solo. É importante lembrar que a contaminação das águas subterrâneas tende a se tornar, cada vez mais, em um problema crítico de saúde pública devido ao aumento do consumo para abastecimento em decorrência da precariedade dos sistemas de saneamento básico das águas superficiais, de sua quantidade insuficiente e considerando-se os custos elevados dos sistemas de tratamento de água a níveis de potabilidade. Atualmente, mais de $71 \%$ dos municípios do Estado de São Paulo é total ou parcialmente abastecidos por águas subterrâneas (CETESB, 1997). 


\section{OBJETIVOS}

Este trabalho tem por objetivos: (1) avaliar a contaminação do solo adjacente à usina termoelétrica de Figueira por metais tóxicos; (2) determinar o coeficiente de partição (Kp) de metais tóxicos no solo; (3) avaliar a influência do uso de diferentes valores de Kp no modelo C-Soil no cálculo do risco à saúde humana.

Os aspectos mais relevantes de originalidade deste trabalho referem-se à obtenção de diferentes valores de Kp de metais em solos especificamente da região de Figueira, Paraná, e avaliar sua influência no cálculo do risco à saúde humana. 


\section{REVISÃO DA LITERATURA}

\subsection{Definição e determinação de Kp}

$\mathrm{Na}$ literatura encontra-se a definição de coeficiente de partição (Kp) de metais em solos descrita de formas diferentes, mas traduzem o mesmo conceito, isto é, na matriz do solo composta por fase sólida, líquida e gasosa, existe uma relação da concentração do metal que está associada à fase sólida do solo com a concentração do metal que está dissolvido na fase líquida, solução do solo, quando o sistema está em equilíbrio (Legoux, 1992; Hassan, 1996; EPA, 1999a; Sauvé, 2000a; Kretzschmar, 2002; Fontes, 2002). O Kp também é conhecido como coeficiente de distribuição $(\mathrm{Kd})$.

A definição e a determinação de Kp foram questionadas para um grupo de discussão de química do solo da Soil Science Society of America (soilchem@soils.org) e diversas respostas foram obtidas. Considerando este grupo de discussão e trabalhos da literatura (Legoux, 1992; Hassan, 1996; Sauvé, 2000a), neste trabalho define-se Kp como a razão entre a concentração do metal na fase sólida do solo, em $\mathrm{mg} \mathrm{kg}^{-1}$, e a concentração do metal na fase líquida, em $\mathrm{mg} \mathrm{L}^{-1}$. A determinação de Kp pode ser obtida por ensaios de sorção (Anderson, 1988; Buchter, 1989; Lee, 1996; Gao, 1997; Echeverría, 1998; Lee, 1998; EPA, 1999a, Gomes, 2001; Chang, 2001; Kretzschmar, 2002; Guilherme, 2002; Marschner, 2002; Veeresh, 2003a e 2003b; Agbenin, 2004; Lin, 2004; Soares, 2004), ensaios de coluna (EPA, 1999a), razão entre a concentração da fase sólida e a concentração da fase líquida obtida por algum tipo de extração do metal no solo (Janssen, 1997; Römkens, 1998; Sauvé, 2000a; Sauvé, 2000b; McBride, 2000; Carlon, 2000; Zelewski, 2001; Kretzschmar, 2002; Staunton, 2002; Seuntjens, 2002; Krishnamurti, 2002; Degryse, 2003; Sastre, 2004), modelo de equilíbrio geoquímico e de especiação (EPA, 1996), modelo de campo (EPA, 1999a) e modelo de sorção (Otte, 2001). 
O Kp determinado por meio de ensaio de sorção é obtido da inclinação da parte linear da curva da concentração do metal adsorvido no solo $\left(A_{i}\right)$ versus a concentração do metal na solução líquida em equilíbrio $\left(C_{i}\right)$. Esta curva é obtida tomando-se por base uma massa conhecida de solo misturado com um volume de solução de concentração variável conhecida do metal, e agitada durante um período de 24 horas para atingir o equilíbrio. A solução é filtrada e no sobrenadante é determinada a concentração $C_{i}$. A concentração $A_{i}$ é determinada por diferença entre a concentração do metal adicionada no ensaio e a concentração do metal no sobrenadante $\left(\mathrm{C}_{\mathrm{i}}\right)$. O Kp é obtido da parte linear da curva $C_{i}$ versus $A_{i}$, e geralmente isto ocorre apenas para baixas concentrações.

O Kp determinado por ensaio de coluna (EPA, 1999a) é obtido por meio da equação do fator de retardamento $\left(R_{f}\right)$ :

$$
R_{f}=1+\frac{K p \times d}{n}
$$

na qual, $K p$ é o coeficiente de partição, $d$ é a densidade do solo e $n$ é a porosidade total do solo. $O$ ensaio de sorção de coluna consiste da introdução de uma solução de metal de concentração conhecida e de um traçador inerte (não adsorvente) numa coluna de solo de densidade e porosidade conhecidas. A concentração do efluente é monitorada em função do tempo. A velocidade do metal $\left(V_{c}\right)$ e a velocidade do traçador $\left(V_{p}\right)$ são calculadas do comprimento da coluna dividida pelo tempo de residência de cada um. $O$ fator de retardamento $\left(R_{f}\right)$ é a razão entre $V_{p}$ que representa a velocidade linear da água e $V_{c}$. Conhecendo-se $R_{f}$, $d$ e $n$, obtém-se o Kp pela equação 3.1.

O Kp determinado pela razão é calculado entre a concentração do metal na fase sólida, obtida por meio de algum tipo de digestão ácida concentrada (por exemplo: $\mathrm{HNO}_{3} ; \mathrm{HNO}_{3}, \mathrm{HCl}, \mathrm{HClO}_{4} ; \mathrm{HNO}_{3}, \mathrm{H}_{2} \mathrm{SO}_{4} ; \mathrm{HClO}_{4}$ ), e a concentração do metal na fase líquida, obtida da extração da solução do solo por centrifugação ou da extração do metal do solo com água destilada, soluções de sais diluídas (por exemplo: $\mathrm{CaCl}_{2}, \mathrm{NaNO}_{3}, \mathrm{KNO}_{3}, \mathrm{Ca}\left(\mathrm{NO}_{3}\right)_{2}, \mathrm{NH}_{4} \mathrm{NO}_{3}, \mathrm{NH}_{4} \mathrm{OAc}$ ) e soluções de agentes complexantes (EDTA, DTPA). Existe um consenso de que a concentração da fase líquida do solo deve ser obtida por centrifugação da solução do solo ou por extração do metal no solo por uma solução de sal diluída. 
O Kp determinado por modelo de equilíbrio geoquímico e de especiação utiliza um programa de computador (por exemplo, o MINTEQA2) que envolve parâmetros de entrada, tais como, concentração do metal e características do solo (por exemplo: pH, óxido de ferro, matéria orgânica) para estimar o Kp (EPA, 1996).

O Kp determinado por meio de modelo de campo (EPA, 1999a) utiliza um modelo de transporte para água subterrânea que envolve o valor de Kp como um parâmetro ajustável conforme a determinação da concentração do metal nos poços de monitoração. Este modelo de transporte também leva em consideração outros parâmetros ajustáveis, tais como, porosidade do solo, dispersão e taxa de fluxo para estimar o valor de Kp.

O Kp determinado por modelo de sorção é obtido por meio de uma equação de regressão que relaciona $\mathrm{Kp} \mathrm{com} \mathrm{as} \mathrm{características} \mathrm{físico-químicas} \mathrm{do}$ solo, ou que relaciona a concentração do metal na solução do solo com a concentração total do metal e as características do solo (Otte, 2001).

\subsubsection{Extração de metais do solo}

Os metais estão associados ao solo por meio de ligações mais fortes ou mais fracas conforme a fração em que eles se encontram. As frações do solo compreendem:

a) Fração solúvel: metais dissolvidos na solução do solo;

b) Fração trocável: metais fracamente ligados ao solo que podem ser trocados por outro metal de mesma carga ou carga diferente;

c) Fração carbonato: metais ligados aos íons carbonatos do solo por coprecipitação ou por adsorção superficial;

d) Fração orgânica: metais ligados à fase sólida orgânica do solo ou dissolvidos na solução do solo por complexação do metal com a matéria orgânica;

e) Fração óxido: metais ligados aos óxidos de Al, Fe, Mn por co-precipitação e adsorção superficial;

f) Fração residual: metais ligados aos silicatos.

Os metais podem ser extraídos das frações do solo por diversas soluções de extração. Na FIG. 3.1 são apresentadas algumas soluções de 
extração relacionadas com a capacidade de extração dos metais nas frações do solo.

Na FIG. 3.1 não foi apresentada a fração carbonato, mas os metais desta fração podem ser extraídos por acetato de sódio acidificado, ácido acético ou EDTA (Ure, 1996).

A relação entre o metal ligado à fase sólida do solo e o metal dissolvido na fase líquida denomina-se coeficiente de partição (item 3.1). O metal ligado à fase sólida do solo pode ser representado pela concentração do metal obtida por algum tipo de digestão ácida e o metal dissolvido na solução do solo pode ser representado pela concentração do metal obtida por centrifugação da solução do solo, extração do metal do solo com água destilada, soluções diluídas de sais e agentes complexantes (Sauvé, 2000a).

Na TAB. 3.1 apresenta-se um resumo de trabalhos relacionados com a extração de metais no solo. Os autores em negrito correspondem a trabalhos que apresentam além da extração de metais no solo, a determinação de Kp.

A digestão ácida apresentada pelos autores Seuntjens (2002), Krishnamurti e Naidu (2002) e Degryse et al. (2003) para representar a fase sólida do solo (TAB. 3.1) são extrações totais, ou seja, a extração do metal corresponde desde o metal solúvel até a fração residual do solo apresentado na FIG. 3.1. A digestão ácida apresentada pelos autores Janssen et al. (1997), Sauvé et al. (2000b), Carlon et al. (2000), Degryse et al. (2003); Sastre et al. (2004) utilizam $\mathrm{HNO}_{3}$ ou água régia $\left(\mathrm{HNO}_{3}\right.$ e $\mathrm{HCl}$ proporção 3:1) que extrai parcialmente o metal do solo, ou seja, a extração do metal corresponde desde o metal solúvel até a fração de óxidos do solo apresentado na FIG. 3.1. Esta extração parcial representa melhor a fração potencialmente disponível para a solução do solo quando comparada com a extração total. 


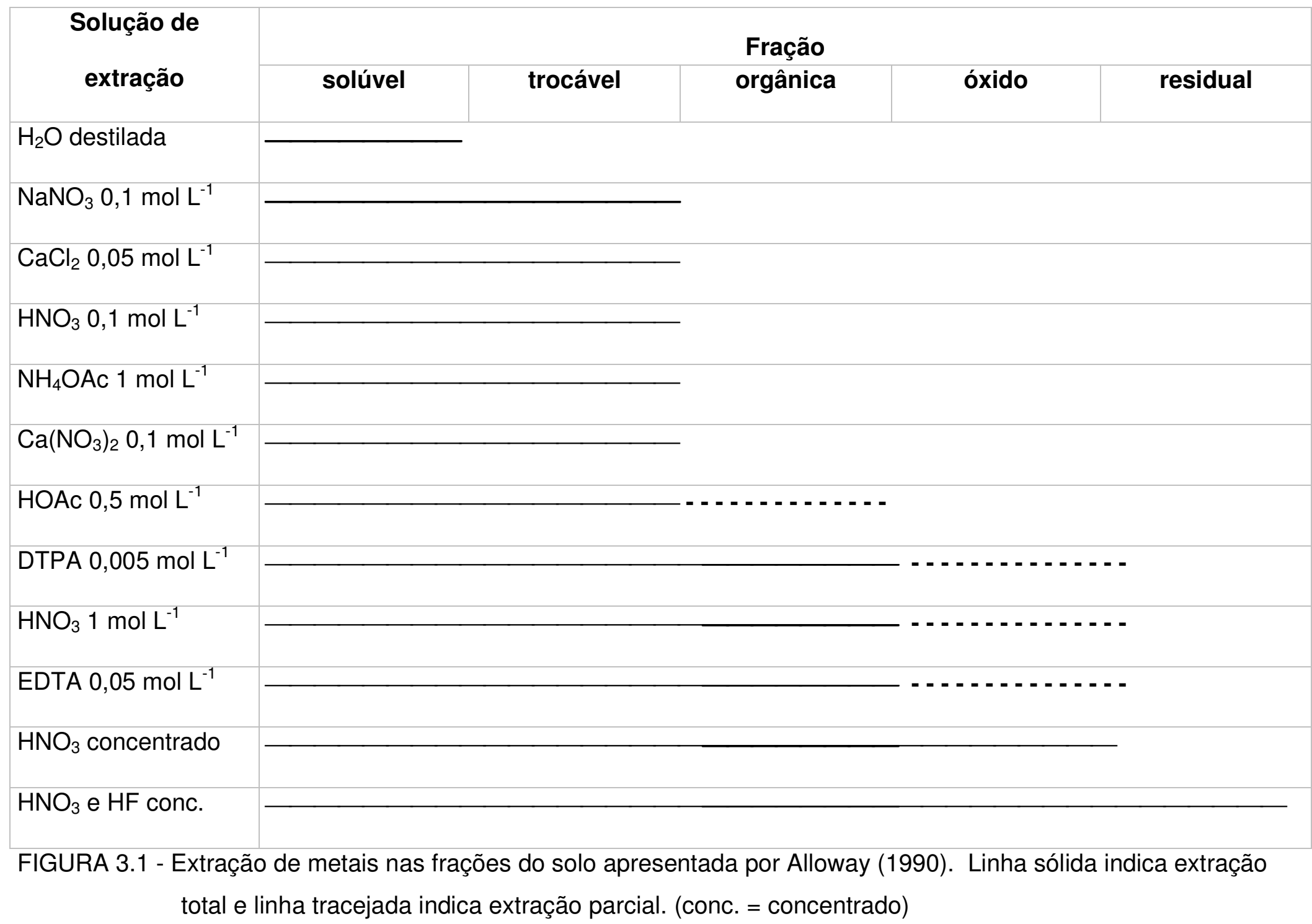


TABELA 3.1 - Literaturas relacionadas com a extração de metais no solo.

\begin{tabular}{|c|c|c|}
\hline METAL & EXTRAÇÃO & LITERATURA \\
\hline \multirow{11}{*}{ Fase sólida do solo } & $\mathrm{HNO}_{3} 0,43 \mathrm{~mol} \mathrm{~L}^{-1}$ & Gooddy, 1995 \\
\hline & $\mathrm{CaCl}_{2} 0,01 \mathrm{~mol} \mathrm{~L}^{-1}$ & Gooddy, 1995; Dumat, 2001 \\
\hline & $\mathrm{Ba}\left(\mathrm{NO}_{3}\right)_{2} 0,1 \mathrm{~mol} \mathrm{~L}^{-1}$ & Gooddy, 1995 \\
\hline & $\mathrm{HNO}_{3}, \mathrm{H}_{2} \mathrm{SO}_{4}$ e $\mathrm{HClO}_{4}$, concentrados & Römkens, 1998 \\
\hline & $\mathrm{HNO}_{3}$ concentrado & Sauvé, 2000b; Janssen, 1997; EPA, 2003 \\
\hline & $\mathrm{HNO}_{3}$ e $\mathrm{HClO}_{4}$, concentrados & McBride, 2000 \\
\hline & Água régia $\left(\mathrm{HNO}_{3}+\mathrm{HCl}\right.$, proporção 3:1) & Carlon, 2000; Degryse, 2003; Sastre, 2004; LABO, 2004 \\
\hline & $\mathrm{Na}_{4} \mathrm{P}_{2} \mathrm{O}_{7} 0,1 \mathrm{~mol} \mathrm{~L}^{-1}$ & Dumat, 2001 \\
\hline & Citrato de sódio + acetato $0,2 \mathrm{~mol} \mathrm{~L}^{-1}$ & Dumat, 2001 \\
\hline & $\mathrm{HF} \mathrm{e} \mathrm{HClO}_{4}$ concentrados & Krishnamurti, 2002 \\
\hline & $\mathrm{HNO}_{3}, \mathrm{HCl}, \mathrm{H}_{3} \mathrm{PO}_{4}, \mathrm{HBF}_{4}$ e HF concentrados & Seuntjens, 2002; Degryse, 2003 \\
\hline \multirow{11}{*}{ Fase líquida do solo } & $\mathrm{NaNO}_{3} \quad 0,1 \mathrm{~mol} \mathrm{~L}^{-1}$ & Gupta, 1993; Lebourg, 1998 \\
\hline & $\mathrm{NH}_{4} \mathrm{NO}_{3} \quad 0,1$ ou $1 \mathrm{~mol} \mathrm{~L}^{-1}$ & Gupta, 1993; Lebourg, 1998; Sager, 1999 \\
\hline & $\mathrm{KNO}_{3} \quad 0,01$ ou $0,1 \mathrm{~mol} \mathrm{~L}^{-1}$ & Gupta, 1993; Sauvé, 2000b; McBride, 2000; \\
\hline & $\mathrm{CaCl}_{2} \quad 0,01,0,05$ ou $0,1 \mathrm{~mol} \mathrm{~L}^{-1}$ & $\begin{array}{l}\text { Gupta, 1993; Janssen, 1997; Lebourg, 1998; Wasay, 1998; } \\
\text { Carlon, 2000; Degryse, 2003 }\end{array}$ \\
\hline & $\mathrm{Ca}\left(\mathrm{NO}_{3}\right)_{2} \quad 0,05,0,1$ ou $0,5 \mathrm{~mol} \mathrm{~L}^{-1}$ & Mench, 1994; Weissenhorn, 1995; Basta, 2000; Conder, 2001 \\
\hline & Centrifugação da solução do solo & $\begin{array}{l}\text { Gooddy, 1995; Janssen, 1997; Römkens, 1998; Dumat, } \\
\text { 2001; Seuntjens, 2002; Degryse, } 2003\end{array}$ \\
\hline & EDTA $0,05 \mathrm{~mol} \mathrm{~L}^{-1}$ & Ure, 1996; McGrath, 1996 \\
\hline & DTPA $0,005 \mathrm{~mol} \mathrm{~L}^{-1}$ & McGrath, 1996 \\
\hline & HOAc 0,1 ou $0,43 \mathrm{~mol} \mathrm{~L}^{-1}$ & Ure, 1996; Carlon, 2000 \\
\hline & $\mathrm{NH}_{4} \mathrm{OAc} \quad 0,5$ ou $1 \mathrm{~mol} \mathrm{~L}^{-1}$ & Ure, 1996; Sager, 1999 \\
\hline & água destilada & Krishnamurti, 2002; Degryse, 2003; Sastre, 2004 \\
\hline
\end{tabular}

Autores em negrito correspondem a literaturas que apresentam a determinação do Kp. 
A Agência de Proteção Ambiental dos Estados Unidos (EPA) utiliza o $\mathrm{HNO}_{3}$ (método 3051) para extração do metal no solo (EPA, 2003). Este método tem sido utilizado internacionalmente para avaliar contaminação de solo, e se mostrou mais adequado que outros métodos, segundo Quináglia (2001). Ao passo que a agência ambiental Bund-Länder-Arbeitsgemeinschaft Bodenschutz da Alemanha utiliza a digestão ácida concentrada de água régia (LABO, 2004).

Entre as soluções de extração de metais no solo que poderiam representar a fase líquida do solo (TAB. 3.1), as soluções diluídas de sais extraem metais das frações solúvel e trocável (FIG. 3.1), ao passo que soluções de agentes complexantes (EDTA, DTPA) extraem metais destas frações mais fração orgânica e parcialmente da fração dos óxidos.

Na TAB. 3.1 observa-se que a centrifugação da solução do solo e a solução de extração $\mathrm{CaCl}_{2}$ são os métodos mais utilizados para representar o metal dissolvido na fase líquida do solo.

$\mathrm{O} \mathrm{CaCl}_{2}$ interage como um trocador de cátions $\left(\mathrm{Ca}^{2+}\right.$ da solução substitui o metal ligado ao solo) ou como um complexante $\left(\mathrm{Cl}^{-}\right.$pode formar complexos com Cd e Zn (Gupta, 1993; Ure, 1996; Lebourg, 1998)). O cátion amônio da solução de $\mathrm{NH}_{4} \mathrm{NO}_{3}$ ou $\mathrm{NH}_{4} \mathrm{OAc}$ também pode interagir como um complexante de Cu, Ni e Cr (Gupta, 1993) e de Cd, Cu e Zn (Lebourg, 1998), além de poder alterar o pH do meio (Gupta, 1993; Ure, 1996). Por outro lado, o ânion nitrato não complexa com metais e também não altera $\mathrm{opH}$ do meio. Soluções de sais que possuem um ânion ou um cátion que formam complexos com os metais, tendem a extrair maior quantidade de metal do solo que soluções de sais que interagem apenas como um trocador de cátions.

Gupta e Aten (1993) apresentaram que $\mathrm{CaCl}_{2} 0,05 \mathrm{~mol} \mathrm{~L}^{-1}$ extraiu maior quantidade de $\mathrm{Cd}$ e $\mathrm{Zn}$ em treze solos quando comparado com outras soluções de extração $\left(\mathrm{KNO}_{3} \quad 0,1 \mathrm{~mol} \mathrm{~L}^{-1}, \mathrm{NaNO}_{3} \quad 0,1 \mathrm{~mol} \mathrm{~L}^{-1}\right.$ e $\left.\mathrm{NH}_{4} \mathrm{NO}_{3} \quad 0,1 \mathrm{~mol} \mathrm{~L}^{-1}\right)$. Os autores comentam que este fato pode ter ocorrido por causa da formação de cloro-complexos. Wasay et al (1998) observaram que $\mathrm{BaCl}_{2}$ 0,1 $\mathrm{mol} \mathrm{L}^{-1}$ extraiu maior quantidade de $\mathrm{Zn}$ e $\mathrm{Cd}$ do solo que as soluções $\mathrm{CaCl}_{2} 0,1 \mathrm{~mol} \mathrm{~L}^{-1}$ e $\mathrm{MgCl}_{2}$ $0,1 \mathrm{~mol} \mathrm{~L}^{-1}$. Este fato foi explicado pelo tamanho iônico do $\mathrm{Ba}^{+2}$ ser maior que os demais cátions, $\mathrm{Ca}^{+2} \mathrm{e} \mathrm{Mg}^{+2}$, constituintes das soluções utilizadas. Lebourg et al (1998) verificaram que $\mathrm{NH}_{4} \mathrm{NO}_{3} 1 \mathrm{~mol} \mathrm{~L}^{-1}$ extraiu maior quantidade de $\mathrm{Cd}, \mathrm{Cu}, \mathrm{Pb}$ 
e $\mathrm{Zn}$ quando comparado com as soluções de $\mathrm{CaCl}_{2}$ 0,01 mol L-1 e $\mathrm{NaNO}_{3}$ 0,1 mol $\mathrm{L}^{-1}$.

Existem alguns procedimentos europeus para extração de metais em solos para avaliação de biodisponibilidade para plantas que são padronizados. Estes procedimentos utilizam soluções, tais como, $\mathrm{NaNO}_{3} 0,1 \mathrm{~mol} \mathrm{~L}^{-1}$ (Suíça), $\mathrm{NH}_{4} \mathrm{NO}_{3} 1 \mathrm{~mol} \mathrm{~L}^{-1}$ (Alemanha) e na Holanda tem sido recomendado a utilização de $\mathrm{CaCl}_{2}$ 0,01 $\mathrm{mol} \mathrm{L}^{-1}$ (Lebourg, 1998).

As soluções de EDTA e de sais têm se mostrado um reagente de extração de metais em solos que se correlacionam com os metais absorvidos pelas plantas (Ure, 1996; Singh, 1996; Hooda, 1997; Brun, 2001). O EDTA apresenta correlação do metal encontrado no solo com o metal absorvido pelas plantas para mais tipos de plantas e metais que outras soluções, tais como, $\mathrm{NH}_{4} \mathrm{NO}_{3}$ e $\mathrm{CaCl}_{2}$ (Ure, 1996; Hooda, 1997). Mas como a capacidade de extração da solução para predizer a biodisponibilidade para as plantas depende da espécie da planta, do metal, da concentração do metal, da solução extratora e das características do solo (Hooda, 1997), outras soluções, tais como, $\mathrm{NH}_{4} \mathrm{NO}_{3}$, $\mathrm{CaCl}_{2}, \mathrm{Ca}\left(\mathrm{NO}_{3}\right)_{2}$, DTPA, podem ser mais adequadas dependendo da planta ou do metal (Hooda, 1997; Brun, 1998; Pinamonti, 1999; Basta, 2000).

Sager (1999) participou de uma análise interlaboratório referente à extração dos metais $\mathrm{Cd}, \mathrm{Cr}, \mathrm{Cu}, \mathrm{Ni}, \mathrm{Pb}$ e $\mathrm{Zn}$ em três amostras de solo, utilizando soluções de extração $\mathrm{NH}_{4} \mathrm{NO}_{3} 1 \mathrm{~mol} \mathrm{~L}^{-1}, \mathrm{NH}_{4} \mathrm{OAc} 1 \mathrm{~mol} \mathrm{~L}^{-1}$ e LiCl $1 \mathrm{~mol} \mathrm{~L}^{-1}$. Estas soluções extraíram pequena quantidade dos metais no solo e apresentaram um coeficiente de variação mais alto quando comparado com a solução de EDTA $0,05 \mathrm{~mol} \mathrm{~L}^{-1}$ ou HOAc $0,1 \mathrm{~mol} \mathrm{~L}^{-1}$. O autor recomenda a utilização de ácidos ou agentes complexantes (EDTA, DTPA) para lixiviação de metais no solo.

\subsection{Variação de $\mathrm{Kp}$ de metais em relação às características físico-químicas do solo, concentração e forma química do metal e metodologia}

O Kp de um metal no solo depende da sua concentração e forma química do metal (Hassan, 1996; Sauvé, 2000a; Sauvé, 2000b) e das características do solo, $\mathrm{pH}$, argila, óxidos, matéria orgânica (MO), capacidade de troca catiônica (CTC) e potencial de oxi-redução (Buchter, 1989; Hassan, 1996; Janssen, 1997; Sauvé, 2000a; Sauvé, 2000b; Otte, 2001). 
$\mathrm{O}$ pH do solo é o principal parâmetro que controla a troca iônica, dissolução e precipitação, redução e oxidação, adsorção e complexação dos metais (McBride, 1994). Desta forma pH está relacionado com a distribuição do metal nas fases sólida e líquida do solo. De um modo geral, os metais tendem ter um Kp mais baixo para solos ácidos, ou seja, os metais tendem estar mais disponíveis para a água subterrânea ou para as plantas.

Na TAB 3.2 são apresentados valores de Kp de metais e características físico-químicas dos solos correspondentes das literaturas citadas. A nomenclatura citada, $\mathrm{Kp}$ ou $\mathrm{Kd}$, que diz respeito a mesma relação, será mantida conforme o autor considerado. Observa-se que as características do solo variam bastante, os valores de Kp também variam bastante, os métodos de determinação do Kp são diferentes e os únicos trabalhos que relacionaram diretamente $\mathrm{Kp}$ com as características do solo por meio de regressão múltipla foram Anderson e Christensen (1988), Janssen et al. (1997), Römkens e Salomons (1998), Sauvé et al. (2000a, b), Seuntjens (2002), Krishnamurti e Naidu (2002) e Soares (2004). É difícil comparar dados tão distintos e $\mathrm{Kp}$ do metal que está relacionado com vários parâmetros simultaneamente. No entanto, estes autores apresentaram informações interessantes.

Anderson e Christensen (1988) analisaram a distribuição dos metais $\mathrm{Cd}$, Co, Ni e Zn tomando-se por base o Kd em 38 amostras de solos provenientes de 13 áreas de agricultura. As amostras de solo foram coletadas em 3 profundidades: 0 a $20 \mathrm{~cm}, 20$ a $50 \mathrm{~cm}$ e 50 a $100 \mathrm{~cm}$. O Kd foi determinado por meio de ensaio de adsorção e relacionado com as características do solo (TAB 3.2). Estes autores concluíram que $\mathrm{pH}$ é o fator de maior influência na distribuição de $\mathrm{Cd}$, Co, $\mathrm{Ni}$ e $\mathrm{Zn}$ nos solos estudados, sendo o $\mathrm{Zn}$ o mais sensível à flutuação de $\mathrm{pH}$. A argila e os óxidos de $\mathrm{Fe}$ e $\mathrm{Mn}$ também foram significativos na distribuição destes metais no solo, mas em menor proporção que o pH. Entre os coeficientes de distribuição dos metais, o Co apresentou ser o mais móvel, ou seja, o de menor Kd. 
TABELA 3.2 - Trabalhos da literatura que relacionam Kp de metais com as características físico-químicas do solo e a concentração do metal, e metodologia adotada para determinação de Kp.

\begin{tabular}{|c|c|c|c|c|c|}
\hline $\begin{array}{c}\text { Características do } \\
\text { solo }\end{array}$ & $\begin{array}{l}\text { [Metal] } \text { mg kglo }^{-1} \\
\text { mg kg }^{-1}\end{array}$ & $\mathbf{N}$ & $\mathrm{Kp}\left(\mathrm{L} \mathrm{kg}^{-1}\right)$ & Metodologia & Literatura \\
\hline $\begin{array}{l}\mathrm{pH}_{\mathrm{H}_{2} \mathrm{O}}: 6,2(4,6- \\
7,3)\end{array}$ & $\begin{array}{l}\text { Cd } \\
\text { n.m. }\end{array}$ & 38 & $\begin{array}{l}\log \mathrm{Kd}=0,545 \mathrm{pH}+0,178 \log \mathrm{Mn}_{\mathrm{Ox}}+0,564 \log \mathrm{CO}- \\
0,422 \log \mathrm{Al}_{\mathrm{Ox}}-1,216 \\
\left(\mathrm{R}^{2}=0,926\right)\end{array}$ & $\begin{array}{l}\text { Ensaio de } \\
\text { adsorção }\end{array}$ & $\begin{array}{c}\text { Anderson e } \\
\text { Christensen, } \\
1988\end{array}$ \\
\hline \multicolumn{6}{|l|}{$\begin{array}{l}\text { CTC }\left(\text { meq } \mathrm{kg}^{-1}\right) \text { : } \\
112(24-288)\end{array}$} \\
\hline $\begin{array}{l}\text { CO }\left(\mathrm{mg} \mathrm{C} \mathrm{g}^{-1}\right): 9,7 \\
(1,7-23,0)\end{array}$ & Co & & $\begin{array}{l}\log K d= \\
0,571 \mathrm{pH}+0,312 \log \mathrm{Mn}_{\mathrm{Ox}}+0,327 \log \mathrm{CO}+0,502 \text { logArgila- }\end{array}$ & & \\
\hline \multicolumn{6}{|l|}{$\begin{array}{l}\text { Argila (\%): } 13,0 \\
(2,4-41,4)\end{array}$} \\
\hline $\begin{array}{l}\mathrm{Al}_{\mathrm{Ox}}\left(\mathrm{mg} \mathrm{g}^{-1}\right): 1,72 \\
(0,4-4,1)\end{array}$ & Ni & & $\begin{array}{l}\log K d= \\
0,529 p H+0,291 \log \mathrm{Mn}_{\mathrm{Ox}}+0,399 \log \mathrm{CO}+0,597 \log \mathrm{Fe}_{\mathrm{D}}-1,764 \\
\left(\mathrm{R}^{2}=0,895\right)\end{array}$ & & \\
\hline \multicolumn{6}{|l|}{$\begin{array}{l}\mathrm{Fe}_{\text {ox }}\left(\mathrm{mg} \mathrm{g}^{-1}\right): 2,6 \\
(0,5-9,5)\end{array}$} \\
\hline $\begin{array}{l}\operatorname{Mn}_{\mathrm{Ox}}\left(\mathrm{mg} \mathrm{g}^{-1}\right): 0,19 \\
(<0,01-0,59)\end{array}$ & $\mathrm{Zn}$ & & $\begin{array}{l}\log K d=0,792 p H+0,194 \log M_{O x}+0,822 \log C T C-3,361 \\
\left(R^{2}=0,958\right)\end{array}$ & & \\
\hline \multicolumn{6}{|l|}{$\begin{array}{l}\mathrm{Fe}_{\mathrm{D}}\left(\mathrm{mg} \mathrm{g}^{-1}\right): 7,0 \\
(2,2-17,8)\end{array}$} \\
\hline $\begin{array}{l}\mathrm{pH}_{\mathrm{H}_{2} \mathrm{O}}: 5,9(3,9- \\
8,5)\end{array}$ & $\begin{array}{c}\text { As } \\
\text { n.m. }\end{array}$ & 11 & $47(8,5-1500)$ & $\begin{array}{l}\text { Isoterma de } \\
\text { adsorção de } \\
\text { Freundlich }\end{array}$ & $\begin{array}{l}\text { Buchter et al., } \\
1989\end{array}$ \\
\hline $\begin{array}{l}\text { CTC }\left(\mathrm{cmol}_{\mathrm{c}} \mathrm{kg}^{-1}\right): \\
14,5(0,8-48,1)\end{array}$ & $\begin{array}{c}\text { Cd } \\
\text { n.m. }\end{array}$ & & $60(5,5-755)$ & & \\
\hline $\begin{array}{l}\text { CO }(\%): 2,9(0,2- \\
11,6)\end{array}$ & $\begin{array}{l}\text { Co } \\
\text { n.m. }\end{array}$ & & $38(2,5-363)$ & & \\
\hline $\begin{array}{l}\text { Argila (\%): } 15,2 \\
(0,5-54,7)\end{array}$ & $\begin{array}{l}\mathrm{Cr} \\
\text { n.m. }\end{array}$ & & $11(3,4-63)$ & & \\
\hline $\begin{array}{l}\mathbf{A l}_{\text {Ox }}(\%): 0,79 \\
(0,016-3,67)\end{array}$ & $\begin{array}{c}\mathrm{Cu} \\
\text { n.m. }\end{array}$ & & $317(54-6353)$ & & \\
\hline
\end{tabular}


TABELA 3.2 - Trabalhos da literatura que relacionam Kp de metais com as características físico-químicas do solo e a concentração do metal, e metodologia adotada para determinação de Kp.

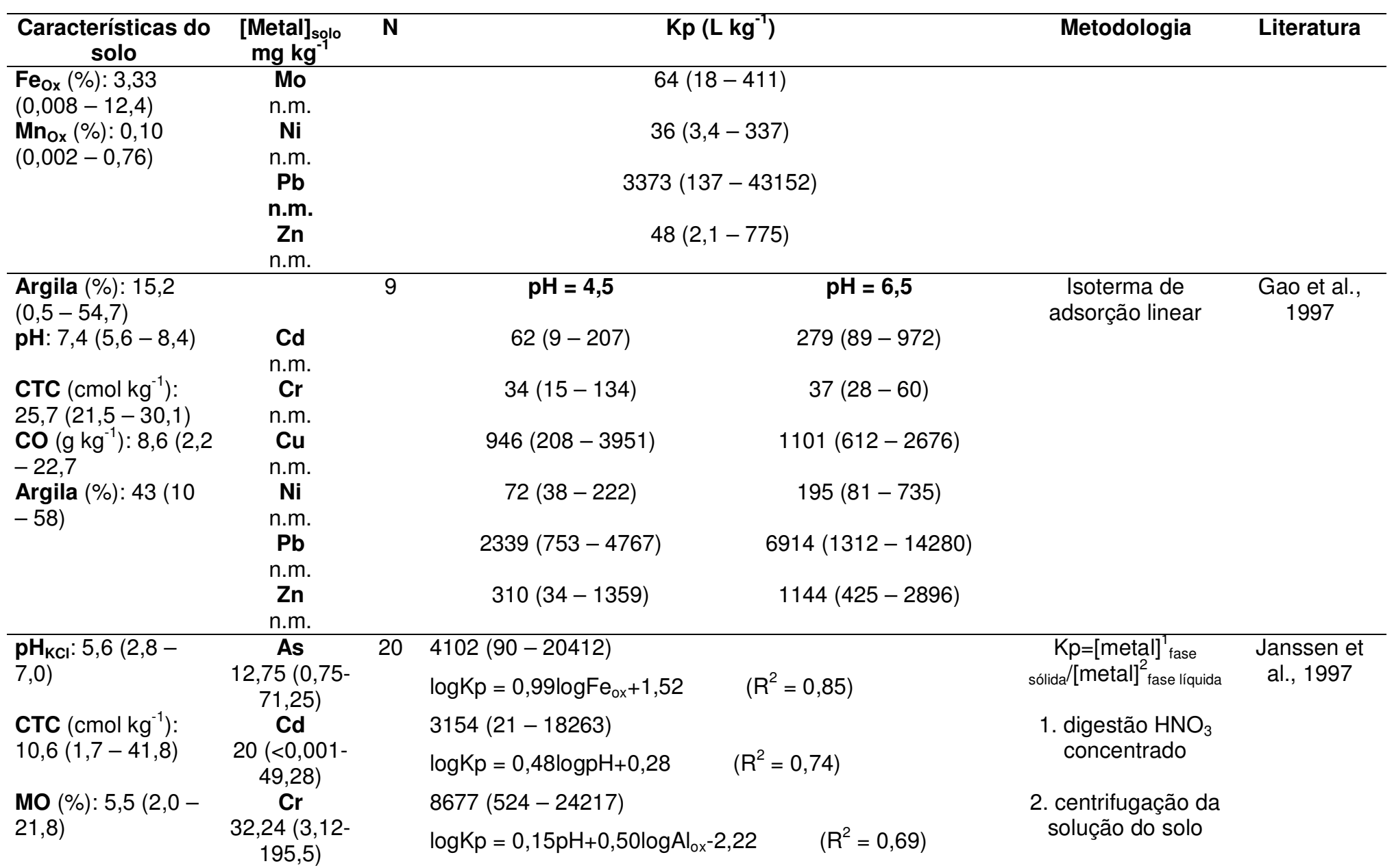


TABELA 3.2 - Trabalhos da literatura que relacionam Kp de metais com as características físico-químicas do solo e a concentração do metal, e metodologia adotada para determinação de Kp.

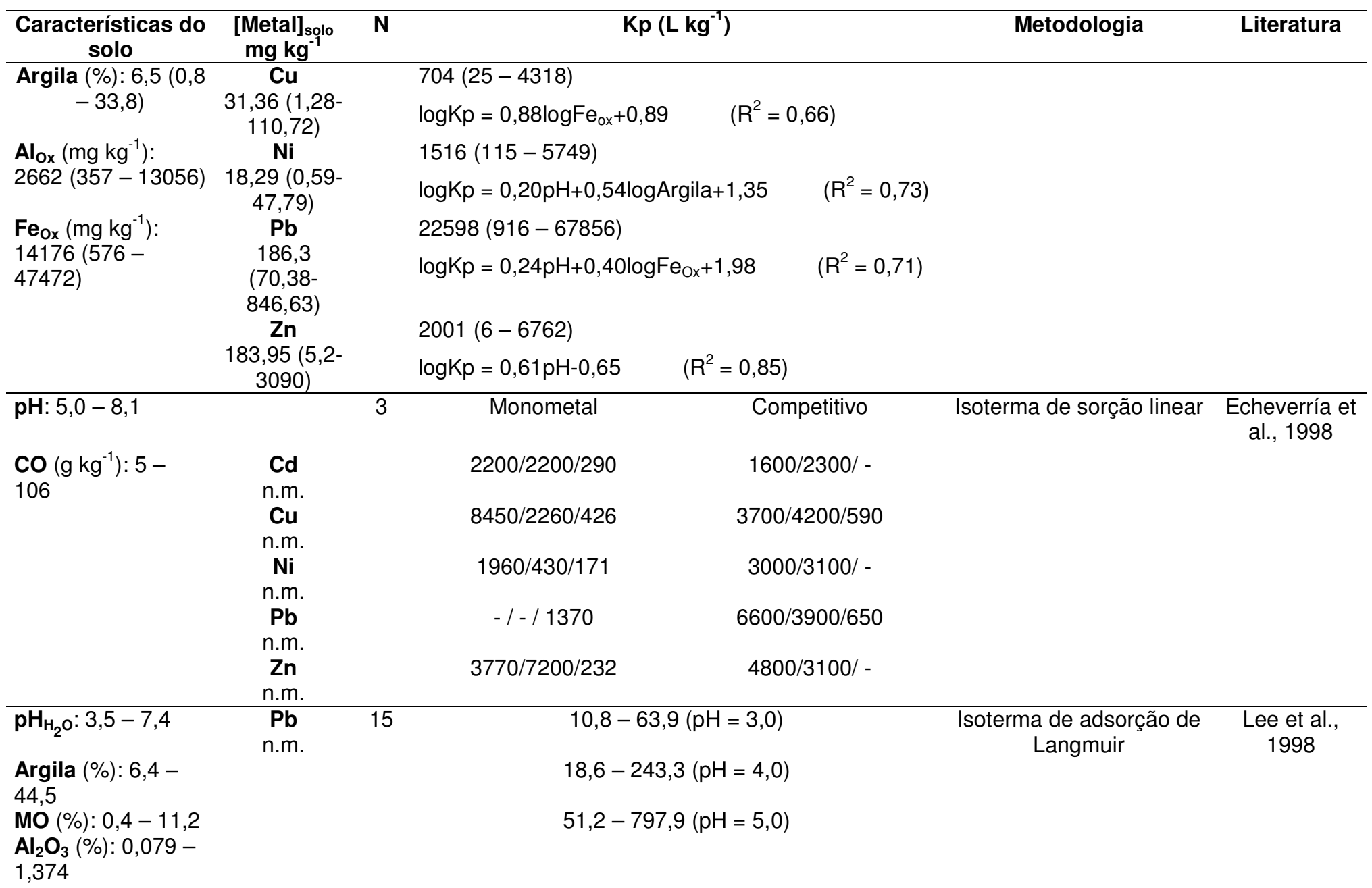


TABELA 3.2 - Trabalhos da literatura que relacionam Kp de metais com as características físico-químicas do solo e a concentração do metal, e metodologia adotada para determinação de Kp.

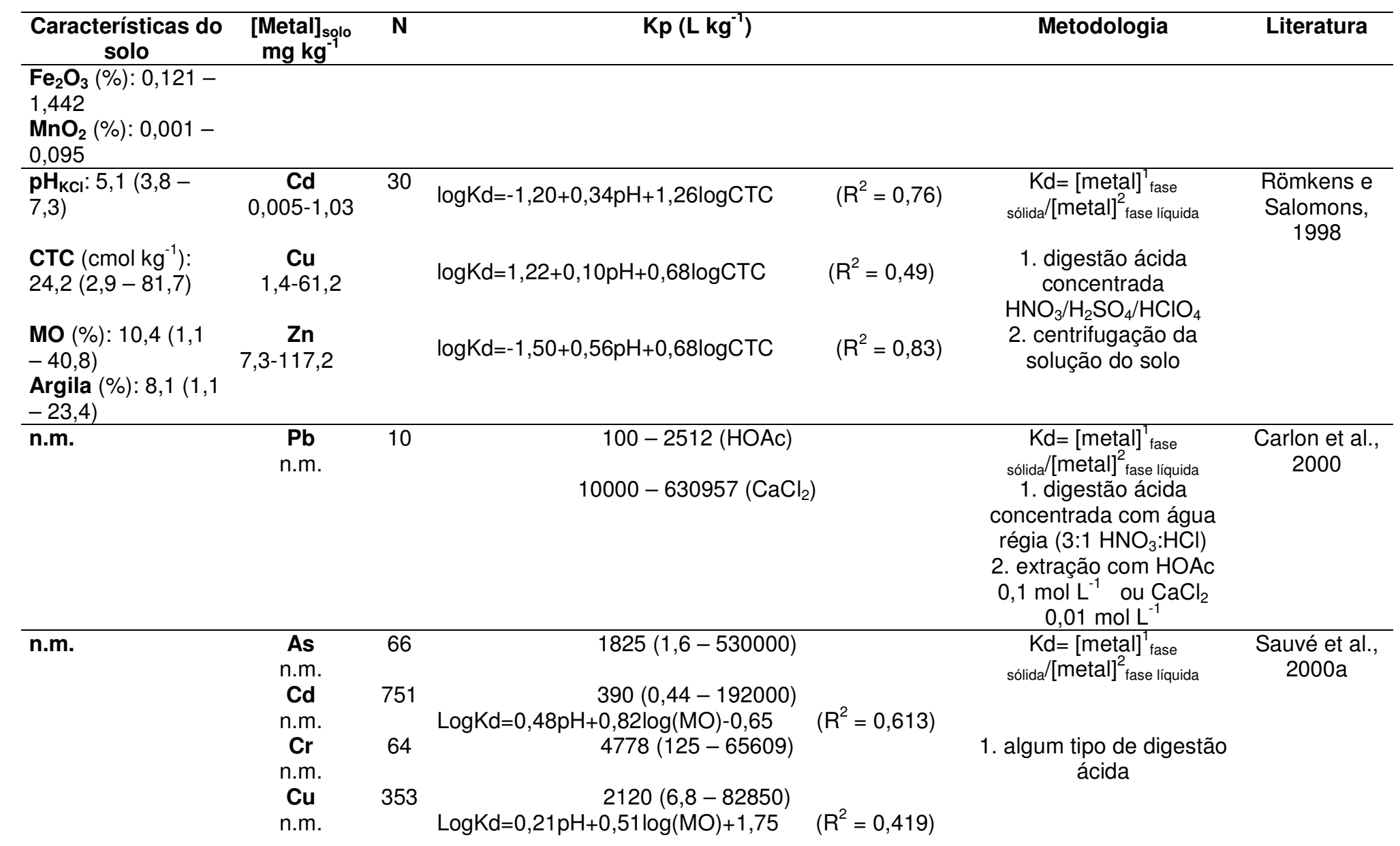


TABELA 3.2 - Trabalhos da literatura que relacionam Kp de metais com as características físico-químicas do solo e a concentração do metal, e metodologia adotada para determinação de Kp.

\begin{tabular}{|c|c|c|c|c|c|}
\hline $\begin{array}{c}\text { Características do } \\
\text { solo }\end{array}$ & $\begin{array}{l}{[\text { Metal }]_{\text {solo }}} \\
\mathrm{mg} \mathrm{kg}^{-1}\end{array}$ & $\mathbf{N}$ & $\mathrm{Kp}\left(\mathrm{L} \mathrm{kg}^{-1}\right)$ & Metodologia & Literatura \\
\hline & Mo & 4 & $38(14-52)$ & $\begin{array}{l}\text { 2. extração da solução do } \\
\text { solo por centrifugação, } \\
\text { extração do metal do solo } \\
\text { com água destilada, } \\
\text { soluções diluídas de sais } \\
\text { e agentes complexantes }\end{array}$ & \\
\hline & $\begin{array}{l}\mathrm{Ni} \\
\mathrm{n} \cdot \mathrm{m} . \\
\mathrm{Pb} \\
\mathrm{n} . \mathrm{m} . \\
\mathrm{Zn} \\
\text { n.m. }\end{array}$ & $\begin{array}{r}69 \\
204 \\
298\end{array}$ & 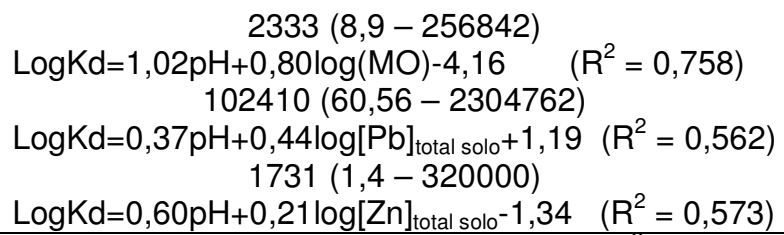 & & \\
\hline $\begin{array}{l}\mathrm{pH}_{\mathrm{KNO}_{3}}: 6,3(3,5- \\
8,5) \\
\mathrm{MO}\left(\mathrm{g} \mathrm{C} \mathrm{kg}^{-1}\right): 32,6 \\
(8,0-107,6)\end{array}$ & $\begin{array}{c}\text { Cd } \\
6,7(0,1- \\
38,1)\end{array}$ & 64 & $\log K d=-0,23+0,54 \mathrm{pH}-0,23 \log [\mathrm{Cd}]_{\text {solo }} \quad\left(R^{2}=0,763\right)$ & $\begin{array}{l}\mathrm{Kd}=[\mathrm{Cdl}]_{\text {fase sólida }}^{1} /[\mathrm{Cd}]_{\text {fase }}^{2} \\
\text { líquida } \\
\text { 1. digestão } \mathrm{HNO}_{3} \\
\text { concentrada } \\
\text { 2. extração } \mathrm{KNO}_{3} 0,01 \\
\text { mol L }^{-1}\end{array}$ & $\begin{array}{l}\text { Sauvé et al., } \\
2000 b\end{array}$ \\
\hline $\begin{array}{l}\text { pH: } 6,74(6,23- \\
7,46) \\
\text { CO }(\%): 6,9(5,3- \\
9,0)\end{array}$ & $\begin{array}{c}\mathbf{C d} \\
2,52-34,0 \\
\mathbf{C u} \\
73,2-676 \\
\mathbf{N i} \\
23,0-551 \\
\mathbf{Z n} \\
351-4280\end{array}$ & 3 & $\begin{array}{c}9333 \\
7781(3467-11749) \\
11749 \\
10471\end{array}$ & $\begin{array}{c}\mathrm{Kd}=[\text { metal }]^{1} \text { fase } \\
\text { sólida } /[\text { metal }]^{2} \text { fase líquida } \\
\text { 1. digestão ácida } \\
\text { concentrada } \mathrm{HNO}_{3} / \mathrm{HClO}_{4} \\
\text { 2. extração } \mathrm{KNO}_{3} 0,01 \\
\text { mol L-1 }\end{array}$ & $\begin{array}{l}\text { McBride et } \\
\text { al., } 2000\end{array}$ \\
\hline $\begin{array}{l}\mathbf{p H}_{\mathrm{H}_{2} \mathrm{O}}: 3,8-4,9 \\
\text { CTC }\left(\mathrm{cmol} \mathrm{kg}^{-1}\right): \\
6,54-8,57\end{array}$ & $\begin{array}{c}\text { Cd } \\
\text { n.m. } \\
\text { Cu } \\
\text { n.m. }\end{array}$ & 1 & $\begin{array}{l}2,71-5,04 \\
5,33-9,63\end{array}$ & $\begin{array}{l}\text { Isoterma de sorção linear, } \\
\text { de Langmuir e Freundlich }\end{array}$ & $\begin{array}{c}\text { Chang et al. } \\
2001\end{array}$ \\
\hline
\end{tabular}


TABELA 3.2 - Trabalhos da literatura que relacionam Kp de metais com as características físico-químicas do solo e a concentração do metal, e metodologia adotada para determinação de Kp.

\begin{tabular}{|c|c|c|c|c|c|}
\hline $\begin{array}{c}\text { Características do } \\
\text { solo }\end{array}$ & $\begin{array}{l}{[\text { Metal] }} \\
\text { mg kglo }^{-1}\end{array}$ & $\mathbf{N}$ & $\mathrm{Kp}\left(\mathrm{L} \mathrm{kg}^{-1}\right)$ & Metodologia & Literatura \\
\hline \multicolumn{6}{|l|}{$\begin{array}{l}\text { MO }\left(\mathrm{g} \mathrm{kg}^{-1}\right): 1,06- \\
2,09 \\
\text { Argila }\left(\mathrm{g} \mathrm{kg}^{-1}\right): 387 \\
-419\end{array}$} \\
\hline n.m. & $\begin{array}{l}\text { Cu } \\
10-39 \\
\text { Zn } \\
15-84\end{array}$ & 1 & 22000 & $\begin{array}{c}\mathrm{Kd}=[\text { metal }]^{1} \text { fase } \\
\text { sólida } /[\text { metal }]^{2} \text { fase líquida } \\
\text { 1. n.m. } \\
\text { 2. extração da água } \\
\text { subterrânea }\end{array}$ & $\begin{array}{l}\text { Zelewski et } \\
\text { al., } 2001\end{array}$ \\
\hline pH: $3,4-4,5$ & $\begin{array}{c}\mathbf{C d} \\
<0,25- \\
3,60\end{array}$ & 14 & $\begin{array}{r}11,5-41,3 \\
\log K d=0,40+0,76 \log \mathrm{CO}+0,24 \mathrm{pH}\end{array}$ & $\begin{array}{c}\mathrm{Kd}=[\text { metal }]_{\text {fase }}^{1} \\
\text { sólida } /[\text { metal }]_{\text {fase líquida }}\end{array}$ & $\begin{array}{l}\text { Seuntjens, } \\
2002\end{array}$ \\
\hline $\begin{array}{l}\text { CTC }\left(\mathrm{mmol} \mathrm{kg}^{-1}\right): \\
6,2-96,7 \\
\text { CO (\%): } 0,08- \\
8,17\end{array}$ & & & & $\begin{array}{c}\text { 1. digestão ácida } \\
\text { concentrada } \\
\mathrm{HNO}_{3} / \mathrm{HCl} / \mathrm{H}_{3} \mathrm{PO}_{4} / \mathrm{HBF}_{4} / \\
\mathrm{HF} \\
\text { 2. centrifugação da } \\
\text { solução do solo }\end{array}$ & \\
\hline $\mathrm{pH}_{\mathrm{H}_{2} \mathrm{O}}: 4,9-8,4$ & $\begin{array}{l}\text { Cu } \\
9,7(3,8- \\
18,8)\end{array}$ & 11 & $\begin{array}{l}71,1(13,9-152,4) \\
\text { logKdCu=-0,10+0,13pH+1,14log[Cu- } \\
\text { complexofúlvico]-1,28log[Cu-trocável }]\end{array}$ & $\begin{array}{c}\mathrm{Kd}=[\text { metal }]_{\text {fase }}^{1} \\
\text { sólida } /[\text { metal }]_{\text {fase líquida }}\end{array}$ & $\begin{array}{l}\text { Krishnamurti } \\
\text { e Naidu, } \\
2002\end{array}$ \\
\hline $\begin{array}{l}\text { Argila (\%): 3,2 - } \\
29,7\end{array}$ & $\begin{array}{c}\mathbf{Z n} \\
20,9(8,1- \\
32,2)\end{array}$ & & $\begin{array}{c}99,6(22,6-266,3) \\
\log K d Z n=0,50+0,14 p H+0,8 \log _{\text {complexofúlvico }}\left(R^{2}=0,81\right)\end{array}$ & $\begin{array}{c}\text { 1. digestão ácida } \\
\text { concentrada } \mathrm{HF} / \mathrm{HClO}_{4}\end{array}$ & \\
\hline $\begin{array}{l}\text { CO (\%): } 0,35- \\
2,38\end{array}$ & & & & 2. extração $\mathrm{H}_{2} \mathrm{O}$ destilada & \\
\hline $\begin{array}{l}\text { pH: } 6,02(3,49- \\
7,53)\end{array}$ & $\begin{array}{c}\mathbf{C d} \\
16,0(0,5- \\
118)\end{array}$ & 74 & $5-5800$ & $\begin{array}{c}\mathrm{Kd}=[\text { metal }]^{1} \text { fase } \\
\text { sólida } /[\text { metal }]_{\text {fase líquida }}\end{array}$ & $\begin{array}{l}\text { Degryse et } \\
\text { al., } 2003\end{array}$ \\
\hline
\end{tabular}


TABELA 3.2 - Trabalhos da literatura que relacionam Kp de metais com as características físico-químicas do solo e a concentração do metal, e metodologia adotada para determinação de Kp.

\begin{tabular}{|c|c|c|c|c|c|c|}
\hline $\begin{array}{c}\text { Características do } \\
\text { solo }\end{array}$ & $\begin{array}{l}{[\text { Metal }]_{\text {solo }}} \\
\text { mg kg }^{-1}\end{array}$ & $\mathbf{N}$ & \multicolumn{2}{|c|}{$\mathrm{Kp}\left(\mathrm{L} \mathrm{kg}^{-1}\right)$} & Metodologia & Literatura \\
\hline $\begin{array}{l}\text { CTC }\left(\mathrm{cmol}_{\mathrm{C}} \mathrm{kg}^{-1}\right) \text { : } \\
9,7(0,3-24,9) \\
\text { CO }(\%): 6,0(0,9- \\
38)\end{array}$ & $\begin{array}{c}\mathrm{Zn} \\
1274(53- \\
34100)\end{array}$ & & \multicolumn{2}{|c|}{$3-8900$} & $\begin{array}{c}\text { 1. digestão ácida } \\
\text { concentrada } \\
\mathrm{HNO}_{3} / \mathrm{HCl} / \mathrm{H}_{3} \mathrm{PO}_{4} / \mathrm{HBF}_{4} / \\
\mathrm{HF} \text { ou água régia }(3: 1 \\
\left.\mathrm{HNO}_{3}: \mathrm{HCl}\right) \\
\text { 2. centrifugação da } \\
\text { solução do solo ou } \\
\text { extração com } \mathrm{H}_{2} \mathrm{O} \\
\text { destilada }\end{array}$ & \\
\hline pH: $5,2-8,6$ & & 3 & Solo controle & Solo tratado & $\begin{array}{c}\text { Isoterma de adsorção } \\
\text { linear }\end{array}$ & $\begin{array}{l}\text { Veeresh et } \\
\text { al., 2003a }\end{array}$ \\
\hline $\begin{array}{l}\text { CTC }\left(\mathrm{cmol} \mathrm{kg}^{-1}\right): \\
5,5-32,7\end{array}$ & $\begin{array}{c}\text { Cd } \\
0,75-0,93 \\
\text { ppm }\end{array}$ & & $1,9-162$ & $1,9-171$ & & \\
\hline $\begin{array}{l}\text { CO }\left(\mathrm{g} \mathrm{kg}^{-1}\right): 5,1- \\
6,2\end{array}$ & $\begin{array}{c}\text { Cu } \\
10,67- \\
25,41 \text { ppm }\end{array}$ & & $10,9-275$ & $13,3-286$ & & \\
\hline $\begin{array}{l}\text { Argila (\%): 14,8- } \\
63,2\end{array}$ & $\begin{array}{c}\mathbf{N i} \\
6,45- \\
29,03 \text { ppm }\end{array}$ & & $2,4-165$ & $2,7-166$ & & \\
\hline Al (\%): 2,98-6,49 & $\begin{array}{c}\mathbf{P b} \\
11,52- \\
18,82 \text { ppm }\end{array}$ & & $64-389$ & $113-610$ & & \\
\hline Fe (\%): 1,27 - 3,64 & $\begin{array}{c}\text { Zn } \\
18,89- \\
54,85 \text { ppm }\end{array}$ & & $6,3-171$ & $8,0-193$ & & \\
\hline $\begin{array}{l}\text { Ácido fúlvico } \\
\left(\mathrm{g} \mathrm{kg}^{-1}\right): 1,7-1,9 \\
\text { Ácido húmico } \\
\left(\mathrm{g} \mathrm{kg}^{-1}\right): 0,5-0,8\end{array}$ & & & & & & \\
\hline
\end{tabular}


TABELA 3.2 - Trabalhos da literatura que relacionam Kp de metais com as características físico-químicas do solo e a concentração do metal, e metodologia adotada para determinação de Kp.

\begin{tabular}{|c|c|c|c|c|c|}
\hline $\begin{array}{c}\text { Características do } \\
\text { solo }\end{array}$ & $\begin{array}{l}{[\text { Metal }]_{\text {solo }}} \\
\mathrm{mg} \mathrm{kg}^{-1}\end{array}$ & $\mathbf{N}$ & $\mathrm{Kp}\left(\mathrm{L} \mathrm{kg}^{-1}\right)$ & Metodologia & Literatura \\
\hline pH: 5,2-8,6 & $\begin{array}{c}\text { Cd } \\
6,65-8,27 \\
\mu \mathrm{M} \mathrm{kg}^{-1}\end{array}$ & 3 & $9-22$ & $\begin{array}{l}\text { Isoterma de adsorção } \\
\text { linear }\end{array}$ & $\begin{array}{l}\text { Veeresh et } \\
\text { al., } 2003 \mathrm{~b}\end{array}$ \\
\hline $\begin{array}{l}\text { CTC }\left(\mathrm{cmol} \mathrm{kg}^{-1}\right): \\
5,5-32,7\end{array}$ & $\begin{array}{c}\mathrm{Ni} \\
129-324 \\
\mu \mathrm{M} \mathrm{kg}^{-1}\end{array}$ & & $9-329$ & & \\
\hline $\begin{array}{l}\mathrm{CO}\left(\mathrm{g} \mathrm{kg}^{-1}\right): 5,1- \\
6,2\end{array}$ & $\begin{array}{c}\mathrm{Pb} \\
55,6-90,8 \\
\mu \mathrm{M} \mathrm{kg} \mathrm{kg}^{-1}\end{array}$ & & $87-7083$ & & \\
\hline \multicolumn{6}{|l|}{$\begin{array}{l}\text { Argila (\%): } 14,8- \\
63,2 \\
\text { Al }\left(\mathrm{g} \mathrm{kg}^{-1}\right): 30-65\end{array}$} \\
\hline \multicolumn{6}{|l|}{$\mathrm{Fe}\left(\mathrm{g} \mathrm{kg}^{-1}\right): 13-36$} \\
\hline \multicolumn{6}{|l|}{$\begin{array}{l}\operatorname{Mn}\left(\mathrm{g} \mathrm{kg}^{-1}\right): 0,06- \\
0,53\end{array}$} \\
\hline $\mathrm{pH}_{\mathrm{CaCl}_{2}}: 5,1$ & $\begin{array}{c}\mathrm{Cu} \\
0,56\end{array}$ & 1 & 530 & Ensaio de adsorção & $\begin{array}{l}\text { Agbenin \& } \\
\text { Olojo, 2004 }\end{array}$ \\
\hline $\begin{array}{l}\text { CTC }\left(\mathrm{mmol}_{\mathrm{c}} \mathrm{kg}^{-1}\right): \\
82,2 \\
\text { CO }\left(\mathrm{g} \mathrm{kg}^{-1}\right): 3,4\end{array}$ & $\begin{array}{c}\mathrm{Zn} \\
0,26\end{array}$ & & 134 & & \\
\hline \multicolumn{6}{|l|}{ Argila $\left(\mathrm{g} \mathrm{kg}^{-1}\right): 390$} \\
\hline $\mathrm{pH}: 3,1-8,1$ & $\begin{array}{c}\text { As } \\
15-766\end{array}$ & 3 & $25-136000$ & $\begin{array}{c}\mathrm{Kd}=[\text { metal }]^{1} \text { fase } \\
\text { sólida/[metal }]_{\text {fase líquida }}\end{array}$ & $\begin{array}{l}\text { Sastre et al., } \\
2004\end{array}$ \\
\hline $\begin{array}{l}\text { CTC }\left(\mathrm{cmol}_{\mathrm{C}} \mathrm{kg}^{-1}\right): \\
8,4-59,0\end{array}$ & $\begin{array}{c}\text { Cd } \\
0,33-6,09\end{array}$ & & $0,18-411$ & $\begin{array}{l}\text { 1. digestão ácida } \\
\text { concentrada com água } \\
\text { régia }\left(3: 1 \mathrm{HNO}_{3}: \mathrm{HCl}\right)\end{array}$ & \\
\hline CO (\%): $0,39-1,7$ & $\begin{array}{c}\mathrm{Cu} \\
54-344\end{array}$ & & $1,10-1400$ & $\begin{array}{c}\text { 2. extração com água } \\
\text { destilada }\end{array}$ & \\
\hline
\end{tabular}


TABELA 3.2 - Trabalhos da literatura que relacionam Kp de metais com as características físico-químicas do solo e a concentração do metal, e metodologia adotada para determinação de Kp.

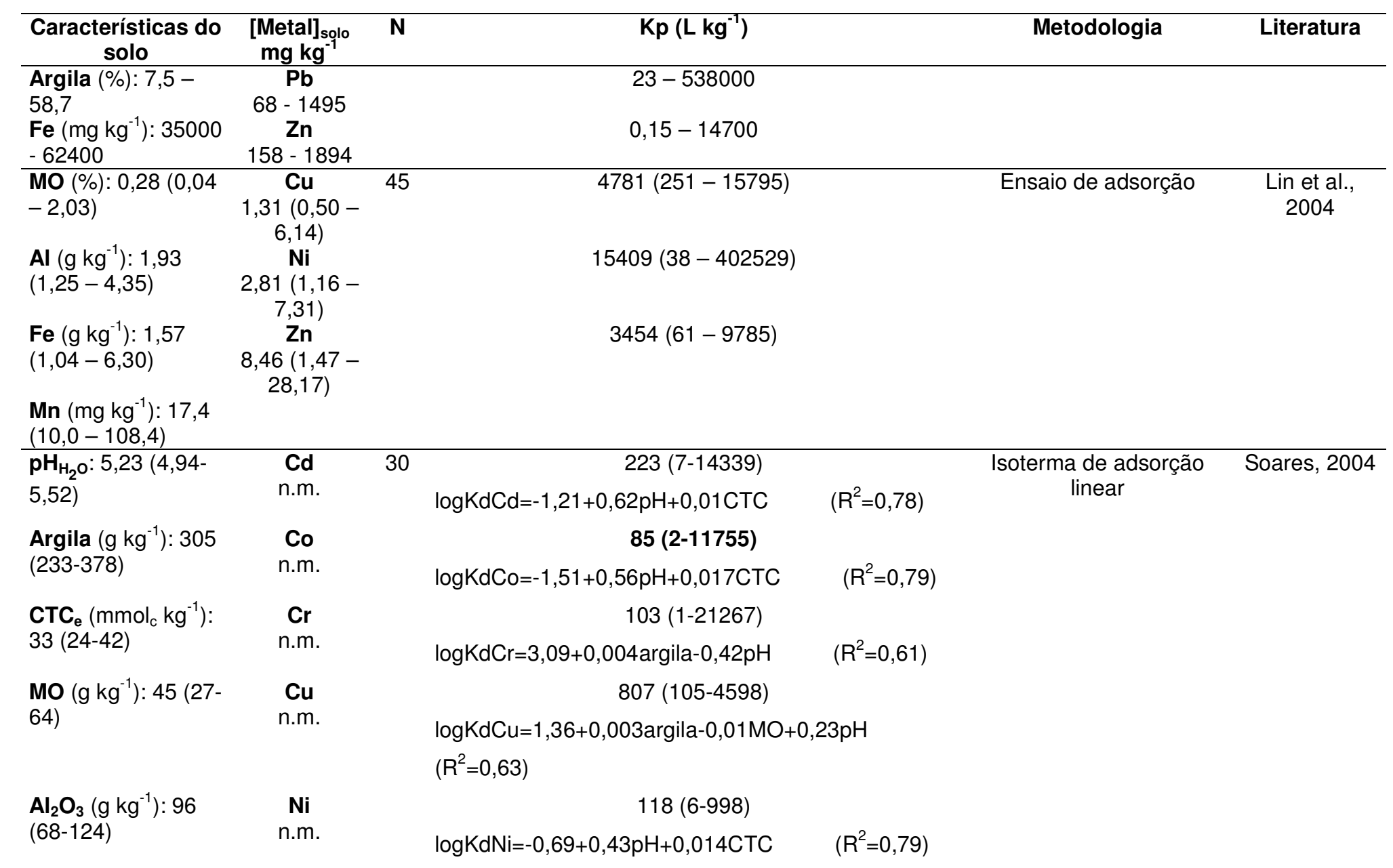


TABELA 3.2 - Trabalhos da literatura que relacionam Kp de metais com as características físico-químicas do solo e a concentração do metal, e metodologia adotada para determinação de Kp.

\begin{tabular}{|c|c|c|c|c|c|c|}
\hline $\begin{array}{c}\text { Características do } \\
\text { solo }\end{array}$ & $\begin{array}{c}\text { [Metal] }]_{\text {solo }} \\
\mathrm{mg} \mathrm{kg}^{-1}\end{array}$ & $\mathbf{N}$ & $\mathrm{Kp}\left(\mathrm{L} \mathrm{kg}^{-1}\right)$ & & Metodologia & Literatura \\
\hline \multirow{2}{*}{$\begin{array}{l}\mathrm{Fe}_{2} \mathrm{O}_{3}\left(\mathrm{~g} \mathrm{~kg}^{-1}\right): 76 \\
(40-112)\end{array}$} & $\mathrm{Pb}$ & & $2131(121-7020)$ & & & \\
\hline & n.m. & & log $\mathrm{KdPb}=0,97+0,001$ argila $+0,35 \mathrm{pH}$ & $\left(R^{2}=0,63\right)$ & & \\
\hline \multirow{2}{*}{$\begin{array}{l}\operatorname{MnO}\left(\mathrm{g} \mathrm{kg}^{-1}\right): 5,1 \\
(2,0-8,2)\end{array}$} & $\mathrm{Zn}$ & & $137(5-123849)$ & & & \\
\hline & n.m. & & $\operatorname{logKdZn}=-3,86+0,002$ argila $+1,05 \mathrm{pH}$ & $\left(R^{2}=0,71\right)$ & & \\
\hline
\end{tabular}

CTC: capacidade de troca catiônica

CO: carbono orgânico

Alox: óxido de alumínio

$\mathrm{Fe}_{\mathrm{Ox}}$ : óxido de ferro

$\mathrm{Mn}_{\mathrm{Ox}}$ : óxido de manganês

MO: matéria orgânica total

n: número de amostras de solo

n.m.: não mencionado

$\mathrm{Fe}_{\mathrm{D}}$ : ferro livre 
Buchter et al. (1989) estudaram a retenção de As, Cd, Co, Cr, Cu, Mo, $\mathrm{Ni}, \mathrm{Pb}, \mathrm{Zn}$, em 11 tipos de solo. Os valores de Kd são apresentados na TAB 3.2. Estes autores concluíram que o fator mais importante que afetou o $\mathrm{Kd}$ dos metais nos solos estudados foi o $\mathrm{pH}$. Outras conclusões apresentadas foram: CTC influencia Kd para espécies catiônicas e óxidos de $\mathrm{Al}$, Fe e $\mathrm{Mn}$ retém tanto espécies catiônicas quanto aniônicas; o Kd dos metais $\mathrm{Cd}$, Co, Ni e Zn foram similares entre si e baixos, ao passo que o $\mathrm{Kd}$ para os metais de $\mathrm{Cu}$ e $\mathrm{Pb}$ foram altos, ou seja, maior retenção no solo; e relações significativas entre as características do solo e a retenção do metal existem num grupo de solos de características bem diferentes.

Allen et al. (1995) estudaram a adsorção de Cd em amostras de solo dos horizontes A e B de cinco sítios em Nova Jersey, determinando o Kd por meio de ensaio de adsorção e por desorção de $\mathrm{Cd}$ em coluna do solo estudado. O Kd foi determinado pela relação entre a concentração do $\mathrm{Cd}$ no solo e a concentração do $\mathrm{Cd}$ na solução. A proporção do solo:solução e as concentrações adicionadas de Cd foram as mesmas para ambos os ensaios (de adsorção e coluna de desorção). O Kd obtido por ensaio de adsorção apresentou boa correlação $(0,90)$ com o Kd obtido pela coluna de desorção. Graficamente o Kd de Cd obtido por ensaio de adsorção variou aproximadamente entre 1 e $10^{4} \mathrm{~mL} \mathrm{~g}^{-1}$ em função do aumento do $\mathrm{pH}$ entre 3 a 9 dos solos estudados.

Gooddy et al. (1995) determinaram Kd de Cd, Co, Cu, Ni, Pb, Zn para dois perfis (de 0 a $100 \mathrm{~cm}$ ) do mesmo tipo de solo, coletado em floresta $(\mathrm{pH} \mathrm{2,52}$ - 4,13), utilizando três métodos $\left(\mathrm{Kd}_{1}=[\text { metal }]_{\mathrm{HNO}_{3}} 0,43 \mathrm{~mol} \mathrm{~L}^{-1 /}[\text { metal }]_{\text {solução do solo }} ; \mathrm{Kd}_{2}\right.$ $=[\text { metal }]_{\mathrm{CaCl}_{2}} 0,01 \mathrm{~mol} \mathrm{~L}^{-1} /[\text { metal }]_{\text {solução do solo }} ; \mathrm{Kd}_{3}=[\text { metal }]_{\mathrm{Ba}\left(\mathrm{NO}_{3}\right)_{2}} 0,1 \mathrm{~mol} \mathrm{~L}-1 /[\text { metal }]_{\text {solução }}$ do solo). Os valores de $\mathrm{Kd}$ foram apresentados graficamente em função da profundidade. Foi observado que o $\mathrm{Kd}$ dos metais para a camada de solo superficial foi maior que o Kd para a camada mais inferior, variando de 3 a 4 ordens de grandeza de diferença. $\mathrm{O}$ método $\mathrm{Kd}_{1}$ apresentou um valor de $\mathrm{Kd}$ maior que os valores dos outros dois métodos, $\mathrm{Kd}_{2}$ e $\mathrm{Kd}_{3}$, para a camada de solo superficial. Estes autores também observaram as seqüências decrescentes de Kd:

$$
\begin{aligned}
& \mathrm{Kd}_{1}: \mathrm{Pb}>\mathrm{Ni}>\mathrm{Cd}>\mathrm{Co}>\mathrm{Zn}>\mathrm{Cu} \\
& \mathrm{Kd}_{2}: \mathrm{Cd}>\mathrm{Co}>\mathrm{Zn}>\mathrm{Pb}>\mathrm{Ni}>\mathrm{Cu}
\end{aligned}
$$




$$
\mathrm{Kd}_{3}: \mathrm{Cd}>\mathrm{Pb}>\mathrm{Ni}>\mathrm{Zn}
$$

Estas seqüências de $\mathrm{Kp}$ não mostraram uma seletividade dos metais no solo como seria esperada. $\mathrm{O} \mathrm{Cu}$ apresentou o menor valor de $\mathrm{Kd}$ que poderia ser explicado pela alta concentração de matéria orgânica dissolvida (DOM) na solução do solo e o Cu estaria ligado à matéria orgânica na forma dissolvida.

Hassan e Garrison (1996) determinaram Kd para cromo, por meio de isoterma de adsorção, em três tipos de solo de diferentes características físicas e químicas, ajustando o pH entre 3,6 a 7,4 para $\mathrm{Cr}$ (III) e 1,8 a 12 para $\mathrm{Cr}$ (VI). Os valores de $\mathrm{Kd}$ para $\mathrm{Cr}(\mathrm{VI})$ variaram entre 1 a $50 \mathrm{~L} \mathrm{~kg}^{-1}$, ao passo que para $\mathrm{Cr}$ (III) variaram entre 850 a $5600 \mathrm{~L} \mathrm{~kg}^{-1}$. Estes autores observaram que para $\mathrm{Cr}$ (III) o Kd aumentou com a elevação do $\mathrm{pH}$, ao passo que para o $\mathrm{Cr}(\mathrm{VI})$ o Kd diminui com a elevação do $\mathrm{pH}$. Este comportamento diferente para o $\mathrm{Cr}(\mathrm{VI})$ pode ser explicado pela sua natureza aniônica. Em meio ácido os sítios de adsorção são positivamente carregados e o $\mathrm{Cr}(\mathrm{VI})$ será adsorvido por atração eletrostática, aumentando os valores de Kd. Em meio alcalino, ocorre repulsão eletrostática e menos $\mathrm{Cr}(\mathrm{VI})$ é adsorvido, portanto, os valores de Kd são menores. Buchter et al (1989) também discutiram que solo de pH baixo retém mais espécies aniônicas que solo de $\mathrm{pH}$ alto, que é contrário à retenção de cátions.

Lee et al. (1996) analisaram a adsorção de Cd em 15 solos representativos da maioria dos tipos de solo em Nova Jersey. A concentração do solo natural foi negligenciada. A adsorção de Cd foi representada por isoterma de Langmuir e os dados de adsorção foram transformados em $\mathrm{Kd}$, dividindo a concentração de $\mathrm{Cd}$ adsorvido pela concentração de $\mathrm{Cd}$ em solução após o equilíbrio. Os autores apresentaram graficamente que $\mathrm{Kd}$ aumentou com o aumento de $\mathrm{pH}$ e consideraram o $\mathrm{pH}$ o parâmetro mais importante, mas não o único controlador da adsorção de $\mathrm{Cd}$ no solo. Numa tentativa de melhor predizer a partição de $\mathrm{Cd}$ no solo, os autores desenvolveram um modelo de sorção em pH fixo (por exemplo: $\mathrm{pH} 4,0,5,0$ ou 6,0), considerando valores variáveis dos parâmetros matéria orgânica e óxidos de $\mathrm{Al}$, Fe e Mn. O Kd determinado por meio do modelo apresentou correlação com o Kd determinado experimentalmente para solo com pH fixo, mas não apresentou correlação para solo com o pH original, ou seja, pH variável. Os autores comentaram que o modelo desenvolvido é diferente de outros modelos encontrados na literatura porque não considera o $\mathrm{pH}$ um 
parâmetro independente. Segundo os autores a sorção de Cd e outros metais nos óxidos e matéria orgânica é dependente do $\mathrm{pH}$.

Gao et al. (1997) determinaram Kd da inclinação da isoterma de adsorção para metais, analisados individualmente, em 9 tipos de solos tratados com lodo de esgoto ajustando o $\mathrm{pH}$ para 4,5 e 6,5. Os valores de $\mathrm{Kd}$ dos metais são apresentados em função do pH ajustado (TAB 3.2). Os metais $\mathrm{Cr}$, $\mathrm{Cu}$ e $\mathrm{Pb}$ apresentaram maiores valores de $\mathrm{Kd}$ para o $\mathrm{pH}$ mais baixo, 4,5, para dois tipos de solo que apresentaram maior porcentagem de carbono orgânico. Sabe-se que o $\mathrm{Cu}$ e o $\mathrm{Pb}$ têm grande afinidade com a matéria orgânica para formar complexos (Gao, 1997; McBride, 1994). O Pb foi o elemento mais fortemente adsorvido no solo quando comparado com outros metais tóxicos. Estes autores mostraram a afinidade dos metais no solo com base nos valores de $\mathrm{Kd}$ : $\mathrm{Pb}>\mathrm{Cu}>\mathrm{Zn}>\mathrm{Ni}>\mathrm{Cd} \cong \mathrm{Cr}$ em $\mathrm{pH} 4,5$ e $\mathrm{Pb}>\mathrm{Cu} \cong \mathrm{Zn}>\mathrm{Cd}>\mathrm{Ni}>\mathrm{Cr}$ em $\mathrm{pH}$ 6,5.

Janssen et al. (1997) desenvolveram modelos matemáticos para Kp em função das características físico-químicas de 20 solos da Holanda, coletados de 0 a $20 \mathrm{~cm}$, de níveis elevados de $\mathrm{As}, \mathrm{Cd}, \mathrm{Cr}, \mathrm{Cu}, \mathrm{Ni}, \mathrm{Pb}$ e $\mathrm{Zn}$ quando comparados com solos naturais, e utilizaram este mesmo modelo para solos da Holanda com baixa concentração dos metais tóxicos. Os coeficientes de partição foram semelhantes, para baixas ou altas concentrações dos metais, podendo indicar que Kp independe da concentração do metal. Nos modelos de Kp em função das características dos solos apresentados por Janssen et al. (1997) foi demonstrado que óxido de ferro tem um importante papel na partição de solo-líquido de $\mathrm{As}$, Cu e $\mathrm{Pb}$, e para o arsênio foi o único parâmetro considerado no modelo (TAB 3.2). A adsorção de metais no óxido de ferro é fortemente dependente de $\mathrm{pH}$ relativamente baixo (entre 4-5,5) para $\mathrm{Cu}$ e $\mathrm{Pb}$ e elevado para As (entre 7,5-8,5) (Dzombak, 1990). Estes autores também demonstraram que carbono orgânico dissolvido (DOC) é um parâmetro importante para a partição dos metais $\mathrm{Cr}$, Cu e $\mathrm{Ni}$ no solo. Este fato pode ser explicado pela forte ligação entre estes metais e o carbono orgânico dissolvido, reduzindo desta maneira a ligação destes metais na fase sólida do solo (Gooddy, 1995).

Echeverría et al. (1998) estudaram a sorção competitiva de $\mathrm{Cd}, \mathrm{Cu}, \mathrm{Ni}$, $\mathrm{Pb}$ e $\mathrm{Zn}$ em 3 tipos de solos coletados com $15 \mathrm{~cm}$ de profundidade. Os valores de Kd destes metais foram obtidos da inclinação linear da isoterma de sorção (TAB 3.2). Os resultados da sorção monometal e competitiva revelaram que a presença 
de outros cátions investigados diminuiu a sorção de todos os metais quando foi comparado os parâmetros de sorção da isoterma de Langmuir e Freundlich. O mesmo não foi observado para Kd (parâmetro de sorção) obtido da parte linear da isoterma (TAB 3.2). A presença de $\mathrm{Cu}$ e $\mathrm{Pb}$ no sistema afetou na sorção de $\mathrm{Ni}, \mathrm{Cd}$ e $\mathrm{Zn}$ mais que o inverso. Os autores também observaram que os solos estudados retiveram mais $\mathrm{Pb}$ e $\mathrm{Cu}$ que $\mathrm{Zn}, \mathrm{Cd}$ e $\mathrm{Ni}$.

Num outro trabalho Lee et al. (1998) estudaram a adsorção de Pb em 15 solos que representam a distribuição da maioria dos tipos de solo de Taiwan, por isoterma de adsorção de Langmuir, utilizando a mesma metodologia de Lee et al. (1996). A concentração de Pb encontrada no solo não foi significante. Os

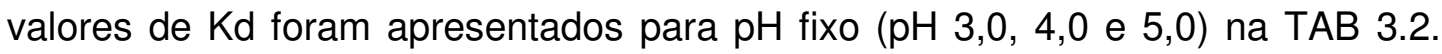
Segundo os autores, o pH é o parâmetro mais importante, mas não é o único controlador da adsorção de $\mathrm{Pb}$ nestes solos. O Kd determinado por meio do modelo apresentou correlação com o Kd determinado experimentalmente para solo com pH fixo, mas não apresentou correlação para solo com o pH original, ou seja, $\mathrm{pH}$ variável. Isto poderia ser atribuído pelo fato da variação de $\mathrm{Kd}$ em relação ao $\mathrm{pH}$ e este não ser considerado no modelo. Os resultados, para pH fixo, indicaram que a matéria orgânica é a fração do solo mais importante na retenção de $\mathrm{Pb}$.

Römkens e Salomons (1998) estabeleceram modelos de Kp dos metais $\mathrm{Cd}$, Cu e Zn em função das características do solo, pH e CTC (TAB 3.2). Os solos estudados foram provenientes de solos de agricultura e de floresta. Os autores consideraram que CTC estaria representando as características de adsorção da matéria orgânica e da argila. Isto foi demonstrado pela correlação de CTC determinada experimentalmente e CTC calculada pela equação:

$$
\text { CTC }=1,92 M O(\%)+0,48 \operatorname{Argila}(\%) \quad R^{2}=0,97
$$

Celardim (1999) propôs um molelo relacionando metal mobilizável (M) e totalmente móvel ou livre (m). Para Cd, Ni, Pb e Zn:

$$
\log [(M / m)-1]=x p H+x \log C T C-\log K_{S}
$$


e para Cu:

$$
\log [(M / m)-1]=x \log C T C-\log K_{S} \cdot K_{M L}\left(K_{L H}\right)^{x}
$$

no qual $\mathrm{K}$ são constantes de equilíbrio $\left(\mathrm{K}_{\mathrm{S}}\right.$ : equilíbrio entre metal e sítios de sorção da fase sólida do solo; $\mathrm{K}_{\mathrm{ML}}$ : equilíbrio entre metal e matéria orgânica dissolvida; $\mathrm{K}_{\mathrm{LH}}$ : equilíbrio entre $\mathrm{H}^{+}$e matéria orgânica dissolvida) e $[(\mathrm{M} / \mathrm{m})-1]$ é o Kd entre o solo e a solução. Introduzindo dados disponíveis da literatura no modelo proposto, o autor mostrou graficamente correlação de Kd em função do pH mais matéria orgânica para Cd e Zn.

Elzinga et al. (1999) derivaram equações de Freundlich (isoterma de adsorção) para $\mathrm{Cd}, \mathrm{Zn}$ e $\mathrm{Cu}$ aplicando regressão múltipla linear em dados de adsorção obtidos na literatura, para vários tipos de solo com características do solo e condições experimentais diferentes, variando as concentrações do metal em até cinco ordens de magnitude. Tomando-se por base os dados da isoterma de adsorção, desenvolveram-se modelos que relacionam a concentração do metal adsorvido com a concentração do metal em solução, CTC, pH e concentração de Ca em solução. Estes autores aplicaram os dados de partição do metal no solo de Janssen et al. (1997) nos modelos estabelecidos e concluíram que o uso de isotermas para estimar a disponibilidade do metal no solo foi mais apropriado para $\mathrm{Cd}$ e $\mathrm{Zn}$, nas concentrações totais do metal no solo entre 0,1 e 1 $\mathrm{mg} \mathrm{kg}^{-1}$ e 1 e $100 \mathrm{mg} \mathrm{kg}^{-1}$, respectivamente, ao passo que para $\mathrm{Cu}$, ou $\mathrm{Zn}$ e $\mathrm{Cd}$ em concentrações maiores que as citadas não foi apropriado.

Carlon et al. (2000) determinaram valor de $\mathrm{Kd}$ de $\mathrm{Pb}$ para fins de avaliação de risco à saúde humana de uma área industrial abandonada. O Kd foi determinado pela razão entre a concentração de $\mathrm{Pb}$ no solo obtida por digestão com água régia e a concentração de $\mathrm{Pb}$ na solução obtida por dois métodos de lixiviação, um com HOAc $0,1 \mathrm{~mol} \mathrm{~L}^{-1}$ e outro com $\mathrm{CaCl}_{2} 0,01 \mathrm{~mol} \mathrm{~L}^{-1}$. Os valores de $\mathrm{Kd}$ de $\mathrm{Pb}$ variaram de 100 a $2512 \mathrm{~L} \mathrm{~kg}^{-1}$ quando utilizado o HOAc e de $10000 \mathrm{a}$ $630957 \mathrm{~L} \mathrm{~kg}^{-1}$ quando utilizado o $\mathrm{CaCl}_{2}$ (TAB 3.2). Desde que o menor valor de $\mathrm{Kd}$ corresponde a maior mobilidade, o uso do Kd pela extração com HOAc é mais conservativo. 
Mesquita et al. (2000) estudaram a competição de Cu e Zn nos sítios de adsorção em 4 solos do tipo calcáreo, coletados de 0 a $20 \mathrm{~cm}$. A concentração do metal no solo variou de 14 a $33 \mathrm{mg} \mathrm{kg}^{-1}$ para Cu e de 28 a $57 \mathrm{mg} \mathrm{kg}^{-1}$ para Zn. A sorção destes cátions no solo foi descrita por isotermas de Langmuir ou Freundlich. No geral, os autores mostraram graficamente que o valor de $\mathrm{Kd}$ de $\mathrm{Cu}$ e $\mathrm{Zn}$ foi maior quando estes cátions foram estudados separadamente, ao passo que o valor de $\mathrm{Kd}$ diminuiu quando ambos estavam presentes no ensaio de adsorção. O valor de $\mathrm{Kd}$ de $\mathrm{Cu}$ e $\mathrm{Zn}$, obtido pela isoterma individual ou mistura dos cátions, também diminuiu quando a concentração destes cátions, separadamente, aumentou na solução após o equilíbrio. A adsorção de $\mathrm{Cu}$ foi mais afetada pelo $\mathrm{Zn}$ que a adsorção de $\mathrm{Zn}$ pelo $\mathrm{Cu}$.

Sauvé et al. (2000a) avaliaram $\mathrm{Kd}$ dos metais $\mathrm{Cd}, \mathrm{Cu}, \mathrm{Ni}, \mathrm{Pb}$ e $\mathrm{Zn}$ no solo tomando-se por base dados heterogêneos quanto às características do solo e condições experimentais de 70 estudos coletados na literatura. Destes estudos, os autores estabeleceram modelos de Kd em função da concentração do metal e das características químicas ( $\mathrm{pH}$ e matéria orgânica) para os metais $\mathrm{Cd}, \mathrm{Cu}, \mathrm{Ni}$, $\mathrm{Pb}$ e Zn por meio de regressão múltipla (TAB 3.2). A argila e os óxidos não foram considerados por apresentaram grandes diferenças de propriedades entres os trabalhos levantados da literatura.

Sauvé et al. (2000b) desenvolveram um modelo de Kp de Cd em função do $\mathrm{pH}$ e da concentração de $\mathrm{Cd}$ no solo contaminado, e mostraram que o $\mathrm{Kd}$ tem correlação significativa com o pH e a concentração, sobretudo com o pH (TAB $3.2)$.

McBride et al. (2000) determinaram Kd dos metais $\mathrm{Cd}$, Cu, Ni e Zn num solo tratado com lodo de esgoto. Os valores de $\mathrm{Kd}$ foram próximos à $10^{4}$ (TAB 3.2) que podem ser atribuídos à ligação do metal com a matéria orgânica de alto teor e pH próximo de 7.

Dumat et al. (2001) analisaram $\mathrm{Pb}, \mathrm{Cu}$ e $\mathrm{Cd}$ em dois perfis de solo coletados numa área que tem sido impactada por uma fábrica de fundição de metais. Um perfil de solo foi coletado em campo de agricultura e o outro foi coletado a $500 \mathrm{~m}$ da fábrica. A concentração do metal no solo variou de $<0,1 \mathrm{a}$ $39,9 \mathrm{mg} \mathrm{kg}^{-1}$ para Cd, de 8,6 a $127 \mathrm{mg} \mathrm{kg}^{-1}$ para Cu e de 14,7 a $4264 \mathrm{mg} \mathrm{kg}^{-1}$ para $\mathrm{Pb}$. Os maiores valores de concentração para estes metais representam o topo do perfil do solo estudado, variando uma ordem de grandeza entre o topo e a 
camada mais profunda do solo $(100 \mathrm{~cm})$. O Kd foi determinado por 3 métodos: $\mathrm{Kd}_{1}=[\text { metal }]_{\mathrm{CaCl}_{2}} 0,01 \mathrm{~mol} \mathrm{~L}^{-1 /} /[\text { metal }]_{\text {solução do solo, }}$ representando a fração trocável; $\mathrm{Kd}_{2}$ $=[\text { metal }]_{\mathrm{Na}_{4} \mathrm{P}_{2} \mathrm{O}_{7}} 0,1 \mathrm{~mol} \mathrm{~L}^{-1} /[\text { metal }]_{\text {solução do solo, }}$ representando à fração de matéria

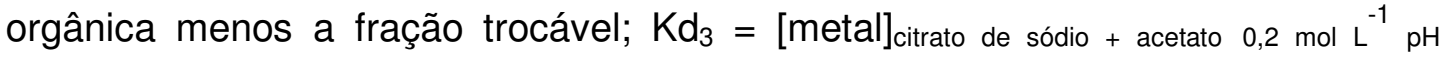

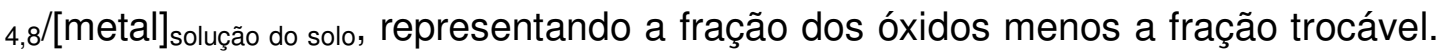
Os autores mostraram graficamente que para os dois perfis de solo coletados, 0 $\mathrm{Kd}$ de $\mathrm{Pb}$ variou até duas ordens de grandeza entre os métodos $\mathrm{Kd}_{2}$ e $\mathrm{Kd}_{3}$, ao passo que, os valores de $\mathrm{Kd}$ de $\mathrm{Cd}$ e Cu foram da mesma ordem de grandeza para os métodos adotados. Em geral, o valor de $\mathrm{Kd}_{3}$ de $\mathrm{Pb}$ foi maior que o valor de $\mathrm{Kd}_{2}$. Os valores de $\mathrm{Kd}$ em ordem decrescente corresponderam a: $\mathrm{Pb}>\mathrm{Cu}>$ $\mathrm{Cd}$. E ambos os metais, $\mathrm{Cu}$ e $\mathrm{Pb}$, diminuíram com a profundidade. A extração química mostrou que a matéria orgânica e os óxidos de $\mathrm{Fe}$ e Mn controlam a especiação de $\mathrm{Pb}$, Cu e $\mathrm{Cd}$ no solo, ao passo que a modelagem mostrou que a especiação de $\mathrm{Pb}$ e $\mathrm{Cu}$ é dominada pela matéria orgânica dissolvida e $\mathrm{Cd}$ é particularmente encontrado em solução como íon livre.

Chang et al. (2001) examinaram isotermas de sorção linear e não linear (Langmuir e Freundlich) individualmente para esclarecer o transporte de $\mathrm{Cd}$ e $\mathrm{Cu}$ em uma coluna de um solo silte argiloso de $50 \mathrm{~cm}$. Os valores de $\mathrm{Kd}$ foram obtidos da isoterma linear, variando de 9,63 a 5,33 $\mathrm{L} \mathrm{kg}^{-1}$ para Cu e 5,04 a 2,71 L $\mathrm{kg}^{-1}$ para $\mathrm{Cd}$ (TAB 3.2), dos quais o valor de $\mathrm{Kd}$ mais alto para cada metal representa a camada superficial da coluna de solo. Os autores mostraram que a isoterma de Freundlich representou melhor o dado experimental de adsorção, ao passo que a isoterma linear, da qual foi obtida o valor de $\mathrm{Kd}$, representou os dados experimentais apenas para baixas concentrações do metal na solução após o equilíbrio e para concentrações mais elevadas a inclinação da curva da isoterma linear foi menor que a inclinação da curva para os dados experimentais de adsorção.

Zelewski et al. (2001) determinaram valores de $\mathrm{Kd}$ no aqüífero para $\mathrm{Cu}$ e Zn pela razão entre a concentração do metal no solo e concentração do metal na água subterrânea. Os valores de Kd foram $22000 \mathrm{~L} \mathrm{~kg}^{-1}$ para Cu e $23000 \mathrm{~L} \mathrm{~kg}^{-1}$ para Zn (TAB 3.2).

Gomes et al. (2001) determinaram Kd para metais em sete tipos de solos brasileiros por ensaio de adsorção. A adsorção foi obtida de $20 \mathrm{~mL}$ da 
mistura solução de $\mathrm{Cd}, \mathrm{Cr}, \mathrm{Cu}, \mathrm{Ni}, \mathrm{Pb}$ e $\mathrm{Zn}$ de diferentes concentrações (5, 15, 25, 35 e $50 \mathrm{mg} \mathrm{L}^{-1}$ ) com $1 \mathrm{~g}$ de solo. Para cada concentração dos metais adicionada na mistura foi apresentado um valor de Kd. Não foi possível obter Kd da própria isoterma de adsorção, pois a curva não apresentou linearidade. Tomando-se por base um único ponto da curva (concentração de $25 \mathrm{mg} \mathrm{L}^{-1}$ adicionada) os autores apresentaram duas seqüências de adsorção mais freqüentes: $\mathrm{Cr}>\mathrm{Pb}>\mathrm{Cu}>\mathrm{Cd}$ $>\mathrm{Zn}>\mathrm{Ni}$ e $\mathrm{Pb}>\mathrm{Cr}>\mathrm{Cu}>\mathrm{Cd}>\mathrm{Ni}>\mathrm{Zn}$, nas quais $\mathrm{Cr}$ e $\mathrm{Pb}$, e $\mathrm{Ni}$ e $\mathrm{Zn}$ alternaram na seqüência conforme o tipo de solo, mas no geral, $\mathrm{Cr}$, $\mathrm{Cu}$ e $\mathrm{Pb}$ foram os metais mais adsorvidos e $\mathrm{Cd}$, $\mathrm{Ni}$ e $\mathrm{Zn}$ os menos adsorvidos nos solos. Além disso, a análise da correlação de $\mathrm{Kd}$ versus as características do solo mostrou que $\mathrm{Cd}, \mathrm{Cr}$ e Ni tem correlação com pH e CTC, $\mathrm{Cu}$ com $\mathrm{CO}$, argila e óxidos, Pb com CTC e Zn não apresentou correlação com as características do solo.

Seuntjens (2002) estudou a migração de Cd num perfil heterogêneo de $1 \mathrm{~m}$ de profundidade de um solo arenoso. $\mathrm{O}$ valor de Kd foi obtido da razão:

$$
K d=\frac{C_{T}-w_{i} C_{w}}{C_{w}}
$$

na qual $\mathrm{C}_{\mathrm{T}}$ é a concentração total de $\mathrm{Cd}$ no solo obtida por digestão ácida (TAB 3.2), $\mathrm{C}_{\mathrm{w}}$ é a concentração de $\mathrm{Cd}$ da solução do solo, $w_{\mathrm{i}}$ é o conteúdo de água gravimétrico da amostra de solo úmida coletada em campo. Para valores grandes de $K d$, a razão é simplificada para:

$$
K d=\frac{C_{T}}{C_{w}}
$$

que é uma aproximação razoável para metais fortemente adsorvidos. Os valores variaram de 11,5 a 41,3 $\mathrm{L} \mathrm{kg}^{-1}$, dos quais o maior valor de $\mathrm{Kd}$ foi obtido para a camada mais superficial e o menor valor de Kd para a camada mais inferior do perfil do solo.

Krishnamurti e Naidu (2002) avaliaram Cu e Zn em 11 solos típicos da Austrália, não contaminados, coletados da superfície $(0-15 \mathrm{~cm}) . \mathrm{O} \mathrm{Kd}$ foi determinado pela razão entre a concentração do metal no solo obtido por digestão ácida e a concentração do metal na solução do solo (TAB 3.2). A regressão linear 
entre logKd e o pH da solução do solo explicou apenas $49 \%$ e $55 \%$ da variabilidade dos valores de $\mathrm{Kd}$ nos solos para $\mathrm{Cu}$ e $\mathrm{Zn}$, respectivamente. A variabilidade dos valores de $\mathrm{Kd}$ para $\mathrm{Cu}$ e $\mathrm{Zn}$ foi melhorada para 82 e 81\%, respectivamente, quando foram introduzidos na regressão múltipla os fatores, concentração do metal nas frações trocável e complexo fúlvico (TAB 3.2).

Staunton et al. (2002) avaliaram a influência da proporção solo:solução $(1: 1 ; 1: 2 ; 1: 5 ; 1: 10)$ na determinação de $\mathrm{Kd}$ de $\mathrm{Ni}$ em dois tipos de solo de diferentes ocupações, um de agricultura e outro de floresta. O Kd foi determinado da razão entre a concentração de ${ }^{63} \mathrm{Ni}$ no solo $\left(\mathrm{Bq} \mathrm{kg}^{-1}\right)$ e na solução $\left(\mathrm{Bq} \mathrm{dm}^{-3}\right)$. A concentração de ${ }^{63} \mathrm{Ni}$ na solução remanescente após o equilíbrio (mistura do solo com ${ }^{63} \mathrm{Ni}$ ) foi medida por um cintilador líquido e a concentração de ${ }^{63} \mathrm{Ni}$ associado ao solo foi obtida da diferença entre a concentração inicial de ${ }^{63} \mathrm{Ni}$ adicionada e a da solução após o equilíbrio. Estes autores observaram graficamente que os valores de $\mathrm{Kd}$ diminuíram marcadamente quando a suspensão foi mais concentrada, ou seja, quando a razão entre solo:solução diminuiu.

Degryse et al. (2003) determinaram Kd de Cd e Zn em solos superficiais (de 0 a $15 \mathrm{~cm}$ ou $20 \mathrm{~cm}$ ), coletados na Bélgica (47 solos), França (17), Hungria (4) e Inglaterra (6), com concentrações elevadas destes metais (TAB 3.2). Os valores de Kd foram determinados pela razão entre a concentração do metal no solo obtido por digestão ácida e a concentração obtida da solução do solo (TAB 3.2). Estes autores observaram que o $\mathrm{pH}$ do solo explicou a maioria da variação de $\log K d\left(R^{2}=0,55\right.$ para $\mathrm{Cd}$ e 0,70 para $\left.\mathrm{Zn}\right)$. Estes autores também representaram a concentração do metal na solução do solo por meio da extração dos metais no solo por $\mathrm{CaCl}_{2}$ 0,01 mol L-1 . Eles propuseram uma modificação na relação do $\mathrm{Kd}$ introduzindo um fator de correção para a proporção solo:solução, para complexação com $\mathrm{Cl}^{-}$(no caso do $\mathrm{Cd}$ ) e para a diferença de concentração de $\mathrm{Ca}$ entre a solução do solo obtida por centrifugação e a obtida por extração com $\mathrm{CaCl}_{2}$. Desta forma eles concluíram que as concentrações de $\mathrm{Cd}$ e $\mathrm{Zn}$ na solução do solo de solos contaminados podem ser preditas com base na extração destes metais com $\mathrm{CaCl}_{2} 0,01 \mathrm{~mol} \mathrm{~L}^{-1}$.

Veeresh et al. (2003a) estudaram a sorção competitiva dos metais $\mathrm{Pb}$, $\mathrm{Cu}, \mathrm{Zn}, \mathrm{Ni}$ e $\mathrm{Cd}$ em três tipos de solo da Índia. Os solos foram tratados com diferentes proporções da mistura: cinza mais lodo de esgoto. O valor de $\mathrm{Kd}$ foi obtido da inclinação da isoterma de adsorção para cada metal, na qual mostrou 
que a sorção do metal foi linearmente relacionada com a concentração na solução em equilíbrio. Todo o solo tratado apresentou maior valor de $\mathrm{Kd}$ que os respectivos controles (TAB 3.2). A afinidade dos metais no solo com base nos valores de $\mathrm{Kd}$ foi: $\mathrm{Pb}>\mathrm{Cu}>\mathrm{Zn}>\mathrm{Ni}>\mathrm{Cd}$. Os autores também observaram que 0 aumento na adição do metal intensificou a competição entre os metais nos sítios de troca. Todos os valores de Kd dos metais analisados para os solos tratados apresentaram boa correlação com o pH, ácido húmico, CTC, carbonatos e Fe total. Os autores concluíram que pode ser deduzido que a aplicação de cinza ou lodo de esgoto ou suas misturas aumentará a sorção do metal no solo.

Num outro trabalho, Veeresh et al. (2003b) realizaram experimentos de adsorção individual dos metais $\mathrm{Cd}, \mathrm{Ni}$ e $\mathrm{Pb}$ em três tipos de solos, coletados de 0 a $15 \mathrm{~cm}$, de diferentes regiões agroclimáticas da Índia. Os valores de Kd foram obtidos da inclinação da isoterma de adsorção. Os valores de $\mathrm{Kd}$ em L kg-1 variaram de 9 a 22 para Cd, 9 a 329 para Ni e 87 a 7083 para Pb (TAB 3.2). Os autores observaram que maiores porcentagens do metal extraído da fração trocável corresponderam àqueles sistemas solo-metal com menores valores de Kd. A predominância dos metais associados com a fração trocável junto com valores baixos de $\mathrm{Kd}$ indica alta mobilidade dos metais no solo ácido quando comparado com os outros dois solos.

Agbenin e Olojo (2004) examinaram a adsorção competitiva de Cu e Zn no horizonte $B(15-30 \mathrm{~cm})$ de um tipo de solo que representa mais que $50 \%$ do solo arável da Nigéria. A concentração do metal no solo obtida por extração com DTPA foi de $0,56 \mathrm{mg} \mathrm{kg}^{-1}$ para Cu e 0,26 mg kg-1 para Zn (TAB 3.2). O valor de $\mathrm{Kd}$ destes metais foi obtido por meio de ensaio de adsorção. O valor de $\mathrm{Kd}$ de $\mathrm{Cu}$ foi, aproximadamente, cinco vezes maior que o de $\mathrm{Zn}$ para o solo original. Num outro experimento com a remoção da matéria orgânica do solo o valor de $\mathrm{Kd}$ do $\mathrm{Cu}$ reduziu, aproximadamente, vinte vezes quando comparado com o solo original, ao passo que o $\mathrm{Kd}$ de $\mathrm{Zn}$ foi reduzido pela metade. Similarmente, a remoção do óxido amorfo reduziu Kd de Cu cem vezes, e Kd de Zn por oito vezes quando comparado com o solo original. Os valores médios de $\mathrm{Kd}$ obtidos para $\mathrm{Cu}$ em L kg-1 foram 530 (solo original), 31,8 (solo sem a matéria orgânica) e 7,5 (solo sem os óxidos). Para o Zn, os valores de Kd variaram 134, 77 e 20,2 L kg-1, respectivamente. Parece que as reações com a matéria orgânica e o óxido amorfo são os maiores controladores de $\mathrm{Cu}$, ao passo que para $\mathrm{Zn}$ poderia ser 
amplamente sorvido pela reação de troca catiônica quando em competição com Cu nos sítios de ligação do solo. Os sítios de ligação nos óxidos amorfos e matéria orgânica foram mais seletivos para Cu que $\mathrm{Zn}$.

Staunton (2004) analisou Kd do Ni em treze solos de diferentes regiões da França. O Kd foi determinado pelo radiotraçador ${ }^{63} \mathrm{Ni}$ onde as suspensões foram preparadas pela mistura de $0,4 \mathrm{~g}$ de solo e $4 \mathrm{~mL}$ da solução contendo 1 $\mathrm{kBq} \mathrm{mL}^{-1}$ de ${ }^{63} \mathrm{Ni}$. A solução em equilíbrio foi medida por um cintilador líquido e o valor de Kd foi calculado pela razão entre a atividade de ${ }^{63} \mathrm{Ni}$ adsorvido no solo e a concentração de ${ }^{63} \mathrm{Ni}$ na solução após o equilíbrio. A concentração de Ni no solo variou de 8,6 a $42 \mathrm{~g} \mathrm{~kg}^{-1}$. O autor observou que a adsorção competitiva deixa a sorção do $\mathrm{Ni}$ diminuir quando outros cátions (Co, $\mathrm{Cu}, \mathrm{Zn}, \mathrm{Pd}, \mathrm{Sn}, \mathrm{Pb}$ ) estão presentes. Em geral, o $\mathrm{Kd}$ do $\mathrm{Ni}$ aumentou quando o $\mathrm{pH}$ aumentou, e os valores de Kd obtidos variaram entre 65,3 e 1830,4 $\mathrm{L} \mathrm{kg}^{-1}$.

Sastre el al. (2004) analisaram a distribuição dos metais As, Cd, Cu, Pb e Zn em três solos de agricultura de diferentes características: 1. ácido com textura areia-silte; 2. silte com pH neutro; 3. calcáreo salino com textura argilosa. Os autores calcularam o Kd pela seguinte equação:

$$
K d=\frac{M_{a r}-M_{s s} \cdot V / w}{M_{s s}}
$$

na qual Kd é o coeficiente de distribuição sólido-solução do solo ( $\left.\mathrm{K} \mathrm{kg}^{-1}\right), \mathrm{M}_{\mathrm{ar}}$ é a concentração do metal no solo $\left(\mathrm{mg} \mathrm{kg}^{-1}\right)$ quando quantificado por extração com água régia, $\mathrm{M}_{\mathrm{ss}}$ é a concentração do metal na solução do solo obtida por extração com água destilada $\left(\mathrm{mg} \mathrm{L}^{-1}\right), \mathrm{V}$ é o volume de água adicionado ( $\left.\mathrm{L}\right)$, e w é a quantidade de solo usado para obter a solução do solo. Nesta equação, os autores levaram em consideração o desconto da concentração da solução do solo na concentração do solo e a proporção do solo:água para obter a solução do solo. Os valores de $\mathrm{Kd}$ obtidos (TAB 3.2) para os metais estudados foram muito menores para o solo ácido com textura areia-silte que para os outros dois tipos de solo. Estes autores também comentaram que a concentração do metal na solução do solo foi muito baixa na maioria dos casos, o que provocou grande incerteza nos resultados ou impossibilitou o cálculo de $\mathrm{Kd}$. 
Lin et al. (2004) determinaram valores de Kd para $\mathrm{Cu}$, Ni e $\mathrm{Zn}$ por ensaio de adsorção individual em 45 pontos de solo coletados de uma empresa de tratamento de efluentes municipal em Israel em três profundidades diferentes, de 0 a $15 \mathrm{~cm}, 30$ a $60 \mathrm{~cm}$ e 90 a $120 \mathrm{~cm}$ (TAB 3.2). Estes autores mostraram que $\mathrm{Kd}$ de $\mathrm{Cu}$, $\mathrm{Ni}$ e $\mathrm{Zn}$ foram positivamente correlacionados com o pH da solução em equilíbrio, explicando $71 \%$, 82\% e 96\%, respectivamente, a variabilidade de $\mathrm{Kd}$.

Soares (2004) avaliou a retenção dos metais $\mathrm{Cd}, \mathrm{Co}, \mathrm{Cr}, \mathrm{Cu}, \mathrm{Ni}, \mathrm{Pb}$ e Zn em 30 solos representativos do Estado de São Paulo, coletados em áreas com mínima perturbação antrópica, por meio da quantificação dos valores de Kd (TAB 3.2). O valor de Kd para o mesmo metal variou entre os solos de uma até cinco ordens de grandeza, e a afinidade do metal pelo solo foi $\mathrm{Pb} \gg>\mathrm{Cu} \gg>\mathrm{Cd}>\mathrm{Zn} \approx$ $\mathrm{Ni} \approx \mathrm{Cr}>\mathrm{Co}$. A variação de $\mathrm{Kd}$ de $\mathrm{Cd}$, Co, $\mathrm{Ni}$ e $\mathrm{Zn}$ foi explicada pelo $\mathrm{pH}$ por mais de $55 \%$, e cerca de $80 \%$ considerando o pH e CTC para os metais Cd, Co e $\mathrm{Ni}$. No caso dos metais $\mathrm{Cu}, \mathrm{Pb}$ e $\mathrm{Cr}$, o pH e a argila explicaram cerca de $63 \%$ da variação dos valores de $\mathrm{Kd}$ para $\mathrm{Cu}$ e $\mathrm{Pb}$ e $61 \%$ para $\mathrm{Cr}$. 


\subsection{Importância de Kp de metal em solo em avaliação de risco à saúde humana}

O Kp do metal em solo é um parâmetro que está relacionado com a disponibilidade do metal para a solução do solo. Quanto menor o Kp, maior a concentração do metal na solução do solo e maior a disponibilidade do metal para migrar para a água subterrânea e ser absorvido pelas plantas. Normalmente, estas vias de exposição, água subterrânea e plantas, fazem parte dos modelos de avaliação de risco à saúde humana.

O Kp não é um valor constante e pode variar ordens de grandeza conforme as características do solo e do metal (Buchter, 1989; Janssen, 1997; Otte, 2001), e diferentes métodos experimentais (EPA, 1996) como apresentado na TAB. 3.2. Esta variação de $\mathrm{Kp}$ pode afetar o risco calculado por meio de modelos de avaliação de risco à saúde humana.

Os modelos de avaliação de risco à saúde humana são utilizados para determinar valores de intervenção da substância no solo ou para cálculo do risco da área de um solo diagnosticado contaminado tomando-se por base valores de intervenção, para fins de remediação. O Kp é um dos parâmetros envolvidos dos modelos.

A utilização de valores genéricos de $\mathrm{Kp}$ em modelos de avaliação de risco à saúde humana pode provocar erros no cálculo do risco de uma área diagnosticada contaminada e de necessidade de remediação. Portanto, é importante determinar $\mathrm{Kp}$ do metal em solo de uma área que necessita de remediação (EPA, 1999a; Otte, 2001). 
TABELA 3.3 - Valores de $\mathrm{Kp}\left(\mathrm{L} \mathrm{Kg}^{-1}\right)$ de metais em solo estabelecidos por agências ambientais.

\begin{tabular}{|c|c|c|c|c|c|c|}
\hline \multirow{3}{*}{ Metal } & \multicolumn{6}{|c|}{ Valores de Kp } \\
\hline & \multicolumn{2}{|c|}{$\mathrm{EPA}^{\mathrm{a}}$} & \multicolumn{2}{|c|}{ RIVM $^{b}$} & \multirow[b]{2}{*}{$\begin{array}{l}\text { C-Soil revisado } \\
\text { (pH 5, MO 5\%, } \\
\text { argila 15\%) }\end{array}$} & \multirow[t]{2}{*}{ CETESB } \\
\hline & Valor & intervalo & C-Soil atual & $\begin{array}{c}\text { C-Soil revisado } \\
\text { (pH 6, MO } \\
10 \% \text {, argila } \\
25 \% \text { ) }\end{array}$ & & \\
\hline As & 29 & $25-31$ & 980 & 1800 & 1800 & 980 \\
\hline Cd & 162 & $15-4300$ & 190 & 2560 & 720 & 190 \\
\hline Co & 45 & - & 120 & 120 & 120 & 120 \\
\hline $\mathrm{Cr}$ & - & $1200-4,3.10^{6}$ & 14400 & 4800 & 4800 & 14400 \\
\hline $\mathrm{Cu}$ & 22 & - & 540 & 2120 & 2120 & 540 \\
\hline Mo & 20 & - & 20 & 36000 & 11000 & 20 \\
\hline $\mathrm{Ni}$ & 82 & $16-1900$ & 560 & 40 & 40 & 560 \\
\hline $\mathbf{P b}$ & 900 e 280.000 & - & 2380 & 2000 & 1000 & 2400 \\
\hline $\mathrm{Zn}$ & 62 e 40 & $16-530$ & 250 & 2600 & 520 & 250 \\
\hline
\end{tabular}

a .EPA, 1999b

b. Otte et al., 2001

c. CETESB, 2001 


\subsection{Valores de Kp de metais em solo estabelecidos por agências ambientais}

Os valores de $\mathrm{Kp}$ de metais em solo apresentados na TAB 3.3 foram obtidos das agências ambientais: EPA (Enviromental Protection Agency Agência de Proteção Ambiental) dos Estados Unidos da América, RIVM (National Institute of Public Health and the Environment - Instituto Nacional de Saúde Pública e Meio Ambiente) da Holanda e CETESB (Companhia de Tecnologia de Saneamento Ambiental) do Estado de São Paulo.

Os valores de Kp de metais em solo da EPA apresentados na TAB. 3.3, que têm sido utilizados em avaliação de risco de casos dos EUA, foram obtidos de um estudo preliminar da EPA (1999b). Estes valores foram determinados do modelo de equilíbrio geoquímico e de especiação, MINTEQA2 (EPA, 1996). Neste mesmo documento (EPA, 1999b) a EPA apresentou valores médios e intervalos de Kp de metais em solos obtidos de dados da literatura (TAB. 3.4). Embora a EPA tenha levantado estes dados de $\mathrm{Kp}$ da literatura, eles não foram considerados para casos de avaliação de risco, pois geralmente estes dados são de origem variada.

TABELA 3.4 - Valores de logKp de metais em solos obtidos da literatura, apresentados pela EPA (1999b).

\begin{tabular}{cccc}
\hline Metal & Média & $\begin{array}{c}\left.\text { Valores de log Kp } \mathbf{~ ( \mathbf { ~ k g }} \mathbf{~}^{-1}\right) \\
\text { intervalo }\end{array}$ & $\mathbf{n}$ \\
\hline $\mathbf{A s}$ & 3,4 & $0,3-4,3$ & 22 \\
$\mathbf{C d}$ & 2,9 & $0,1-5,0$ & 41 \\
$\mathbf{C o}$ & 2,1 & $(-1,2)-4,2$ & 11 \\
$\mathbf{C r}$ (III) & 3,9 & $1,0-4,8$ & 43 \\
$\mathbf{C r}$ (VI) & 1,1 & $(-0,7)-3,3$ & 24 \\
$\mathbf{C u}$ & 2,7 & $0,2-3,6$ & 20 \\
$\mathbf{M o}$ & 1,1 & $(-0,2)-2,7$ & 8 \\
$\mathbf{N i}$ & 3,1 & $1,0-3,8$ & 18 \\
$\mathbf{P b}$ & 4,2 & $0,7-5,0$ & 33 \\
$\mathbf{Z n}$ & 3,1 & $(-1,0)-5,0$ & 21 \\
\hline
\end{tabular}

n: número de literaturas consultadas

Os valores de Kp de metais em solo apresentados pelo RIVM da TAB. 3.3 foram divididos em três partes: a primeira coluna considera os valores atuais de Kp do modelo de avaliação de risco C-Soil (Otte, 2001) e a segunda e terceira coluna consideram um valor de $\mathrm{Kp}$ revisado com dois solos padrões em cada 
uma. Os valores de Kp da primeira coluna foram obtidos da média geométrica de valores empíricos e calculados da literatura (Berg, 1991). O valor de Kp calculado, por exemplo, foi estimado de uma equação que relaciona $\mathrm{Kp}$ com o fator de bioconcentração solo-planta (Baes, 1984). Os valores de Kp de As, Cd, Cr, Cu, $\mathrm{Pb}, \mathrm{Mo}, \mathrm{Ni}$ e $\mathrm{Zn}$ revisados das colunas 2 e 3 foram obtidos de equações que relacionam Kp com as características físico-químicas do solo (Sauvé, 2000a; Otte, 2000; Janssen, 1996), considerando dois solos padrões, um solo de $\mathrm{pH} 5, \mathrm{MO}$ 5\% e argila $15 \%$ e outro solo de $\mathrm{pH} 6, \mathrm{MO} 6 \%$ e argila $25 \%$. O valor de $\mathrm{Kp}$ de Co foi mantido do C-Soil atual por falta de dados suficientes da literatura.

A CETESB adotou os valores nominais de $\mathrm{Kp}$ atuais do modelo C-Soil (TAB. 3.3) para determinar os valores de intervenção de metais para solos do Estado de São Paulo (CETESB, 2001). 


\section{CARACTERÍSTICAS DOS METAIS: MOBILIDADE, TOXICIDADE, CONCENTRAÇÃO EM SOLOS NATURAIS E TRANSFERÊNCIA SOLO/PLANTA}

Solos são sólidos porosos formados na superfície da terra por processos de intemperismo derivados de fenômenos biológicos, geológicos e hidrológicos. A parte sólida do solo é composta de 95\% de material inorgânico (por exemplo, argilominerais) e 5\% de matéria orgânica, com teores variáveis dependendo das características regionais (Sposito, 1989). A matéria orgânica e a argila são os principais constituintes responsáveis pela sorção do metal no solo. Um solo é formado por camadas distintas denominadas de horizontes, que são diferenciados pela cor, textura, estrutura, consistência, presença de carbonato (Brady, 1989).

A mobilidade dos metais no solo faz parte de um processo de desorção ou dissolução do metal seguido de transporte. Por outro lado, a resorção ou precipitação podem imobilizar o metal num outro ponto do solo.

A FIG. 4.1 representa a solubilidade, disponibilidade e mobilidade do metal no solo. Esta figura mostra as possíveis interações do íon (metálico) solúvel com as frações do solo. $O$ íon se liga às frações, matéria orgânica e óxidos, por troca iônica (ligação eletrostática) e complexação (ligação covalente), particularmente por complexação, o que faz desta interação uma ligação mais forte, necessitando de agentes extratores mais fortes para romper a ligação do íon com o solo (FIG. 3.1). A interação do íon com as argilas, tais como, esmectitas, vermiculitas, montmorrilonitas, ilitas, caolinitas, se ligam por troca iônica. Os precipitados podem se formar por meio da interação de um cátion com os ânions $\mathrm{CO}_{3}{ }^{2-}, \mathrm{S}^{2-}, \mathrm{SO}_{4}{ }^{2-}, \mathrm{OH}^{-}, \mathrm{PO}_{4}{ }^{3-}$.

A mobilidade dos metais vai depender das características do metal (forma química e concentração) e das características do solo (física, química, mineralógica e biológica). 
A seguir serão descritas propriedades importantes dos metais tóxicos estudados neste trabalho, relacionadas com a mobilidade de cada um. Considerando também a sua toxicidade e concentração natural em solos. Estas informações abaixo foram retiradas dos livros McBride (1994), Alloway (1990) e Kabata et al., 1984. Na TAB. 4.1 apresenta-se a forma química do metal encontrada em solos ácidos e alcalinos e na TAB. 4.2 apresenta-se a toxicidade, a concentração dos metais em solos naturais e o fator de transferência solo/planta.

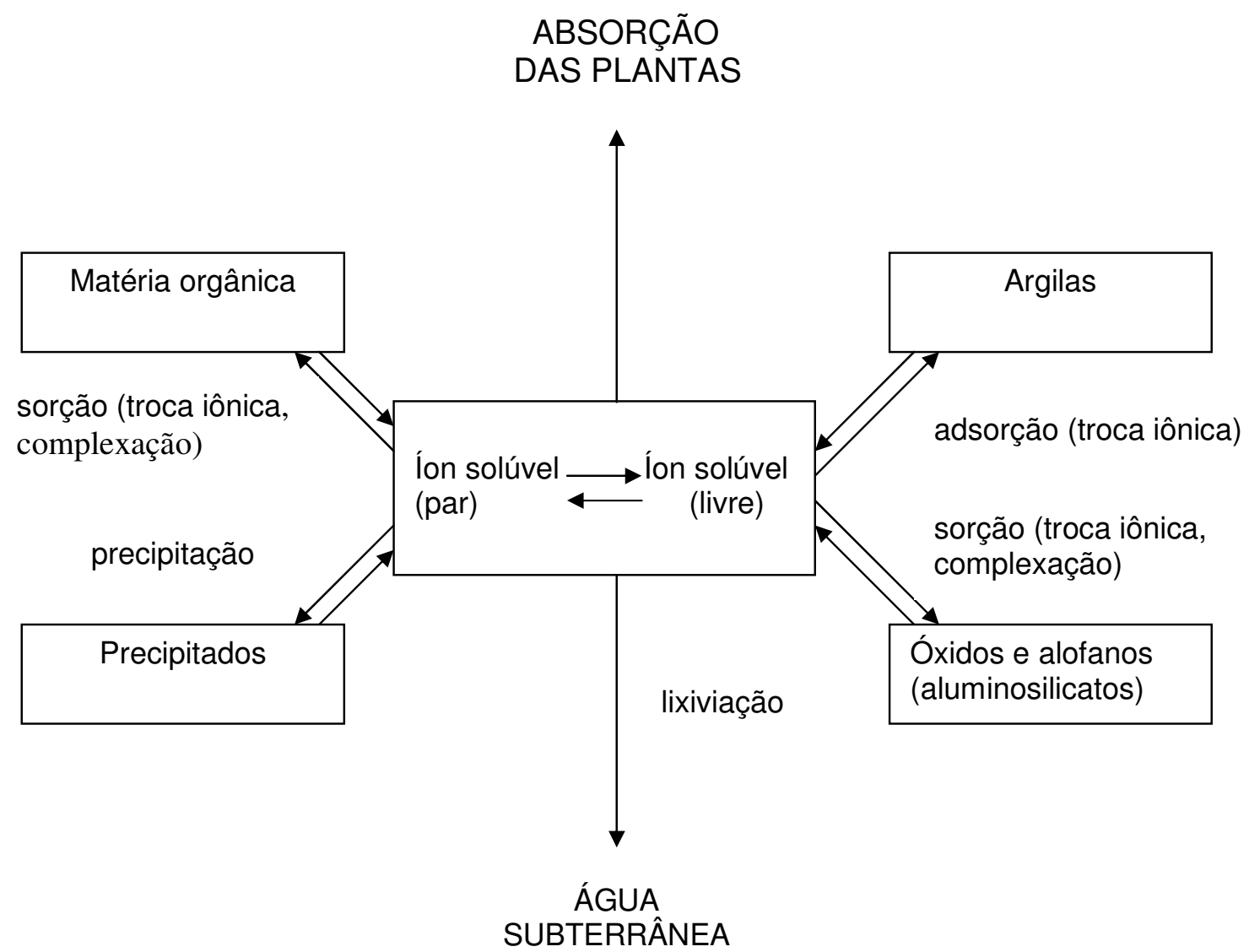

FIGURA 4.1 - Representação de solubilidade, disponibilidade e mobilidade do metal no solo (adaptado de McBride, 1994). 
TABELA 4.1 - Principais formas químicas dos metais em solução do solo, em condições oxidantes (Alloway, 1990).

\begin{tabular}{|c|c|c|}
\hline \multirow[t]{2}{*}{ Metal } & \multicolumn{2}{|c|}{ Forma química } \\
\hline & Solos ácidos & Solos alcalinos \\
\hline$A s^{a}$ & $\mathrm{H}_{2} \mathrm{AsO}_{4}^{-}$ & $\mathrm{HAsO}_{4}{ }^{-2}$ \\
\hline Cd & $\mathrm{Cd}^{2+}, \mathrm{CdSO}_{4}{ }^{0}, \mathrm{CdCl}^{+}$ & $\mathrm{Cd}^{2+}, \mathrm{CdCl}^{+}, \mathrm{CdSO}_{4}{ }^{0}, \mathrm{CdHCO}^{+}$ \\
\hline $\mathrm{Cr}$ & $\mathrm{CrOH}_{2}^{+}, \mathrm{CrO}_{4}^{2-}$ & $\mathrm{CrO}_{4}{ }^{2-}, \mathrm{Cr}(\mathrm{OH})_{4}^{-}$ \\
\hline $\mathrm{Cu}$ & $\mathrm{CO}, \mathrm{Cu}^{2+}$ & $\mathrm{CuCO}_{3}, \mathrm{CO}, \mathrm{CuB}(\mathrm{OH})_{4}{ }^{+}, \mathrm{Cu}\left(\mathrm{B}(\mathrm{OH})_{4}\right)_{2}{ }^{0}$, \\
\hline Mo & $\mathrm{H}_{2} \mathrm{MoO}_{4}^{0}, \mathrm{HMoO}_{4}^{-}$ & $\mathrm{HMoO}_{4}^{-}, \mathrm{MoO}_{4}^{2-}$ \\
\hline $\mathrm{Ni}$ & $\mathrm{Ni}^{2+}, \mathrm{NiSO}_{4}{ }^{0}, \mathrm{NiHCO}_{3}^{+}, \mathrm{CO}$ & $\mathrm{NiCO}_{3}, \mathrm{NiHCO}_{3}^{+}, \mathrm{Ni}^{2+}, \mathrm{NiB}(\mathrm{OH})_{4}^{+}$ \\
\hline $\mathbf{P b}$ & $\mathrm{Pb}^{2+}, \mathrm{CO}, \mathrm{PbSO}_{4}{ }^{0}, \mathrm{PbHCO}_{3}{ }^{+}$, & $\mathrm{PbCO}_{3}^{0}, \mathrm{PbHCO}_{3}^{+}, \mathrm{Pb}\left(\mathrm{CO}_{3}\right)_{2}^{2-}, \mathrm{PbOH}^{+}$ \\
\hline Zn & $\mathrm{Zn}^{2+}, \mathrm{ZnSO}_{4}^{0}$ & $\mathrm{ZnHCO}_{3}{ }^{+}, \mathrm{ZnCO}_{3}{ }^{0}, \mathrm{Zn}^{2+}, \mathrm{ZnB}(\mathrm{OH})_{4}{ }^{+}$ \\
\hline
\end{tabular}

a. Yong e Mulligan (2003)

CO: complexo orgânico

TABELA 4.2 - Toxicidade (McBride, 1994), concentração dos metais em solos naturais (Kabata, 1984) e fator de transferência solo/planta (Blume, 1992).

\begin{tabular}{|c|c|c|c|c|c|}
\hline \multirow[t]{2}{*}{ Metal } & \multicolumn{2}{|c|}{ Toxicidade } & \multicolumn{2}{|c|}{$\begin{array}{l}\text { Concentração em solos } \\
\text { naturais }\left(\mathrm{mg} \mathrm{kg}^{-1}\right)\end{array}$} & \multirow{2}{*}{$\begin{array}{l}\text { Fator de } \\
\text { transferência } \\
\text { solo/planta }\end{array}$} \\
\hline & plantas & mamíferos & mundial & EUA & \\
\hline As & $\mathrm{M} / \mathrm{A}$ & A & $2,2-25$ & $3,6-8,8$ & $0,01-0,1$ \\
\hline Cd & $\mathrm{M} / \mathrm{A}$ & A & $0,06-1,1$ & - & $1-10$ \\
\hline Co & $M / A$ & M & $1,6-21,5$ & $1-17$ & $0,01-0,1$ \\
\hline $\mathrm{Cr}$ & $M / A$ & $\mathrm{M}\left(\mathrm{Cr}^{3+}\right) / \mathrm{A}\left(\mathrm{Cr}^{6+}\right)$ & $7-221$ & $20-85$ & $0,01-0,1$ \\
\hline $\mathrm{Cu}$ & $M / A$ & M & $6-80$ & $14-29$ & $0,1-1$ \\
\hline Mo & M & M & $1-3$ & $0,35-5,8$ & $0,1-10$ \\
\hline $\mathrm{Ni}$ & $\mathrm{M} / \mathrm{A}$ & M & $4-55$ & $13-30$ & $0,1-1$ \\
\hline $\mathbf{P b}$ & M & A & $10-84$ & $17-26$ & $0,01-0,1$ \\
\hline Zn & $\mathrm{B} / \mathrm{M}$ & $\mathrm{B} / \mathrm{M}$ & $17-125$ & $34-84$ & $1-10$ \\
\hline
\end{tabular}

A: alta; B: baixa; M: média. 
Arsênio

Os mais prováveis estados de oxidação do As em solos são +3 e +5, embora os estados de oxidação 0 e -3 são encontrados em solos redutores. As espécies mais comuns no solo não são as mais tóxicas. O estado reduzido $\mathrm{As}^{3+}$ (arsenito) é mais provável ser encontrado em solos anaeróbicos e o estado de oxidação $\mathrm{As}^{5+}$ (arsenato) é mais estável em solos aeróbicos.

Arsenato tem comportamento químico similar ao fosfato do solo. É sorvido por óxidos de $\mathrm{Fe}$ e $\mathrm{Al}$ e aluminosilicatos não cristalinos. Arsenato é sorvido mais efetivamente em $\mathrm{pH}$ baixo, portanto, sua mobilidade é baixa em solos ácidos com alto conteúdo de argila ou óxidos. Em solos neutros e alcalinos o arsenato é mais solúvel. A atividade microbiana do solo ou óxido de Mn pode oxidar o arsenito para o arsenato sob condições aeróbicas.

A sorção do arsenito em óxidos no solo é mais fraca que a sorção do arsenato em $\mathrm{pH}$ abaixo de 7. Arsenato parece sorver mais efetivamente em $\mathrm{pH}$ entre 7 e 9.

Solos tratados com sais ferrosos, que oxidam a $\mathrm{Fe}(\mathrm{OH})_{3}$, e calcita, que sorve arsenato e forma precipitado de arsenato de cálcio, parece diminuir o nível de toxicidade de As em solos.

\section{Cádmio}

As condições oxidantes do intemperismo no solo liberam $\mathrm{Cd}$ como um íon solúvel e móvel, $\mathrm{Cd}^{2+}$. Este cátion é mais solúvel que $\mathrm{Zn}^{2+}$ em soluções ácidas oxidantes e é conhecido como ter de média a alta mobilidade em solos ácidos bem drenados. A alta mobilidade é atribuída ao fato de $\mathrm{Cd}^{2+}$ adsorver fracamente na matéria orgânica, argilas e óxidos, a menos que o $\mathrm{pH}$ for maior que 6 . Acima de $\mathrm{pH} 7, \mathrm{Cd}^{2+}$ pode coprecipitar com $\mathrm{CaCO}_{3}$ ou precipitar como $\mathrm{CO}_{3}{ }^{2-}, \mathrm{PO}_{4}{ }^{3-}$ ou $\mathrm{S}^{2-}$ se a concentração de Cd for alta, podendo limitar a sua solubilidade. Portanto, mobilidade e biodisponibilidade de $\mathrm{Cd}$ em solos neutros e alcalinos são baixas.

A combinação de alta biodisponibilidade em solos e alta toxicidade para animais e humanos tem feito de $\mathrm{Cd}$ o elemento de maior preocupação considerando solos tratados com lodo de esgoto. 
Cobalto

Cobalto é encontrado no solo em dois estados de oxidação, $\mathrm{Co}^{2+} \mathrm{e}$ $\mathrm{Co}^{3+}$, mas $\mathrm{Co}^{2+}$ é dominante na solução do solo. Este metal está associado preferencialmente com óxidos de $\mathrm{Fe}$ e $\mathrm{Mn}$ por causa da sorção e coprecipitação. Existe evidência que o óxido de $\mathrm{Mn}$ oxida $\mathrm{Co}^{2+}$ para $\mathrm{Co}^{3+}$ e este é fortemente ligado ao óxido de Mn. Conseqüentemente, em condições fortemente oxidantes do solo, o cobalto tende a ficar retido. Quando o pH aumenta, a solubilidade de Co diminui por causa do aumento da sorção em óxidos e argilas, complexação com a matéria orgânica, e possível precipitação do $\mathrm{Co}(\mathrm{OH})_{2}$. Complexo de $\mathrm{Co}^{2+}$ com a matéria orgânica é móvel, portanto, biodisponível. Cobalto é considerado ser móvel em solos ácidos, mas menos móvel quando o pH se aproxima da neutralidade. Em condições fortemente redutoras, a formação de sulfeto de cobalto pode restringir sua mobilidade.

\section{Cromo}

Cromo em solos ocorre, sobretudo nos estados de oxidação 3+ como cátion $\left(\mathrm{Cr}^{3+}\right)$ e $6+$ como cromato $\left(\mathrm{CrO}_{4}{ }^{2-}\right)$. Entretanto, geralmente as condições do solo favorecem a forma $\mathrm{Cr}^{3+}$, um cátion muito imóvel que complexa fortemente com a matéria orgânica e é sorvido pelos óxidos e argilas, em pH muito baixo. A solubilidade de $\mathrm{Cr}^{3+}$ diminui acima de $\mathrm{pH} 4$ e precipita como $\mathrm{Cr}(\mathrm{OH})_{3}$ acima de $\mathrm{pH}$ 5,5. Além disso, $\mathrm{Cr}^{3+}$ substitui $\mathrm{Fe}^{3+}$ em estruturas minerais. A forma $\mathrm{Cr}^{3+}$, portanto, é muito imóvel na maioria dos solos e geralmente não disponível para as plantas, a menos se o solo não for excessivamente ácido.

$\mathrm{Em} \mathrm{pH}$ mais alto, maior que 5, uma pequena fração de $\mathrm{Cr}^{3+}$ no solo pode ser oxidado a cromato, $\mathrm{CrO}_{4}{ }^{2-}$, uma forma muito tóxica do cromo. A oxidação é promovida por óxidos de $\mathrm{Mn}$. Cromato é menos sorvido que $\mathrm{Cr}^{3+}$, e a sua mobilidade e biodisponibilidade é conseqüentemente maior. Entre $\mathrm{pH}$ 3,6 e $7,4 \circ \mathrm{CrO}_{4}{ }^{2-}$ tende a ficar mais retido no solo para valores de $\mathrm{pH}$ mais baixos ao passo que $\mathrm{Cr}^{3+}$ tende a ficar mais retido para valores de $\mathrm{pH}$ mais altos (Hassan, 1996). Entretanto, se poluentes contendo $\mathrm{CrO}_{4}{ }^{2-}$ são aplicados no solo, a maioria ou todo o cromato é espontaneamente reduzido a $\mathrm{Cr}^{3+}$, especialmente sob condições ácidas e com matéria orgânica presente. A matéria orgânica fornece agentes redutores e grupos complexantes, estabilizando a forma $\mathrm{Cr}^{3+}$. 
Cromo é considerado um metal imóvel que é difícil de ser extraído do solo mesmo por agentes químicos agressivos.

Cobre

O cobre ocorre nas fases líquida e sólida do solo quase que exclusivamente como cátion bivalente $\left(\mathrm{Cu}^{2+}\right)$. Entretanto, redução de $\mathrm{Cu}^{2+}$ para $\mathrm{Cu}^{+}$e $\mathrm{Cu}^{0}$ é possível sob condições redutoras, especialmente se haletos ou sulfetos estão presentes para estabilizar $\mathrm{Cu}^{+}$. Cobre tende associar-se com 0 sulfeto formando minerais muito insolúveis, $\mathrm{Cu}_{2} \mathrm{~S}$ e CuS. Em solos redutores, então, cobre tem baixa mobilidade. A maioria das frações do solo (óxidos de $\mathrm{Mn}$, Al e Fe, argilas e matéria orgânica) sorve $\mathrm{Cu}^{2+}$ fortemente, e esta interação aumenta com o aumento de pH. Em solo com alta concentração de $\mathrm{Cu}$, a precipitação de hidróxido, óxido ou carbonato é possível acima de pH 6. A ligação do complexo de $\mathrm{Cu}^{2+}$ com a matéria orgânica é mais fortemente que qualquer outro metal de transição bivalente. A mobilidade destes complexos é baixa, limitando a biodisponibilidade.

Por causa da alta afinidade de $\mathrm{Cu}^{2+}$ pelas frações do solo, cobre é considerado um elemento de baixa mobilidade em solos neutros. Em solos mais alcalinos, complexos de $\mathrm{Cu}^{2+}$ com hidróxido, carbonato e particularmente com a matéria orgânica, se formam e aumentam a solubilidade do cobre. Conseqüentemente, a mobilidade do cobre pode ser significante sob $\mathrm{pH}$ alto.

\section{Molibdênio}

Molibdênio é mais encontrado no estado de oxidação +6 no solo, na forma do ânion $\mathrm{MoO}_{4}{ }^{2-}$, do que nos estados de oxidação +3 e +4 . Molibdato é sorvido no solo por óxidos, aluminosilicatos não cristalinos e argilas, particularmente por óxidos de $\mathrm{Fe}$ e Al. A sorção do $\mathrm{MoO}_{4}{ }^{2-}$ nestes minerais aumenta quando o $\mathrm{pH}$ é mais baixo. Conseqüentemente, Mo é menos solúvel em solos ácidos, particularmente aqueles que contém óxido de Fe. Em solos básicos a solubilidade do $\mathrm{MoO}_{4}{ }^{2-}$ aumenta por causa da competição deste ânion com 0 íon hidroxila $\left(\mathrm{OH}^{-}\right)$nos sítios de sorção. Adição de fosfato no solo pode liberar molibdato dos sítios de ligação, aumentando a biodisponibilidade do elemento. Precipitação do Mo é considerado pouco provável por causa da baixa concentração do elemento na maioria dos solos. 
Molibdênio tem alta mobilidade em solos neutros e alcalinos, e média mobilidade em solos ácidos. $\mathrm{A}$ adição de $\mathrm{CaCO}_{3}$ (denominado de calagem) aumenta a disponibilidade do elemento.

Em solos pouco drenados o molibdênio se liga à matéria orgânica e se Mo estiver em menor estado de oxidação pode associar-se com o sulfeto, reduzindo desta forma sua solubilidade.

Níquel

O estado de oxidação +2 é a única forma estável do $\mathrm{Ni}$ em solos. O cátion $\mathrm{Ni}^{2+}$ tem eletronegatividade similar ao $\mathrm{Cu}^{2+}$, este fato e sua estrutura eletrônica favorece a formação de complexos com a matéria orgânica que são comparáveis em estabilidade com aqueles de $\mathrm{Cu}^{2+}$. $\mathrm{O} \mathrm{Ni}^{2+}$ coprecipita com óxidos de $\mathrm{Mn}$ e Fe nos solos. A sorção em óxidos, aluminosilicatos não cristalinos e argilas é favorecida acima de $\mathrm{pH} 6$, mas para $\mathrm{pH}$ baixo $\mathrm{Ni}^{2+}$ se encontra nas frações trocável e solúvel. Por causa da solubilidade diminuir com o aumento do $\mathrm{pH}$, a mobilidade do $\mathrm{Ni}$ é considerada média em solos ácidos, tornando-se muito baixa em solos neutros e alcalinos. Em condições redutoras do solo, $\mathrm{Ni}^{2+}$ é incorporado com sulfetos que restringe sua mobilidade. Alto conteúdo de matéria orgânica no solo pode liberar o $\mathrm{Ni}^{2+}$ do solo como complexos orgânicos solúveis, em pH alto.

Chumbo

O chumbo existe nos estados de oxidação +2 e +4 , particularmente como $\mathrm{Pb}^{2+}$ nos solos. Em solos redutores o $\mathrm{Pb}$ é muito insolúvel por causa da sua precipitação com o sulfeto gerado da redução do sulfato. Em condições oxidantes o $\mathrm{Pb}^{2+}$ torna-se menos solúvel quando o $\mathrm{pH}$ é aumentado. A complexação do $\mathrm{Pb}^{2+}$ com a matéria orgânica, sorção em óxidos e argilas, e precipitação como carbonato, hidróxido ou fosfato, são formados em pH mais alto, particularmente a complexação com a matéria orgânica. Em solos alcalinos a solubilidade pode aumentar pela formação de complexos solúveis orgânicos e com hidroxila. $\mathrm{O} \mathrm{Pb}^{2+}$ tem alta afinidade com o óxido de Mn. Pb é o metal tóxico menos móvel no solo, especialmente sob condições redutoras ou não ácidas. 
$\mathrm{O} \mathrm{Pb}$ quando absorvido pelas raízes da planta é pouco transportado para as partes mais altas da planta. Efeitos tóxicos para a planta não têm sido observados, mas sim para os animais.

Zinco

O zinco encontra-se num único estado de oxidação no solo, $\mathrm{Zn}^{2+}$. Em solos ácidos e aeróbicos, Zn tem mobilidade média, ligado na matéria orgânica e nas argilas por troca iônica. Entretanto, em pH mais alto a sorção em óxidos, aluminosilicatos e complexação com a matéria orgânica diminuem a solubilidade do $\mathrm{Zn}^{2+}$. Conseqüentemente, a mobilidade de $\mathrm{Zn}$ em solos neutros é muito baixa. Em solos ligeiramente básicos a formação de complexo orgânico de $\mathrm{Zn}$ pode torná-lo solúvel e aumentar sua mobilidade. Em solos extremamente alcalinos, a formação de complexo aniônico de $\mathrm{Zn}$ com hidroxilas pode aumentar a sua solubilidade.

Em solos contaminados com alta concentração de $\mathrm{Zn}^{2+}$, a precipitação de Zn como óxido, hidróxido ou hidroxicarbonato pode limitar a solubilidade de $\mathrm{Zn}^{2+}$ em pH igual ou maior que 6. Coprecipitação de $\mathrm{Zn}^{2+}$ com óxidos e silicatos é teoricamente possível.

Em solos redutores, a mobilidade de Zn é restringida pela formação de ZnS, extremamente insolúvel. Em solos ácidos e oxidantes, $\mathrm{Zn}^{2+}$ é um dos metais tóxicos mais solúveis e móveis. 


\section{MODELO DE AVALIAÇÃO DE RISCO À SAÚDE HUMANA, C-SOIL}

O modelo matemático de avaliação de risco à saúde humana C-Soil adotado pela CETESB para estabelecer valores de intervenção para solos foi desenvolvido pelo Instituto Nacional de Saúde Pública e Meio Ambiente da Holanda (Berg, 1994). É um modelo de avaliação de risco que considera efeitos toxicológicos que consiste de várias equações que relacionam os processos de transferência das fases (solo/água; solo/ar), transporte e exposição humana à presença de contaminantes no solo. Algumas equações do modelo C-Soil correspondem a submodelos, tais como, Soil Risk (Berge, 1990), HESP (ECETOC, 1990), RIVM (Linders, 1990), Jury (1983) que contemplam vias de exposição diretas e indiretas (Berg, 1994). A somatória das exposições corresponde ao ingresso diário total de um contaminante. O cálculo do coeficiente de risco é efetuado com base no ingresso diário do contaminante comparado ao TDI (ingresso diário tolerável) para as substâncias não cancerígenas e a probabilidade de câncer para as substâncias cancerígenas. Na FIG. 5.1 apresenta-se o modelo conceitual do C-Soil. 


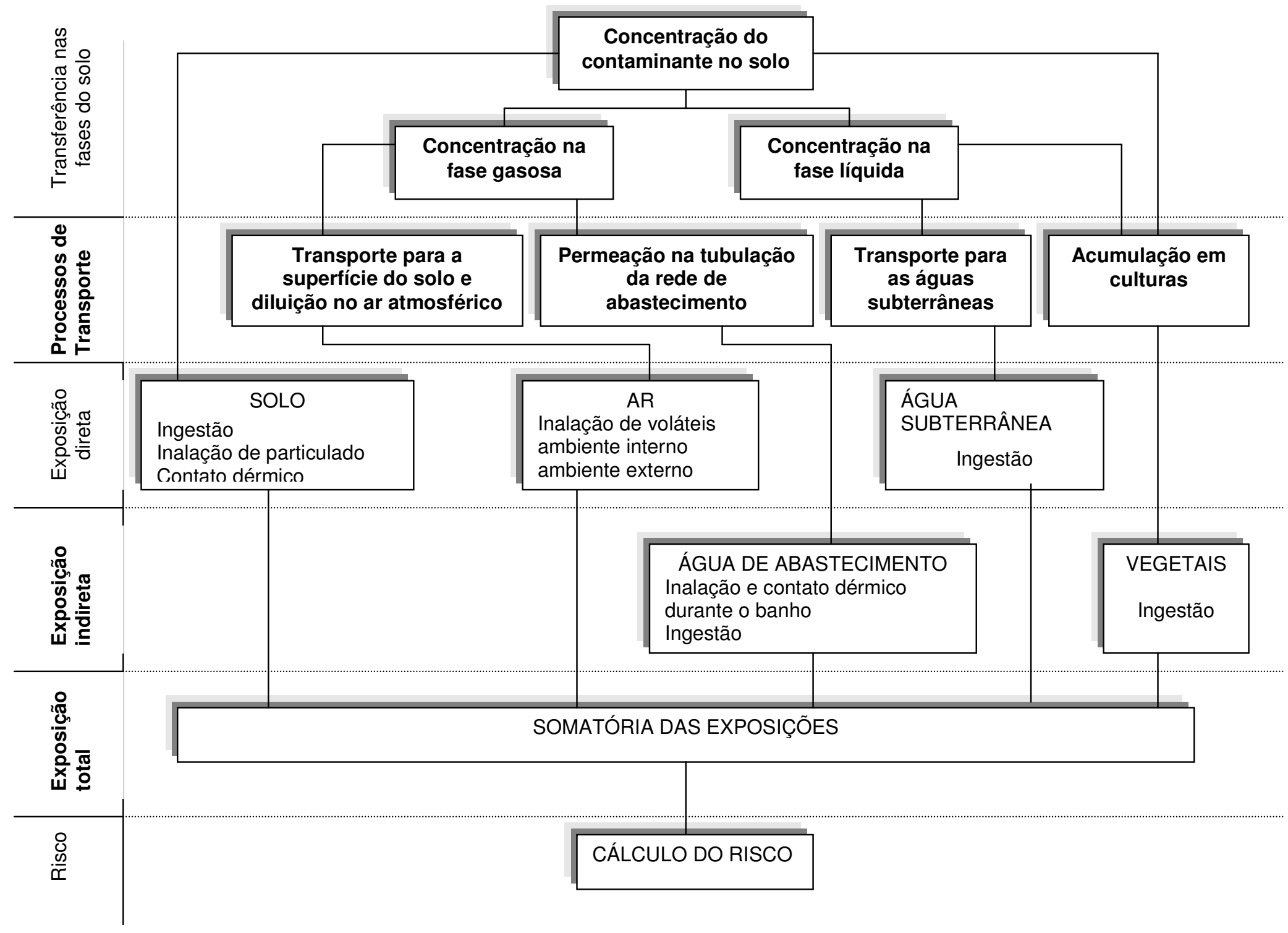

FIGURA 5.1 - Esquema conceitual utilizado pelo modelo C-Soil para cálculo de risco (Berg, 1994). 
O dado de entrada do modelo C-Soil é a concentração do contaminante no solo. Os outros dados são valores nominais de parâmetros estabelecidos no modelo, que podem ser alterados ou não conforme a disponibilidade de dados do local estudado. Segundo o modelo conceitual C-Soil (FIG. 5.1) quando um contaminante é depositado no solo, ele pode sofrer transferência para as fases líquida e gasosa do solo por meio de partição do contaminante entre solo/fase líquida e solo/fase gasosa, respectivamente. O contaminante na fase gasosa pode ser transportado para a superfície do solo e diluído no ar atmosférico e/ou permeado na tubulação da rede de abastecimento. Conseqüentemente o homem poderá estar exposto às vias ar (por inalação de voláteis em ambiente interno e externo) e água de abastecimento (por inalação e contato dérmico durante o banho e ingestão de água de abastecimento), respectivamente. O contaminante na fase líquida pode ser transportado para as águas subterrâneas e acumulados em plantas, onde o homem poderá estar exposto, deste modo, às vias de ingestão de águas subterrâneas e vegetais, respectivamente. Além de o contaminante sofrer transferência do solo para as fases líquida e gasosa, ele pode ser depositado nas folhas das plantas e a via de exposição ao homem será a ingestão de vegetais, ou pode ser uma via direta de exposição ao homem (por ingestão do solo, inalação de particulado e contato dérmico). A somatória de todas as vias de exposição ao homem corresponde ao ingresso diário total de um contaminante. No caso do contaminante ser um metal, que é estudo do presente trabalho, o modelo C-Soil considera a concentração do metal na fase gasosa do solo nula, portanto, as vias de exposição ar e água de abastecimento (FIG. 5.1) não fazem parte da somatória das exposições, somente as vias solo, águas subterrâneas e vegetais.

O modelo C-Soil apresenta algumas limitações, não considerando algumas situações, tais como:

a) as vias de exposição para consumo de alimentos (peixe, carne, leite e ovos) e águas superficiais;

b) a degradação do contaminante ao longo do tempo;

c) grupos distintos de sub-populações, tais como, mulheres grávidas;

d) fontes de contaminação originadas fora do local avaliado;

e) fatores ecotoxicológicos;

f) pluma de contaminação; 
g) mistura de contaminantes.

Os itens "a" e "g" podem ser contornados. Se as vias de exposição de consumo de alimentos e águas superficiais (item a) forem importantes, a quantidade do contaminante presente em cada via absorvida pela população deve ser mensurada e somada ao total das outras vias. A mistura de contaminantes (item g) pode ser estimada por meio da somatória dos riscos calculados separadamente para cada contaminante.

Além destas limitações do modelo C-Soil, os valores nominais dos parâmetros adotados no modelo podem não ser adequados ou não realistas para casos específicos de solos contaminados. Neste trabalho será discutido o parâmetro coeficiente de partição (Kp) para metais em solos que está relacionado com a transferência do metal do solo para a solução do solo. Posteriormente à transferência do metal para a solução do solo o metal sofre um processo de transporte que está relacionado com a ingestão de águas subterrâneas e vegetais.

O coeficiente de partição encontra-se nas etapas de concentração na fase líquida e acumulação em culturas do modelo conceitual do C-Soil (FIG. 5.1).

\subsection{Concentração na fase líquida}

Esta etapa do modelo relaciona a transferência do metal da fase sólida do solo para a líquida. Nesta etapa são consideradas as seguintes equações:

$$
C p w=\frac{C s \cdot S D \cdot P w}{V w}
$$

em que Cpw : concentração na solução do solo $\left(\mathrm{mg} \mathrm{L}^{-1}\right)$

Cs: concentração inicial do contaminante no solo $\left(\mathrm{mg} \mathrm{kg}^{-1}\right)$

SD: densidade do solo $\left(\mathrm{kg} \mathrm{L}^{-1}\right)$

Pw: fração de massa do contaminante na solução do solo

Vw: fração do volume de água

Para metais, 


$$
P w=\frac{V w}{V w+K p . S D}
$$

em que Kp é o coeficiente de partição solo-água $\left(\mathrm{L} \mathrm{kg}^{-1}\right)$

Então,

$$
C p w=\frac{C s . S D}{V w+K p \cdot S D}
$$

A equação (5.3) relaciona a concentração de um determinado metal na solução do solo (Cpw) com sua concentração inicial (Cs), densidade do solo (SD), fração do volume de água ( $\mathrm{Vw}$ ) e coeficiente de partição solo-água (Kp).

A densidade do solo e o valor da fração do volume de água variam pouco quando comparadas com o coeficiente de partição. A densidade do solo varia de 0,9 a $1,5 \mathrm{~g} \mathrm{~cm}^{-3}$ dependendo da estrutura do solo (Ferreira, 1999). A fração do volume de água está relacionada com a umidade do solo que é dada em porcentagem. Portanto, o valor da fração do volume de água introduzido na equação (5.3) varia pouco, entre 0 e 1.

O próprio Instituto Nacional de Saúde Pública e Meio Ambiente da Holanda que desenvolveu o modelo C-Soil apresenta o Kp como um parâmetro sensível do modelo C-Soil e tem reavaliado os valores nominais do modelo (Otte, 2001).

\subsection{Acumulação em culturas}

Esta etapa do modelo relaciona o transporte do metal da solução do solo para os vegetais por absorção. Nesta etapa, para os metais, são consideradas as seguintes equações:

$$
\text { Cpr }=\text { BCFr.Cs }
$$

em que, 
Cpr: concentração nas raízes (tubérculos) (mg metal $/ \mathrm{kg}$ peso seco vegetal) BCFr: fator de bioconcentração nas raízes (mg metal/kg peso seco vegetal)

$$
C p s=B C F s . C s+C d p
$$

em que,

Cps: concentração nas folhas (mg metal $/ \mathrm{kg}$ peso seco vegetal)

BCFs: fator de bioconcentração nas folhas (mg metal/kg peso seco vegetal)

(mg metal/kg solo seco)

Cdp: concentração em folhas devido à deposição $(\mathrm{mg}$ metal $/ \mathrm{kg}$ peso seco vegetal)

$$
C d p=1,089 \cdot 10^{-3} \cdot C s
$$

Se não forem conhecidos BCFr ou BCFs, esses fatores podem ser estimados pela seguinte equação:

$$
\ln B C F r=\ln B C F s=2,67-1,12 \ln K p
$$




\section{METODOLOGIA}

\section{1. Área de estudo}

As amostras de solo analisadas neste trabalho são provenientes da cidade de Figueira, no estado do Paraná, próximas da usina termoelétrica a base de carvão. Esta área foi selecionada pelos seguintes motivos:

- a usina termoelétrica de Figueira é a única indústria de porte da região num raio de $10 \mathrm{~km}$, sendo a única fonte poluidora industrial. A usina tem uma capacidade de $10 \mathrm{MW}$ e já está em operação há aproximadamente 40 anos.

- a área adjacente à usina é predominantemente agrícola e pecuarista, com baixa densidade populacional.

- relevo suave e ondulado.

A área em estudo está localizada a nordeste do Estado do Paraná (latitude $23^{\circ} 52^{\prime} 00^{\prime \prime}$ sul e longitude 50²4'00" W-GR), a $315 \mathrm{~km}$ da capital Curitiba (FIG. 6.1).

O clima da região é subtropical úmido mesotérmico com médias máxima de $26,3^{\circ} \mathrm{C}$ e mínima de $11,7^{\circ} \mathrm{C}$. A umidade relativa do ar apresenta uma média de 67\%. O índice pluviométrico anual médio é de 1397,8 mm.

$\mathrm{Na}$ vegetação local predomina o cerrado com mata e culturas permanentes e temporárias, sobretudo o café. $\mathrm{O}$ relevo é suave e ondulado, constituído por morros de pequena expressão topográfica, sendo que a altitude média local é de $600 \mathrm{~m}$. O solo é representado pela associação podzólicovermelho-amarelo-álico-abrúptico (Morrone, 1985).

A base econômica consiste no extrativismo mineral, especialmente do carvão, tendo sido em 1992, responsável por mais de $70 \%$ da produção de combustíveis minerais comercializados no Estado (Morrone, 1985).

Na FIG. 6.2 apresentam-se as fotos da região de Figueira. 


\subsection{Coleta das amostras de cinzas e solo}

As cinzas que provém do processo de combustão do carvão da usina termoelétrica em estudo para geração de energia foram coletadas em três pontos da usina. Estes pontos correspondem ao fundo de caldeira (cinzas pesadas), e filtros ciclone e manga (cinzas leves) que retêm as frações dos grãos das cinzas antes de ser liberado para a atmosfera pela chaminé.

As amostras de cinzas e carvão foram coletadas num período de 12 meses (entre 2001 e 2002) de 2 em 2 meses, totalizando 6 lotes. Em cada lote foram coletadas aproximadamente $1 \mathrm{~kg}$ de cinzas pesadas (do fundo de caldeira) e cinzas leves (do filtro manga e ciclone), e $1 \mathrm{~kg}$ de carvão pulverizado, matériaprima de entrada no processo de combustão.

As amostras de solo que provém de uma área nas proximidades da usina termoelétrica em estudo, foram coletadas em 1996 e 1997 antes da instalação dos filtros ciclone e manga na usina termoelétrica (1998) e em 2001 após a instalação destes filtros. Estes filtros foram instalados para minimizar a emissão de poluentes para a atmosfera.

As amostras de solo coletadas antes da instalação dos filtros foram obtidas em duas etapas: na primeira etapa, em 1996, foram coletadas em 14 pontos ao redor da usina distantes de $1 \mathrm{~km}$ e $3 \mathrm{~km}$, com profundidade de 0 a 25 cm (pontos cardeais A); na segunda etapa, em 1997, foram coletadas 13 pontos na direção noroeste (NW) de $200 \mathrm{~m}$ da usina até $1200 \mathrm{~m}$ de distância, variando de 100 em 100 m, e outros dois pontos, $2200 \mathrm{~m}$ e 3000 m, e cada ponto foi coletado em duas profundidades (de 0 a $25 \mathrm{~cm}$, transect $A$, e de 25 a $50 \mathrm{~cm}$, transect B). As amostras de solo do transect foram coletadas na direção NW porque a concentração de radionuclídeos nos pontos cardeais foi maior nesta direção (Flues, 2002a). Esta direção NW corresponde à segunda direção predominante dos ventos segundo a estação meteorológica de Telemaco Borba que é distante $70 \mathrm{~km}$ de Figueira, mas é a estação mais próxima da região. $\mathrm{O}$ total de pontos de solo coletados foi de 40 amostras. Na FIG. 6.1 apresentam-se os pontos de coleta de solo. 


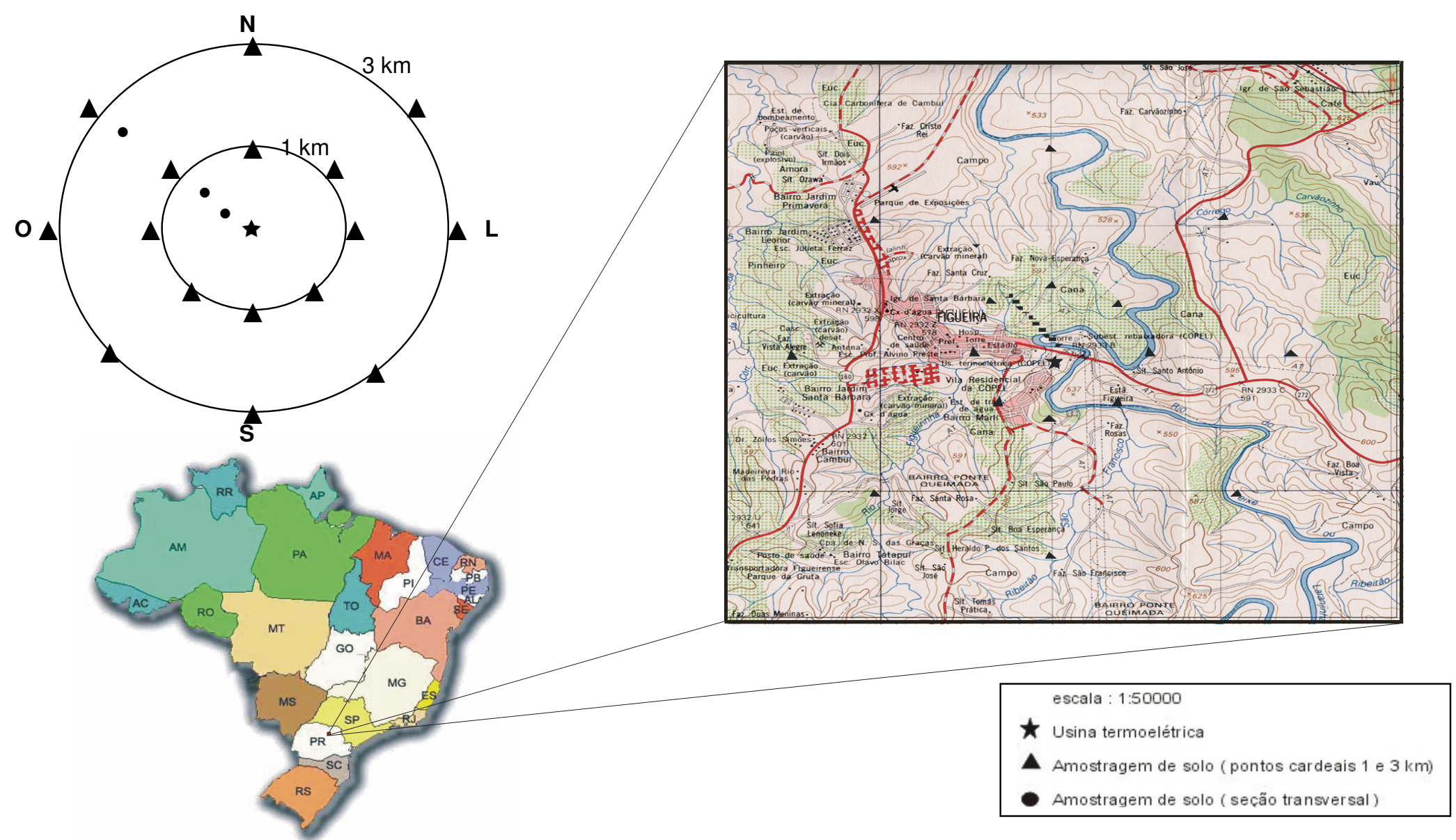

FIGURA 6.1 - Localização de Figueira, da usina termoelétrica e dos pontos de coleta do solo. 

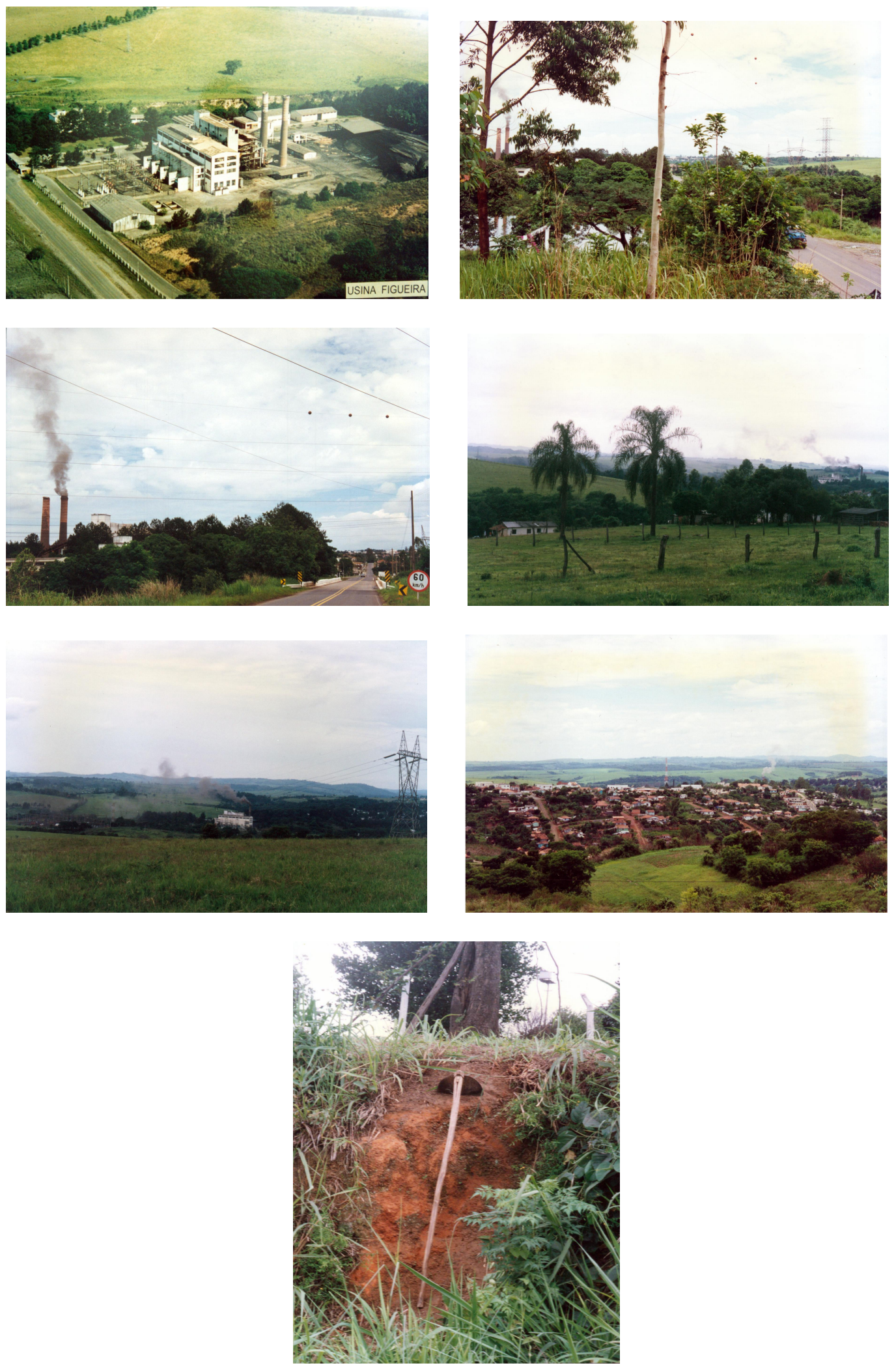

FIGURA 6.2 - Fotos da usina termoelétrica, da região de Figueira próximo da usina e um perfil do solo da região. 
As amostras de solo coletadas em 2001, depois da instalação dos filtros, foram coletadas em dois pontos do transect A, 400 e 600. O ponto 400 foi selecionado por causa do ponto de deposição dos poluentes calculado pela equação de Pasquille (Flues, 2002a) tomando-se por base a altura chaminé da usina, de onde saem os gases e particulados para a atmosfera. $O$ ponto 600 foi selecionado pela proximidade do ponto 400 .

Em cada ponto foram tiradas 3 amostras distantes, aproximadamente, de $50 \mathrm{~cm}$ cada uma, numa projeção triangular. Foi coletado $1 \mathrm{~kg}$ de solo para cada amostra, utilizando um trado.

\subsection{Pré-tratamento das amostras}

As amostras de solo foram secas à temperatura ambiente, trituradas manualmente em almofariz e peneiradas para $2 \mathrm{~mm}$. Posteriormente as amostras foram quarteadas manualmente para tirar uma alíquota representativa para os ensaios de caracterização do solo ou para os ensaios de determinação dos metais nas amostras de solo.

\subsection{Caracterização das amostras de solo}

Os ensaios de caracterização físico-química do solo, granulometria, pH, matéria orgânica (MO) e capacidade de troca catiônica (CTC), foram realizados em duplicata. Todos os reagentes utilizados foram de grau P.A. A seguir serão descritas as referências dos métodos que foram seguidos para estes ensaios. 


\begin{tabular}{|c|c|}
\hline ENSAIO (Método) & REFERÊNCIA \\
\hline $\begin{array}{l}\text { Granulometria } \\
\text { Boyoucos) }\end{array}$ & USDA, 1975 \\
\hline $\begin{array}{l}\mathrm{pH} \text { (em } \mathrm{KCl} \text {, proporção solo:solução } \\
1: 2,5)\end{array}$ & EMBRAPA, 1997 \\
\hline $\begin{array}{lccc}\text { Matéria } & \text { orgânica } & \text { (oxidação } & \text { com } \\
\mathrm{K}_{4} \mathrm{Cr}_{2} \mathrm{O}_{7} & \mathrm{e} & \text { titulação } & \text { com } \\
\left.\mathrm{Fe}\left(\mathrm{NH}_{4}\right)_{2}\left(\mathrm{SO}_{4}\right)_{2}\right) & & \end{array}$ & EMBRAPA, 1997 \\
\hline $\begin{array}{l}\text { Capacidade de troca catiônica efetiva } \\
\text { (saturação com } \mathrm{BaCl}_{2} \text {, troca com } \\
\mathrm{MgSO}_{4} \text { e titulação com EDTA) }\end{array}$ & Rhoades, 1982 \\
\hline Al, Fe e Mn (fluorescência de raios $X$ ) & $\begin{array}{l}\text { Lachance e Claisse, 1995; Wheller, } \\
1998 .\end{array}$ \\
\hline
\end{tabular}

\subsection{Preparação de amostras para determinação da concentração dos metais}

A preparação das amostras de solo foi realizada no estado sólido (pastilhas de dupla camada) e líquido (digestão ácida, extração com EDTA e com $\left.\mathrm{Ca}\left(\mathrm{NO}_{3}\right)_{2}\right)$. A seguir serão descritos os procedimentos adotados para estas preparações.

\subsubsection{Pastilhas de dupla camada}

A preparação das amostras de solo e cinzas no estado sólido (pastilhas de dupla camada) foi realizada em uniplicata. A metodologia adotada, com base no método estabelecido pelo Laboratório de Fluorescência de Raios $\mathrm{X}$ do Centro de Química e Meio Ambiente, foi a seguinte:

\section{Procedimento}

1. Pesou-se aproximadamente $2 \mathrm{~g}$ de amostra;

2. A amostra foi triturada no almofariz de ágata por meia hora;

3. Foi pesado $0,9 \mathrm{~g}$ da amostra triturada e se adicionou $0,1 \mathrm{~g}$ de $\mathrm{H}_{3} \mathrm{BO}_{3}$, que foram triturados juntos por 15 minutos;

4. A base da amostra foi preparada com, aproximadamente, $2 \mathrm{~g}$ de $\mathrm{H}_{3} \mathrm{BO}_{3}$ que recebeu uma carga de 10 toneladas $\mathrm{cm}^{-2}$ durante 1 minuto; 
5. Sobre a base prensada foi adicionada a amostra preparada no item 3 deste procedimento. E aplicou-se uma carga de 15 toneladas $\mathrm{cm}^{-2}$ durante 1 minuto.

\subsubsection{Digestão ácida em forno de microondas}

A preparação das amostras de solo por digestão ácida foi realizada em duplicata. A metodologia adotada, com base no método EPA-3051 da Environmental Protection Agency (EPA, 2003), foi a seguinte:

\section{Procedimento}

1. Foi pesado $500 \mathrm{mg}$ (com precisão de $1 \mathrm{mg}$ ) da amostra de solo seco e moído, e transferida para os frascos de digestão.

2. Adicionou-se $10 \mathrm{~mL}$ de ácido nítrico concentrado. Antes de fechar os frascos, deixou-se em repouso por cerca de 15 minutos.

3. Os frascos foram colocados no forno de microondas (DGT 100 Plus da Provecto Analítica). Programação do forno: a) 2 minutos a $330 \mathrm{~W}$; b) 6 minutos a $800 \mathrm{~W}$; c) 5 minutos a $0 \mathrm{~W}$.

4. Após o término da programação, deixaram-se os frascos em repouso durante 30 minutos.

5. A tampa foi retirada do frasco, adicionou-se $40 \mathrm{~mL}$ de água do mili-Q e as amostras foram homogeneizadas.

6. As amostras foram centrifugadas durante 10 minutos e posteriormente filtradas a vácuo com membrana de filtro.

7. Transferiu-se as amostras para frascos de polietileno para posterior determinação de metais no ICP-AES (espectrometria de emissão atômica com fonte de plasma induzido).

\subsubsection{Extração com EDTA-NH}

A preparação das amostras de solo e cinzas por extração com EDTA foi realizada em duplicata. A metodologia adotada, com base no método de Ure, 1996, foi a seguinte: 


\section{Procedimento}

1. Pesou-se $2 \mathrm{~g}$ de solo seco que foi transferido para um tubo de centrífuga de 50 $\mathrm{mL}$.

2. Adicionou-se $40 \mathrm{~mL}$ de EDTA-NH $40,05 \mathrm{~mol} \mathrm{~L}^{-1}(\mathrm{pH}=7,0)$.

3. A mistura foi agitada verticalmente por uma hora à temperatura ambiente com rotação de aproximadamente $10 \mathrm{rpm}$.

4. A amostra foi centrifugada por 15 minutos, filtrada a vácuo com membrana de filtro e acidificada com $100 \mu \mathrm{L}$ de $\mathrm{HNO}_{3}$ concentrado.

5. Posteriormente, a amostra foi transferida para frascos de polietileno para determinação de metais no ICP-AES.

\subsubsection{Extração com $\mathrm{Ca}\left(\mathrm{NO}_{3}\right)_{2}$}

A metodologia adotada para preparação das amostras de solo por extração com $\mathrm{Ca}\left(\mathrm{NO}_{3}\right)_{2}$, com base no método de Conder et al., 2001, foi a seguinte:

\section{Procedimento}

1. Pesou-se $2 \mathrm{~g}$ de solo seco que foi transferido para um tubo de centrífuga de 50 $\mathrm{mL}$.

2. Adicionou-se $40 \mathrm{~mL}$ de $\mathrm{Ca}\left(\mathrm{NO}_{3}\right)_{2} 0,1 \mathrm{~mol} \mathrm{~L}^{-1}$.

3. A mistura foi agitada horizontalmente por 16 horas à temperatura ambiente com rotação de aproximadamente $170 \mathrm{rpm}$.

4. A amostra foi centrifugada por 15 minutos, filtrada a vácuo com membrana de filtro e acidificada com $100 \mu \mathrm{L}$ de $\mathrm{HNO}_{3}$ concentrado.

5. Posteriormente, a amostra foi transferida para frascos de polietileno para determinação de metais no ICP-AES.

\subsection{Determinação da concentração total, parcial, biodisponível e trocável}

Os metais que foram determinados neste trabalho foram os elementos traços, As, Cd, Co, Cr, Cu, Mo, Ni, Pb, Zn.

As amostras para determinação da concentração total dos metais foram preparadas no estado sólido (pastilhas), item 6.5.1. A concentração total dos 
metais foi obtida por espectrometria de fluorescência de raios $X$ (XRFS) pelo equipamento XRFS RIX 300 da Rigaku.

As amostras para determinação da concentração parcial dos metais foram preparadas por digestão do solo com $\mathrm{HNO}_{3}$ concentrado em forno de microondas (item 6.5.2). As amostras para determinação da concentração biodisponível dos metais foram obtidas por extração com EDTA (item 6.5.3). E as amostras para determinação da concentração trocável dos metais foram obtidas por extração com $\mathrm{Ca}\left(\mathrm{NO}_{3}\right)_{2}$ (item 6.5.4).

Após as extrações dos metais nas amostras de solo a determinação das concentrações parcial, biodisponível e trocável foram obtidas por ICP-AES. O equipamento utilizado foi um ICP-AES SpectroFlame M120 E da Spectro Analytical Instruments, com tocha axial.

\subsection{Determinação do $\mathrm{Kp}$}

O coeficiente de partição, $\mathrm{Kp}$, foi calculado pela razão entre:

$$
\begin{aligned}
& K p_{\text {EОTA }}=\frac{\text { concentração parcial do metal na fase sólida do solo }}{\text { concentração biodisponível do metal na fase líquida do solo }} \\
& K p_{\text {Ca(NO3)2 }}=\frac{\text { concentração parcial do metal na fase sólida do solo }}{\text { concentração trocável do metal na fase líquida do solo }}
\end{aligned}
$$

A concentração parcial dos metais representa a quantidade do metal sorvida no solo em $\mathrm{mg} \mathrm{kg}^{-1}$ e a concentração biodisponível e trocável representa a quantidade do metal na fase líquida do solo em $\mathrm{mg} \mathrm{L}^{-1}$. 


\section{RESULTADOS E DISCUSSÃO}

O solo estudado neste trabalho provém de uma área suspeita de contaminação devido à operação da usina termoelétrica a carvão. A determinação da concentração parcial dos metais pode indicar a contaminação deste solo quando comparado com valores do solo natural (solo com pouco impacto antrópico) da área estudada, valores estabelecidos por agências ambientais ou com valores de solos naturais encontrados mundialmente. Tomando-se por base a concentração parcial pode-se estimar o risco envolvido para cada metal estudado, utilizando o modelo de avaliação de risco C-Soil. Entre os parâmetros adotados no modelo, o coeficiente de partição, $\mathrm{Kp}$, é um parâmetro que pode variar ordens de grandeza segundo as características físico-químicas do solo (Buchter, 1989; EPA, 1996; Janssen, 1997; Otte, 2001) e, portanto, é considerado um parâmetro sensível para avaliação de risco à saúde humana e que deveria ser determinado para a área contaminada em estudo. Como o valor de $\mathrm{Kp}$ do metal depende das características físico-químicas do solo é importante caracterizá-lo.

A seguir serão discutidos alguns tópicos por item, tais como, a contaminação do solo (item 7.1), Kp (item 7.2) e risco (item 7.3).

\subsection{Avaliação da contaminação do solo}

Para avaliar a contaminação do solo de Figueira tomaram-se como base quatro formas de análise: 1. fonte contaminadora dos metais no solo; 2 . concentração do metal versus distância da usina; 3. comparação da concentração do metal com valores mundiais de solos naturais ou estabelecidos por agência ambiental; 4. dispersão da concentração do metal ao redor da usina.

A provável fonte contaminadora de metais no solo de Figueira é a cinza leve que sai da chaminé da usina termoelétrica, e é produzida pela queima do carvão para gerar energia. A cinza leve liberada para a atmosfera contém elementos tóxicos que serão depositados sobre o solo. Elementos tóxicos, tais 
como, As, Be, Cd, Co, Cr, Cu, Mo, Ni, Pb e Zn foram detectados na cinza volante (cinza leve) da chaminé de uma unidade industrial do Rio Grande do Sul (Sánchez, 1987). Outros elementos tóxicos, tais como, $\mathrm{Hg}, \mathrm{Sb}$ e Se, também podem ser emitidos da chaminé de uma usina termoelétrica à carvão para a atmosfera (Blume, 1992).

As amostras de solo foram coletadas antes da instalação dos filtros ciclone e manga na usina (item 6.2). Neste período de coleta do solo, uma parte das cinzas gerada era depositada no fundo de caldeira, outra parte sedimentava no fundo da chaminé e a outra parte era liberada para a atmosfera. Considerando que o tamanho das partículas liberadas pela chaminé no período de coleta dos solos era aproximadamente o tamanho das partículas da cinza retida nos filtros, tomou-se a concentração dos metais nos filtros (cinza ciclone e manga) para se ter um indicativo da fonte contaminadora do solo de Figueira. Na TAB. 7.1 apresentam-se os valores de concentração total e biodisponível dos metais das cinzas (caldeira, ciclone e manga) e do carvão. Observa-se que os metais que apresentam maior concentração total e biodisponível são As, Mo, Pb e Zn. Embora o Cd tenha apresentado concentração mais baixa que estes metais, o Cd é considerado altamente tóxico para mamíferos (TAB. 4.2).

Para avaliar a contaminação dos metais no solo com a distância da usina, construíram-se os gráficos da concentração parcial do metal versus à distância (FIG. 7.1). Observa-se que a concentração dos metais As, Cd, Mo e Zn aumenta nos pontos de coleta de solo, transect $A$, próximos da usina. O declínio da concentração destes metais com a distância indica que houve um incremento destes metais devido à operação da usina termoelétrica a carvão.

Pode-se dizer que um solo está contaminado por um metal quando a concentração deste está acima de valores do solo natural da área estudada, ou valores estabelecidos por agências ambientais referentes a solos limpos (ou solos que não sofreram impacto ambiental devido às atividades antrópicas), ou quando a concentração do metal está acima de valores de solos naturais mundialmente. O ideal seria ter dados da concentração do metal no solo antes da instalação da usina para ter a concentração do metal no solo natural da área e poder afirmar se houve um incremento do metal no solo, ou seja, se o solo foi realmente contaminado. 
Na TAB. 7.2 apresentam-se as médias geométricas e os intervalos da concentração parcial dos metais nas amostras de solo coletadas em 1996 e 1997 (antes da instalação dos filtros na usina) obtidos com base na TAB. A1, os valores orientadores para solos estabelecidos pela CETESB (2001) e os valores mundiais para solos naturais (Kabata, 1984).

Os metais $\mathrm{As}, \mathrm{Cd}, \mathrm{Pb}$ e $\mathrm{Zn}$ apresentaram concentração parcial em alguns pontos de solo coletados maiores que os valores de referência de qualidade (que indicam o limite de qualidade para um solo considerado limpo) e os valores mundiais para solos naturais apresentados por Kabata et al. (1984). O $\mathrm{Co}, \mathrm{Cr}, \mathrm{Cu}$ e $\mathrm{Ni}$ apresentaram concentração no solo menor ou dentro da faixa quando comparados com os valores de referência da CETESB e os valores mundiais. Por outro lado, o Mo foi considerado naturalmente presente no solo quando comparado com o valor de referência da CETESB e acima do valor mundial, para dois pontos de coleta do solo de Figueira (TAB A1). É bom ressaltar que o valor de referência para o Mo estabelecido pela CETESB $\left(<25 \mathrm{mg} \mathrm{kg}^{-1}\right)$ é um valor de limite de detecção pela forma como foi descrito. Embora se desconheça o valor mais provável da concentração do metal, sabe-se que a concentração está abaixo do limite de detecção, e este valor $\left(25 \mathrm{mg} \mathrm{kg}^{-1}\right)$ é considerado alto quando comparado com valores mundiais mais baixos para solos (TAB. 7.2).

Entre os metais considerados contaminantes do solo, $\mathrm{As}, \mathrm{Cd}, \mathrm{Pb}$ e $\mathrm{Zn}$, acima dos valores de referência adotados pela CETESB (2001), o As foi o único que apresentou concentração maior que o valor de intervenção para área de proteção máxima para solos (que indicam o limite de contaminação acima do qual existe risco potencial à saúde humana), para alguns pontos de solo coletados.

De um modo geral, os pontos de solo que apresentaram contaminação dos metais $\mathrm{As}, \mathrm{Cd}, \mathrm{Pb}$ e $\mathrm{Zn}$ foram os pontos do transect $\mathrm{A}$ coletados até $1 \mathrm{~km}$. Para visualizar a localização dos metais ao redor da usina termoelétrica de Figueira traçaram-se gráficos radiais tomando-se por base a concentração parcial dos metais nos pontos cardeais dos solos coletados a $1 \mathrm{~km}$ (FIG. 7.2). O gráfico do Mo não foi traçado, pois os valores da concentração parcial do Mo nos pontos cardeais $\mathrm{A}$ foram menores que o limite de detecção do método. 
$\mathrm{Na}$ FIG. 7.2 é mostrado que os metais As, Cd, Co, $\mathrm{Pb}$ e $\mathrm{Zn}$ apresentam uma maior concentração na direção $\mathrm{NW}$, ao passo que $\mathrm{Cr}$, $\mathrm{Ni}$ e $\mathrm{Cu}$ apresentam uma maior dispersão ao redor de $1 \mathrm{~km}$.

A análise da TAB. 7.1 e 7.2 e da FIG. 7.1 e 7.2 mostram que os metais contaminantes do solo de Figueira são As, $\mathrm{Cd}$ e $\mathrm{Zn}$. O Mo e $\circ \mathrm{Pb}$ também indicam ser contaminantes do solo. $O$ Mo apresenta concentração elevada nas cinzas (fonte contaminadora) (TAB. 7.1), diminuição da concentração de Mo no solo com a distância da usina (FIG. 7.1) e dois pontos de coleta de solo apresentam concentração de Mo maior que os valores mundiais para solos naturais (TAB. 7.2). $\mathrm{O} P \mathrm{~Pb}$ apenas não apresentou um comportamento similar aos demais contaminantes, $\mathrm{As}, \mathrm{Cd}$ e $\mathrm{Zn}$, quanto à diminuição da concentração de $\mathrm{Pb}$ com a distância da usina (FIG. 7.1). Por outro lado, o Co não será considerado contaminante, pois da análise (TAB. 7.1 e 7.2 e da FIG. 7.1 e 7.2), o Co apenas apresentou uma maior concentração do metal na direção NW (FIG. 7.2). 
TABELA 7.1 - Concentração total e biodisponível dos metais em amostras de carvão e cinza coletadas durante 1 ano na usina termoelétrica de Figueira.

\begin{tabular}{|c|c|c|c|c|c|c|c|c|c|}
\hline & \multicolumn{9}{|c|}{ Intervalo da concentração total $\left(\mathrm{mg} \mathrm{kg}^{-1}\right)$} \\
\hline & As & $\overline{C d}$ & Co & $\overline{C r}$ & $\mathrm{Cu}$ & Mo & $\overline{\mathrm{Ni}}$ & $\overline{\mathrm{Pb}}$ & $\overline{Z n}$ \\
\hline Carvão & $239-328$ & $30-35$ & nd & $57-75$ & $20-31$ & $20-34$ & $30-41$ & $50-107$ & $271-711$ \\
\hline Cinza(caldeira) & $127-286$ & $10-44$ & nd & $74-101$ & $31-68$ & $17-43$ & $50-74$ & $66-92$ & $434-649$ \\
\hline Cinza(ciclone) & $380-667$ & $8-10$ & nd & $99-125$ & $37-73$ & $24-40$ & $48-85$ & $95-217$ & $674-1081$ \\
\hline \multirow[t]{3}{*}{ Cinza (manga) } & $889-1915$ & $12-40$ & nd & $135-181$ & $50-88$ & $68-107$ & $63-95$ & $258-627$ & $1309-2453$ \\
\hline & \multicolumn{9}{|c|}{ Intervalo da concentração biodisponível ( $\left.\mathrm{mg} \mathrm{kg}^{-1}\right)$} \\
\hline & As & Cd & Co & $\mathrm{Cr}$ & $\mathrm{Cu}$ & Mo & $\mathbf{N i}$ & $\mathbf{P b}$ & $\mathrm{Zn}$ \\
\hline Carvão & $7-53$ & $0,8-2,1$ & $0,006-4,3$ & $0,3-1,5$ & $1,0-6,3$ & $5-51$ & $1,1-11$ & $16-33$ & $9-216$ \\
\hline Cinza(caldeira) & $114-341$ & $0,1-0,2$ & $<$ LD-0,06 & $0,3-1,6$ & $1,4-5,7$ & $11-20$ & $0,6-1,1$ & $5-12$ & $64-161$ \\
\hline Cinza(ciclone) & $277-654$ & $0,1-1,2$ & $<$ LD-0,07 & $0,5-7,0$ & $0,6-2,4$ & $20-37$ & $0,5-1,3$ & $5-17$ & $62-326$ \\
\hline Cinza (manga) & $813-2323$ & $1,2-4,3$ & $0,04-0,16$ & $2-18$ & $1,5-3,9$ & $56-96$ & $0,7-2,2$ & $9-97$ & $115-360$ \\
\hline
\end{tabular}

nd: não determinado

LD: Co $<0,0021 \mathrm{mg} \mathrm{L}^{-1}$ 

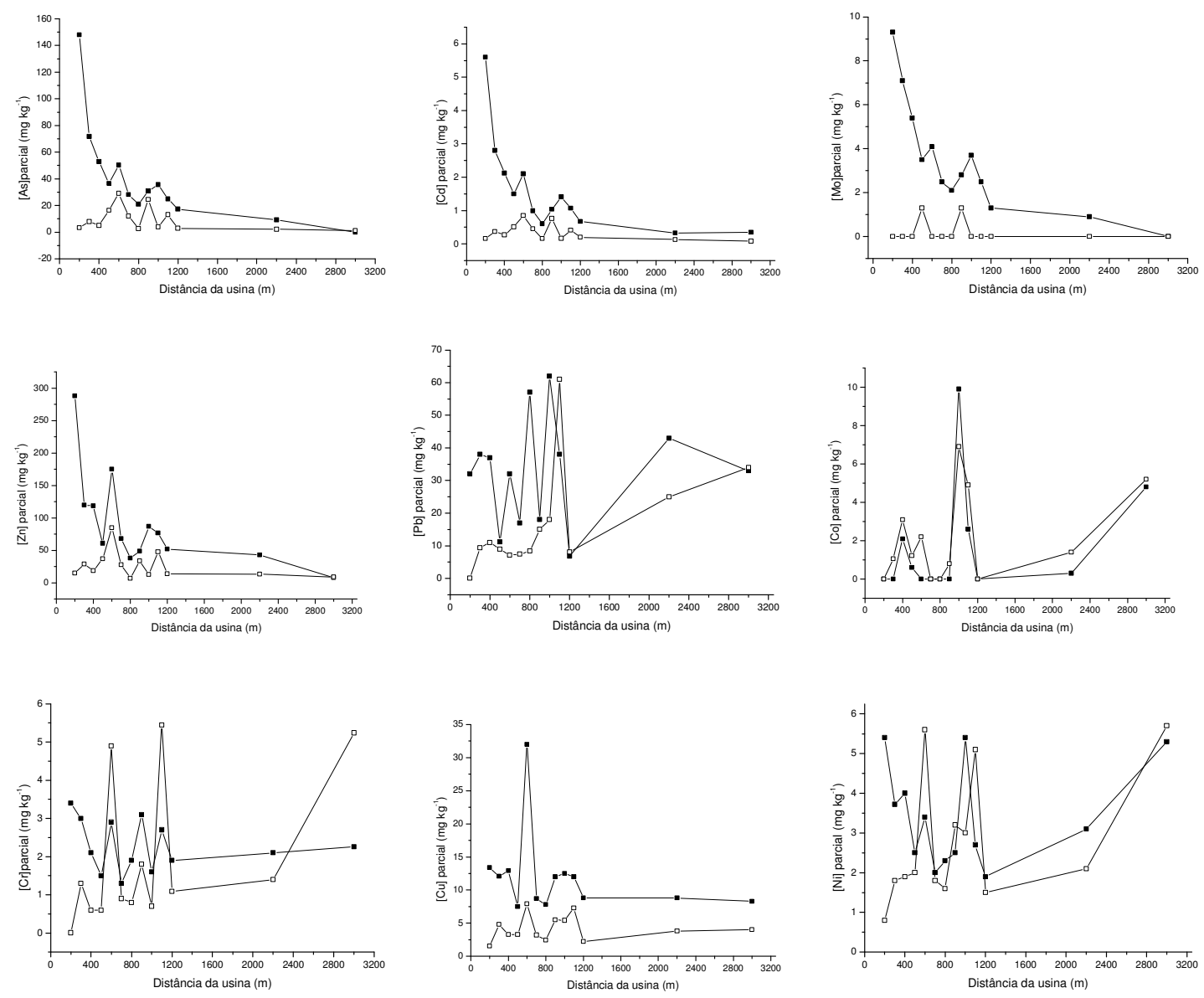

FIGURA 7.1 - Variação da concentração parcial do metal com a distância da usina termoelétrica de Figueira na direção NW (transect). (- - - Transect A: de 0 a $25 \mathrm{~cm}$; - - Transect B: de 25 a $50 \mathrm{~cm}$ ) 
TABELA 7.2 - Concentração parcial dos metais nas amostras de solo coletadas em 1996 e 1997 ao redor da usina termoelétrica de Figueira, valores orientadores para solos adotados pela CETESB e valores mundiais para solos naturais. Valores apresentados em $\mathrm{mg} \mathrm{kg}^{-1}$.

\begin{tabular}{|c|c|c|c|c|c|c|c|c|c|}
\hline Solos & As & Cd & Co & $\mathrm{Cr}$ & $\mathrm{Cu}$ & Mo & $\mathbf{N i}$ & $\mathrm{Pb}$ & $\mathrm{Zn}$ \\
\hline \multicolumn{10}{|l|}{ Figueira } \\
\hline $\mathrm{m}_{\text {geométrica }}$ & 11 & 0,4 & 2,1 & 1,8 & 5,9 & 2,7 & 2,3 & 17 & 32 \\
\hline intervalo & $0,6-148$ & $0,05-5,6$ & $0,3-9,9$ & $0,6-18$ & $1,5-32$ & $0,9-9,3$ & $0,8-5,7$ & $5,9-61$ & $3,4-288$ \\
\hline $\mathbf{n}$ & 31 & 40 & 24 & 38 & 40 & 14 & 40 & 31 & 32 \\
\hline Referência* & 3,5 & $<0,5$ & 13 & 40 & 35 & $<25$ & 13 & 17 & 60 \\
\hline $\begin{array}{c}\text { Alerta* } \\
\text { Intervencão }\end{array}$ & 15 & 3 & 25 & 75 & 60 & 30 & 30 & 100 & 300 \\
\hline APMax ${ }^{*}$ & 25 & 10 & 40 & 300 & 100 & 50 & 50 & 200 & 500 \\
\hline $\begin{array}{c}\text { Valores } \\
\text { mundiais ** }\end{array}$ & $2,2-25$ & $0,06-1,1$ & $1,6-21,5$ & $7-221$ & $6-80$ & $1-3$ & $4-55$ & $10-84$ & $17-125$ \\
\hline $\begin{array}{l}\text { Valores } \\
\text { USA ** }\end{array}$ & $3,6-8,8$ & - & $1-17$ & $20-85$ & $14-29$ & $0,35-5,8$ & $13-30$ & $17-26$ & $34-84$ \\
\hline
\end{tabular}



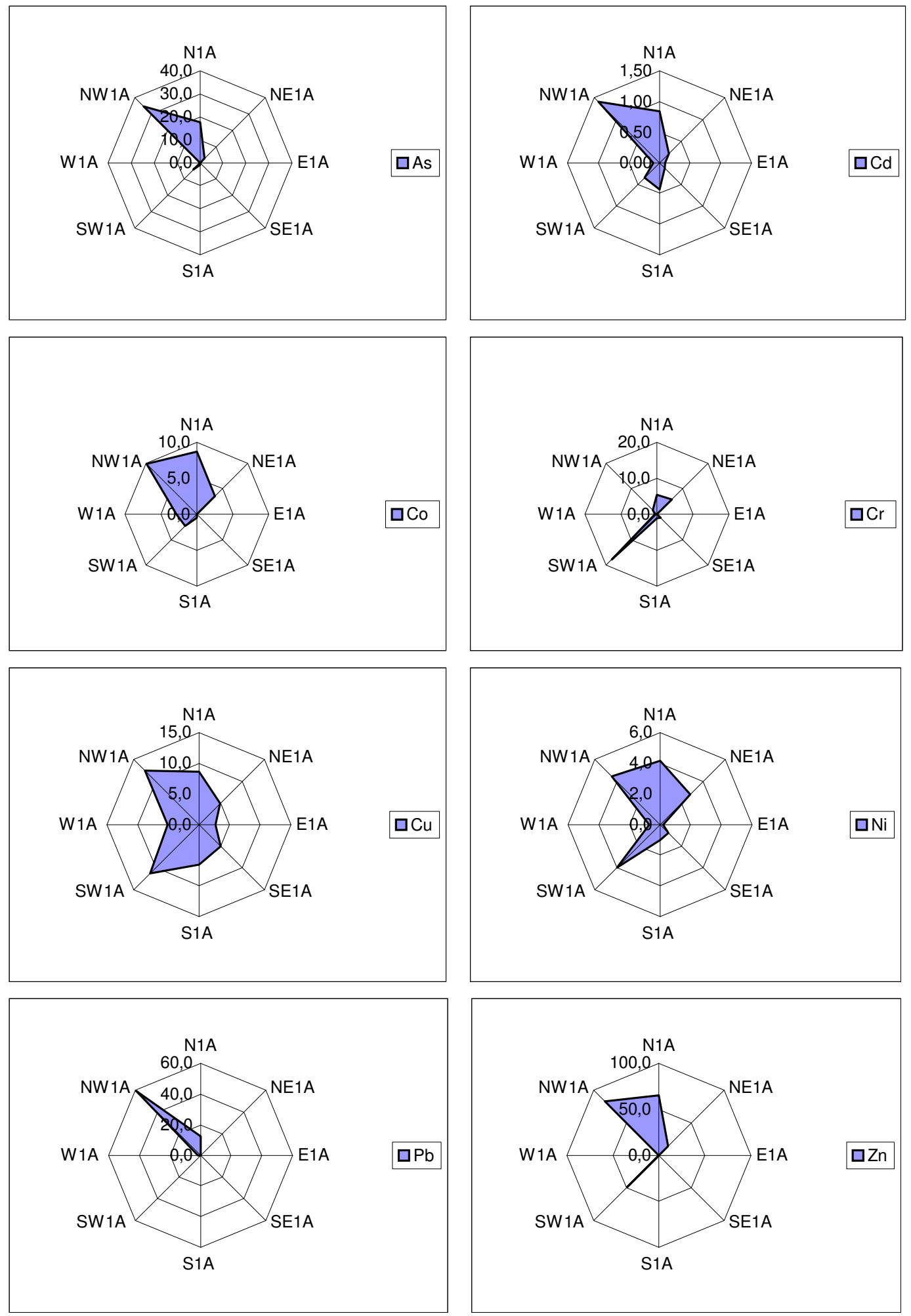

FIGURA 7.2 - Concentração parcial dos metais $\left(\mathrm{mg} \mathrm{kg}^{-1}\right)$ no solo de Figueira (pontos cardeais, de 0 a $25 \mathrm{~cm}$ ) coletados a 1 km, em 1996. 
Para se ter uma idéia da contaminação do solo coletado em 2001 após a instalação dos filtros na usina termoelétrica (medida tomada para diminuir a emissão de poluentes na atmosfera) por estes metais considerados contaminantes (As, Cd, Mo, $\mathrm{Pb}$ e $\mathrm{Zn}$ ), coletou-se dois pontos de solo do transect A, 400 e 600. O ponto 400 foi selecionado por causa do ponto de deposição dos poluentes calculado por meio da equação de Pasquille (Flues, 2002a), considerando a altura da chaminé da usina, de onde saem os gases e particulados para a atmosfera, e o ponto 600 pela proximidade do ponto 400 .

Na TAB. 7.3 apresentam-se os valores médios da concentração parcial para os pontos de solo do transect A, 400 e 600, para os solos coletados antes e depois da instalação dos filtros na usina. Esta tabela foi obtida com base nos valores apresentados na TAB. A1 e A2. Observa-se que a concentração parcial dos metais As, $\mathrm{Cd}, \mathrm{Mo}, \mathrm{Pb}$ e $\mathrm{Zn}$ diminuiu, mas continua acima dos valores de referência adotados pela CETESB, 2001, exceto para o Mo e Pb. E o As continua acima do valor de intervenção $\left(25 \mathrm{mg} \mathrm{kg}^{-1}\right)$ no ponto $600 \mathrm{~A}$. Isto pode indicar que mesmo com a instalação dos filtros para a retenção de poluentes, após 4 anos aproximadamente, o solo ainda apresenta contaminação.

TABELA 7.3 - Concentração parcial do solo 400A e 600A (coletados na direção NW a 400 m e $600 \mathrm{~m}$ da usina, de 0 a $25 \mathrm{~cm}$ ), antes da instalação dos filtros na usina (1997) e depois da instalação (2001).

\begin{tabular}{|c|c|c|c|c|c|}
\hline \multirow{3}{*}{ Metal } & \multicolumn{4}{|c|}{ Concentração parcial do metal (mg kg$\left.{ }^{-1}\right)$} & \multirow{3}{*}{$\begin{array}{l}\text { Valores de } \\
\text { referênciac } \\
\left(\mathrm{mg} \mathrm{kg}^{-1}\right)\end{array}$} \\
\hline & \multicolumn{2}{|c|}{$400 A$} & \multicolumn{2}{|c|}{$600 \mathrm{~A}$} & \\
\hline & $1997^{\mathrm{a}}$ & $2001^{b}$ & $1997^{\mathrm{a}}$ & $2001^{b}$ & \\
\hline As & 53 & 13,8 & 50,2 & 38,5 & 3,5 \\
\hline Cd & 2,12 & 0,5 & 2,1 & 1,2 & $<0,5$ \\
\hline Mo & 5,4 & 1,7 & 4,1 & 1,9 & $<25$ \\
\hline $\mathbf{P b}$ & 37 & 9,5 & 32 & 7,4 & 17 \\
\hline $\mathrm{Zn}$ & 119 & 27,6 & 175 & 92,5 & 60 \\
\hline
\end{tabular}

a. média aritmética de uma amostra.

b. média geométrica de três amostras.

c. valor de referência CETESB (2001). 


\subsection{Avaliação de $K p$}

Como já foi apresentada anteriormente, a determinação de Kp de metal para uma área contaminada é importante quando este parâmetro é utilizado para fins de avaliação de risco à saúde humana. Não existe uma metodologia padronizada para a determinação de Kp, geralmente se determina por isoterma de adsorção ou pela razão entre a concentração do metal obtida por algum tipo de digestão ácida (para representar a concentração do metal na fase sólida do solo) e a concentração do metal obtida pela própria solução do solo ou por extração do metal com água destilada, solução diluída de algum sal ou por agentes complexantes (para representar a fase líquida do solo) (item 3.1).

Neste tópico serão discutidos: diferenças entre os dois métodos utilizados para a determinação de Kp (item 7.2.1); comparação de valores de Kp experimental com valores da literatura (item 7.2.2); valores de Kp determinados por modelo de adsorção da literatura (item 7.2.3); Kp versus características do solo (item 7.2.4); e diferença do valor de $\mathrm{Kp}$ em solo contaminado e não contaminado, e em duas profundidades diferentes (item 7.2.5).

\subsection{1. $K p_{E D T A} X K p_{C a\left(N O_{3}\right)_{2}}$}

Na revisão bibliográfica (item 3.2) foram apresentadas várias literaturas nas quais os autores determinaram valores de $\mathrm{Kp}$ para metais por meio de isoterma ou ensaio de adsorção e razão entre concentração do metal na fase sólida e líquida do solo. Observou-se que os autores que determinaram Kp por meio da razão utilizaram solos contaminados (solos com concentração do metal maior que a concentração do solo natural), ao passo que, autores que determinaram $\mathrm{Kp}$ por meio de isoterma ou ensaio de adsorção utilizaram solos naturais. Soares (2004) comentou que estudos de adsorção normalmente presumem que o elemento de interesse não esteja inicialmente presente no solo. $\mathrm{Na}$ verdade não existe uma maneira padronizada para determinar $\mathrm{Kp}$. A determinação de Kp vai depender do objetivo e da sua aplicação (Otte, 2001; Fontes, 2002).

A utilização de isoterma de adsorção para determinar $\mathrm{Kp}$ de metais em solos contaminados pode não ser adequada, pois o solo contaminado já parte de 
uma concentração elevada do metal, e o Kp determinado por isoterma é obtido da inclinação da parte linear da curva (concentração do metal adsorvido no solo versus concentração do metal na solução líquida em equilíbrio), que normalmente ocorre para baixas concentrações do metal. Por analisar, neste trabalho, um solo contaminado por alguns metais segundo o que foi discutido no item 7.1, optou-se em determinar Kp pela razão da concentração do metal nas fases sólida e líquida.

A determinação de Kp pela razão da concentração do metal nas fases sólida e líquida não é bem estabelecida, ou seja, existem várias soluções de extração para representar a fase sólida e líquida do solo (TAB. 3.1) na literatura. A seleção de uma extração total ou parcial para representar a concentração do metal na fase sólida do solo certamente afetará na razão do cálculo do Kp. Uma solução de extração que envolve o ácido HF (para representar a fase sólida do solo) extrai totalmente o metal do solo (FIG. 3.1), semelhante ao resultado da fluorescência de raios $X$. A utilização desta solução irá gerar um valor de $\mathrm{Kp}$ (equações 6.1 e 6.2) maior ou igual a um determinado por meio da utilização de uma solução de extração $\mathrm{HNO}_{3}$ ou água régia $\left(\mathrm{HNO}_{3} / \mathrm{HCl}\right.$, proporção 3:1) para representar a fase sólida do solo, pois estas soluções extraem menos metal do solo (FIG. 3.1) ou não solubilizam metais presentes na estrutura (silicatos) do solo.

O mesmo raciocínio pode ser utilizado para solução de extração para representar a fase líquida do solo. A água destilada extrai somente metais da fração solúvel do solo (FIG. 3.1), soluções de extração $\mathrm{Ca}\left(\mathrm{NO}_{3}\right)_{2}, \mathrm{KNO}_{3}, \mathrm{NH}_{4} \mathrm{NO}_{3}$, $\mathrm{NH}_{4} \mathrm{OAc}, \mathrm{CaCl}_{2}$ e $\mathrm{NaNO}_{3}$ extraem metais das frações solúvel e trocável e solução de EDTA e DTPA extraem metais das frações solúvel, trocável, orgânica e parcialmente da fração óxidos do solo. Conseqüentemente a solução de EDTA fornece maior concentração de metais na fase líquida do solo que as demais soluções de extração. Portanto, o valor de Kp obtido pela utilização de EDTA será menor que o valor obtido pela utilização das outras soluções de extração para representar a fase líquida do solo. A centrifugação da solução do solo para representar a fase líquida do solo também é comum na literatura (TAB. 3.1). Janssen et al. (1997) e Seuntjens (2002) determinaram o valor de Kp tomando-se por base uma massa de solo da qual foi extraída a solução do solo por centrifugação e depois de retirar a solução do solo foi realizada a digestão ácida 
do solo. Outros autores, Gooddy et al. (1995), Römkens et al. (1998), Dumat et al. (2001) e Degryse et al. (2003) também representaram a fase líquida do solo pela extração da solução do solo por centrifugação, mas não deixaram explícito se a mesma massa de solo da qual foi retirada a solução do solo foi utilizada para realizar a digestão ácida para representar a fase sólida do solo. Em alguns trabalhos (Krishnamurti, 2002; Degryse, 2003; Sastre, 2004) têm sido utilizada a água destilada como solução de extração para representar a fase líquida do solo. Sastre et al. (2004) comentaram que a concentração do metal na solução do solo, obtida por extração com água destilada, foi muito baixa na maioria dos casos, o que provocou grande incerteza nos resultados ou impossibilitou o cálculo do $\mathrm{Kd}$. A capacidade de extração de uma solução diluída de sal (que extrai o metal das frações solúvel e trocável) vai depender do sal e da concentração deste. Gupta e Aten (1993) mostraram que $\mathrm{CaCl}_{2}$ 0,05 $\mathrm{mol} \mathrm{L}^{-1}$ extraiu mais $\mathrm{Cd}$ e $\mathrm{Zn}$ do solo que $\mathrm{NH}_{4} \mathrm{NO}_{3}$ 0,1 mol L-1 , ao passo que Lebourg et al. (1998) mostraram que $\mathrm{NH}_{4} \mathrm{NO}_{3} 1$ mol $\mathrm{L}^{-1}$ extraiu mais $\mathrm{Cd}$ e $\mathrm{Zn}$ que $\mathrm{CaCl}_{2} 0,01 \mathrm{~mol} \mathrm{~L}^{-1}$. Estes resultados representam que $\mathrm{CaCl}_{2}$ é um extrator mais forte que $\mathrm{NH}_{4} \mathrm{NO}_{3}$ quando a concentração do $\mathrm{CaCl}_{2}$ é menor $\left(0,05 \mathrm{~mol} \mathrm{~L}^{-1}\right)$ que a concentração do $\mathrm{NH}_{4} \mathrm{NO}_{3}$ 0,1 mol L-1. Por outro lado, se a concentração do $\mathrm{NH}_{4} \mathrm{NO}_{3}$ for bem maior $\left(1 \mathrm{~mol} \mathrm{~L}^{-1}\right)$ que a do $\mathrm{CaCl}_{2}$, por exemplo $0,01 \mathrm{~mol} \mathrm{~L}^{-1}$, $\circ \mathrm{NH}_{4} \mathrm{NO}_{3}$ passa a ser um extrator mais forte que o $\mathrm{CaCl}_{2}$. Outro fator que pode interferir na extração do metal do solo é a proporção solo:solução. Jopony e Young (1994) estudaram a extração de Cd e Pb do solo utilizando uma solução contendo $\mathrm{CaCl}_{2} 0,005 \mathrm{~mol} \mathrm{~L}^{-1}$ e $\mathrm{Ca}\left(\mathrm{NO}_{3}\right)_{2} \quad 0,005$ mol $L^{-1}$, variando a proporção solo:solução (1:5, 1:10 e 1:20). Estes autores observaram que a concentração do $\mathrm{Pb}$ na solução diminui ligeiramente com o aumento da proporção solo:solução. Staunton et al. (2002) avaliaram a influencia da proporção solo:solução (1:1, 1:2, 1:5 e 1:10) na determinação de Kd de Ni em dois tipos de solo. Estes autores observaram que os valores de $\mathrm{Kd}$ de $\mathrm{Ni}$ diminuíram significantemente quando a suspensão foi mais concentrada, ou seja, quando a razão entre solo:solução diminuiu. Alguns trabalhos mais recentes (Degryse, 2003; Sastre, 2004) têm introduzido no cálculo de Kp um fator de correção para a proporção solo:solução. Toda utilização destes procedimentos irá interferir na determinação de Kp. 
Para representar a concentração do metal na fase sólida do solo optouse por um método de digestão parcial, ou seja, digestão com $\mathrm{HNO}_{3}$ concentrado ou água régia. A extração por meio destas digestões ácidas representa o que potencialmente poderia ser extraído do solo, pois estas digestões ácidas extraem o metal de todas as frações do solo (FIG. 3.1), exceto o metal que está ligado aos silicatos, que faz parte da estrutura do solo e que dificilmente será extraído em condições ambientais. Neste trabalho foi selecionado o método 3051 da EPA que utiliza $\circ \mathrm{HNO}_{3}$ para extração do metal que tem sido utilizado internacionalmente para avaliar contaminação de solo, e se mostrou mais adequado que outros métodos, segundo Quináglia (2001). Além do mais, o $\mathrm{NO}_{3}{ }^{-}$não sofre precipitação com os cátions ao passo que, o $\mathrm{Cl}^{-}$, proveniente da digestão com água régia, poderia precipitar, por exemplo, com $\circ \mathrm{Pb}^{+2}$. Para representar a concentração do metal na fase líquida do solo selecionou-se dois métodos de extração: EDTA e $\mathrm{Ca}\left(\mathrm{NO}_{3}\right)_{2}$. O método EDTA foi selecionado porque a Community Bureau of Reference (BCR) da comunidade européia desenvolveu um método de extração de metais em solos que utiliza o EDTA que apresentou boa exatidão e reprodutibilidade (Ure, 1993). Este estudo resultou num material de referência para solo para este tipo de extração (Ure, 1996). Sager (1999) também recomenda a utilização de ácidos ou agentes complexantes (EDTA, DTPA) para lixiviação de metais no solo, pois participando de uma análise interlaboratório referente à extração de metais no solo, observou que a utilização de soluções de extração $\mathrm{NH}_{4} \mathrm{NO}_{3} 1 \mathrm{~mol} \mathrm{~L}^{-1}, \mathrm{NH}_{4} \mathrm{OAc} 1 \mathrm{~mol} \mathrm{~L}^{-1} \mathrm{e} \mathrm{LiCl} 1 \mathrm{~mol} \mathrm{~L}^{-1}$ apresentaram um coeficiente de variação mais alto quando comparado com a solução de EDTA $0,05 \mathrm{~mol} \mathrm{~L}^{-1}$ ou HOAc $0,1 \mathrm{~mol} \mathrm{~L}^{-1}$. Além do mais, a extração do metal no solo com EDTA poderia representar a extração do metal da solução do solo pelas raízes das plantas, pois a extração com EDTA apresenta correlação com o metal absorvido pelas plantas para mais espécies de plantas e metais que outras soluções de extração, tais como, $\mathrm{NH}_{4} \mathrm{NO}_{3}$ e $\mathrm{CaCl}_{2}$ (Ure, 1996; Hooda, 1997). O método que utiliza a solução de extração de $\mathrm{Ca}\left(\mathrm{NO}_{3}\right)_{2}$ (Conder, 2001) foi selecionado porque o nitrato não forma complexos com os metais e nem altera o pH do meio. Além disso, o nitrato e o cálcio estão presentes na composição da solução do solo (Faquin, 1997; Sparks, 1995) e o $\mathrm{Ca}^{2+}$ é bivalente que se aproxima mais da carga dos metais que serão analisados. A extração do metal no 
solo com $\mathrm{Ca}\left(\mathrm{NO}_{3}\right)_{2}$ poderia representar o metal na solução do solo que seria transportado para a água subterrânea.

$\mathrm{Na}$ TAB. A1, A3 e A4 apresentam-se os valores das concentrações parcial (digestão com $\mathrm{HNO}_{3}$ concentrado), biodisponível (extração com EDTA, $0,05 \mathrm{~mol} \mathrm{~L}^{-1}$ ) e trocável (extração com $\mathrm{Ca}\left(\mathrm{NO}_{3}\right)_{2} 0,1 \mathrm{~mol} \mathrm{~L}^{-1}$ ), respectivamente.

Tomando-se por base as concentrações do metal obtidas por meio da extração com EDTA e $\mathrm{Ca}\left(\mathrm{NO}_{3}\right)_{2}$ em função da concentração parcial do metal construiu-se os gráficos da FIG. 7.3 e 7.4, respectivamente. Estes gráficos foram construídos com todos os pares (concentração parcial, concentração biodisponível ou trocável) obtidos por pontos de coleta do solo, com base nos valores de concentração dos metais da TAB. A1, A3 e A4.

Considerando os gráficos dos metais da FIG. 7.3, a concentração biodisponível dos metais As, Cd, Co, Cu, Mo, Ni e Zn apresenta correlação com a concentração parcial, ou seja, quanto maior a extração do metal do solo com $\mathrm{HNO}_{3}$ concentrado maior a extração com EDTA $0,05 \mathrm{~mol} \mathrm{~L}^{-1}$. Este fato poderia ser explicado por causa das duas soluções $\left(\mathrm{HNO}_{3}\right.$ e EDTA) extraírem o metal das frações do solo, praticamente, da mesma forma. $\mathrm{O} \mathrm{HNO}_{3}$ concentrado e o EDTA $0,05 \mathrm{~mol} \mathrm{~L}^{-1}$ extraem o metal das frações solúvel, trocável, matéria orgânica (FIG. 3.1), e o metal ligado à fração óxido é extraído totalmente pelo $\mathrm{HNO}_{3}$ concentrado, ao passo que o EDTA $0,05 \mathrm{~mol} \mathrm{~L}^{-1}$ extrai parcialmente os metais desta fração. Provavelmente os metais $\mathrm{As}$, $\mathrm{Cd}$, Co, Cu, Mo, Ni e Zn estão mais ligados nas frações solúvel, trocável e matéria orgânica, por isso apresentaram correlação. Por outro lado, $\mathrm{Cr}$ e Pb (FIG. 7.3) não apresentaram correlação entre a concentração parcial e biodisponível, que poderia ser explicado por estes metais estarem mais ligado à fração óxido e provavelmente associados de formas diferentes. É bom ressaltar que a maioria dos valores da concentração biodisponível do $\mathrm{Cr}$ só foi possível considerar uma medida (TAB. A3). Hornburg (1991) mostrou que existe correlação entre concentração do metal obtida por extração com EDTA e concentração total (obtida por digestão com $\mathrm{HNO}_{3}$ e $\mathrm{HClO}_{4}$ ) para os metais $\mathrm{Cd}, \mathrm{Cu}, \mathrm{Pb}$ e $\mathrm{Zn}$. McGrath (1996) também mostrou correlação da concentração do metal extraído do solo por EDTA com a concentração total (obtida por digestão com $\mathrm{HF} \mathrm{e} \mathrm{HClO}_{4}$ ) para os metais $\mathrm{Cd}$, $\mathrm{Cu}$ e 
$\mathrm{Ni}$, ao passo que os metais $\mathrm{Pb}$ e $\mathrm{Zn}$ não apresentaram correlação entre as concentrações.

Na FIG. 7.4 apresenta-se a concentração trocável do metal obtida pela extração com $\mathrm{Ca}\left(\mathrm{NO}_{3}\right)_{2}$ em função da concentração parcial. $\mathrm{O}$ Mo não foi apresentado na FIG. 7.4 porque só apresentou três pares. Os gráficos dos metais $\mathrm{Cd}$ e $\mathrm{Zn}$ apresentaram correlação entre as concentrações, ou seja, quanto maior a extração do metal do solo com $\mathrm{HNO}_{3}$ concentrado maior a extração com $\mathrm{Ca}\left(\mathrm{NO}_{3}\right)_{2}$, $0,1 \mathrm{~mol} \mathrm{~L}^{-1}$. Por outro lado, os demais metais $\mathrm{As}, \mathrm{Co}, \mathrm{Cr}, \mathrm{Cu}, \mathrm{Mo}, \mathrm{Ni}$ e $\mathrm{Pb}$ não apresentaram correlação entre as concentrações. Sabe-se que o Cd é mais encontrado na fração trocável do solo, ao passo que os demais metais estão mais ligados às frações matéria orgânica e óxidos (Wasay, 1998; Podlesáková, 2000; Krishnamurti, 2002; Veeresh, 2003; Lin, 2004). O Zn, às vezes, se encontra mais na fração trocável, ou nas demais frações do solo. Portanto, é de se esperar que o $\mathrm{Cd}$ e o $\mathrm{Zn}$ apresentem correlação entre as concentrações trocável e parcial, pois $\circ \mathrm{Ca}\left(\mathrm{NO}_{3}\right)_{2} 0,1 \mathrm{~mol} \mathrm{~L}^{-1}$ extrai metais apenas das frações solúvel e trocável (FIG. 3.1). McBride et al. (2000) mostraram que existe correlação entre concentração do metal obtida por extração com $\mathrm{KNO}_{3}$, que seria similar a extração com $\mathrm{Ca}\left(\mathrm{NO}_{3}\right)_{2}$ utilizada no presente trabalho, e a concentração total (obtida por digestão ácida concentrada com $\mathrm{HNO}_{3}, \mathrm{HClO}_{4} \mathrm{e} \mathrm{HCl}$ ) para os metais $\mathrm{Cd}, \mathrm{Cu}, \mathrm{Ni}$ e Zn. 

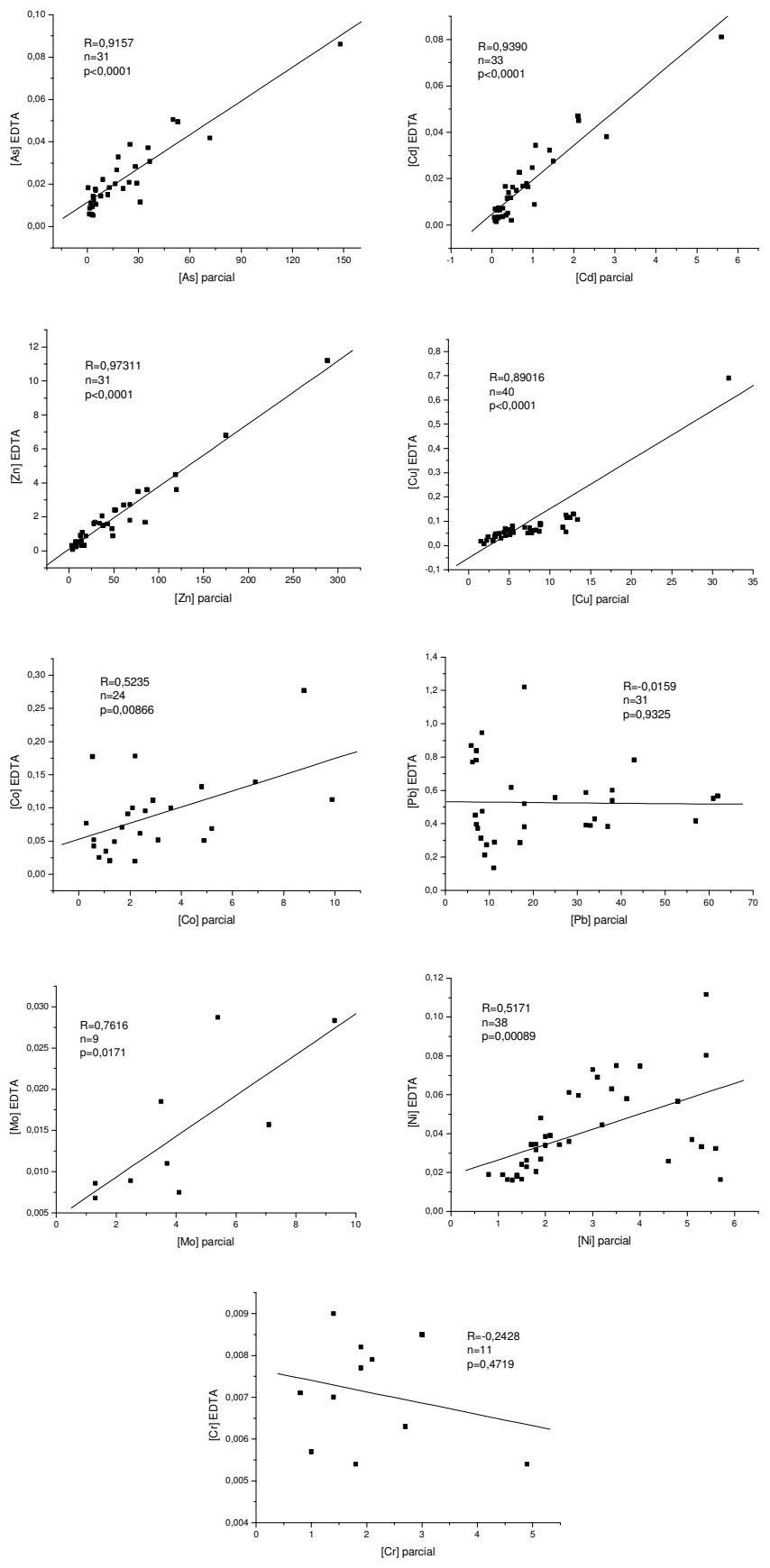

FIGURA 7.3 - Concentração biodisponível do metal $\left(\mathrm{mg} \mathrm{L}^{-1}\right)$ obtida por extração com EDTA $0,05 \mathrm{~mol} \mathrm{~L}^{-1}$ em função da concentração parcial ( $\mathrm{mg} \mathrm{kg}^{-1}$ ) obtida por digestão com $\mathrm{HNO}_{3}$ concentrado. 

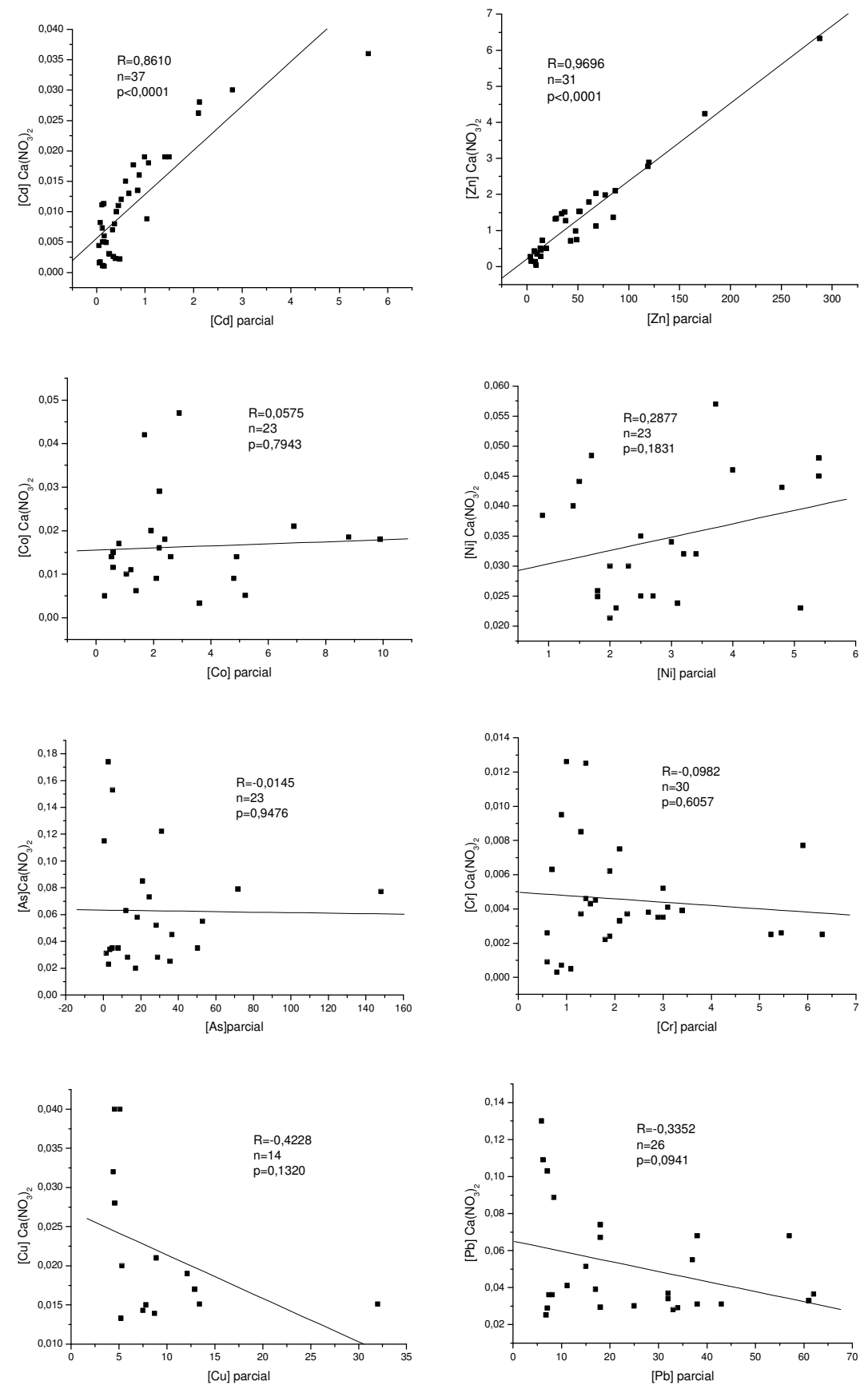

FIGURA 7.4 - Concentração trocável do metal $\left(\mathrm{mg} \mathrm{L}^{-1}\right)$ obtida por extração com $\mathrm{Ca}\left(\mathrm{NO}_{3}\right)_{2} \quad 0,1 \mathrm{~mol} \mathrm{L^{-1 }}$ em função da concentração parcial ( $\left(\mathrm{mg} \mathrm{kg}^{-1}\right.$ ) obtida por digestão com $\mathrm{HNO}_{3}$ concentrado. 
Os valores de $\mathrm{Kp}_{\text {EDTA }}$ e $\mathrm{Kp}_{\mathrm{Ca}\left(\mathrm{NO}_{3}\right)_{2}}$ foram determinados com base nas concentrações apresentadas na TAB. A1, A3 e A4. O Kp razão entre a concentração parcial do metal obtido por digestão com $\mathrm{HNO}_{3}$ concentrado e a concentração biodisponível do metal obtido por extração com

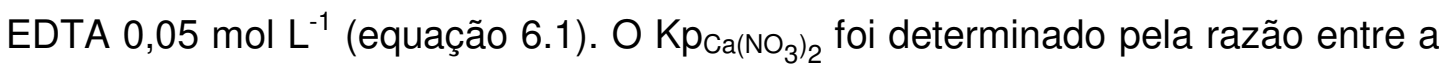
concentração parcial do metal obtido por digestão com $\mathrm{HNO}_{3}$ e a concentração trocável do metal obtido por extração com $\mathrm{Ca}\left(\mathrm{NO}_{3}\right)_{2}$ (equação 6.2). Os coeficientes de partição dos metais são apresentados na TAB. A5 e A6.

$\mathrm{Na}$ FIG. 7.5, construída com base nos dados da TAB. A5 e A6, apresenta-se $\mathrm{Kp}$ dos metais para os dois métodos adotados, EDTA e $\mathrm{Ca}\left(\mathrm{NO}_{3}\right)_{2}$, para extração do metal no solo para representar a concentração do metal na fase líquida do solo, fração biodisponível e trocável, respectivamente. O valor de $\mathrm{Kp}_{\mathrm{Ca}\left(\mathrm{NO}_{3}\right)_{2}}$ do Mo no solo não foi apresentado na FIG. 7.5 por ter apenas três valores de $\mathrm{Kp}_{\mathrm{Ca}\left(\mathrm{NO}_{3}\right)_{2}}$ por causa das concentrações obtidas pela extração ácida e com $\mathrm{Ca}\left(\mathrm{NO}_{3}\right)_{2}$ estarem abaixo do limite de deteç̧ão do método.

Os valores de $\mathrm{Kp}_{\mathrm{Ca}\left(\mathrm{NO}_{3}\right)_{2}}$ apresentaram maior variabilidade que os

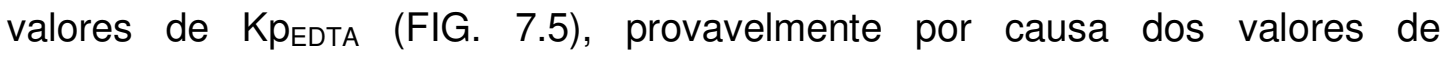
concentração obtidos pela extração com $\mathrm{Ca}\left(\mathrm{NO}_{3}\right)_{2}$ serem baixos e próximos do limite de detecção do método para a maioria dos metais. Isto é devido à solução de $\mathrm{Ca}\left(\mathrm{NO}_{3}\right)_{2}$ extrair o metal de menos frações do solo que a solução de EDTA (FIG. 3.1). A solução de $\mathrm{Ca}\left(\mathrm{NO}_{3}\right)_{2}$ extrai metais encontrados nas frações solúveis e trocáveis do solo, ao passo que, o EDTA extrai metais destas frações e mais das frações orgânica e parcialmente dos óxidos. Esta variabilidade de Kp mostra que o método de extração com EDTA fornece valores de $\mathrm{Kp}$ com menos dispersão que o método de extração com $\mathrm{Ca}\left(\mathrm{NO}_{3}\right)_{2}$, e portanto, seria mais recomendado. Por outro lado, se considerarmos que a extração do metal com $\mathrm{Ca}\left(\mathrm{NO}_{3}\right)_{2}$ do solo é mais representativa do ponto de vista da composição da solução do solo, poder-se-ia dizer que a utilização do $\mathrm{Ca}\left(\mathrm{NO}_{3}\right)_{2}$ é mais razoável.

Os valores de $\mathrm{Kp}_{\mathrm{Ca}\left(\mathrm{NO}_{3}\right)_{2}}$ dos metais no solo foram maiores que os

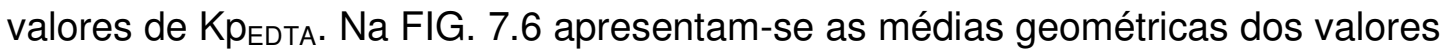
de $\mathrm{Kp}_{\text {EDTA }}$ e $\mathrm{Kp}_{\mathrm{Ca}\left(\mathrm{NO}_{3}\right)_{2}}$ obtidas com base na TAB. A5 e A6 e o valor nominal de $\mathrm{Kp}$ do modelo C-Soil. 
Pode ser observado na FIG. 7.6 que para todos os metais $\mathrm{Kp}_{\mathrm{Ca}\left(\mathrm{NO}_{3}\right)_{2}}$ foi maior ou similar a $\mathrm{Kp}$ EDTA, exceto para o As. Os valores de $\mathrm{Kp}$ para os metais $\mathrm{Cd}$, $\mathrm{Ni}$ e $\mathrm{Zn}$ foram próximos, independente do tipo de extração utilizada, ao passo que para os metais $\mathrm{Co}, \mathrm{Cr}$, $\mathrm{Cu}$ e $\mathrm{Pb}$ os valores de $\mathrm{Kp}$ foram mais influenciados pelo tipo de extração. Na FIG. 7.7 apresenta-se a média geométrica dos valores da razão $\mathrm{Kp}_{\mathrm{Ca}\left(\mathrm{NO}_{3}\right)_{2}} / \mathrm{Kp}_{\mathrm{EDTA}}$ obtidos com base nos valores da TAB. A7 e observa-se que esta razão é maior que 1 , exceto para o As. A variação da razão dos metais foi entre 0,4 e 11,1, sendo a menor razão para o As e a maior para o Pb. Estas diferenças da razão entre $\mathrm{Kp}_{\mathrm{Ca}\left(\mathrm{NO}_{3}\right)_{2}}$ e $\mathrm{Kp}_{\text {EDTA }}$ foram estatisticamente significativas quando averiguada pelo teste Wilcoxon ( $p<0,05$, monocaudal) para todos os metais, ou seja, o valor de $\mathrm{Kp}_{\mathrm{Ca}\left(\mathrm{NO}_{3}\right)_{2}}$ é diferente do $\mathrm{Kp}_{\mathrm{EDTA}}$. Este fato é esperado porque $\mathrm{Ca}\left(\mathrm{NO}_{3}\right)_{2}$ extrai menos metal do solo que EDTA, conseqüentemente a concentração do metal extraída pela solução de $\mathrm{Ca}\left(\mathrm{NO}_{3}\right)_{2}$ é menor, e portanto o $\mathrm{Kp} p_{\mathrm{Ca}\left(\mathrm{NO}_{3}\right)_{2}}$ foi maior que o $\mathrm{Kp}_{\text {EDTA }}$. A razão $\mathrm{Kp}_{\mathrm{Ca}\left(\mathrm{NO}_{3}\right)_{2}} / \mathrm{Kp}_{\text {EDTA }}$ para os metais $\mathrm{Cd}$, $\mathrm{Ni}$ e $\mathrm{Zn}$ foi próxima de 1 que pode ser explicada pela fraca adsorção destes metais em solos ácidos (McBride, 1994), ou seja, estes metais encontram-se preferencialmente nas frações trocáveis ou solúveis do solo que são fáceis de serem removidos. Portanto, ambas as soluções de extração, EDTA e $\mathrm{Ca}\left(\mathrm{NO}_{3}\right)_{2}$, conseguem extrair estes metais do solo de forma similar. A razão

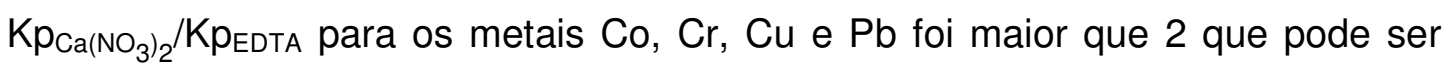
explicado por ligações mais fortes destes metais nas frações do solo, matéria orgânica, óxidos e argila (McBride, 1994). Portanto, a solução de EDTA consegue extrair maior quantidade destes metais no solo ao passo que a solução de $\mathrm{Ca}\left(\mathrm{NO}_{3}\right)_{2}$ extrai os metais apenas nas frações trocáveis e solúveis, portanto,

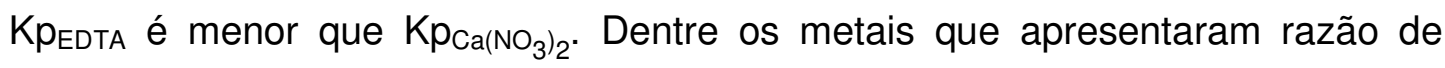

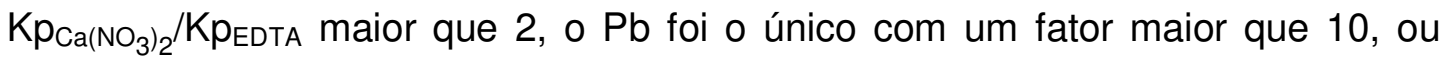
seja, diferença de uma ordem de grandeza, podendo interferir na avaliação de risco que será discutido posteriormente. 

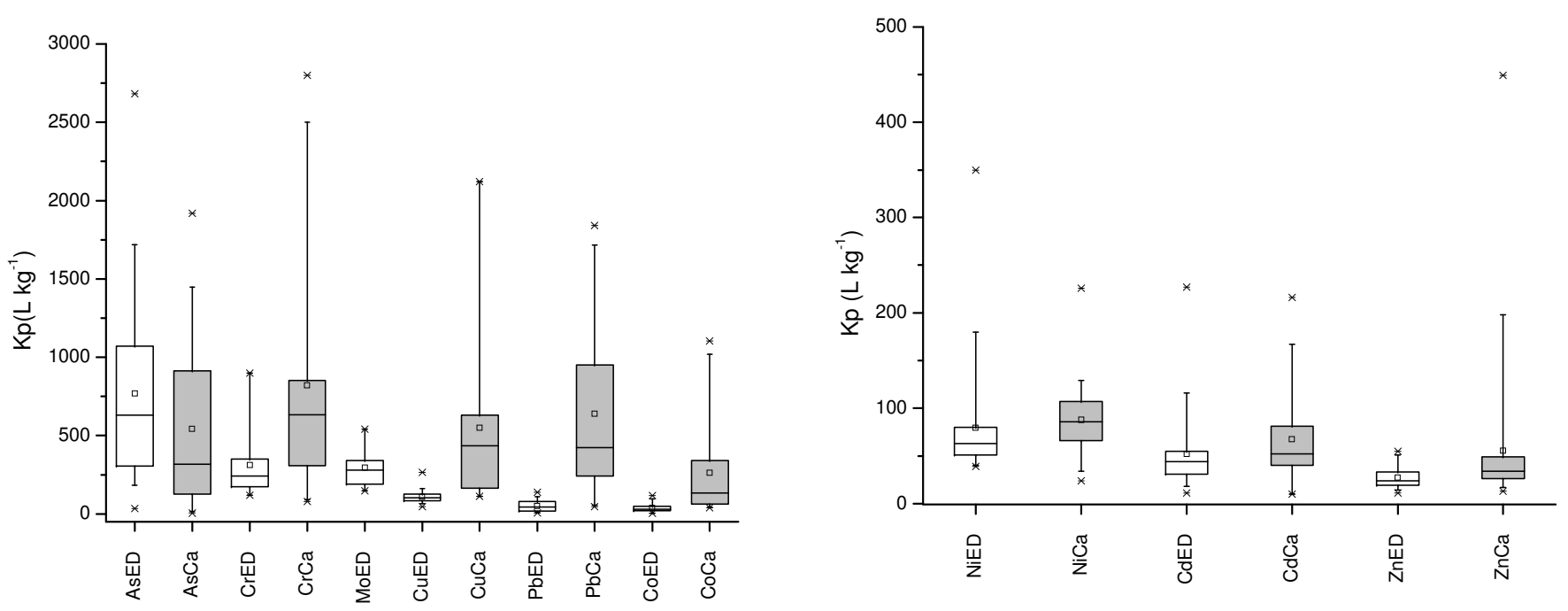

FIGURA 7.5 - Gráficos do tipo box plot dos valores de Kp obtidos pelos métodos de extração com EDTA e $\mathrm{Ca}\left(\mathrm{NO}_{3}\right)_{2}$. ED: extração com EDTA; $\mathrm{Ca}$ : extração com $\mathrm{Ca}\left(\mathrm{NO}_{3}\right)_{2}$.

_ mediana; 口 média aritmética 


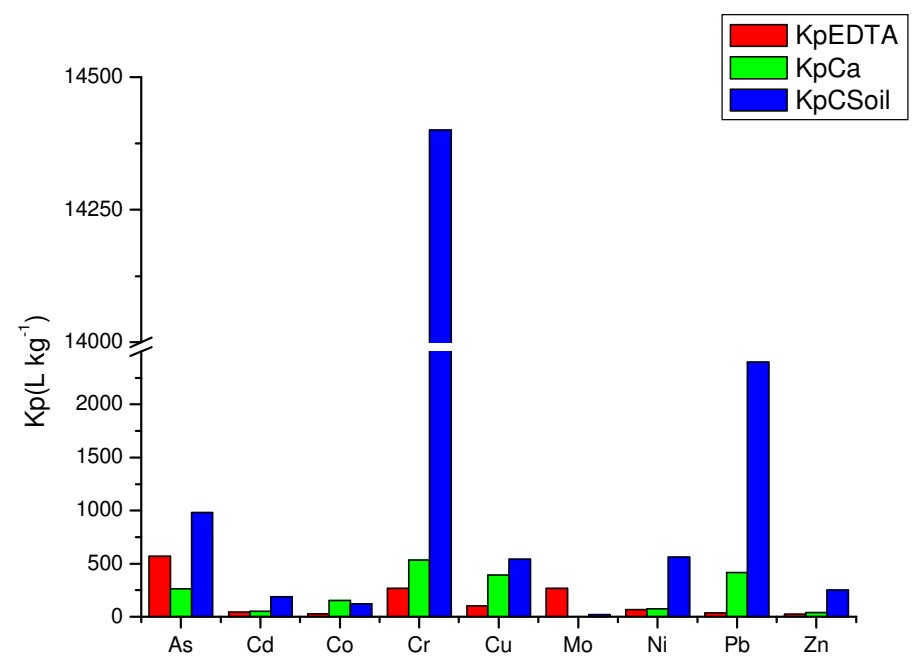

FIGURA 7.6 - Média geométrica dos valores de $\mathrm{Kp}_{\mathrm{EDTA}}$ e $\mathrm{Kp}_{\mathrm{Ca}\left(\mathrm{NO}_{3}\right)_{2}}$ e valor nominal de $\mathrm{Kp}$ do modelo C-Soil. Ca corresponde a $\mathrm{Ca}\left(\mathrm{NO}_{3}\right)_{2}$.

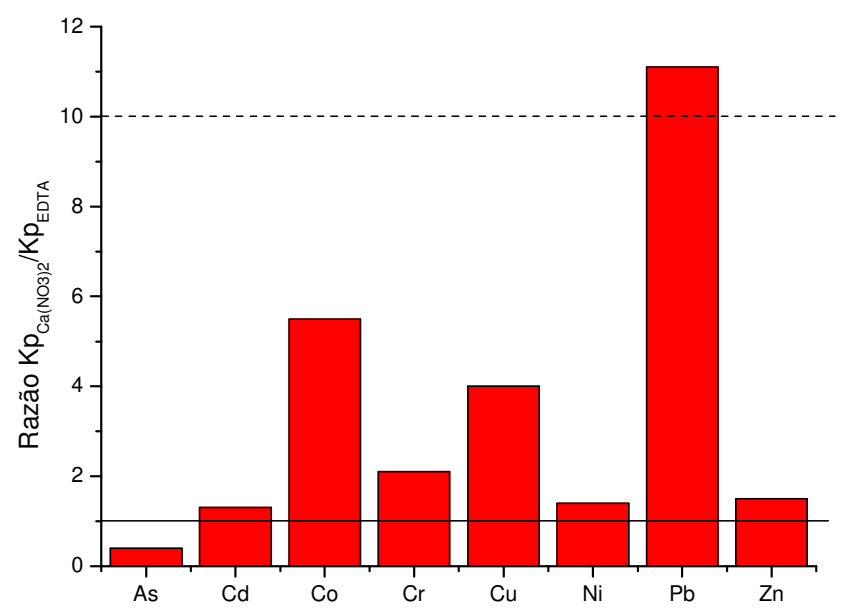

FIGURA 7.7 - Média geométrica dos valores da razão $\mathrm{Kp}_{\mathrm{Ca}\left(\mathrm{NO}_{3}\right)_{2}} / \mathrm{Kp}_{\mathrm{EDTA}}$.

$\mathrm{Na}$ FIG. 7.6 quando os valores de $\mathrm{Kp}_{\mathrm{EDTA}}$ e $\mathrm{Kp}_{\mathrm{Ca}\left(\mathrm{NO}_{3}\right)_{2}}$ foram comparados com o valor de Kp nominal do modelo C-Soil, observa-se que os valores de $\mathrm{Kp}$ do modelo são maiores que os valores de $\mathrm{Kp}$ experimentais deste trabalho, exceto para o Mo. Na FIG. 7.8 apresenta-se a média geométrica dos valores da razão $\mathrm{Kp}_{\mathrm{CSoi}} / \mathrm{Kp}_{\mathrm{EDTA}}$ e $\mathrm{Kp}_{\mathrm{CSoi}} / \mathrm{Kp}_{\mathrm{Ca}\left(\mathrm{NO}_{3}\right)_{2}}$ obtidos com base nos valores 
da TAB. A8 e A9. Observa-se que a razão $K \mathrm{~K}_{\mathrm{CS} \text { oil }} / \mathrm{Kp}_{\mathrm{EDTA}}$ é maior que a razão $\mathrm{Kp}$ CSoil $/ \mathrm{Kp}_{\mathrm{Ca}\left(\mathrm{NO}_{3}\right)_{2}}$, exceto para $\circ \mathrm{As}$, isto significa que 0 valor de $\mathrm{Kp} \mathrm{pa}_{\mathrm{Ca}}\left(\mathrm{NO}_{3}\right)_{2}$ se aproxima mais do valor nominal de $\mathrm{Kp}$ do modelo do que o valor de K $\mathrm{p}_{\text {EDTA. }}$ Os valores da razão de $\mathrm{Kp}$ para ambos os métodos ( $\mathrm{Kp}_{\mathrm{EDTA}}$ e $\left.\mathrm{Kp}_{\mathrm{Ca}\left(\mathrm{NO}_{3}\right)_{2}}\right)$ foram inferiores a 10, exceto para $\circ \mathrm{Cr}, \mathrm{Pb}$ e $\mathrm{Zn}$. $\mathrm{O} \mathrm{Zn}$ apresentou razão aproximadamente igual a 10 para a relação $K p_{\text {CSoil }} / K p_{\text {EDTA. }} \mathrm{O} \mathrm{Cr}$ e $\circ \mathrm{Pb}$ apresentaram valores de $\mathrm{K}_{\mathrm{EDTA}}$ bem menores que o valor nominal do modelo para estes metais, 54 e 69 vezes menores, respectivamente. O Mo apresentou valores de Kp $p_{\text {EDTA }}$ maiores que o valor nominal do modelo, aproximadamente 14 vezes maior. A razão de $\mathrm{Kp}$ maior que 10 (diferença de uma ou mais ordens de grandeza) pode indicar que a utilização dos valores de Kp nominal do modelo pode implicar num erro no cálculo do risco à saúde humana. Por outro lado, para os demais metais, que apresentaram razão de Kp próximo a 1 ou inferior a 10, o valor de $\mathrm{Kp}$ nominal do modelo poderia ser utilizado sem implicar num erro significativo.

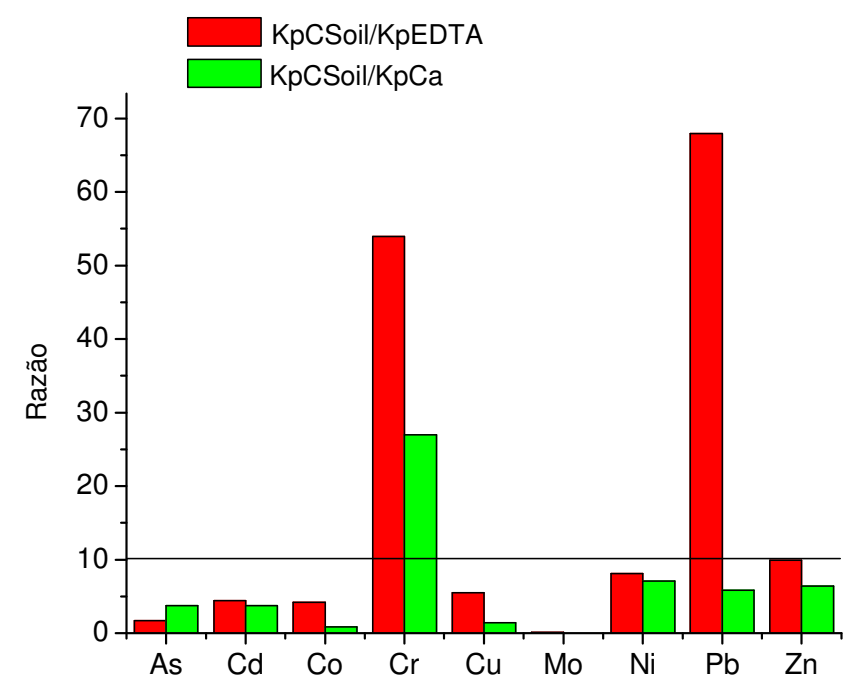

FIGURA 7.8 - Média geométrica dos valores da razão $K p_{\text {CSoil }} / K_{\text {EDTA }} e$

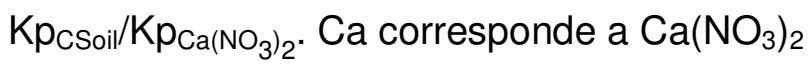




\subsubsection{Valores de $K p_{E D T A}$ dos pontos 400 e 600 do transect A, coletados após a instalação dos filtros na usina}

Os valores de $\mathrm{KP}_{\mathrm{EDTA}}$ determinados experimentalmente apresentados no item 7.2.1 foram obtidos dos solos de Figueira coletados em 1996 e 1997, antes da instalação dos filtros (1998) na usina termoelétrica. Em 2001 foram coletadas amostras de solo em dois pontos do transect A, 400 e 600, na direção NW, que fazem parte de um novo cenário, após a instalação dos filtros.

Os valores de Kp foram determinados pela equação 6.1 para se ter uma idéia se os valores sofreram alteração após a instalação dos filtros. Os metais considerados para a determinação de $K p_{\text {EDTA }}$ foram apenas os considerados contaminantes (As, $\mathrm{Cd}, \mathrm{Mo}, \mathrm{Pb}$ e $\mathrm{Zn}$ ) no item 7.1, pois se partiu do princípio que os demais metais que não foram considerados contaminantes antes da instalação dos filtros, teoricamente não seriam contaminantes depois da instalação.

$\mathrm{Na}$ TAB. 7.4, obtida com base nos valores da TAB. A5 e A10, apresenta-se os valores médios de Kp $\mathrm{p}_{\text {EDTA }}$ dos metais considerados contaminantes (As, $\mathrm{Cd}, \mathrm{Mo}, \mathrm{Pb}$ e $\mathrm{Zn}$ ) no item 7.1 para os pontos de solo do transect A, 400 e 600, para os solos coletados antes e depois da instalação dos filtros na usina. Observa-se que os valores de KpEDTA dos metais não variaram, exceto para o $\mathrm{Pb}$ que pode ter diminuído pelo decréscimo da concentração parcial (TAB. 7.3). Sauvé et al. (2000a) estabeleceram uma equação de regressão múltipla para o Kd de $\mathrm{Pb}$ e Zn (TAB. 3.2) que relaciona a concentração do metal no solo positivamente, ou seja, se a concentração do metal aumenta o Kd aumenta também. Sauvé et al. (2000b) mostraram graficamente que quanto maior a concentração de $\mathrm{Cd}$ em solos contaminados, maior o valor de $\mathrm{Kd}$. Esta observação pode indicar que outros metais podem ter o mesmo comportamento, ou seja, que o Kp aumenta com o aumento da concentração do metal. 
TABELA 7.4. Valores de Kp $\mathrm{P}_{\mathrm{EDTA}}$ para os metais considerados contaminantes nos pontos de solo do transect A, 400 e 600 (coletados na direção NW a $400 \mathrm{~m}$ e $600 \mathrm{~m}$ da usina, de 0 a $25 \mathrm{~cm}$ ), antes da instalação dos filtros na usina (1997) e depois da instalação (2001).

\begin{tabular}{|c|c|c|c|c|}
\hline \multirow[t]{3}{*}{ Metal } & \multicolumn{4}{|c|}{$\mathrm{Kp}_{\text {EDTA }}\left(\mathrm{L} \mathrm{kg}^{-1}\right)$} \\
\hline & \multicolumn{2}{|c|}{$400 A$} & \multicolumn{2}{|c|}{$600 A$} \\
\hline & $1997^{\mathrm{a}}$ & $2001^{b}$ & $1997^{\mathrm{a}}$ & $2001^{b}$ \\
\hline As & 1071 & 1208 & 996 & 930 \\
\hline Cd & 47 & 45 & 45 & 50 \\
\hline Mo & 187 & 222 & 540 & $128^{\mathrm{c}}$ \\
\hline $\mathrm{Pb}$ & 96 & 17 & 54 & 19 \\
\hline $\mathrm{Zn}$ & 27 & 32 & 26 & 22 \\
\hline
\end{tabular}

a. média aritmética de uma amostra de solo

b. média geométrica de três amostras de solo

c. única determinação

\subsubsection{Comparação dos valores de Kp experimentais com os da literatura}

$\mathrm{Na}$ TAB. 7.5 apresentam-se os valores de Kp determinados neste trabalho e valores de $\mathrm{Kp}$ de metais em solos apresentados na literatura. Observase uma variação dos valores de $\mathrm{Kp}$ muito grande. Esta variação pode ser explicada pelas diferenças das características do solo, das metodologias e da forma química do metal. Numa tentativa de comparar os valores de Kp obtidos neste trabalho com os da literatura, selecionou-se Soares (2004) que estudou os solos do Estado de São Paulo, e portanto, uma realidade mais próxima do solo de Figueira, e CETESB (2001) que utilizou valores nominais de Kp do modelo matemático de avaliação de risco à saúde humana, C-Soil, para estabelecer valor de intervenção para solos do Estado de São Paulo. Os valores experimentais de $\mathrm{Kp}$ apresentados neste trabalho foram menores que os valores apresentados por Soares (2004), exceto para o Co quando comparado com o valor de $\mathrm{Kp}_{\mathrm{Ca}\left(\mathrm{NO}_{3}\right)_{2}}$ e o Cr. É bom ressaltar que o $\mathrm{Cr}$ utilizado no trabalho de Soares (2004) foi na forma de $\mathrm{CrO}_{4}{ }^{-2}$, ou seja, no estado de oxidação +6 , ao passo que no presente trabalho provavelmente é $\mathrm{Cr}^{+3}$ (discussão no item 7.2.4), e o valor de $\mathrm{Kp}_{\mathrm{Cr}}{ }^{+6}$ é menor que o 
valor de $\mathrm{Kp}_{\mathrm{Cr}}{ }^{+3}$. Mas a diferença foi inferior a 10 , exceto para $\circ \mathrm{Pb}$ quando

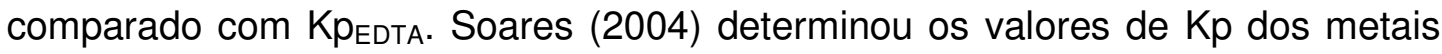
por isoterma de adsorção para 30 tipos de solos representativos do Estado de São Paulo. Os valores de $\mathrm{Kp}$ determinados no presente trabalho também foram menores que os valores apresentados pela CETESB (2001), exceto para o Co quando comparado com o valor de $\mathrm{Kp}_{\mathrm{Ca}\left(\mathrm{NO}_{3}\right)_{2}}$ e o Mo. Mas com um fator inferior a 10, exceto para o $\mathrm{Cr}$ e o Mo, e para o $\mathrm{Pb}$ e $\mathrm{Zn}$ quando comparado como o valor de Kp EDTA.

\subsubsection{Valores de $K p$ calculados por equações de regressão múltipla da literatura}

Utilizando as equações de regressão múltipla da literatura que relacionam $\mathrm{Kp}$ com as características físico-químicas do solo e a concentração do metal (TAB. 3.2), determinou-se Kp com o valor médio das características físicoquímicas do solo de Figueira e a média geométrica da concentração parcial da TAB. 7.6, obtida com base nos valores da TAB. A1, A11 e A12. Os modelos de adsorção da TAB. 3.2 utilizados foram dos autores Anderson et al. (1988), Janssen et al. (1997), Römkens et al. (1998), Sauvé et al. (2000a), Sauvé et al. (2000b), Seuntjens (2002) e Soares (2004).

$\mathrm{Na}$ TAB. 7.7 apresentam-se os valores de Kp calculados por meio de equação de regressão múltipla selecionados anteriormente e os valores de $\mathrm{Kp}$ determinados experimentalmente neste trabalho. De um modo geral os valores de $\mathrm{Kp}$ calculados foram muito maiores que os valores determinados experimentalmente, em particular para o As, apresentando quatro ordens de grandeza de diferença (TAB. 7.7), embora que para o As foi calculado apenas um valor de $\mathrm{Kp}$, pois só foi apresentada uma equação por um dos autores. Os valores de Kp calculados pelas equações estabelecidas por Soares (2004) foram mais baixos que os valores determinados experimentalmente, mas a diferença entre eles é inferior a um fator de 10 (TAB. 7.7), exceto para o Cr. Para os metais Cd e $\mathrm{Zn}$ o valor de Kp experimental e de Kp calculado (TAB. 7.7) foi da mesma ordem de grandeza, indicando que os modelos de adsorção da literatura poderiam ser utilizados para estes metais no estudo de caso. Para o $\mathrm{Cu}$, o valor de $\mathrm{Kp}$ experimental foi da mesma ordem de grandeza do $\mathrm{Kp}$, quando foi calculado pelas 
equações estabelecidas por Römkens et al. (1998), Sauvé et al. (2000a) e Soares (2004), e diferente quando utilizada a equação de Janssen et al. (1997). É bom ressaltar que Janssen et al. (1997) apresentaram valores baixos de Kp para $\mathrm{Cu}$ quando comparado com $\mathrm{As}, \mathrm{Pb}$ e $\mathrm{Cr}$, que indicam que este metal é bastante disponível, ao passo que no presente trabalho $\mathrm{O} \mathrm{Cu}$ apresentou um comportamento de retenção no solo como o As e o $\mathrm{Cr}$. O Cu é um metal que tende a ficar retido no solo, mas segundo o autor Hornburg (1991) em pH menor que 5 e maior que 7 , o Cu pode se tornar mais solúvel em solo agrícola e de pasto, tornando-se mais disponível.

As diferenças entre os valores de $\mathrm{Kp}$ calculados e determinados experimentalmente podem ser devido às diferentes características físico-químicas do solo (TAB. 3.2), forma química do metal e aos diferentes métodos utilizados para a determinação de $\mathrm{Kp}$ dos metais. O método da literatura que mais se aproxima do método utilizado no presente trabalho para determinação de $\mathrm{Kp}$ foi o de Sauvé et al. (2000b). No entanto, a solução de $\mathrm{KNO}_{3}$ 0,01 mol L-1 utilizada por estes autores tende a extrair menos metal do solo que $\circ \mathrm{Ca}\left(\mathrm{NO}_{3}\right)_{2} \quad 0,1 \mathrm{~mol} \mathrm{~L}^{-1}$ utilizado no presente trabalho. Isto é por causa do cátion bivalente (por exemplo, o $\mathrm{Ca}^{2+}$ ) trocar mais facilmente nos pontos de adsorção do solo que um cátion monovalente (por exemplo, o $\mathrm{K}^{+}$), e ao fato da concentração do cálcio ser maior que a concentração do potássio. Portanto, é coerente que o valor de Kp para Cd obtido com base na equação determinada pelos autores Sauvé et al. (2000b) seja

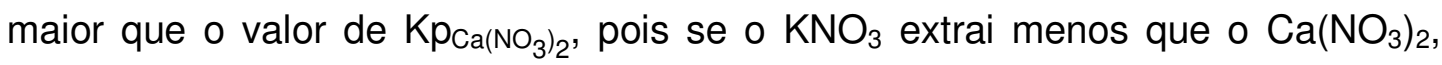
então, a razão entre $[\mathrm{Cd}]_{\mathrm{HNO}_{3}} /[\mathrm{Cd}]_{\mathrm{KNO}_{3}}$ será maior que a razão $[\mathrm{Cd}]_{\mathrm{HNO}_{3}} /[\mathrm{Cd}]_{\mathrm{Ca}\left(\mathrm{NO}_{3}\right)_{2}}$, que corresponde ao $\mathrm{Kp}$ calculado e determinado experimentalmente, respectivamente. 
TABELA 7.5 - Valores de Kp experimentais, $\mathrm{Kp}_{\mathrm{EDTA}}$ e $\mathrm{Kp}_{\mathrm{Ca}\left(\mathrm{NO}_{3}\right)_{2}}$, do solo de Figueira e valores de $\mathrm{Kp}$ de metais em solo da literatura, em $\mathrm{L} \mathrm{kg}^{-1}$.

\begin{tabular}{|c|c|c|c|c|c|c|c|c|c|}
\hline & As & Cd & Co & $\mathrm{Cr}$ & $\mathrm{Cu}$ & Mo & $\mathbf{N i}$ & $\mathbf{P b}$ & $\mathrm{Zn}$ \\
\hline$K p_{\text {EDTA }}$ & 570 & 43 & 29 & 265 & 104 & 270 & 69 & 35 & 25 \\
\hline $\mathrm{Kp} p_{\mathrm{Ca}\left(\mathrm{NO}_{3}\right)_{2}}$ & 263 & 52 & 153 & 535 & 394 & nd & 78 & 415 & 39 \\
\hline Butcher (1989) & 47 & 60 & 38 & 11 & 317 & 64 & 36 & 3373 & 48 \\
\hline Janssen (1997) & 2079 & 1103 & - & 6322 & 310 & - & 852 & 11098 & 530 \\
\hline Carlon (2000) & - & - & - & - & - & - & - & $\begin{array}{c}398^{a} \\
79433^{b}\end{array}$ & - \\
\hline Sauvé (2000a) & 1825 & 390 & - & 4778 & 2120 & 38 & 2333 & 102410 & 1731 \\
\hline McBride (2000) & 13119 & 10471 & - & - & 7781 & - & 11749 & - & 9333 \\
\hline CETESB (2001) & 980 & 190 & 120 & 14400 & 540 & 20 & 560 & 2400 & 250 \\
\hline Chang (2001) & - & 3,48 & - & - & 7,06 & - & - & - & - \\
\hline Zelewski (2001) & - & - & - & - & 22000 & - & - & - & 23000 \\
\hline $\begin{array}{l}\text { Seuntjens } \\
(2002)\end{array}$ & - & 21,6 & - & - & - & - & - & - & - \\
\hline $\begin{array}{l}\text { Krishnamurti } \\
\text { (2002) }\end{array}$ & - & - & - & - & 71,1 & - & - & - & 99,6 \\
\hline Degryse (2003) & - & $5-5800$ & - & - & - & - & - & - & $3-8900$ \\
\hline $\begin{array}{l}\text { Veeresh } \\
(2003 b)\end{array}$ & - & 16 & - & - & - & - & 42 & 768 & - \\
\hline Agbenin (2004) & - & - & - & - & 530 & - & - & - & 134 \\
\hline Sastre (2004) & 2222 & 25 & - & - & 243 & - & - & 7381 & 161 \\
\hline Lin (2004) & - & - & - & - & 4781 & - & 15409 & - & 3454 \\
\hline Soares (2004) & - & 223 & 85 & 103 & 807 & - & 118 & 2131 & 137 \\
\hline
\end{tabular}

a,b: valores obtidos por diferentes métodos de extração 
TABELA 7.6 - Características físico-químicas do solo, concentração do metal total e parcial e \% do metal na fração residual do solo.

\begin{tabular}{|c|c|c|c|}
\hline & $\mathbf{n}$ & $\begin{array}{c}\text { Média } \\
\text { geométrica }\end{array}$ & Intervalo \\
\hline \multicolumn{4}{|l|}{ Características } \\
\hline $\mathrm{pH}$ & 40 & $4,3^{\mathrm{a}}$ & $3,4-5,9$ \\
\hline CTC $\left(\mathrm{cmol} \mathrm{kg}^{-1}\right)$ & 40 & $18^{\mathrm{a}}$ & $5-28$ \\
\hline $\mathrm{MO}(\%)$ & 40 & $2,9^{a}$ & $0,5-6,4$ \\
\hline Argila (\%) & 40 & $26^{a}$ & $3-51$ \\
\hline Areia (\%) & 40 & $44^{a}$ & $18-84$ \\
\hline Silte (\%) & 40 & $31^{a}$ & $11-44$ \\
\hline $\mathrm{Al}(\%)$ & 40 & $5^{a}$ & $1,97-12,34$ \\
\hline $\mathrm{Fe}(\%)$ & 40 & $2,3^{a}$ & $0,213-11,82$ \\
\hline $\mathrm{Mn}\left(\mathrm{mg} \mathrm{kg}^{-1}\right)$ & 40 & $1181^{a}$ & $94-5260$ \\
\hline \multicolumn{4}{|l|}{$\begin{array}{l}\text { Concentração total do metal } \\
\left(\mathrm{mg} \mathrm{kg}^{-1}\right)\end{array}$} \\
\hline As & 23 & 14 & $1,0-98$ \\
\hline $\mathrm{Cr}$ & 25 & 24 & $6,8-111$ \\
\hline $\mathrm{Cu}$ & 25 & 34 & $13-76$ \\
\hline $\mathrm{Ni}$ & 26 & 43 & $31-60$ \\
\hline $\mathrm{Pb}$ & 26 & 59 & $22-155$ \\
\hline $\mathrm{Zn}$ & 25 & 289 & $20-799$ \\
\hline \multicolumn{4}{|l|}{$\begin{array}{l}\text { Concentração parcial do metal } \\
\left(\mathrm{mg} \mathrm{kg}^{-1}\right)\end{array}$} \\
\hline As & 31 & 11 & $0,6-148$ \\
\hline $\mathrm{Cd}$ & 40 & 0,4 & $0,05-5,6$ \\
\hline Co & 24 & 2,0 & $0,3-9,9$ \\
\hline $\mathrm{Cr}$ & 38 & 1,8 & $0,6-18$ \\
\hline $\mathrm{Cu}$ & 40 & 6,0 & $1,5-32$ \\
\hline Mo & 14 & 2,7 & $0,9-9,3$ \\
\hline $\mathrm{Ni}$ & 40 & 2,2 & $0,8-5,7$ \\
\hline $\mathrm{Pb}$ & 31 & 16 & $5,9-62$ \\
\hline $\mathrm{Zn}$ & 32 & 33 & $3,4-288$ \\
\hline \multicolumn{4}{|l|}{$\begin{array}{l}\text { \% do metal na fração residual } \\
\text { do solo }\end{array}$} \\
\hline As & 9 & 21 & $3-50$ \\
\hline $\mathrm{Cr}$ & 25 & 91 & $77-97$ \\
\hline $\mathrm{Cu}$ & 25 & 79 & $54-91$ \\
\hline $\mathrm{Ni}$ & 26 & 93 & $85-98$ \\
\hline $\mathrm{Pb}$ & 23 & 60 & $10-88$ \\
\hline $\mathrm{Zn}$ & 25 & 85 & $55-95$ \\
\hline
\end{tabular}

a. média aritmética

n: número de determinações

CTC: capacidade de troca cationica

MO: matéria orgânica 
TABELA 7.7 - Média geométrica dos valores de Kp do solo de Figueira obtidos experimentalmente, e valores de $\mathrm{Kp}$ calculados por meio das equações de regressão múltipla da literatura, utilizando as características físico-químicas do solo de Figueira.

\begin{tabular}{|c|c|c|c|c|c|c|}
\hline Metal & Kp exp & erimental & $\begin{array}{c}\text { Kp } \\
\text { calculado }\end{array}$ & & Eator & Literatura \\
\hline & $K p_{\text {EDTA }}$ & $\mathrm{Kp}_{\mathrm{Ca}\left(\mathrm{NO}_{3}\right)_{2}}$ & & $K \mathbf{p}_{\text {calc. }} / K_{p_{\text {EDTA }}}$ & $\mathrm{Kp}_{\text {calc. }} / \mathrm{Kp}_{\mathrm{Ca}\left(\mathrm{NO}_{3}\right)_{2}}$ & \\
\hline Cd & 43 & 52 & 3 & $14^{\mathrm{a}}$ & $17^{\mathrm{a}}$ & Anderson \\
\hline Co & 29 & 153 & 304 & 11 & 2,0 & (1988) \\
\hline $\mathrm{Ni}$ & 69 & 78 & 50816 & 737 & 652 & \\
\hline $\mathrm{Zn}$ & 25 & 39 & 346 & 14 & 8,9 & \\
\hline As & 570 & 263 & 1174898 & 2061 & 4467 & Janssen \\
\hline Cd & 43 & 52 & 219 & 5,1 & 4,2 & (1997) \\
\hline $\mathrm{Cr}$ & 265 & 535 & 9 & $29^{a}$ & $59^{a}$ & \\
\hline $\mathrm{Cu}$ & 104 & 394 & 87096 & 838 & 221 & \\
\hline $\mathbf{N i}$ & 69 & 78 & 955 & 14 & 12 & \\
\hline $\mathrm{Pb}$ & 35 & 415 & 70795 & 2023 & 171 & \\
\hline $\mathrm{Zn}$ & 25 & 39 & 93 & 3,7 & 2,4 & \\
\hline Cd & 43 & 52 & 71 & 1,7 & 1,4 & Römkens \\
\hline $\mathrm{Cu}$ & 104 & 394 & 324 & 3,1 & 1,2 & (1998) \\
\hline $\mathrm{Zn}$ & 25 & 39 & 59 & 2,4 & 1,5 & \\
\hline Cd & 43 & 52 & 40 & $1,1^{a}$ & $1,3^{\mathrm{a}}$ & Sauvé \\
\hline $\mathrm{Cu}$ & 104 & 394 & 589 & 5,7 & 1,5 & (2000a) \\
\hline $\mathbf{N i}$ & 69 & 78 & 3 & $23^{\underline{a}}$ & $26^{\underline{a}}$ & \\
\hline $\mathrm{Pb}$ & 35 & 415 & 2089 & 60 & 5 & \\
\hline $\mathrm{Zn}$ & 25 & 39 & 36 & 1,4 & $1,1^{a}$ & \\
\hline Cd & 43 & 52 & 151 & 3,5 & 2,9 & $\begin{array}{l}\text { Sauvé } \\
\text { (2000b) }\end{array}$ \\
\hline Cd & 43 & 52 & 41 & 1,1 & 1,3 & Seuntjens \\
\hline
\end{tabular}

(2002) 
TABELA 7.7 - Média geométrica dos valores de Kp do solo de Figueira obtidos experimentalmente, e valores de $\mathrm{Kp}$ calculados por meio das equações de regressão múltipla da literatura, utilizando as características físico-químicas do solo de Figueira.

\begin{tabular}{|c|c|c|c|c|c|c|}
\hline \multirow[t]{2}{*}{ Metal } & \multicolumn{2}{|c|}{ Kp experimental } & $\begin{array}{c}\mathrm{Kp} \\
\text { calculado }\end{array}$ & \multicolumn{2}{|c|}{ Fator } & \multirow[t]{2}{*}{ Literatura } \\
\hline & $\mathrm{Kp} \mathbf{p}_{\text {EDTA }}$ & $\mathrm{Kp} \mathrm{Ca}\left(\mathrm{NO}_{3}\right)_{2}$ & & $\mathrm{Kp} \mathrm{p}_{\text {calc. }} / \mathrm{Kp}_{\mathrm{EDTA}}$ & $\mathrm{Kp}_{\text {calc. }} / \mathrm{Kp}_{\mathrm{Ca}\left(\mathrm{NO}_{3}\right)_{2}}$ & \\
\hline Cd & 43 & 52 & 44 & 1,0 & $1,2^{a}$ & Soares \\
\hline Co & 29 & 153 & 16 & $1,8^{\mathrm{a}}$ & $9,6^{\mathrm{a}}$ & (2004) \\
\hline $\mathrm{Cr}$ & 265 & 535 & 24 & $11^{\mathrm{a}}$ & $22^{\mathrm{a}}$ & \\
\hline $\mathrm{Cu}$ & 104 & 394 & 251 & 2,4 & $1,6^{\mathrm{a}}$ & \\
\hline $\mathbf{N i}$ & 69 & 78 & 26 & $2,7^{\mathrm{a}}$ & $3,0^{\mathrm{a}}$ & \\
\hline $\mathbf{P b}$ & 35 & 415 & 324 & 9,3 & $1,3^{\mathrm{a}}$ & \\
\hline $\mathrm{Zn}$ & 25 & 39 & 5 & $5,0^{\mathrm{a}}$ & $7,8^{\mathrm{a}}$ & \\
\hline
\end{tabular}

Kp calc: Kp calculado

a. Fator determinado inversamente, ou seja, $\mathrm{Kp}_{\mathrm{EDTA}} / \mathrm{Kp}_{\text {calc. }}$ e $\mathrm{Kp}_{\mathrm{Ca}\left(\mathrm{NO}_{3}\right)_{2}} / \mathrm{Kp}_{\text {Ecalc. }}$.

\subsubsection{Kp X características do solo}

Segundo Morrone (1985), a cidade de Figueira, Paraná, apresenta um tipo de solo que é uma associação podzólica vermelho-amarelo, álico e abrúptica. Atualmente a nomenclatura podzólico foi substituída para argissolo (Prado, 2003). Na FIG. 7.9 apresentam-se alguns tipos de solos do Paraná (IBGE, 2005). 


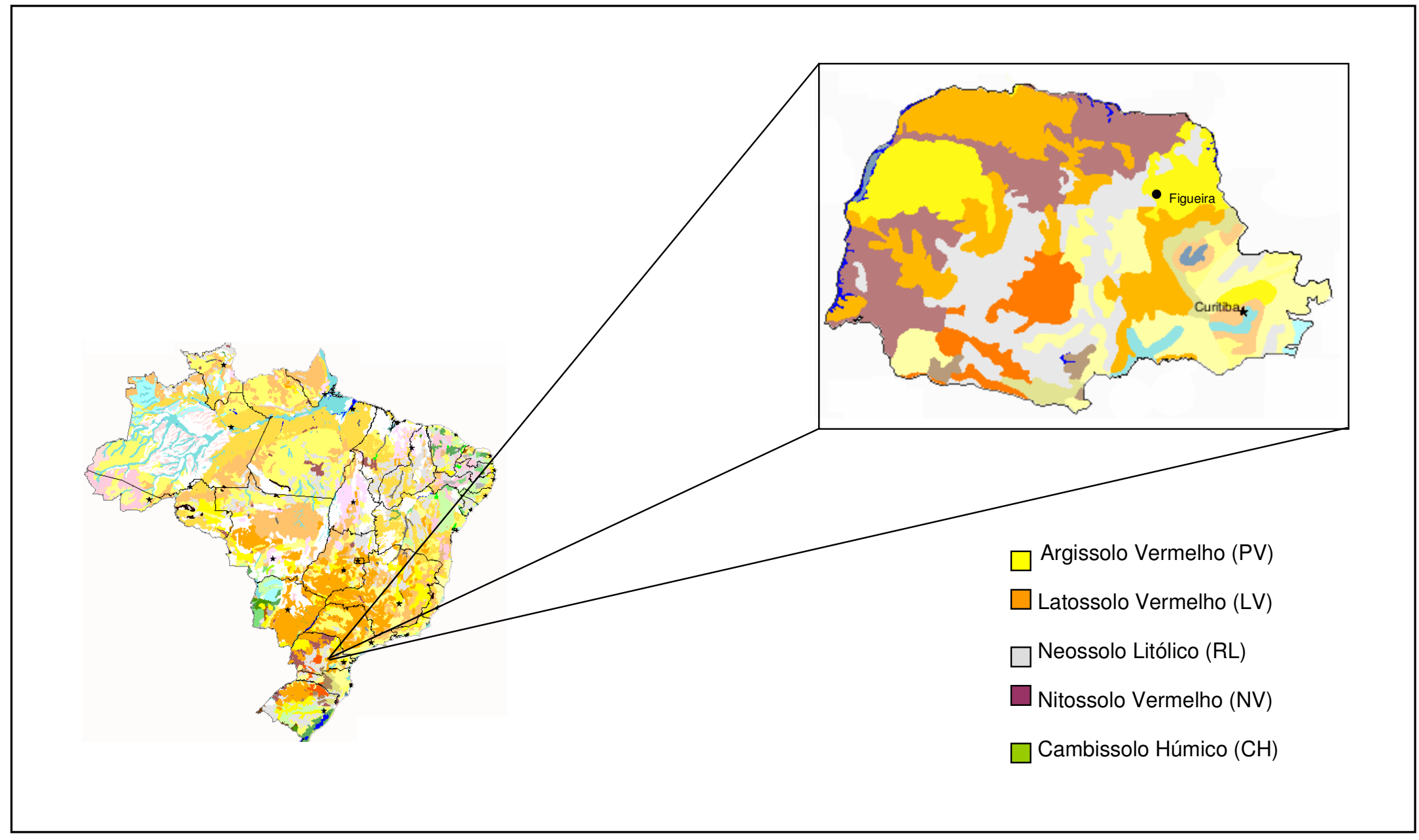

Figura 7.9 - Localização de Figueira no mapa de solos do Paraná, Brasil (IBGE, 2005). 
Na TAB. 7.6 apresenta-se a média e o intervalo das características físico-químicas do solo ( $\mathrm{pH}, \mathrm{CTC}, \mathrm{MO}$, argila, areia, silte, Al, $\mathrm{Fe}$ e $\mathrm{Mn}$ ), concentração total do metal determinado por fluorescência de raios $X$ (item 6.5.1), concentração parcial do metal determinado por digestão com $\mathrm{HNO}_{3}$ (item 6.5.2) e a fração residual dos metais no solo, obtida pela diferença entre a concentração total e a concentração parcial. O solo apresentou características ácidas, variando de 3,4 a 5,9, que de um modo geral, favorecem a desorção dos metais do solo para a solução do solo. Por outro lado, a argila e a matéria orgânica influenciam na retenção dos metais no solo. Os solos apresentaram uma média de 2,9\% para a matéria orgânica, que os caracterizaram como solos minerais segundo Brady (1989), e uma média de $26 \%$ para a argila, $31 \%$ para silte e $44 \%$ para areia que classifica a textura do solo como franco (mistura de partículas silte, argila e areia) segundo o triângulo americano adotado pela USDA (United State Departament of Agriculture Soil Staff, 1975). Na FIG. 7.10 apresenta-se a distribuição das partículas argila, silte e areia do solo de Figueira no triângulo americano. A CTC, que relaciona a capacidade de troca de cátions nos sítios de adsorção do solo de forma reversível, apresentou uma média de $18 \mathrm{cmol} \mathrm{kg}^{-1}$ que caracteriza um solo de CTC média segundo a classificação do laboratório canadense AGVISELABS (http://www.agviselabs.com). Observa-se na TAB. 7.6 que boa parte dos metais, $\mathrm{Cr}, \mathrm{Cu}, \mathrm{Ni}$ e $\mathrm{Zn}$, estão na fração residual do solo, ou seja, praticamente não disponível para a solução do solo. Os metais As e Pb encontram-se em menor porcentagem na fração residual, $21 \%$ e $60 \%$, respectivamente. Os demais metais estudados, Cd, Co e Mo, não foram determinados na fração residual, pois não foi possível medir a concentração total por fluorescência de raios $X$. Podlesáková et al. (2000) analisaram As, Cd, Co, Cr, Cu, Ni, Pb, Zn em diferentes frações do solo com diferentes características físico-químicas e níveis de contaminação. Estes autores observaram que $\mathrm{Cd}$ foi encontrado, sobretudo, nas frações móveis (solúveis) e facilmente mobilizáveis (trocáveis). Cromo e Ni foram encontrados mais na fração residual, ao passo que os metais $\mathrm{As}$ e $\mathrm{Pb}$ foram os menos encontrados na fração residual, aproximadamente de 10 a 60\% para As e de 10 a $40 \%$ para $\mathrm{Pb}$. Cobre e $\mathrm{Pb}$ mostraram maior afinidade pela matéria orgânica do solo e As pela fração de óxidos de Fe. Cobalto e Zn apresentaram distribuição nas frações orgânica e óxidos de Fe. 
Considerando as características físico-químicas apresentadas na TAB. 7.6, aplicou-se a análise de componentes principais (FIG. 7.11) e observou-se que os pontos de solo coletados em Figueira fazem parte de um mesmo grupo, ou seja, este resultado indica que se trata de um mesmo tipo de solo, embora exista alguma variação nos resultados das características físico-químicas do solo (TAB. A11). Os pontos de solo coletados que foram distintos do grupo foram os pontos 200A, E1A, SE1A, N3A, E3A, SW3A. Estes pontos apresentaram concentração total de $\mathrm{Mn}$ entre 94 e $208 \mathrm{mg} \mathrm{kg}^{-1}$ (TAB. A11), menor que a média de todos os pontos coletados, $1181 \mathrm{mg} \mathrm{kg}^{-1}$ (TAB. 7.6). Observou-se durante a análise do componente principal que o $\mathrm{Mn}$ foi a variável que agrupou os solos coletados.

$\mathrm{O}$ coeficiente de partição, Kp, é um parâmetro que pode variar ordens de grandeza segundo as características físico-químicas do solo. As características mais comuns que se correlacionam com o valor de $\mathrm{Kp}$ do metal são o pH, CTC, MO, argila, óxidos de Al, Fe e Mn (Anderson, 1988; Buchter, 1989; Janssen, 1997; Römkens, 1998; Soares, 2004). Alguns autores também consideram a concentração do metal um fator importante que se relaciona com o Kp (Sauvé, 2000a; Sauvé, 2000b).

Considerando os valores de $\mathrm{Kp}$ do metal (TAB. A5 e A6), as características físico-químicas do solo (TAB. A11) e a concentração parcial dos metais (TAB. A1) aplicou-se correlação de Pearson para Kp e logKp em função das características do solo e da concentração do metal (TAB. 7.8). O Kp $\left.\mathrm{Ka}_{\mathrm{CaO}} \mathrm{N}_{2}\right)_{2}$ do Mo não foi considerado, por apresentar apenas 3 valores. Observa-se que

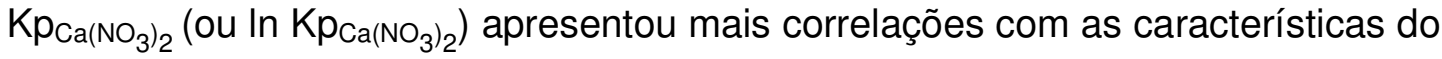
solo quando comparado com $\mathrm{Kp}_{\mathrm{EDTA}}$ (ou In $\mathrm{Kp}_{\mathrm{EDTA}}$ ) para os metais As, Cd, Co, Cr, $\mathrm{Cu}$, Ni e Pb. O Kp apresentou correlação com a concentração do metal para todos os metais, exceto Zn. Sauvé et al. (2000a) estabeleceram uma equação de regressão múltipla para o $\mathrm{Kd}$ de $\mathrm{Pb}$ e $\mathrm{Zn}$ (TAB. 3.2) que relaciona $\circ \mathrm{pH}$ e a concentração de $\mathrm{Pb}$ no solo positivamente, ou seja, se o pH ou a concentração do metal aumenta o Kd aumenta também. Sauvé et al. (2000b) mostraram graficamente que quanto maior $\mathrm{opH}$ ou a concentração de $\mathrm{Cd}$ em solos contaminados, maior o valor de $\mathrm{Kd}$. Vários autores apresentam o $\mathrm{pH}$ como o fator mais importante na distribuição dos metais no solo (Anderson, 1988; Buchter 1989; McBride, 1994; Janssen, 1997; Lee, 1998; Sauvé, 2000a; Sauvé, 2000b; 
Krishnamurti, 2002; Degryse, 2003; Lin, 2004; Soares, 2004). No entanto, apenas o Kp dos metais As, Co, Cu e $\mathrm{Pb}$ apresentaram correlação com o pH do solo (TAB. 7.8). O Kp de As apresentou correlação com o Fe (TAB. 7.8) e a literatura mostra esta tendência (McBride, 1994; Janssen, 1997; Podlesáková, 2000; Brouwere, 2004). Sabe-se que $\mathrm{Cu}$ tem afinidade com a matéria orgânica (McBride, 1994; Podlesáková, 2000; Krishnamurti, 2002) e o Kp $\mathrm{Ca}_{\left(\mathrm{NO}_{3}\right)_{2}}$ apresentou correlação com a matéria orgânica.

Inicialmente tinha-se idéia de estabelecer uma equação de Kp para cada metal em função das características físico-químicas do solo de Figueira. Embora exista variação das características físico-químicas do solo (TAB. 7.6) e do valor de $\mathrm{Kp}$ dos metais (TAB. A5 e A6), descartou-se esta idéia porque se trata de um único tipo de solo. Segundo Buchter et al. (1989), relação entre as características do solo e parâmetros de retenção existe para um grupo de solos com características bem diferentes. 


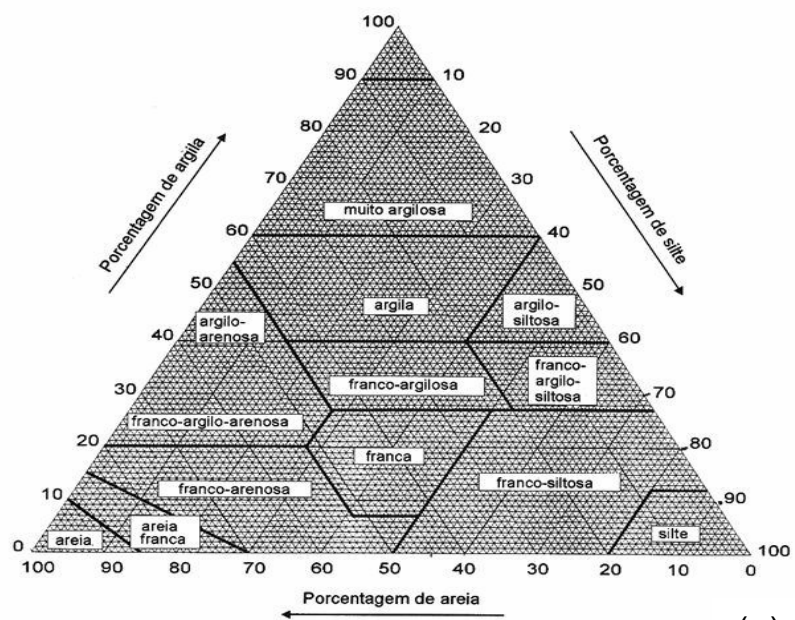

(a)

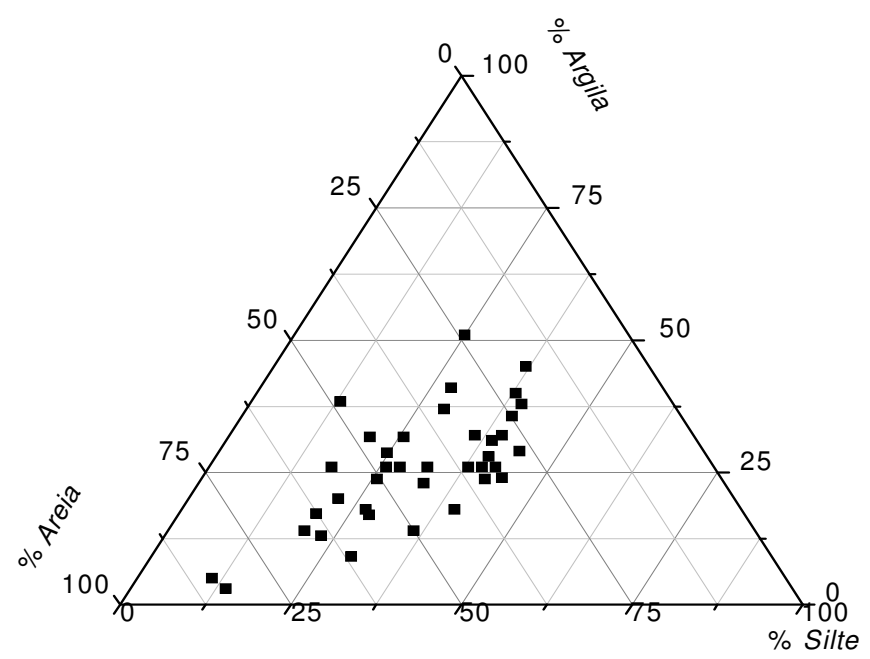

(b)

FIGURA 7.10 - Classificação textural do solo de acordo com a USDA (a) e do solo de Figueira (b). 


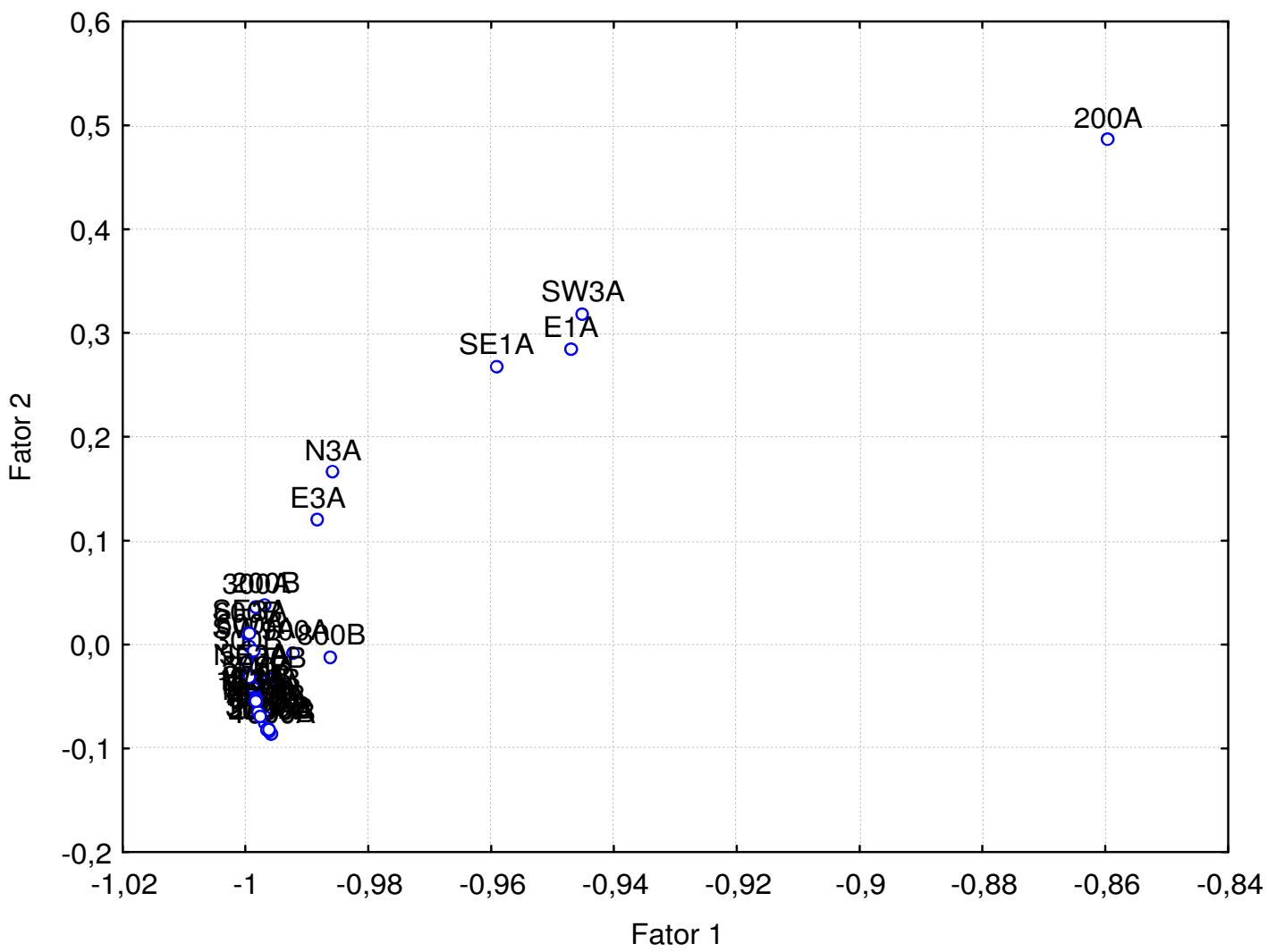

FIGURA 7.11 - Componente principal das características físico-químicas das amostras do solo de Figueira. 
TABELA 7.8 - Correlação de Pearson $(p<0,05)$ dos valores de $\mathrm{Kp}$ com as características físico-químicas do solo e a concentração parcial do metal.

\begin{tabular}{|c|c|c|c|c|c|c|c|c|c|c|c|}
\hline $\begin{array}{l}\text { Metal } \\
\left(\mathrm{n}_{1}, \mathrm{n}_{2}\right)\end{array}$ & & [metal] & $\mathrm{pH}$ & MO & Argila & Areia & Silte & CTC & Al & $\mathrm{Fe}$ & Mn \\
\hline \multirow{4}{*}{$\begin{array}{l}\text { As } \\
(31,23)\end{array}$} & & 0,66 & 0,001 & 0,35 & $-0,10$ & $-0,02$ & 0,25 & 0,43 & $-0,11$ & 0,50 & $-0,33$ \\
\hline & $\operatorname{lnKp_{\text {EDTA}}}$ & 0,60 & 0,05 & 0,40 & $-0,15$ & 0,05 & 0,16 & 0,48 & $-0,05$ & 0,41 & $-0,23$ \\
\hline & & 0,83 & 0,61 & 0,76 & $-0,63$ & 0,33 & 0,38 & 0,21 & 0,45 & 0,66 & 0,16 \\
\hline & $\operatorname{lnK} \mathrm{pp}_{\mathrm{Ca}}$ & 0,64 & 0,44 & 0,62 & $-0,45$ & 0,14 & 0,43 & 0,34 & 0,38 & 0,44 & 0,18 \\
\hline \multirow{3}{*}{$\begin{array}{l}\text { Cd } \\
(33,37)\end{array}$} & & 0,13 &,- 016 & $-0,06$ & 0,18 & $-0,06$ & $-0,06$ & $-0,03$ & $-0,11$ & 0,21 & $-0,13$ \\
\hline & $\operatorname{lnKp_{\text {EDTA}}}$ & 0,27 & $-0,05$ & 0,06 & 0,20 & $-0,11$ & $-0,02$ & 0,07 & $-0,11$ & 0,35 & $-0,21$ \\
\hline & $\mathrm{Kp} \mathrm{Ka}_{\mathrm{Ca}}$ & 0,37 & $\begin{array}{l}0,26 \\
02\end{array}$ & 0,01 & $\begin{array}{l}-0,20 \\
-017\end{array}$ & 0,20 & $-0,09$ & $-0,03$ & $-0,07$ & 0,33 & $\begin{array}{l}-0,09 \\
-0,0\end{array}$ \\
\hline \multirow{3}{*}{$\begin{array}{l}\text { Co } \\
(24,23)\end{array}$} & $\mathrm{Kp}_{\text {EDTA }}$ & $\begin{array}{l}0,42 \\
0,49\end{array}$ & $\begin{array}{l}0,32 \\
0,12\end{array}$ & $\frac{0,13}{0,11}$ & $\frac{-0,17}{0,24}$ & $\begin{array}{l}0,06 \\
-0,22\end{array}$ & $\begin{array}{l}0,12 \\
0,10\end{array}$ & $\begin{array}{l}0,10 \\
0,25\end{array}$ & $\begin{array}{l}0,01 \\
0,34\end{array}$ & $\begin{array}{l}0,30 \\
0,03\end{array}$ & $\begin{array}{l}-0,02 \\
0,09\end{array}$ \\
\hline & InKp & 0,54 & 0,15 & 0,02 & 0,29 & $-0,20$ & 0,01 & 0,34 & 0,39 & 0,11 & 0,11 \\
\hline & $\begin{array}{l}\mathrm{Kp}_{\mathrm{Ca}} \\
\operatorname{lnK}_{\mathrm{Ka}}\end{array}$ & $\begin{array}{l}0,60 \\
0,74\end{array}$ & $\begin{array}{l}0,51 \\
0,56\end{array}$ & $\begin{array}{l}0,14 \\
0,30\end{array}$ & $\begin{array}{l}0,41 \\
0,34\end{array}$ & $\begin{array}{l}-0,63 \\
-0,63\end{array}$ & $\begin{array}{l}0,49 \\
0,56\end{array}$ & $\begin{array}{l}0,39 \\
0,49\end{array}$ & $\begin{array}{l}0,31 \\
0,50\end{array}$ & $\begin{array}{l}0,01 \\
-0,03\end{array}$ & $\begin{array}{l}0,24 \\
\mathbf{0 , 4 3}\end{array}$ \\
\hline \multirow{4}{*}{$\begin{array}{l}\mathrm{Cr} \\
(11,30)\end{array}$} & $\mathrm{Kp}_{\text {EDTA }}$ & 0,96 & 0,26 & 0,10 & $-0,24$ & 0,12 & 0,12 & 0,08 & 0.01 & 0,45 & $\frac{0,40}{-0,10}$ \\
\hline & $\operatorname{InK} p_{E}$ & 0,95 & 0,37 & 0,25 & $-0,30$ & 0,11 & 0,21 & 0,20 & 0,15 & 0,50 & 0,01 \\
\hline & $\mathrm{Kp}_{\mathrm{Ca}}$ & 0,47 & $-0,09$ & $-0,10$ & 0,51 & $-0,55$ & 0,26 & 0,19 & $-0,11$ & 0,05 & $-0,29$ \\
\hline & InKp & 0,54 & $-0,03$ & 0,18 & 0,43 & $-0,59$ & 0,46 & 0,45 & $-0,10$ & 0,21 & $-0,29$ \\
\hline \multirow{4}{*}{$\begin{array}{l}\mathrm{Cu} \\
(40,14)\end{array}$} & $\mathrm{Kp}_{\mathrm{ED}}$ & $-0,16$ & $-0,05$ & $-0,00$ & $-0,06$ & $-0,04$ & 0,20 & 0,21 & $-0,22$ & $-0,01$ & $-0,21$ \\
\hline & $\operatorname{lnKp}$ & $-0,23$ & 0,03 & 0,07 & $-0,12$ & $-0,06$ & 0,29 & 0,17 & $-0,17$ & $-0,02$ & $-0,11$ \\
\hline & $\mathrm{Kp}_{\mathrm{Ca}}$ & 0,98 & 0,43 & 0,64 & $-0,28$ & $-0,19$ & 0,58 & 0,23 & 0,29 & 0,46 & $-0,13$ \\
\hline & & 0,8 & 0,59 & 0,74 & $-0,24$ & -0 & 0,73 & 0,46 & 0,53 & 0,56 & $-0,01$ \\
\hline \multirow{3}{*}{$\begin{array}{l}\text { Mo } \\
\text { (9) }\end{array}$} & $\mathrm{Kp}_{\text {EDTA }}$ & 0,45 & 0,21 & 0,74 & 0,01 & $-0,35$ & 0,70 & 0,36 & 0,04 & 0,38 & $-0,15$ \\
\hline & $\operatorname{lnK} p_{\text {EDTA }}$ & 0,51 & 0,21 & 0,83 & 0,04 & $-0,42$ & 0,77 & 0,47 & 0,15 & 0,43 & $-0,08$ \\
\hline & $\mathrm{Kp}_{\mathrm{ED}}$ & 0,5 & $-0,12$ & $-0,20$ & 0,35 & $-0,25$ & $-0,01$ & $-0,00$ & 0,10 & 0,01 & $-0,10$ \\
\hline \multirow{3}{*}{$\begin{array}{l}\mathbf{N i} \\
(38,23)\end{array}$} & $\ln K p$ & 0 , & $-0,25$ & $-0,23$ & 0 & $-0,20$ & $-0,07$ & 0,03 & 0,02 & 0,06 & $-0,19$ \\
\hline & $\mathrm{Kp}_{\mathrm{Ca}}$ & 0,73 & 0,20 & 0,29 & 0,10 & $-0,41$ & 0,55 & 0,22 & 0,35 & 0,14 & 0,24 \\
\hline & & 7 & 0,28 & $0 M$ & . & & 0 & 39 & 0,42 & 0,20 & 0,29 \\
\hline \multirow{4}{*}{$\begin{array}{l}\mathbf{P b} \\
(31,26)\end{array}$} & $\mathrm{Kp}_{\text {EDTA }}$ & 0,87 & 0,42 & 0,34 & 0,01 & $-0,20$ & 0,34 & 0,19 & 0,46 & 0,24 & 0,26 \\
\hline & $\operatorname{lnK} p_{E D}$ & 0,79 & 049 & 0,38 & 0,02 & $-0,28$ & 0,49 & רכ0 & 0,51 & 0,25 & 0,28 \\
\hline & $\mathrm{Kp} \mathrm{Ca}_{\mathrm{Ca}}$ & 0,90 & 0,38 & 0,32 & $-0,01$ & $-0,30$ & 0,51 & 0,09 & 0,61 & 0,05 & 0,46 \\
\hline & IIKn & 00 & & 0 & & & & & & & 0,45 \\
\hline \multirow{4}{*}{$\begin{array}{l}\mathbf{Z n} \\
(31,31)\end{array}$} & $K p_{\text {EDTA }}$ & 0,07 & $-0,09$ & 0,10 & 0,01 & $-0,23$ & 0,43 & 0,20 & $-0,13$ & 0,06 & $-0,10$ \\
\hline & $\operatorname{lnK} p_{\text {EDTA }}$ & 0,17 & $-0,05$ & 0,21 & $-0,04$ & $-0,25$ & 0,50 & 0,26 & $-0,09$ & 0,11 & $-0,08$ \\
\hline & $\mathrm{Kp}_{\mathrm{Ca}}$ & $-0,11$ & 0,05 & $-0,11$ & 0,05 & $-0,24$ & 0,35 & $-0,13$ & 0,23 & $-0,13$ & 0,25 \\
\hline & $\operatorname{lnKp}$ & 0,08 & 0,15 & 0,06 & & $-0,30$ & 0,53 & $-0,01$ & 0,27 & $-0,01$ & 0,27 \\
\hline
\end{tabular}




\subsubsection{Sorção dos metais no solo}

A sorção dos metais no solo está relacionada com o Kp. Quanto menor o Kp, menor a retenção do metal no solo, ou seja, o metal está mais disponível na fase líquida do solo para migrar para a água subterrânea ou ser absorvido pelas plantas. E ao contrário disto, quanto maior o Kp, maior a retenção do metal no solo.

Os valores da média geométrica de Kp (FIG. 7.6) foram colocados em ordem decrescente de $\mathrm{Kp}_{\mathrm{EDTA}}$ e $\mathrm{Kp} \mathrm{Pa}_{\mathrm{C}\left(\mathrm{NO}_{3}\right)_{2}}$.

$$
\begin{aligned}
& \mathrm{KP}_{\text {EDTAA }}: \quad \mathrm{As}>\mathrm{Mo}>\mathrm{Cr}>\mathrm{Cu}>\mathrm{Ni}>\mathrm{Cd}>\mathrm{Pb}>\mathrm{Co}>\mathrm{Zn} \\
& \mathrm{Kp}_{\mathrm{Ca}\left(\mathrm{NO}_{3}\right)_{2}}: \mathrm{Cr}>\mathrm{Pb}>\mathrm{Cu}>\mathrm{As}>\mathrm{Co}>\mathrm{Ni}>\mathrm{Cd}>\mathrm{Zn}
\end{aligned}
$$
7.6), o comportamento dos metais foi similar à sorção no solo, exceto para o Pb. Observou-se que As, $\mathrm{Cr}$, Cu e Mo são mais retidos pelo solo e Zn é menos retido seguido por $\mathrm{Cd}$, Co e Ni. Este comportamento é concordante com a literatura (McBride, 1994). Entre os metais mais móveis ( $\mathrm{Zn}, \mathrm{Cd}$, Co e Ni), o Cd é o mais preocupante por causa da sua toxicidade. $\mathrm{O} \mathrm{Pb}$ apresentou um comportamento duplo, ou seja, a seqüência de $\mathrm{K}_{\mathrm{EDTA}}$ mostrou que o $\mathrm{Pb}$ é menos retido pelo solo

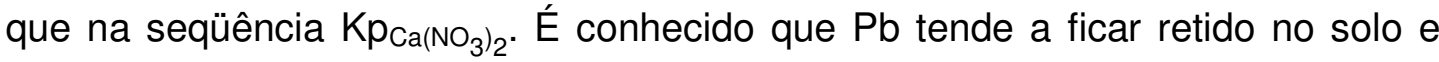
tem grande afinidade com a matéria orgânica (McBride, 1994). Portanto seria esperado que $\mathrm{Pb}$ estivesse próximo dos metais $\mathrm{Cu}$ e $\mathrm{Cr}$ na seqüência de sorção. No entanto, K $p_{\text {EDTA }}$ para o $\mathrm{Pb}$ apresentou um valor menor que os valores de $\mathrm{Kp}_{\text {EDTA }}$ dos metais $\mathrm{Cr}$, Cu, Ni e Cd. Hornburg (1991) apresentou graficamente a influência do $\mathrm{pH}$ na solubilidade de $\mathrm{Pb}$ e $\mathrm{Cu}$ para solos de floresta e pasto. A solubilidade de $\mathrm{Cu}$ em solo de pasto ( $\mathrm{pH}$ aproximadamente 6) em função do $\mathrm{pH}$ foi mais afetada que a solubilidade de $\mathrm{Pb}$, tanto quando comparada com a concentração total do metal quanto com a concentração do metal obtida por extração com EDTA. Por outro lado, em solo de floresta ( $\mathrm{pH}$ aproximadamente 3), a solubilidade de $\mathrm{Pb}$ foi mais afetada em função do $\mathrm{pH}$ do que a solubilidade de $\mathrm{Cu}$ quando comparada com a concentração total do metal, mas quando comparada com a concentração do metal obtida por extração com EDTA, tanto a solubilidade de $\mathrm{Pb}$ quanto a de $\mathrm{Cu}$ foi afetada pelo $\mathrm{pH}$. Este trabalho pode indicar que dependendo do solo, do pH e da solução de extração do metal no solo, o Pb 
pode ter um comportamento similar ou diferente de Cu. Então, o fato do $\mathrm{Pb}$ apresentar um comportamento diferente em relação ao $\mathrm{Cu}$ no presente trabalho quando foi analisado pelo $\mathrm{Kp}_{\text {EDTA }}$ poderia ser esperado. Sabe-se também que o EDTA é muito utilizado para descontaminação do solo com $\mathrm{Pb}$, por ser considerado um agente quelante eficiente na remoção deste metal (Heil, 1996; Heil, 1999; Sun, 2001; Lim, 2004; Lim, 2005; Tawinteung, 2005). Num outro trabalho, Gooddy et al. (1995) apresentaram uma seqüência de Kd para metais obtido por diferentes soluções de extração, $\mathrm{CaCl}_{2} 0,01 \mathrm{~mol} \mathrm{~L}^{-1}$ e $\mathrm{HNO}_{3}$ 0,43 $\mathrm{mol} \mathrm{L}^{-}$ 1, para representar a fase sólida do solo. Estes autores mostraram que para a solução de $\mathrm{CaCl}_{2}$, o $\mathrm{Pb}$ e $\mathrm{Cu}$ foram menos retidos no solo que $\mathrm{Cd}$, Co, Ni e $\mathrm{Zn}$, ao passo que para a solução de $\mathrm{HNO}_{3} \circ \mathrm{Pb}$ foi o mais retido que os demais metais.

O comportamento dos metais no solo estudado neste trabalho foi concordante com o comportamento dos metais nos solos analisados por Wasay (1998). Wasay et al. (1998) analisaram a distribuição dos metais Cd, Cr, Cu, Pb e Zn nas frações de solos contaminados de diferentes características. Estes autores concluíram que $\mathrm{Cd}$ e $\mathrm{Zn}$ foram, particularmente, encontrados na fração trocável do solo e $\mathrm{Cr}$, $\mathrm{Cu}$ e $\mathrm{Pb}$ foram encontrados em óxidos de $\mathrm{Fe}$ e $\mathrm{Mn}$ e matéria orgânica. Portanto Cd e Zn são mais móveis e os outros metais são mais retidos pelo solo.

Outros autores também apresentaram uma seqüência de sorção do metal que foi similar ao do presente trabalho. Gomes et al. (2001) avaliaram a sorção de $\mathrm{Cd}, \mathrm{Cr}, \mathrm{Cu}, \mathrm{Ni}, \mathrm{Pb}$ e $\mathrm{Zn}$ pelo $\mathrm{Kp}$ determinado por ensaio de adsorção em sete solos brasileiros de diferentes características. Estes autores concluíram que $\mathrm{Cu}, \mathrm{Cr}$ e $\mathrm{Pb}$ foram os metais mais retidos pelo solo e $\mathrm{Cd}$, $\mathrm{Ni}$ e $\mathrm{Zn}$ foram os metais menos retidos. Gao et al. (1997) estudaram a sorção dos mesmos metais analisados por Gomes et al. (2001) pelo Kp determinado por isoterma de adsorção em nove solos de diferentes características em pH ajustados para 4,5 e 6,5. Estes autores apresentaram duas seqüências de sorção: $\mathrm{Pb}>\mathrm{Cu}>\mathrm{Zn}>\mathrm{Ni}>$ $\mathrm{Cd} \sim \mathrm{Cr}$, para $\mathrm{pH}$ ajustado em 4,5 e $\mathrm{Pb}>\mathrm{Cu} \sim \mathrm{Zn}>\mathrm{Cd}>\mathrm{Ni}>\mathrm{Cr}$ para $\mathrm{pH}$ ajustado em 6,5. O cromo apresentou um comportamento mais móvel que os demais metais, que pode ser explicado pelo fato que o cromo introduzido no ensaio de adsorção foi na forma de ânion, ou seja, no estado de oxidação +6 . Hassan et al. (1996) estudaram a distribuição das formas químicas do cromo $\left(\mathrm{Cr}^{3+}\right.$ e $\mathrm{CrO}_{4}{ }^{2-}$ ) no solo, e observaram que $\mathrm{Kp}$ do $\mathrm{CrO}_{4}{ }^{2-}$ é 10 vezes menor que o $\mathrm{Kp}$ do 


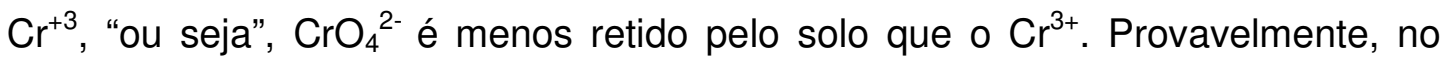
presente trabalho, o cromo está na forma $\mathrm{Cr}^{3+}$, que apresenta um comportamento menos móvel no solo.

Janssen et al. (1997) apresentaram os valores de Kp para metais para vinte solos coletados. Partindo-se destes valores, no presente trabalho, calculouse a média geométrica dos valores de Kp para colocá-los em uma seqüência decrescente de Kp. A seqüência de Kp obtida foi: $\mathrm{Pb}>\mathrm{Cr}>\mathrm{As}>\mathrm{Cd}>\mathrm{Zn}>\mathrm{Ni}>$ $\mathrm{Cu}$. Esta seqüência corresponde ao comportamento apresentado por McBride (1994) e pelo presente trabalho, exceto para o Cu que demonstrou ser o metal mais disponível, ao passo que o $\mathrm{Cu}$ deveria ficar mais retido como o $\mathrm{Pb}$ e $\circ \mathrm{Cr}$. Os autores comentam no trabalho que $\mathrm{Kp}$ de $\mathrm{Cu}$ tem boa correlação com a matéria orgânica dissolvida (DOM) dos solos estudados e que este fato pode aumentar a solubilidade de $\mathrm{Cu}$, pois se o $\mathrm{Cu}$ forma complexo com a matéria orgânica e esta está dissolvida na fase líquida do solo, então, o complexo formado (Cu-matéria orgânica) será solúvel, o que torna o Cu mais disponível na solução do solo. Num outro trabalho da literatura, Hornburg (1991) apresentou um aumento da disponibilidade de $\mathrm{Cu}$ no solo para $\mathrm{pH}$ menor que 5 e maior que 7 para dois tipos diferentes de uso de solo (pasto e agrícola).

Todos estes trabalhos apresentam informações sobre o Kp de um metal que pode sofrer alteração, tornando o metal mais retido ou menos retido no solo, conforme algumas condições, tais como: $\mathrm{pH}$ do solo, por exemplo, metal na forma catiônica tende a ficar mais retido no solo com o aumento de $\mathrm{pH}$, ao passo que, na forma aniônica tende a ficar menos retido no solo, e o inverso é recíproco; o estado de oxidação do metal, por exemplo, o cromo (Kp de $\mathrm{Cr}^{3+}$ é maior que $\mathrm{Kp}$ de $\mathrm{CrO}_{4}{ }^{2-}$ ); a utilização de uma solução de extração para representar a fase sólida e líquida do solo; a afinidade do metal com a matéria orgânica, por exemplo, o $\mathrm{Cu}$, em que Kp de Cu pode ser maior quando a matéria orgânica está na forma sólida do solo e Kp de Cu pode ser menor quando a matéria orgânica está na forma dissolvida na fase líquida do solo.

\subsection{5. $\mathrm{Kp}$ em solo contaminado $\mathrm{x}$ solo não contaminado e $\mathrm{Kp} \times$ profundidade}

A idéia de se avaliar se o valor de Kp de um metal varia de um solo contaminado para um solo não contaminado, para fins de avaliação de risco à 
saúde humana, sugere que se houver diferença, o Kp do metal deveria ser determinado no solo contaminado para cálculo do risco. Quanto à profundidade, se o valor de Kp variar ao longo do solo, sugere que a utilização de Kp do metal determinado no topo do solo pode não representar adequadamente o transporte do metal do topo do solo até a água subterrânea.

Neste item discutiu-se se existe diferença entre o valor de Kp de um metal num solo contaminado de um solo não contaminado com base no trabalho de Janssen et al. (1997), e entre as duas frações A e B de profundidades diferentes, de 0 a $25 \mathrm{~cm}$ e de 25 a $50 \mathrm{~cm}$, respectivamente, com base nos trabalhos de Gooddy et al. (1995), Dumat et al. (2001) Chang et al. (2001), Seuntjens (2002).

Janssen et al. (1997) desenvolveram um modelo que relaciona coeficiente de partição em função das características do solo, por meio de regressão múltipla. O modelo foi desenvolvido para $\mathrm{As}, \mathrm{Cd}, \mathrm{Cr}, \mathrm{Cu}, \mathrm{Ni}, \mathrm{Pb}$ e $\mathrm{Zn}$ em solos holandeses com elevados níveis destes metais comparados com valores de solos naturais. Estes pesquisadores aplicaram este mesmo modelo em solos naturais holandeses e concluíram que o modelo pode ser aplicado para ambos os casos, solos contaminados e não contaminados. O trabalho de Janssen et al. (1997) indica que os valores de Kp para metais são independentes de solos contaminados ou não contaminados, ou seja, independe da concentração do metal. Gooddy et al. (1995), Dumat et al. (2001) Chang et al. (2001), Seuntjens (2002) determinaram Kd de metais para perfil de solo e observaram que o Kd dos metais para a camada de solo superficial foi igual ou maior que o $\mathrm{Kd}$ para as camadas mais inferiores, variando até quatro ordens de grandeza de diferença.

Considerando os metais As, $\mathrm{Cd}, \mathrm{Pb}$ e $\mathrm{Zn}$ como contaminantes, segundo os valores de referência estabelecidos pela CETESB, discutidos no item 7.1, separaram-se os pontos de coleta de solo entre solos contaminados e não contaminados.

A razão entre a média geométrica de $\mathrm{Kp}$ dos solos contaminados e não contaminados foram determinados, TAB. 7.9. Os metais $\mathrm{Cd}$ e $\mathrm{Zn}$ apresentaram uma razão mais próxima de 1, Pb apresentou 3,2 e 5,2 e As 3,6 e 13 para os

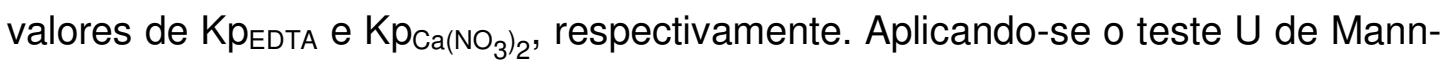
Whitney ( $p<0,05$, monocaudal) confirmou-se que o valor de Kp destes metais para solos contaminados foi maior que o valor de $\mathrm{Kp}$ para solos não 
contaminados. Estatisticamente, os valores de $\mathrm{Kp}$ para metais dos solos contaminados foram maiores que os dos solos não contaminados, que é contraditório à indicação de Janssen et al. (1997). Uma diferença entre ambos os estudos é que no presente trabalho os valores de Kp foram determinados em um único tipo de solo no qual existe pouca variação das características do solo ao passo que Janssen et al. (1997) determinaram o Kp de metais em solo que apresentaram diferentes características. Além disso, a concentração de $\mathrm{Cd}, \mathrm{Pb}$ e $\mathrm{Zn}$ nos solos estudados por Janssen et al. (1997) é bem maior que a concentração destes metais nos solos de Figueira (TAB. 3.2).

TABELA 7.9 - Razão de Kp entre solos contaminados e não contaminados de Figueira para os dois métodos utilizados, EDTA e $\mathrm{Ca}\left(\mathrm{NO}_{3}\right)_{2}$.

\begin{tabular}{ccc}
\hline Metal & \multicolumn{2}{c}{ Razão de Kp } \\
& solos contaminados/solos não contaminados \\
\hline As & EDTA $\left(\mathbf{n}_{1}, \mathbf{n}_{2}\right)$ & $\mathbf{C a}\left(\mathrm{NO}_{3}\right)_{2}\left(\mathbf{n}_{1}, \mathbf{n}_{2}\right)$ \\
$\mathbf{C d}$ & $3,6(23,8)$ & $13(18,5)$ \\
$\mathbf{P b}$ & $1,3(14,19)$ & $1,6(14,23)$ \\
$\mathbf{Z n}$ & $3,2(15,16)$ & $5,2(15,11)$ \\
& $1,2(10,21)$ & $1,1(10,21)$ \\
\hline
\end{tabular}

$\mathrm{n}_{1}$. número de pontos de solo coletados contaminados

$\mathrm{n}_{2}$. número de pontos de solo coletados não contaminados

Por outro lado, a diferença entre os valores de $\mathrm{Kp}$ para solo contaminado e não contaminado foi um fator inferior a 10 para ambos os métodos, ou seja, menor que uma ordem de grandeza, exceto para o As no caso do $\mathrm{Kp}_{\mathrm{Ca}\left(\mathrm{NO}_{3}\right)_{2}}$ (TAB. 7.9). Esta diferença provavelmente não é significativa para avaliação de risco que será discutida posteriormente.

A razão entre a média geométrica de $K p$ do metal no solo transect $A$ (solo coletado na direção NW de 0 a $25 \mathrm{~cm}$ ) e no solo transect B (solo coletado na direção NW de 25 a $50 \mathrm{~cm}$ ) foi apresentada na TAB. 7.10. De um modo geral, a razão de Kp entre transect $A$ e $B$ foi próxima de 1. O As que apresentou a maior razão, 2,0 e 3,9, para $\mathrm{Kp}_{\text {EDTA }}$ e $\mathrm{Kp} \mathrm{pa}_{\mathrm{C}\left(\mathrm{NO}_{3}\right)_{2}}$, respectivamente. Esta razão mostra que o valor de $\mathrm{Kp}$ dos metais nas frações $\mathrm{A}$ e $\mathrm{B}$ não variou uma ordem de grandeza. Aplicando-se o teste Wilcoxon ( $<<0,05$, monocaudal) obteve-se que 0 
valor de $\mathrm{Kp}$ dos metais $\mathrm{Cu}$, $\mathrm{Ni}$ e $\mathrm{Zn}$ foram similares para os solos do transect $\mathrm{A} \mathrm{e}$

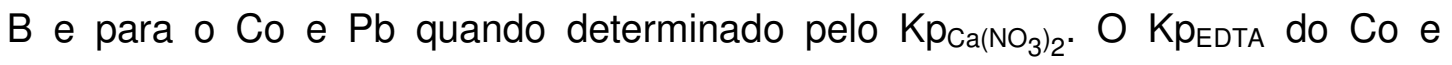
$\mathrm{Kp}_{\mathrm{Ca}\left(\mathrm{NO}_{3}\right)_{2}}$ do $\mathrm{Cr}$ do transect $\mathrm{B}$ foi maior que o do transect $\mathrm{A}$. Apenas os valores de $\mathrm{Kp}$ de $\mathrm{As}$ e $\mathrm{Cd}$ e de $\mathrm{Kp} \mathrm{p}_{\text {EDTA }}$ do $\mathrm{Pb}$ do transect $\mathrm{A}$ foram maiores que os valores de $\mathrm{Kp}$ respectivos do transect B. Gooddy et al. (1995) analisaram dois perfis do mesmo tipo de solo, um com uma profundidade de $50 \mathrm{~cm}$ coletado em frações de $10 \mathrm{~cm}$ e outro de $100 \mathrm{~cm}$ coletado em frações de $20 \mathrm{~cm}$. Estes autores mostraram que o valor de $\mathrm{Kp}$ dos metais $\mathrm{Cd}, \mathrm{Co}, \mathrm{Cu}, \mathrm{Pb}$ e $\mathrm{Zn}$ foram maiores no topo do solo que na fração inferior, e a diferença dos valores de $\mathrm{Kp}$ foi no máximo de três a quatro ordens de grandeza. Dumat et al. (2001) analisaram dois perfis de solo de $100 \mathrm{~m}$, com cinco frações de $20 \mathrm{~cm}$ cada, coletados numa área que tem sido impactada por uma fábrica de fundição de metais. Os autores mostraram graficamente que para os dois perfis de solo coletados, o $\mathrm{Kd}$ de $\mathrm{Pb}$ variou até duas ordens de grandeza, ao passo que, os valores de $\mathrm{Kd}$ de $\mathrm{Cd}$ e $\mathrm{Cu}$ foram da mesma ordem de grandeza. Chang et al. (2001) analisaram $\mathrm{Cd}$ e Cu em um perfil de solo de $50 \mathrm{~cm}$ com fração de $10 \mathrm{~cm}$ cada. Os autores mostraram que o Kd destes metais é da mesma ordem de grandeza ao longo do perfil. Seuntjens (2002) estudou a migração de Cd num perfil de solo de $1 \mathrm{~m}$ de profundidade. Este autor mostrou que o $\mathrm{Kd}$ de $\mathrm{Cd}$ foi da mesma ordem de grandeza ao longo do perfil.

TABELA 7.10 - Razão entre a média geométrica de Kp do metal no solo coletado na direção NW, de 0 a $25 \mathrm{~cm}$ (transect A) e 25 a $50 \mathrm{~cm}$ (transect $B)$, para os dois métodos estudados.

\begin{tabular}{ccc}
\hline Metal & \multicolumn{2}{c}{ Razão de Kp } \\
& Transect A/Transect B \\
\hline & $2,0(12)$ & $\mathbf{C a}\left(\mathrm{NO}_{3}\right)_{2}(\mathbf{n})$ \\
$\mathbf{A s}$ & $1,4(13)$ & $3,9(6)$ \\
$\mathbf{C d}$ & $0,4(6)$ & $1,6(13)$ \\
$\mathbf{C o}$ & $-^{a}$ & $1,0(5)$ \\
$\mathbf{C r}$ & $1,2(13)$ & $0,6(10)$ \\
$\mathbf{C u}$ & $0,8(13)$ & -6 \\
$\mathbf{N i}$ & $1,7(12)$ & $0,9(6)$ \\
$\mathbf{P b}$ & $1,2(12)$ & $1,6(9)$ \\
$\mathbf{Z n}$ & $1,0(13)$ \\
\hline
\end{tabular}

n. número de pontos de solos coletados

a. razão não foi determinada por apresentar apenas uma amostra pareada

b. razão não foi determinada porque $\mathrm{Kp}_{\mathrm{Ca}\left(\mathrm{NO}_{3}\right)_{2}}$ do transect $\mathrm{B}$ não foi possível determinar (TAB. A6) 
Embora estatisticamente os valores de Kp dos metais As, Cd, Co (para $\left.\mathrm{Kp}_{\text {EDTA }}\right), \mathrm{Cr}$ (para $\left.\mathrm{Kp}_{\mathrm{Ca}\left(\mathrm{NO}_{3}\right)_{2}}\right)$ e $\mathrm{Pb}$ foram diferentes entre as duas frações, a razão foi menor que 4 , ou seja, a diferença do $\mathrm{Kp}$ foi menor que uma ordem de grandeza e provavelmente esta diferença não afeta significantemente a avaliação de risco como no caso de solos contaminados e não contaminados.

\subsection{Avaliação de risco}

\subsubsection{Influência do Kp no cálculo do risco utilizando o modelo de avaliação de risco à saúde humana, $C$-Soil}

O Kp está relacionado no modelo de avaliação de risco à saúde humana C-Soil na etapa de concentração da fase líquida, ou seja, na transferência do metal da fase sólida para a fase líquida do solo (item 5.1) e na acumulação em cultura (item 5.2).

Para avaliar a influência de Kp na estimativa do risco para cada metal, utilizou-se os diferentes valores experimentais e nominal de $\mathrm{Kp}\left(\mathrm{Kp}_{\mathrm{EDTA}}, \mathrm{Kp} \mathrm{Pa}_{\mathrm{CaO}} \mathrm{N}_{3}\right.$

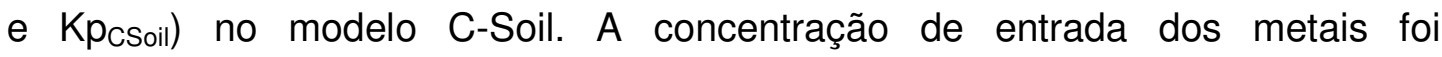
considerada a média geométrica da concentração parcial dos metais nos solos coletados.

O modelo C-Soil é um programa desenvolvido em planilha Excel, XS V7UK da Tauw Milieu Consultancy de 1997, que foi adquirido pela CETESB para fins de estudos. Para calcular o risco foram consideradas todas as vias de exposição atribuídas no modelo C-Soil para metais: ingestão de solo, vegetal e água subterrânea e inalação de partículas. A área de exposição para efeito de cálculo do risco foi a de proteção máxima / agrícola. Os valores das variáveis do modelo não foram alterados, assim como os valores estabelecidos pela CETESB para as variáveis da população, tempo de permanência no cenário de exposição, condições do solo e outros fatores.

Para substâncias não carcinogênicas, tais como, todos os metais estudados no presente trabalho, exceto As, o quociente do risco (Q) foi determinado pela expressão: 


$$
Q=\frac{D O}{T D I}
$$

na qual $D O$ é a exposição diária média durante todo o período de exposição (somatória de todas as vias de exposição para crianças e adultos) e TDI é o ingresso diário tolerável. Ambos, DO e TDI, são dados em $\mathrm{mg} \mathrm{kg}^{-1} \mathrm{dia}^{-1}$.

O quociente do risco pode ser no máximo igual a 1 (CETESB, 2001), ou seja, o ingresso de um contaminante pelo ser humano pode ser, no máximo, igual ao ingresso diário tolerável, a partir do qual existe risco potencial à saúde humana.

Para substâncias carcinogênicas, por exemplo, o As, o risco foi determinado pela equação:

$$
R=1-\exp (-D O . F C)
$$

na qual $F C$ é o fator de carcinogenicidade.

Considerando ser difícil estabelecer uma concentração abaixo da qual não ocorra nenhum risco de efeito adverso à saúde pública, o risco aceitável para substâncias carcinogênicas foi admitido como sendo a possibilidade de ocorrer um caso adicional de tumor letal em cada 10.000 pessoas, ou seja, $10^{-4}$ (Swartjes et al., 1993).

A CETESB (2001) para estabelecer os valores de intervenção para os metais As, Cd, Co, Cr, Cu, Mo, Ni, Pb e Zn nos solos do Estado de São Paulo por meio do modelo matemático de avaliação de risco C-Soil adotou os seguintes valores de risco apresentados na TAB. 7.11. Observa-se que para os metais não carcinogênicos, apenas para o $\mathrm{Cd}$, Co e Mo foi considerado um risco próximo de 1. Para $\mathrm{Cr}$ foi considerado um risco de 0,316 e para $\mathrm{Pb}$ de 0,41 , pois para este risco, considerando crianças e adultos, a exposição para crianças já apresentou um valor de exposição maior que o valor TDI, ou seja, um risco maior que 1 . E uma vez que as conseqüências são severas à saúde e as crianças são um grupo mais suscetíveis, foi selecionado um risco que garantisse proteção à criança. Para os metais $\mathrm{Cu}, \mathrm{Ni}$ e $\mathrm{Zn}$ foi considerado a baixa toxicidade destes metais, então, o valor de intervenção derivado do modelo de avaliação de risco à saúde humana foi dividido por um fator de segurança de 10. 
TABELA 7.11 - Risco adotado pela CETESB para metais para calcular o valor de intervenção para solos por meio do modelo matemático de avaliação de risco C-Soil.

\begin{tabular}{ccc}
\hline Metal & Risco & $\begin{array}{c}\text { Valor de intervenção } \\
\left(\mathbf{m g ~ k g}^{\mathbf{1}}\right)\end{array}$ \\
\hline $\begin{array}{c}\text { carcinogênico } \\
\text { As }\end{array}$ & $4,4.10^{-4}$ & 25 \\
\hline não carcinogênico & \\
Cd & 1,108 & 10 \\
Co & 1,095 & 40 \\
Cr & 0,316 & 300 \\
Cu & 0,025 & 100 \\
Mo & 1,07 & 50 \\
Ni & 0,03 & 50 \\
Pb & 0,41 & 200 \\
Zn & 0,035 & 500
\end{tabular}

a. para área de proteção máxima/agrícola

Na TAB. 7.12 apresentam-se os valores de risco calculado para cada metal tomando-se por base as concentrações parciais e os valores de $\mathrm{Kp}$ dos metais. Os valores das concentrações parciais e de $\mathrm{Kp}_{\mathrm{EDTA}}$ e $\mathrm{Kp}_{\mathrm{Ca}\left(\mathrm{NO}_{3}\right)_{2}}$ dos metais foram obtidos da média geométrica dos valores da TAB. A1, A5 e A6, respectivamente.

A FIG. 7.12 foi construída com base nos dados da TAB. 7.12. Tomando-se por base estes resultados de risco a discussão será dividida em três itens: avaliação da contaminação do solo (7.3.1.1), necessidade de determinar Kp de Figueira (7.3.1.2) e avaliação da metodologia $\mathrm{Kp}_{\mathrm{EDTA}}$ e $\mathrm{Kp}_{\mathrm{Ca}\left(\mathrm{NO}_{3}\right)_{2}}$ (7.3.1.3). 
TABELA 7.12 - Valores de risco médio calculados tomando-se por base a concentração parcial e o valor de $\mathrm{Kp}_{\mathrm{C} \text {-Soil, }} \mathrm{Kp}_{\mathrm{EDTA}}$ e $\mathrm{Kp} \mathrm{pa}_{\mathrm{C}\left(\mathrm{NO}_{3}\right)_{2}}$ dos metais.

\begin{tabular}{|c|c|c|c|c|c|c|c|}
\hline Metal & $\begin{array}{c}{[\text { metal }]_{\text {parcial }}{ }^{a}} \\
\left(\mathrm{mg} \mathrm{kg}^{-1}\right)\end{array}$ & $\begin{array}{l}\mathrm{Kp}_{\text {EDTA }}{ }^{\mathrm{a}} \\
\left(\mathrm{L} \mathrm{kg}^{-1}\right)\end{array}$ & $\begin{array}{l}\text { Risco } \\
\text { Kp } p_{\text {EDTA }}\end{array}$ & $\begin{array}{c}\mathrm{Kp}_{\mathrm{Ca}\left(\mathrm{NO}_{3}\right)_{2}{ }^{\mathrm{a}}}\left(\mathrm{L} \mathrm{kg}^{-1}\right)\end{array}$ & $\begin{array}{c}\text { Risco } \\
\mathrm{Kp}_{\mathrm{Ca}\left(\mathrm{NO}_{3}\right)_{2}}\end{array}$ & $\begin{array}{l}\mathrm{Kp}_{\mathrm{C}-\mathrm{Soil}} \\
\left(\mathrm{L} \mathrm{kg}^{-1}\right)\end{array}$ & $\begin{array}{l}\text { Risco } \\
\text { Kp csoil }\end{array}$ \\
\hline As & 11 & 545 & $2,5.10^{-4}$ & 270 & $4,0.10^{-4}$ & 980 & $1,9.10^{-4}$ \\
\hline Cd & 0,4 & 45 & $7,2.10^{-2}$ & 55 & $6,4 \cdot 10^{-2}$ & 190 & $4,0 \cdot 10^{-2}$ \\
\hline Co & 2,0 & 30 & $2,4.10^{-1}$ & 148 & $5,5.10^{-2}$ & 120 & $6,6 \cdot 10^{-2}$ \\
\hline $\mathrm{Cr}$ & 1,8 & 270 & $7,8 \cdot 10^{-3}$ & 545 & $4,6.10^{-3}$ & 14400 & $1,7 \cdot 10^{-3}$ \\
\hline $\mathrm{Cu}$ & 6,0 & 99 & $2,9.10^{-3}$ & 403 & $1,4.10^{-3}$ & 540 & $1,3 \cdot 10^{-3}$ \\
\hline Mo & 2,7 & 270 & $1,2.10^{-2}$ & nd & nd & 20 & $7,1 \cdot 10^{-2}$ \\
\hline $\mathrm{Ni}$ & 2,2 & 67 & $3,8.10^{-3}$ & 81 & $3,4.10^{-3}$ & 560 & 1,2. $10^{-3}$ \\
\hline $\mathrm{Pb}$ & 16 & 37 & $5,8 \cdot 10^{-1}$ & 403 & $7,5.10^{-2}$ & 2400 & $3,1 \cdot 10^{-2}$ \\
\hline $\mathrm{Zn}$ & 33 & 25 & $7,7 \cdot 10^{-3}$ & 40 & $5,4 \cdot 10^{-3}$ & 250 & $2,1 \cdot 10^{-3}$ \\
\hline
\end{tabular}

a. os valores correspondem a média geométrica dos dados experimentais das tabelas (TAB. A1, A5 e A6). 

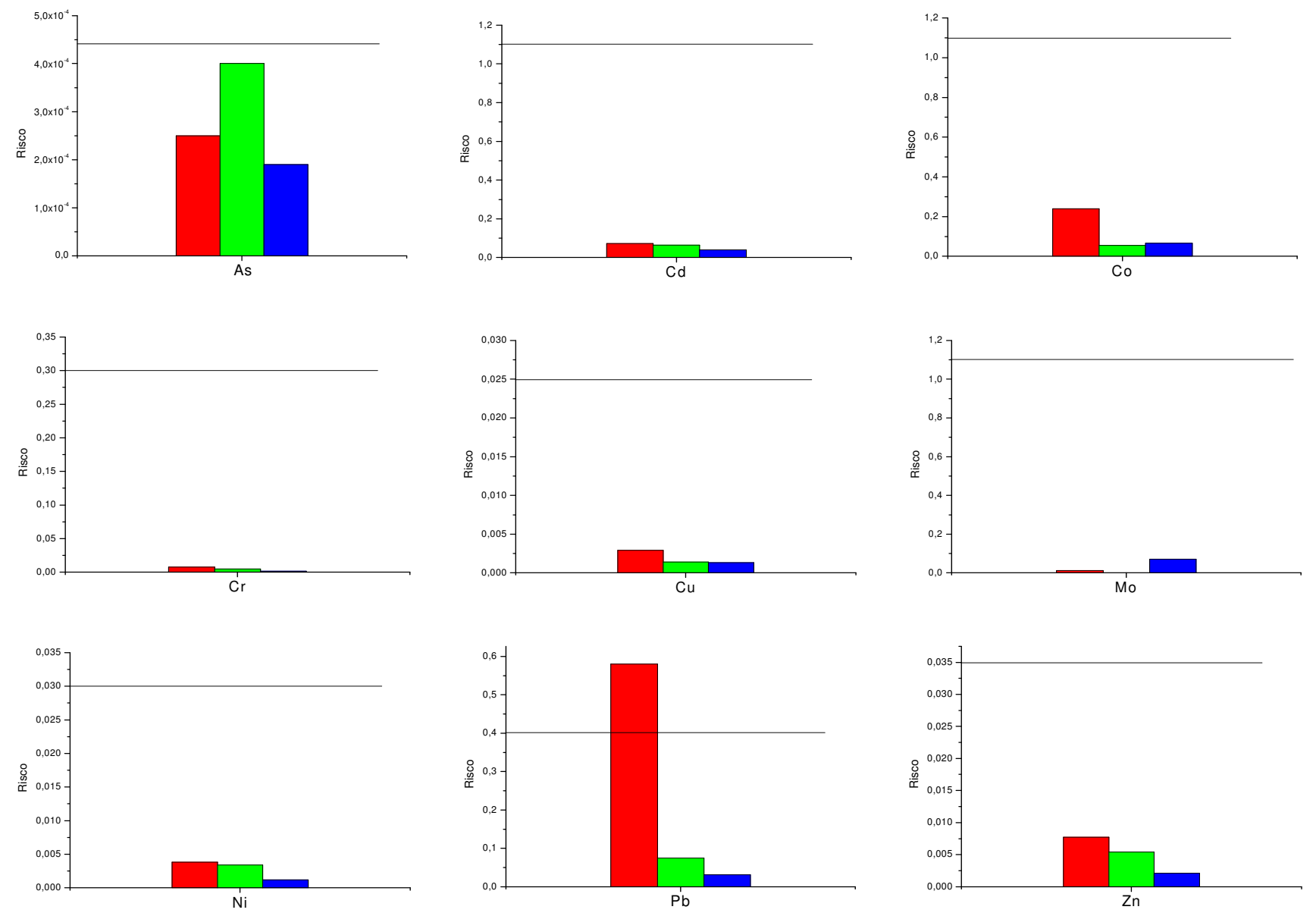

FIGURA 7.12 - Risco calculado tomando-se por base as médias geométricas da concentração parcial do metal e do valor de Kp, utilizando o modelo de avaliação de risco C-Soil. Linha cheia corresponde ao risco adotado pela CETESB (2001) para calcular os valores de intervenção dos metais para solos. (RiscoKp

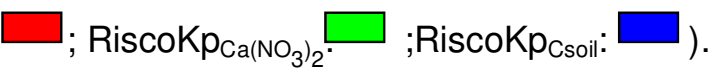




\subsubsection{Avaliação da contaminação do solo}

Para avaliar o risco estimado de cada metal do solo de Figueira, foi considerado o risco médio que foi calculado pela média geométrica da concentração parcial e pelo valor de Kp experimental. Observa-se que o risco médio calculado tomando-se por base os valores de $\mathrm{Kp} \mathrm{EDTA}_{\mathrm{E}}, \mathrm{Kp}_{\mathrm{Ca}\left(\mathrm{NO}_{3}\right)_{2}}$ e $\mathrm{Kp}$ CSoil para todos os metais foi inferior ao risco adotado pela CETESB (2001) para calcular os valores de intervenção para solos (FIG. 7.12), de uma a duas ordens de grandeza, exceto para o $\mathrm{Pb}$ que foi maior quando o risco foi calculado pelo $K p_{E D T A}$ e para o As que foi da mesma ordem de grandeza, $10^{-4}$, para todos os valores de $\mathrm{Kp}$. Isto indica que o As é um metal preocupante do ponto de vista de saúde pública. É bom ressaltar que esta avaliação foi feita com amostras de solo coletadas antes da instalação dos filtros na usina termoelétrica, em 1997, ou seja, num antigo cenário. Mas se for considerar as amostras de solo coletadas depois da instalação dos filtros (coletadas em 2001), a concentração parcial de As (TAB. 7.3) foi maior que a concentração média apresentada na TAB. 7.12 para o cálculo do risco, ou seja, mesmo com a instalação dos filtros na usina (1998), depois de aproximadamente três anos, poder-se-ia dizer que o As continua sendo um metal preocupante.

A avaliação do risco estimado para o As confirma o que já foi discutido no item 7.1, que o As seria o único metal preocupante dentre aqueles analisados no presente trabalho.

\subsubsection{Necessidade de determinar Kp de Figueira}

De um modo geral, observa-se na FIG. 7.12 que o risco calculado pelos valores de $\mathrm{Kp}$ experimentais $\left(\mathrm{Kp}_{\mathrm{EDTA}}\right.$ e $\mathrm{Kp} \mathrm{p}_{\mathrm{Ca}\left(\mathrm{NO}_{3}\right)_{2}}$ ) foi maior que o risco calculado pelo valor nominal de Kp do modelo C-Soil, exceto para o Mo. Isto mostra que a utilização do valor nominal de Kp pode implicar num valor de risco à saúde humana diferente do valor mais próximo da realidade quando for utilizado valor de $\mathrm{Kp}$ local da área em estudo. Na TAB. 7.13 apresenta-se a razão do

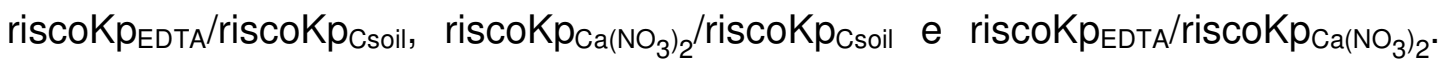
Observa-se que a razão do riscoKp $p_{E D T A} /$ riscoKp $p_{C S o i l}$ é maior que a razão 
riscoKp $\mathrm{Ca}_{\mathrm{C}\left(\mathrm{NO}_{3}\right)_{2}} /$ riscoKp $\mathrm{pssil}_{\text {, }}$ exceto para $\circ \mathrm{As}$, pois $\circ \mathrm{Kp}_{\mathrm{Ca}\left(\mathrm{NO}_{3}\right)_{2}}$ para este metal é maior que o Kp $p_{E D T A}$, como foi apresentado no item 7.2. Isto indica que a utilização do valor de $\mathrm{Kp}_{\mathrm{Ca}\left(\mathrm{NO}_{3}\right)_{2}}$ para o cálculo do risco é mais próximo do valor de $\mathrm{Kp}$ CsoilAlém disso, os valores da razão do riscoKp $p_{E D T A} /$ riscoKp $p_{\text {Csoil }} e$ riscoKp $\mathrm{Ca}_{\mathrm{C}\left(\mathrm{NO}_{3}\right)_{2}} /$ riscoKp $_{\mathrm{Csoil}}$ foram inferiores a 10, exceto para o $\mathrm{Pb}$. A razão inferior a 10 significa dizer que o risco calculado pelo $\mathrm{Kp}_{\mathrm{EDTA}}, \mathrm{Kp}_{\mathrm{Ca}\left(\mathrm{NO}_{3}\right)_{2}}$ ou $\mathrm{Kp}_{\mathrm{CSoil}}$ não apresenta uma ordem de grandeza de diferença. Portanto, qualquer dos valores de $\mathrm{Kp}$ poderia ser utilizado, exceto para o $\mathrm{Pb}$, no caso de $\mathrm{Kp}_{\mathrm{EDTA}}$.

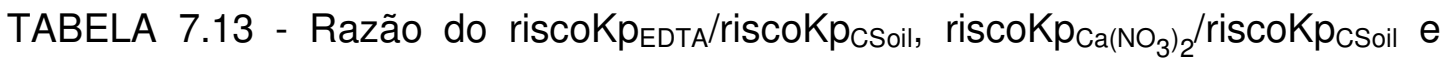
riscoKp $p_{\mathrm{EDTA}} /$ riscoKp $\mathrm{pa}_{\mathrm{C}\left(\mathrm{NO}_{3}\right)_{2}}$.

\begin{tabular}{|c|c|c|c|}
\hline Metal & $\begin{array}{l}\text { riscoKp } p_{E D T A} / \\
\text { riscoKp }\end{array}$ & $\begin{array}{l}\text { riscoKpa } \mathrm{Pa}_{\left(\mathrm{NO}_{3}\right)_{2}} \\
\text { riscoKp } \\
\text { Csoil }\end{array}$ & $\begin{array}{l}\text { riscoKp } \\
\text { riscoKtA } \\
\mathrm{Kp}_{\mathrm{Ca}\left(\mathrm{NO}_{3}\right)_{2}}\end{array}$ \\
\hline As & 1,3 & 2,1 & 0,6 \\
\hline Cd & 1,8 & 1,6 & 1,1 \\
\hline Co & 3,6 & 0,8 & 4,4 \\
\hline $\mathrm{Cr}$ & 4,6 & 2,7 & 1,7 \\
\hline $\mathrm{Cu}$ & 2,2 & 1,1 & 2,1 \\
\hline Mo & 0,2 & - & - \\
\hline $\mathrm{Ni}$ & 3,2 & 2,8 & 1,1 \\
\hline $\mathrm{Pb}$ & 18,7 & 2,4 & 7,7 \\
\hline $\mathrm{Zn}$ & 3,7 & 2,6 & 1,4 \\
\hline
\end{tabular}

\subsubsection{Avaliação da metodologia $K p_{E D T A}$ e $K p_{C a\left(\mathrm{NO}_{3}\right)_{2}}$}

Observa-se na FIG. 7.12 que o risco calculado pelos valores de Kp

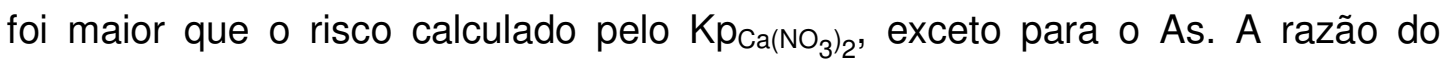
riscoKp os metais (TAB. 7.13), ou seja, o risco calculado tomando-se por base o K $\mathrm{K}_{\text {EDTA }} \mathrm{e}$ - $\mathrm{Kp}_{\mathrm{Ca}\left(\mathrm{NO}_{3}\right)_{2}}$ não apresenta uma ordem de grandeza de diferença. Considerando que os valores de $\mathrm{Kp}$ experimentais representam melhor a área de estudo, tanto a metodologia de $\mathrm{Kp} \mathrm{p}_{\mathrm{EDTA}}$ quanto a $\mathrm{Kp}_{\mathrm{Ca}\left(\mathrm{NO}_{3}\right)_{2}}$ poderia ser utilizada para determinar $\mathrm{o}$ valor de Kp dos metais estudados. 


\subsubsection{Influência do BCF calculado pelo $K p_{E D T A}$ e $K p_{C a\left(N_{3}\right)_{2}}$ na determinação do risco}

O fator de bioconcentração, BCF, é um parâmetro que está relacionado no modelo de avaliação de risco à saúde humana C-Soil na etapa de acumulação em culturas nas equações 5.4 e 5.5 do modelo (item 5.2). Na ausência de valores conhecidos BCFr (fator de bioconcentração nas raízes) ou BCFs (fator de bioconcentração na folhas), esses fatores podem ser estimados pela equação 5.7 (item 5.2).

A idéia de se utilizar o $\mathrm{Kp}_{\text {EDTA }}$ para se determinar o valor de $\mathrm{BCF}$ foi com base em que o EDTA apresenta correlação do metal encontrado no solo com o metal absorvido pelas plantas para mais tipos de plantas e metais que outras soluções extratoras (Ure, 1996; Hooda, 1997), e portanto, a extração do metal no solo por EDTA poderia representar o metal dissolvido na solução do solo para ser absorvido pelas plantas. Embora a capacidade de extração da solução para predizer a biodisponibilidade para as plantas dependa da espécie da planta, do metal, da concentração do metal, da solução extratora e das características do solo (Hooda, 1997). E dependendo da planta ou do metal, outras soluções, tais como, $\mathrm{NH}_{4} \mathrm{NO}_{3}, \mathrm{CaCl}_{2}, \mathrm{Ca}\left(\mathrm{NO}_{3}\right)_{2}$, DTPA, podem ser mais adequadas (Hooda, 1997; Brun, 1998; Pinamonti, 1999; Basta, 2000).

A estimativa do risco para cada metal foi calculada por meio do modelo de avaliação de risco C-Soil, levando em conta as mesmas considerações apresentadas no item 7.3.1. Na TAB. 7.14 apresentam-se os valores de risco calculados para cada metal utilizando as médias geométricas das concentrações parciais e dos valores de Kp $p_{\text {EDTA }}$ dos metais, os valores nominais do BCF dos metais e os valores de BCF calculados pelo Kp $\mathrm{EDTA}_{\text {E }}$. Na TAB. 7.15 apresentam-se os valores de risco calculados pelos valores nominais do BCF e dos determinados

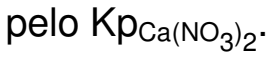

Observa-se que o risco determinado pelos valores nominais do BCF dos metais e pelos valores de BCF calculados pelo Kp $p_{\text {EDTA }}$ foi da mesma ordem de grandeza (TAB. 7.14), ou seja, a utilização do valor do BCF determinado pelo $\mathrm{Kp}_{\mathrm{EDTA}}$ não influenciou no cálculo do risco dos metais no solo de Figueira e, 
portanto, o valor nominal do BCF pode ser utilizado neste caso. Esta observação também é válida quando o $\mathrm{BCF}$ foi determinado pelo $\mathrm{Kp}_{\mathrm{Ca}\left(\mathrm{NO}_{3}\right)_{2}}$ (TAB. 7.15). 
TABELA 7.14 - Valores de risco calculados para cada metal tomando-se por base as médias geométricas das concentrações parciais e dos valores de Kp $\mathrm{EDTA}_{\mathrm{E}}$ dos metais, utilizando os valores nominal do BCF dos metais e os valores de BCF calculados pelo Kp $\mathrm{p}_{\mathrm{ETT}}$.

\begin{tabular}{|c|c|c|c|c|c|c|}
\hline Metal & $\begin{array}{c}\text { [metal] }]_{\text {parcial }} \\
\left(\mathrm{mg} \mathrm{Kg}^{-1}\right)\end{array}$ & $\begin{array}{l}\mathrm{Kp}_{\text {EDTA }} \\
\left(\mathrm{L} \mathrm{Kg}^{-1}\right)\end{array}$ & $\begin{array}{c}\text { BCF } \\
\text { calculado }\end{array}$ & Risco $^{a}$ & $\begin{array}{c}\text { BCF } \\
\text { valor nominal }\end{array}$ & Risco $^{b}$ \\
\hline As & 11 & 545 & 0,012 & $2,23.10^{-4}$ & $\begin{array}{l}0,015^{\mathrm{c}} \\
0,030^{\mathrm{d}}\end{array}$ & $2,52.10^{-4}$ \\
\hline Cd & 0,4 & 45 & 0,204 & 0,0580 & $\begin{array}{c}0,15^{\mathrm{c}} \\
0,7^{\mathrm{d}}\end{array}$ & 0,0720 \\
\hline Co & 2 & 30 & 0,333 & 0,3143 & $\begin{array}{c}0,015^{c} \\
0,03^{d}\end{array}$ & 0,2357 \\
\hline $\mathrm{Cr}$ & 1,8 & 270 & 0,027 & 0,0090 & $\begin{array}{l}0,002^{c} \\
0,02^{d}\end{array}$ & 0,0078 \\
\hline $\mathrm{Cu}$ & 6 & 99 & 0,082 & 0,0028 & $\begin{array}{l}0,1^{\mathrm{c}} \\
0,1^{\mathrm{d}}\end{array}$ & 0,0029 \\
\hline Mo & 2,7 & 270 & 0,027 & 0,0068 & $\begin{array}{c}0,015^{\mathrm{c}} \\
0,3^{\mathrm{d}}\end{array}$ & 0,012 \\
\hline $\mathrm{Ni}$ & 2,2 & 67 & 0,135 & 0,0044 & $\begin{array}{c}0,07^{c} \\
0,1^{d}\end{array}$ & 0,0038 \\
\hline $\mathrm{Pb}$ & 16 & 37 & 0,247 & 0,7778 & $\begin{array}{c}0,001^{c} \\
0,03^{d}\end{array}$ & 0,5833 \\
\hline $\mathrm{Zn}$ & 33 & 25 & 0,407 & 0,0088 & $\begin{array}{l}0,1^{\mathrm{c}} \\
0,4^{\mathrm{d}}\end{array}$ & 0,0077 \\
\hline
\end{tabular}

BCF: fator de bioconcentração

a. Risco determinado pelo BCF calculado

b. Risco determinado pelo valor nominal do BCF

c. BCF das raízes

d. BCF da folhas 
TABELA 7.15 - Valores de risco calculados para cada metal tomando-se por base as médias geométricas das concentrações parciais e os valores de $\mathrm{Kp}_{\mathrm{Ca}\left(\mathrm{NO}_{3}\right)_{2}}$ dos metais, utilizando os valores nominal do $\mathrm{BCF}$ dos metais e os valores de

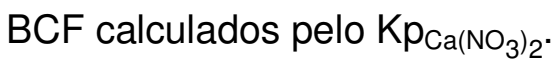

\begin{tabular}{|c|c|c|c|c|c|c|}
\hline Metal & $\begin{array}{c}\text { [metal] }]_{\text {parcial }} \\
\left(\mathrm{mg} \mathrm{Kg}^{-1}\right)\end{array}$ & $\begin{array}{c}\mathrm{Kp}_{\mathrm{Ca}\left(\mathrm{NO}_{3}\right)_{2}} \\
\left(\mathrm{~L} \mathrm{Kg}^{-1}\right)\end{array}$ & $\begin{array}{c}\text { BCF } \\
\text { calculado }\end{array}$ & Risco $^{a}$ & $\begin{array}{c}\text { BCF } \\
\text { valor nominal }\end{array}$ & Risco $^{b}$ \\
\hline As & 11 & 270 & 0,027 & $4,15 \cdot 10^{-4}$ & $\begin{array}{l}0,015^{c} \\
0,030^{d}\end{array}$ & $3,97.10^{-4}$ \\
\hline Cd & 0,4 & 55 & 0,165 & 0,0480 & $\begin{array}{c}0,15^{\mathrm{c}} \\
0,7^{\mathrm{d}}\end{array}$ & 0,0640 \\
\hline Co & 2 & 148 & 0,055 & 0,0643 & $\begin{array}{c}0,015^{\mathrm{c}} \\
0,03^{\mathrm{d}}\end{array}$ & 0,0550 \\
\hline $\mathrm{Cr}$ & 1,8 & 545 & 0,012 & 0,0048 & $\begin{array}{c}0,002^{c} \\
0,02^{d}\end{array}$ & 0,0046 \\
\hline $\mathrm{Cu}$ & 6 & 403 & 0,018 & 0,0008 & $\begin{array}{l}0,1^{c} \\
0,1^{d}\end{array}$ & 0,0014 \\
\hline Mo & 2,7 & nd & - & & $\begin{array}{c}0,015^{\mathrm{c}} \\
0,3^{\mathrm{d}}\end{array}$ & \\
\hline $\mathrm{Ni}$ & 2,2 & 81 & 0,1 & 0,0036 & $\begin{array}{c}0,07^{\mathrm{c}} \\
0,1^{\mathrm{d}}\end{array}$ & 0,0034 \\
\hline $\mathrm{Pb}$ & 16 & 403 & 0,018 & 0,0778 & $\begin{array}{c}0,001^{c} \\
0,03^{d}\end{array}$ & 0,0750 \\
\hline $\mathrm{Zn}$ & 33 & 40 & 0,223 & 0,0054 & $\begin{array}{l}0,1^{\mathrm{c}} \\
0,4^{\mathrm{d}}\end{array}$ & 0,0054 \\
\hline
\end{tabular}

BCF: fator de bioconcentração

a. Risco determinado pelo BCF calculado

b. Risco determinado pelo valor nominal do BCF

c. BCF das raízes

d. BCF da folhas 


\section{CONCLUSÕES}

As principais conclusões, de acordo com os objetivos, foram:

Os metais contaminantes do solo de Figueira foram As, $\mathrm{Cd}, \mathrm{Mo}, \mathrm{Pb}$ e $\mathrm{Zn}$, e o As foi o elemento mais crítico.

Tanto o valor de $\mathrm{Kp}_{\mathrm{Ca}\left(\mathrm{NO}_{3}\right)_{2}}$ quanto o de $\mathrm{Kp}_{\text {EDTA }}$ poderiam ser utilizados no cálculo do risco à saúde humana por serem da mesma ordem de grandeza, exceto para o $\mathrm{Pb}$. Mas o $\mathrm{KP}_{\mathrm{EDTA}}$ seria mais recomendado, por apresentar valores com menor dispersão.

Os valores nominais de $\mathrm{Kp}_{\mathrm{csoil}}$ dos metais poderiam ser utilizados para o cálculo de risco à saúde humana no caso de Figueira, ou seja, não teria necessidade de se determinar valores de $\mathrm{Kp}$ locais $\left(\mathrm{Kp}_{\mathrm{EDTA}}\right.$ e $\left.\mathrm{Kp} \mathrm{pa}_{\mathrm{CaO}} \mathrm{N}_{2}\right)$ ), pois a razão $\mathrm{Kp}_{\mathrm{CS} \text { oil }} / \mathrm{Kp}_{\mathrm{EDTA}}$ e $\mathrm{Kp}_{\mathrm{CS} \text { oil }} / \mathrm{Kp}_{\mathrm{Ca}\left(\mathrm{NO}_{3}\right)_{2}}$ mostra que os valores de $\mathrm{Kp}$ são da mesma ordem de grandeza, exceto para o $\mathrm{Pb}$.

As conclusões adicionais foram:

$\mathrm{O} \mathrm{Cr}$ e o $\mathrm{Pb}$ apresentaram valores de $\mathrm{Kp}_{\mathrm{EDTA}}$ bem menores que o valor nominal do modelo matemático de avaliação de risco à saúde humana, C-Soil, para estes metais, 54 e 69 vezes menores, respectivamente. No entanto, quando foi considerado a razão do riscoKp apresentou uma razão inferior a $10 \mathrm{e}$, então, o $\mathrm{Kp}_{\mathrm{C} \text {-Soil }}$ poderia ser utilizado para o cálculo do risco, ao passo que o $\mathrm{Pb}$ apresentou uma razão acima de $10 \mathrm{e}$, portanto, a utilização do $\mathrm{Kp}_{\mathrm{C} \text {-Soil }}$ para o cálculo do risco é maior que uma ordem de grandeza quando comparado com a utilização de Kp

Os valores de $\mathrm{Kp}_{\mathrm{EDTA}}$ e $\mathrm{Kp}_{\mathrm{Ca}\left(\mathrm{NO}_{3}\right)_{2}}$ apresentaram uma diferença menor que uma ordem de grandeza em relação aos valores de Kp determinados, por isoterma de adsorção, para solos representativos do Estado de São Paulo, exceto 
para o $\mathrm{Pb}$ quando comparado com Kp $\mathrm{p}_{\text {EDTA. }}$. Ou seja, os valores de $\mathrm{Kp}$ para solos do Estado de São Paulo também poderiam ser utilizados no caso de Figueira.

As equações de regressão múltipla da literatura que relacionam $\mathrm{Kp}$ em função das características físico-químicas do solo e concentração do metal poderiam ser utilizadas para determinar o valor de $\mathrm{Kp}$ dos metais $\mathrm{Cd}$ e $\mathrm{Zn}$ no caso de Figueira.

$\mathrm{Na}$ seqüência decrescente dos valores de $\mathrm{Kp}$, os metais $\mathrm{As}, \mathrm{Cr}$ e $\mathrm{Cu}$ foram os mais retidos pelo solo de Figueira e $\mathrm{Zn}$ foi o mais móvel seguido por $\mathrm{Cd}$, Co e Ni. O Kp $p_{\text {EDTA }}$ mostrou que o $\mathrm{Pb}$ é menos retido pelo solo quando comparado

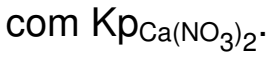

A diferença entre os valores de Kp para solo contaminado e não contaminado, com base nos valores de referência da CETESB (2001), foi menor que uma ordem de grandeza para $\mathrm{Cd}, \mathrm{Pb}$ e $\mathrm{Zn}$, e As para o Kp $\mathrm{p}_{\mathrm{EDTA}}$. Portanto, o valor de Kp pode ser determinado para todos os solos coletados de Figueira, independente da concentração parcial destes metais no solo.

A razão dos valores de $\mathrm{Kp}$ entre os solos coletados nas profundidades de 0 a $25 \mathrm{~cm}$ e de 25 a $50 \mathrm{~cm}$ foi menor que 4 (menor que uma ordem de grandeza). Portanto, a determinação de $\mathrm{Kp}$ independe dos solos coletados nas duas profundidades consideradas, no caso de Figueira. 


\section{APÊNDICE A}


TABELA A1 - Concentração média parcial dos metais $\left(\mathrm{mg} \mathrm{kg}^{-1}\right)$ nas amostras do solo de Figueira coletadas ao redor da usina termoelétrica, em 1996 e 1997, antes da instalação dos filtros.

\begin{tabular}{|c|c|c|c|c|c|c|c|c|c|c|c|c|c|c|c|c|c|c|}
\hline & As & $\mathbf{s}$ & Cd & $\mathbf{s}$ & Co & $\mathbf{s}$ & $\mathrm{Cr}$ & $\mathbf{s}$ & $\mathrm{Cu}$ & $\mathbf{s}$ & Mo & $\mathbf{s}$ & $\mathrm{Ni}$ & $\mathbf{s}$ & $\mathrm{Pb}$ & $\mathbf{s}$ & $\mathrm{Zn}$ & $\mathbf{s}$ \\
\hline $200 A$ & 148 & 1 & 5,6 & 0,1 & $<L D$ & & 3,4 & 0,1 & 13,4 & 0,1 & 9,3 & 0,1 & 5,4 & 0,2 & 32 & 1 & 288 & 4 \\
\hline $300 A$ & 71,8 & 0,2 & 2,8 & 0,1 & $<L D$ & & 3,0 & 0,1 & 12,1 & 0,1 & 7,1 & 0,1 & 3,72 & 0,01 & 38 & 11 & 120 & 1 \\
\hline $400 A$ & 53 & 1 & 2,12 & 0,01 & 2,1 & 0,1 & 2,1 & 0,1 & 12,9 & 0,1 & 5,4 & 0,3 & 4,0 & 0,1 & 37 & 3 & 119 & 2 \\
\hline $500 A$ & 36,6 & 0,4 & 1,5 & 0,2 & 0,6 & & 1,5 & 0,3 & 7,5 & 0,1 & 3,5 & 0,1 & 2,5 & 0,5 & 11,2 & 0,2 & 61 & 7 \\
\hline $600 A$ & 50,2 & 0,1 & 2,1 & 0,1 & $<$ LD & & 2,9 & 0,3 & 32,0 & 0,2 & 4,1 & 0,3 & 3,4 & 0,4 & 32 & 1 & 175 & 7 \\
\hline $700 A$ & 28,2 & 0,5 & 0,99 & 0,03 & $<L D$ & & 1,3 & 0,3 & 8,7 & 0,1 & 2,48 & 0,04 & 2,0 & 0,01 & 17 & 6 & 68 & 1 \\
\hline $800 A$ & 21 & 1 & 0,6 & 0,1 & $<L D$ & & 1,9 & 0,5 & 7,8 & 0,2 & 2,1 & 0,2 & 2,3 & 0,2 & 57 & 11 & 38 & 2 \\
\hline $900 A$ & 31 & 1 & 1,04 & 0,04 & $<L D$ & & 3,10 & 0,04 & 12 & 1 & 2,8 & 0,1 & 2,5 & 0,2 & 18 & 1 & 49 & 1 \\
\hline $1000 \mathrm{~A}$ & 35,6 & 0,2 & 1,41 & 0,05 & 9,9 & 0,1 & 1,6 & 0,1 & 12,5 & 0,1 & 3,7 & 0,4 & 5,4 & 0,6 & 62 & 1 & 87 & 4 \\
\hline $1100 A$ & 25 & 1 & 1,071 & 0,001 & 2,6 & 0,4 & 2,7 & 0,5 & 12,0 & 0,4 & 2,48 & 0,03 & 2,7 & 0,7 & 38 & 2 & 77 & 1 \\
\hline 1200A & 17,2 & 0,2 & 0,67 & 0,03 & $<L D$ & & 1,9 & 0,1 & 8,8 & 0,1 & 1,3 & 0,1 & 1,9 & 0,1 & 6,8 & 0,7 & 52 & 4 \\
\hline 2200A & 9,2 & 0,1 & 0,33 & 0,01 & 0,3 & 0,1 & 2,1 & 0,4 & 8,8 & 0,2 & 0,9 & 0,2 & 3,1 & 0,1 & 43 & 1 & 43 & 3 \\
\hline $3000 A$ & $<L D$ & & 0,35 & 0,44 & 4,8 & 0,1 & 2,26 & 0,05 & 8,3 & 0,1 & $<L D$ & & 5,3 & 0,7 & 33 & 4 & 8,0 & 1,2 \\
\hline 200B & 3,3 & 0,3 & 0,16 & 0,02 & $<L D$ & & $<$ LD & & 1,53 & 0,02 & $<L D$ & & 0,8 & 0,1 & $<L D$ & & 15 & 2 \\
\hline $300 \mathrm{~B}$ & 7,9 & 0,3 & 0,37 & 0,02 & 1,06 & 0,02 & 1,3 & 0,1 & 4,8 & 0,1 & $<L D$ & & 1,8 & 0,6 & 9,4 & 1,8 & 29 & 3 \\
\hline $400 B$ & 5,12 & 0,01 & 0,267 & 0,001 & 3,1 & 0,1 & 0,6 & 0,1 & 3,3 & 0,1 & $<L D$ & & 1,9 & 0,1 & 11 & 1 & 19 & 3 \\
\hline $500 \mathrm{~B}$ & 16,4 & 0,2 & 0,51 & 0,01 & 1,22 & 0,04 & 0,6 & 0,1 & 3,3 & 0,2 & 1,3 & 0,1 & 2,0 & 0,1 & 9,0 & 0,5 & 37 & 2 \\
\hline $600 \mathrm{~B}$ & 29 & 1 & 0,85 & 0,01 & 2,2 & 0,1 & 4,9 & 0,3 & 7,9 & 0,2 & $<L D$ & & 5,6 & 0,1 & $7,1^{*}$ & & 85 & 7 \\
\hline $700 B$ & 12 & 1 & 0,45 & 0,03 & $<L D$ & & 0,9 & 0,1 & 3,2 & 0,1 & $<L D$ & & 1,8 & 0,4 & 7,4 & 1,1 & 27,8 & 0,4 \\
\hline $800 B$ & 2,7 & 0,2 & 0,16 & 0,02 & $<L D$ & & 0,8 & 0,1 & 2,42 & 0,02 & $<L D$ & & 1,6 & 0,1 & 8,4 & 2,4 & 7,2 & 0,4 \\
\hline $900 \mathrm{~B}$ & 24,5 & 0,4 & 0,76 & 0,01 & 0,8 & 0,1 & 1,8 & 0,1 & 5,5 & 0,1 & 1,3 & 0,1 & 3,2 & 0,2 & 15 & 2 & 34 & 3 \\
\hline 1000B & 3,9 & 0,3 & 0,161 & 0,003 & 6,9 & 0,7 & $0,7^{*}$ & & 5,4 & 0,2 & $<L D$ & & 3,0 & 0,1 & 18 & 1 & 13 & 3 \\
\hline 1100B & 13 & 1 & 0,41 & 0,00 & 4,9 & 0,2 & 5,45 & 0,02 & 7,3 & 0,1 & $<L D$ & & 5,1 & 0,2 & 61 & 1 & 48 & 3 \\
\hline 1200B & 2,9 & 0,3 & 0,20 & 0,06 & $<L D$ & & 1,09 & 0,05 & 2,24 & 0,03 & $<L D$ & & 1,5 & 0,6 & $8,1^{*}$ & & 14 & 4 \\
\hline 2200B & 2,15 & 0,01 & 0,13 & 0,01 & 1,4 & 0,2 & 1,4 & 0,1 & 3,8 & 0,2 & $<L D$ & & 2,1 & 0,3 & 25 & 1 & $13,6^{*}$ & \\
\hline $3000 B$ & 1,2 & 0,1 & 0,08 & 0,01 & 5,2 & 0,1 & 5,24 & 0,03 & 4,0 & 0,3 & $<L D$ & & 5,7 & 0,4 & 34 & 1 & 9,0 & 4,9 \\
\hline
\end{tabular}


TABELA A1 - Concentração média parcial dos metais $\left(\mathrm{mg} \mathrm{kg}^{-1}\right)$ nas amostras do solo de Figueira coletadas ao redor da usina termoelétrica, em 1996 e 1997, antes da instalação dos filtros.

\begin{tabular}{|c|c|c|c|c|c|c|c|c|c|c|c|c|c|c|c|c|c|c|}
\hline & As & $\mathbf{s}$ & Cd & $\mathbf{s}$ & Co & $\mathbf{s}$ & $\mathrm{Cr}$ & $\mathbf{s}$ & $\mathrm{Cu}$ & $\mathbf{s}$ & Mo & $\mathbf{s}$ & $\mathrm{Ni}$ & $\mathbf{s}$ & $\mathrm{Pb}$ & $\mathbf{s}$ & $\mathrm{Zn}$ & $\mathbf{s}$ \\
\hline N1A & 18,2 & 0,2 & 0,88 & 0,05 & 8,8 & 0,1 & 5,9 & 0,5 & 8,9 & 0,1 & $<L D$ & & 4,8 & 0,2 & 18 & 4 & 68 & 2 \\
\hline NE1A & 3,5 & 0,3 & 0,26 & 0,04 & 3,6 & 0,5 & 6,3 & 0,2 & 5,2 & 0,4 & $<L D$ & & 3,5 & 0,5 & $<L D$ & & 17 & 3 \\
\hline E1A & $<\mathrm{LD}$ & & 0,13 & 0,02 & $<\mathrm{LD}$ & & $<L D$ & & 3,0 & 1,4 & $<L D$ & & $0,8^{*}$ & & $<L D$ & & $<\mathrm{LD}$ & \\
\hline SE1A & $<\mathrm{LD}$ & & 0,16 & 0,01 & $<$ LD & & 1,9 & 0,1 & 5,3 & 0,1 & $<L D$ & & 1,4 & 0,6 & $<L D$ & & $<\mathrm{LD}$ & \\
\hline S1A & 1,6 & 0,3 & 0,48 & 0,21 & 0,6 & 0,1 & 1,6 & 0,1 & 6,9 & 0,1 & $<L D$ & & 1,6 & 0,1 & $<L D$ & & 3,4 & \\
\hline SW1A & 4,8 & 0,5 & 0,39 & 0,03 & 2,4 & 0,1 & 18 & 1 & 11,6 & 1,2 & $<L D$ & & 4,6 & 0,9 & $<L D$ & & 51 & 2 \\
\hline W1A & $<\mathrm{LD}$ & & 0,139 & 0,001 & 2,9 & 0,1 & 1,1 & 0,1 & 5,4 & 0,3 & $<\mathrm{LD}$ & & 1,3 & 0,1 & 7,0 & 0,3 & $<\mathrm{LD}$ & \\
\hline N3A & $<\mathrm{LD}$ & & 0,0785 & 0,0003 & $<\mathrm{LD}$ & & 0,8 & 0,1 & 1,9 & 0,2 & $<L D$ & & 1,2 & 0,1 & 8,3 & & $<\mathrm{LD}$ & \\
\hline NE3A & $<\mathrm{LD}$ & & 0,06 & 0,01 & 0,54 & 0,01 & 0,7 & 0,2 & 3,0 & 0,1 & $<L D$ & & 1,1 & 0,3 & $<L D$ & & $<\mathrm{LD}$ & \\
\hline E3A & $<\mathrm{LD}$ & & $0,05^{\star}$ & & $<\mathrm{LD}$ & & 3,0 & 0,1 & 5,3 & 0,2 & $<\mathrm{LD}$ & & 1,8 & 0,5 & $<L D$ & & $<\mathrm{LD}$ & \\
\hline SE3A & $<$ LD & & 0,12 & 0,03 & 1,693 & 0,004 & 1,3 & 0,1 & 4,56 & 0,04 & $<L D$ & & 1,4 & 0,1 & 7,1 & 0,6 & $<\mathrm{LD}$ & \\
\hline S3A & $<$ LD & & 0,08 & 0,01 & 1,92 & 0,05 & 0,9 & 0,1 & 4,4 & 0,2 & $<L D$ & & 0,9 & 0,3 & 6,2 & 0,5 & $<\mathrm{LD}$ & \\
\hline SW3A & 4,9 & 0,1 & 0,15 & 0,02 & $<\mathrm{LD}$ & & 1,4 & 0,1 & 5,1 & 0,2 & $<L D$ & & 1,5 & 0,1 & 5,9 & 0,1 & 4,2 & 1,5 \\
\hline W3A & $0,6^{*}$ & & 0,11 & 0,01 & 2,21 & 0,02 & 1,0 & 0,1 & 4,54 & 0,01 & $<L D$ & & 1,7 & 0,2 & $<L D$ & & 10 & 3 \\
\hline
\end{tabular}

s: desvio padrão

LD (limite de detecção) mg L-1: As 0,0081; Cd 0,0004; Co 0,0007; Cr 0,0047; Cu 0,0034; Mo 0,0046; Ni 0,0099; Pb 0,0353; Zn 0,0436.

* única determinação 
TABELA A2 - Concentração parcial dos metais nas amostras do solo de Figueira coletadas em 2001 depois da instalação dos filtros na usina.

\begin{tabular}{|c|c|c|c|c|c|c|c|c|c|}
\hline \multirow{2}{*}{$\begin{array}{l}\text { Ponto } \\
\text { de } \\
\text { coleta }\end{array}$} & \multicolumn{9}{|c|}{ Concentração (mg kg-1) } \\
\hline & As & Cd & Co & $\mathrm{Cr}$ & $\mathrm{Cu}$ & Mo & $\mathbf{N i}$ & $\mathrm{Pb}$ & $\mathrm{Zn}$ \\
\hline \multicolumn{10}{|l|}{ 400A } \\
\hline 1 & 27,8 & 0,61 & 0,36 & 3,9 & 4,5 & 1,9 & 3,2 & 6,9 & 53 \\
\hline 2 & 19,1 & 0,74 & $<\mathrm{LD}$ & 1,3 & 4 & 1,5 & 1,5 & 12,7 & 36 \\
\hline 3 & 5 & 0,21 & $<\mathrm{LD}$ & 1 & 3,2 & $<\mathrm{LD}$ & 1,3 & 9,7 & 11 \\
\hline \multicolumn{10}{|l|}{ 600A } \\
\hline 1 & 29,1 & 0,94 & $<\mathrm{LD}$ & 1,1 & 4,5 & 1,9 & 2,7 & 9 & 54 \\
\hline 2 & 43,8 & 1,26 & 0,63 & 2,8 & 6,9 & 2,1 & 4,7 & 6,4 & 120 \\
\hline 3 & 44,7 & 1,3 & 0,87 & 2,9 & 7 & 1,7 & 4,4 & 7 & 122 \\
\hline
\end{tabular}


TABELA A3 - Concentração média biodisponível dos metais $\left(\mathrm{mg} \mathrm{L}^{-1}\right)$ nas amostras do solo de Figueira coletadas ao redor da usina termoelétrica, em 1996 e 1997, antes da instalação dos filtros.

\begin{tabular}{|c|c|c|c|c|c|c|c|c|c|c|c|c|c|c|c|c|c|c|}
\hline & As & s & Cd & s & Co & $\mathbf{s}$ & $\mathrm{Cr}$ & $\mathbf{s}$ & $\mathrm{Cu}$ & $\mathbf{s}$ & Mo & $\mathbf{s}$ & $\mathrm{Ni}$ & s & $\mathrm{Pb}$ & s & $\mathrm{Zn}$ & s \\
\hline $400 A$ & 495 & 0004 & 450 & 003 & 1001 & 0,0029 & $D$ & & & 0,0022 & & & & & & 0368 & 49 &, 03 \\
\hline $600 A$ & 0504 & 013 & 470 & 11 & 275 & 0,0002 & $D$ & & & 78 & 0,0075 & 4 & & & & & 6,8 & 0,2 \\
\hline $700 A$ & 0283 & 0005 & 247 & 0,0008 & 0172 & 0,0006 & $D$ & & 0578 & 0,0023 & $<L D$ & & 35 & 53 & 0,2 & 99 & 2,72 &, 04 \\
\hline $800 A$ & 0180 & 0001 & 0149 & 03 & 310 & 0,0030 & $D$ & & & 0,0006 & $<L D$ & & & & & & 50 & 01 \\
\hline $1100 A$ & 0388 & 0,0002 & 0343 & 0,0001 & 0954 & 0,0019 & $0063^{*}$ & & 58 & 0,0023 & $0,0089^{*}$ & & 96 & 26 & 99 & 07 & 3,48 & 0,01 \\
\hline $1200 A$ & 0267 & 0004 & 2227 & 0,0004 & 291 & 0,0001 & $0077^{*}$ & & 834 & 0,0037 & $<$ & & & 35 & 0 , & 42 & 39 &, 01 \\
\hline $2200 A$ & 0222 & 7 & 6 & & 7 & 0,0005 & 0,0079 & 0,0006 & 12 & & & & & & & & ,58 & 01 \\
\hline $3000 A$ & 0098 & 0005 & 0042 & 0,0004 & 1320 & 0,0006 & KLD & & 26 & 0,0002 & $<L D$ & & & 0,0034 & 86 & 20 & 0,24 &, 04 \\
\hline 200B & 0053 & 0002 & 0035 & 0,0006 & 0079 & 0,0017 & -D & & & & & 0,0060 & & & & & 1,09 & ,04 \\
\hline $300 \mathrm{~B}$ & 0,0144 & 0001 & 0115 & 0,0008 & 346 & 0,0023 & D & & & 0,0011 & 0,0 & & & & & & 68 & 0,0 \\
\hline $800 B$ & 0,0058 & 0,0003 & 0030 & 0,0002 & 0178 & 0,0030 & 007 & & 59 & 0,0023 & $<L D$ & & 61 & 32 & & & 0,52 & 0,01 \\
\hline $900 \mathrm{~B}$ & 0,0209 & 0,0003 & 168 & & 3 & 0,0025 & 005 & & & & & 0,0019 & & & & & 1,62 & 0,01 \\
\hline $1000 \mathrm{~B}$ & 0,0125 & 0,0001 & 0073 & 0,0003 & 0,1388 & 0,0022 & LD & & 02 & 0,0029 & $0,0050^{*}$ & & & & & 0,0445 & ,897 &, 001 \\
\hline 1100B & 0,0184 & 0008 & 0,0139 & 0,0007 & 0,0507 & 0,0006 & LLD & & & 0,0042 & $<L D$ & & & 0,0008 & &, 0537 & 1,3 & 0,1 \\
\hline $1200 B$ & 0,0095 & 0,0005 & 0064 & 0,0008 & 0,0228 & 0,0009 & $<L D$ & & 0,0488 & 0,0047 & $<L D$ & & 0,0241 & 0,0037 & 0,3138 & 0,0340 & 0,60 & 0,01 \\
\hline 2200B & 0,0110 & 0020 & 0065 & 0,0016 & 0488 & 0,0012 & $0,0070^{*}$ & & & & & & 0,0390 & 0,0033 & 0,5564 & 0,0382 & 0,33 & 0,02 \\
\hline 3000B & 0,0060 & 0007 & 0,0019 & 0,0001 & 0,0688 & 0,0132 & $<\mathrm{LD}$ & & 0,0298 & 0,0040 & $<\mathrm{LD}$ & & $0,0163^{*}$ & & 0,4284 & 0,0849 & $<\mathrm{LD}$ & \\
\hline
\end{tabular}


TABELA A3 - Concentração média biodisponível dos metais $\left(\mathrm{mg} \mathrm{L}^{-1}\right)$ nas amostras do solo de Figueira coletadas ao redor da usina termoelétrica, em 1996 e 1997, antes da instalação dos filtros.

\begin{tabular}{|c|c|c|c|c|c|c|c|c|c|c|c|c|c|c|c|c|c|}
\hline & As & s & $\mathrm{Cd}$ & s & Co & $\mathbf{s}$ & $\mathrm{Cr}$ & $\mathrm{Cu}$ & s & Mo & s & $\mathrm{Ni}$ & s & $\mathrm{Pb}$ & s & $\mathrm{Zn}$ & s \\
\hline N1A & 0328 & 0,0013 & 0,0164 & 0,0006 & 0,2769 & 0,0195 & $<\mathrm{LD}$ & 0,0878 & 0,0001 & 0,0078 & 0028 & 0,0566 & 0,0033 & 1,2199 & 0,0672 & 1,8 & 0,1 \\
\hline NE1A & ,0143 & 0,0033 & 0,0036 & 0,0016 & 0,0998 & 0,0062 & $<L D$ & 0,0611 & 0,0078 & $<$ LD & & 0,0750 & 0,0018 & 0,6494 & 0,0636 & 0,324 & 0,004 \\
\hline E1A & 0,0117 & 0,0009 & $<L D$ & & 0,0321 & 0,0012 & $<L D$ & 0,0186 & 0,0059 & $<$ LD & & $<L D$ & & 0,5369 & 0,0502 & 0,16 & 0,03 \\
\hline SE1A & 0,0049 & 0,0001 & $<L D$ & & 0,0140 & 0,0016 & $0,0082^{*}$ & 0,0645 & 0,0017 & $<L D$ & & 0,0179 & 0,0021 & 0,2996 & 0,0714 & 0,05 & 0,01 \\
\hline S1A & 0,0087 & 0,0001 & 0,0021 & 0,0002 & 0,0423 & 0,0008 & $<L D$ & 0,0744 & 0,0042 & $0,0084^{*}$ & & 0,0229 & 0,0008 & 0,3938 & 0,0022 & 0,32 & 0,01 \\
\hline SW1A & 0,0177 & 0,0017 & 0,0051 & 0,0013 & 0,0614 & 0,0020 & $<L D$ & 0,0747 & 0,0052 & $0,0090^{*}$ & & 0,0258 & 0,0023 & 0,7359 & 0,0106 & 2,4 & 0,9 \\
\hline W1A & 0,0138 & 0,0004 & $<L D$ & & 0,1113 & 0,0025 & $<L D$ & 0,0668 & 0,0039 & $<$ LD & & 0,0160 & 0,0011 & 0,7804 & 0,0269 & 0,08 & 0,02 \\
\hline N3A & 0,0203 & 0,0044 & $0,0069^{*}$ & & 0,0463 & 0,0021 & $<L D$ & 0,0071 & 0,0027 & $<L D$ & & $0,0163^{*}$ & & 0,9459 & 0,0191 & $0,0559^{*}$ & \\
\hline NE3A & 0,0310 & 0,0250 & $0,0033^{*}$ & & 0,1772 & 0,1242 & $<L D$ & 0,0213 & 0,0018 & $<L D$ & & $0,0188^{*}$ & & 2,0639 & 1,8208 & 0,10 & 0,06 \\
\hline E3A & 0,0149 & 0,0003 & $<\mathrm{LD}$ & & 0,0435 & 0,0004 & $0,0085^{\star}$ & 0,0620 & 0,0050 & $<L D$ & & 0,0205 & 0,0037 & 0,8519 & 0,0219 & 0,091 & 0,004 \\
\hline SE3A & 0,0132 & 0,0004 & $<L D$ & & 0,0706 & 0,0043 & $<L D$ & 0,0402 & 0,0000 & $<$ LD & & $0,0187^{*}$ & & 0,8379 & 0,0021 & $0,0517^{*}$ & \\
\hline S3A & 0,0145 & 0,0007 & $<L D$ & & 0,0909 & 0,0019 & $<\mathrm{LD}$ & 0,0541 & 0,0036 & 0,0065 & 0,0008 & $<L D$ & & 0,7689 & 0,0530 & $<L D$ & \\
\hline SW3A & 0,0173 & 0,0001 & $<L D$ & & 0,0504 & 0,0001 & 0,0090 & 0,0429 & 0,0028 & $<L D$ & & 0,0165 & 0,0007 & 0,8684 & 0,0410 & 0,09 & 0,01 \\
\hline W3A & 0,0183 & 0,0000 & $0,0014^{*}$ & & 0,1780 & 0,0003 & $0,0057^{\star}$ & 0,0694 & 0,0010 & $<L D$ & & 0,0344 & 0,0020 & 0,9414 & 0,0269 & 0,53 & 0,02 \\
\hline
\end{tabular}

s: desvio padrão

LD (limite de detecção) mg L'-1: As 0,0008; Cd 0,0013; Co 0,0029; Cr 0,0049; Cu 0,0049; Mo: 0,0049; Ni 0,0145; Pb 0,052; Zn 0,0331.

* única determinação 
TABELA A4 - Concentração média trocável dos metais $\left(\mathrm{mg} \mathrm{L}^{-1}\right)$ nas amostras do solo de Figueira coletadas ao redor da usina termoelétrica, em 1996 e 1997, antes da instalação dos filtros.

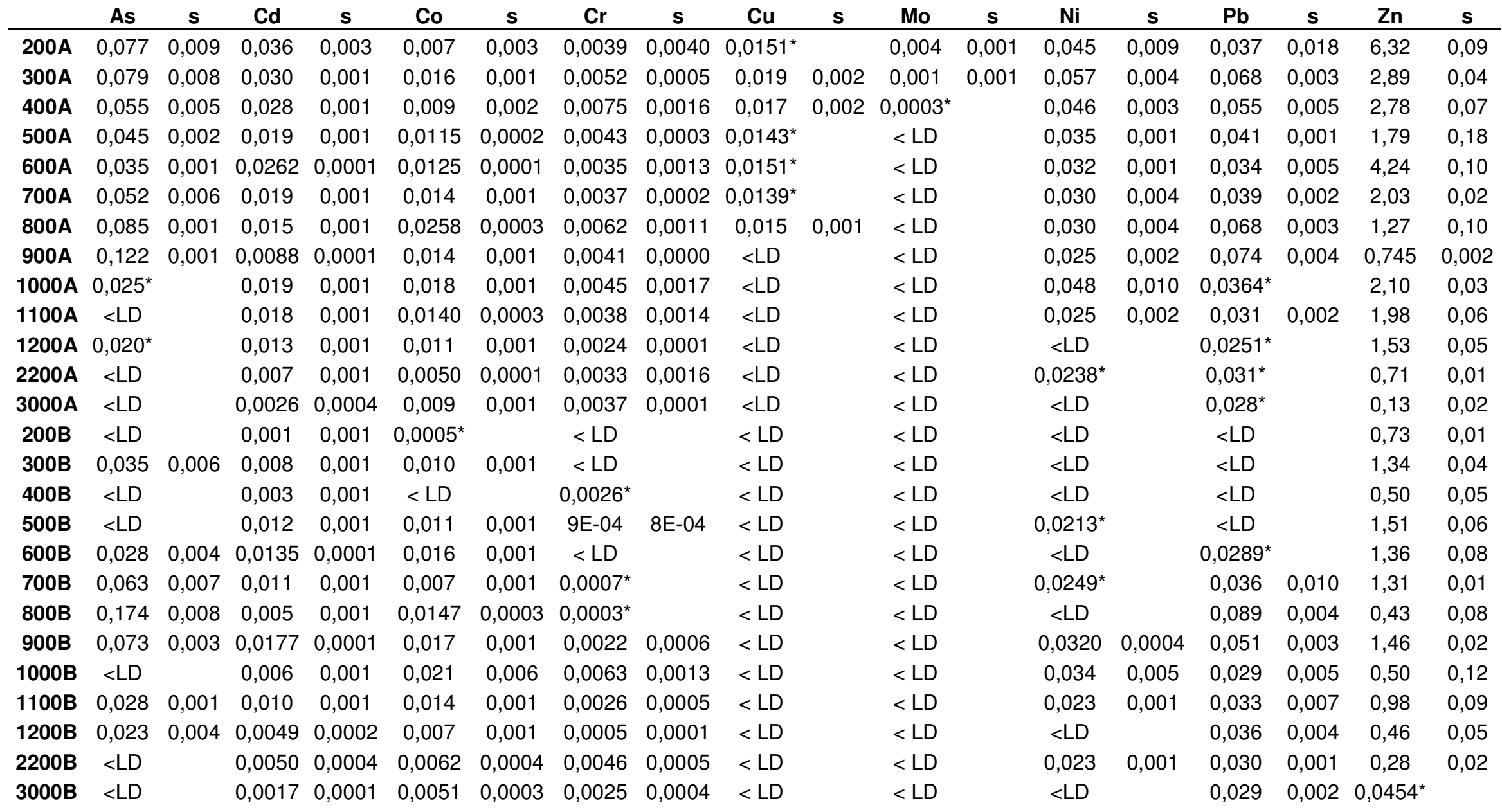


TABELA A4 - Concentração média trocável dos metais $\left(\mathrm{mg} \mathrm{L}^{-1}\right)$ nas amostras do solo de Figueira coletadas ao redor da usina termoelétrica, em 1996 e 1997, antes da instalação dos filtros.

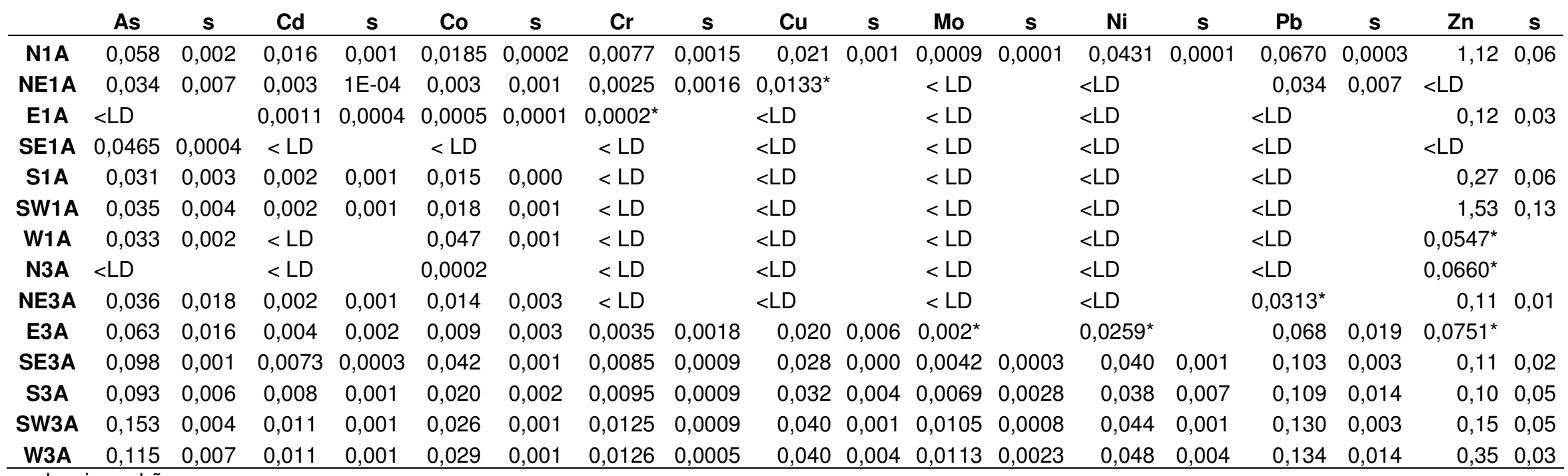

s: desvio padrão

LD (limite de detecção) mg L ${ }^{-1}$ : As 0,0185; Cd 0,0011; Co 0,0003; Cr 0,0011; Cu 0,0128; Mo 0,0003; Ni 0,0202; Pb 0,0230; Zn 0,0415.

* única determinação 
TABELA A5 - Valores de Kp coletadas ao redor da usina termoelétrica, em 1996 e 1997, antes da instalação dos filtros.

\begin{tabular}{|c|c|c|c|c|c|c|c|c|c|}
\hline & \multicolumn{9}{|c|}{$K p_{\text {EDTA }}$} \\
\hline & As & Cd & Co & $\mathrm{Cr}$ & $\mathrm{Cu}$ & Mo & $\mathrm{Ni}$ & $\mathrm{Pb}$ & $\mathrm{Zn}$ \\
\hline $200 A$ & 1715 & 69 & nd & nd & 126 & 329 & 67 & 83 & 26 \\
\hline $300 A$ & 1718 & 74 & nd & nd & 105 & 455 & 64 & 70 & 33 \\
\hline $400 A$ & 1071 & 47 & 21 & nd & 100 & 187 & 53 & 96 & 27 \\
\hline $500 \mathrm{~A}$ & 1192 & 54 & 11 & nd & 104 & 191 & 41 & 36 & 23 \\
\hline $600 \mathrm{~A}$ & 996 & 45 & nd & nd & 46 & 540 & 54 & 54 & 26 \\
\hline $700 A$ & 996 & 40 & nd & nd & 150 & nd & 52 & 58 & 25 \\
\hline $800 A$ & 1150 & 43 & nd & nd & 153 & nd & 66 & 137 & 25 \\
\hline $900 \mathrm{~A}$ & 2681 & 116 & nd & nd & 218 & nd & 70 & 47 & 55 \\
\hline $1000 \mathrm{~A}$ & 957 & 44 & 88 & nd & 108 & 340 & 48 & 110 & 24 \\
\hline $1100 \mathrm{~A}$ & 631 & 31 & 27 & 432 & 95 & 279 & 46 & 64 & 22 \\
\hline $1200 A$ & 644 & 29 & nd & 243 & 106 & nd & 39 & 15 & 22 \\
\hline $2200 A$ & 414 & 20 & 4 & 266 & 97 & nd & 44 & 55 & 27 \\
\hline $3000 A$ & nd & 83 & 36 & nd & 133 & nd & 158 & 85 & 33 \\
\hline $200 B$ & 622 & 47 & nd & nd & 91 & nd & 41 & nd & 14 \\
\hline $300 \mathrm{~B}$ & 548 & 32 & 31 & nd & 74 & nd & 51 & 34 & 17 \\
\hline $400 B$ & 488 & 37 & 60 & nd & 70 & nd & 72 & 83 & 22 \\
\hline $500 \mathrm{~B}$ & 813 & 31 & 60 & nd & 91 & 148 & 60 & 43 & 18 \\
\hline $600 \mathrm{~B}$ & 1434 & 47 & 116 & 900 & 126 & nd & 172 & 18 & 50 \\
\hline $700 \mathrm{~B}$ & 790 & 38 & nd & nd & 83 & nd & 57 & 20 & 18 \\
\hline $800 B$ & 473 & 55 & nd & 118 & 67 & nd & 61 & 18 & 14 \\
\hline $900 \mathrm{~B}$ & 1171 & 45 & 30 & 341 & 105 & 191 & 73 & 24 & 21 \\
\hline 1000B & 309 & 22 & 50 & nd & 67 & nd & 40 & 35 & 15 \\
\hline $1100 \mathrm{~B}$ & 712 & 29 & 96 & nd & 142 & nd & 138 & 110 & 35 \\
\hline $1200 \mathrm{~B}$ & 305 & 32 & nd & nd & 109 & nd & 63 & 26 & 24 \\
\hline 2200B & 195 & 21 & 30 & 201 & 78 & nd & 53 & 45 & 41 \\
\hline $3000 \mathrm{~B}$ & 205 & 44 & 75 & nd & 135 & nd & 350 & 80 & nd \\
\hline N $1 A$ & 555 & 54 & 32 & nd & 102 & nd & 84 & 14 & 37 \\
\hline NE 1A & 245 & 72 & 36 & nd & 85 & nd & 46 & nd & 51 \\
\hline E 1A & nd & nd & nd & nd & 160 & nd & nd & nd & nd \\
\hline SE 1A & nd & nd & nd & 232 & 82 & nd & 80 & nd & nd \\
\hline S 1A & 184 & 227 & 14 & nd & 92 & nd & 71 & nd & 11 \\
\hline SW 1A & 271 & 75 & 39 & nd & 155 & nd & 180 & nd & 22 \\
\hline W 1A & nd & nd & 26 & nd & 81 & nd & 83 & 9 & nd \\
\hline N $3 A$ & nd & 11 & nd & nd & 265 & nd & 71 & 9 & nd \\
\hline NE 3A & nd & 18 & 3 & nd & 141 & nd & 60 & nd & nd \\
\hline E $3 A$ & nd & nd & nd & 351 & 85 & nd & 88 & nd & nd \\
\hline SE 3A & nd & nd & 24 & nd & 113 & nd & 74 & 9 & nd \\
\hline S 3A & nd & nd & 21 & nd & 81 & nd & nd & 8 & nd \\
\hline SW $3 A$ & 283 & nd & nd & 157 & 118 & nd & 90 & 7 & 48 \\
\hline W $3 A$ & 33 & 78 & 12 & 174 & 65 & nd & 49 & nd & 19 \\
\hline
\end{tabular}


TABELA A6 - Valores de $\mathrm{Kp}_{\mathrm{Ca}\left(\mathrm{NO}_{3}\right)_{2}}$ dos metais nas amostras do solo de Figueira coletadas ao redor da usina termoelétrica, em 1996 e 1997, antes da instalação dos filtros.

\begin{tabular}{|c|c|c|c|c|c|c|c|c|c|}
\hline & \multicolumn{9}{|c|}{$\mathrm{Kp}_{\mathrm{Ca}\left(\mathrm{NO}_{3}\right)_{2}}$} \\
\hline & As & Cd & Co & $\mathrm{Cr}$ & $\mathrm{Cu}$ & Mo & $\mathrm{Ni}$ & $\mathrm{Pb}$ & $\mathrm{Zn}$ \\
\hline $200 A$ & 1918 & 157 & nd & 861 & 889 & 2385 & 120 & 881 & 46 \\
\hline $300 \mathrm{~A}$ & 913 & 93 & nd & 575 & 630 & 10205 & 66 & 554 & 41 \\
\hline $400 A$ & 958 & 76 & 227 & 285 & 740 & 17919 & 86 & 665 & 43 \\
\hline $500 \mathrm{~A}$ & 819 & 80 & 52 & 339 & 522 & nd & 71 & 274 & 34 \\
\hline $600 A$ & 1440 & 80 & nd & 826 & 2121 & nd & 106 & 950 & 41 \\
\hline $700 A$ & 541 & 52 & nd & 359 & 623 & nd & 66 & 423 & 33 \\
\hline $800 A$ & 244 & 43 & nd & 311 & 526 & nd & 75 & 839 & 30 \\
\hline $900 \mathrm{~A}$ & 255 & 118 & nd & 755 & nd & nd & 103 & 243 & 66 \\
\hline $1000 \mathrm{~A}$ & 1447 & 75 & 551 & 354 & nd & nd & 113 & 1716 & 41 \\
\hline $1100 \mathrm{~A}$ & nd & 60 & 187 & 716 & nd & nd & 107 & 1234 & 39 \\
\hline $1200 \mathrm{~A}$ & 882 & 53 & nd & 780 & nd & nd & nd & 270 & 34 \\
\hline $2200 A$ & nd & 46 & 64 & 638 & nd & nd & 129 & 1394 & 61 \\
\hline $3000 \mathrm{~A}$ & nd & 135 & 541 & 612 & nd & nd & nd & 1186 & 61 \\
\hline $200 \mathrm{~B}$ & nd & 149 & nd & nd & nd & nd & nd & nd & 21 \\
\hline $300 \mathrm{~B}$ & 224 & 44 & 108 & nd & nd & nd & nd & nd & 22 \\
\hline $400 \mathrm{~B}$ & nd & 81 & nd & 219 & nd & nd & nd & nd & 39 \\
\hline $500 \mathrm{~B}$ & nd & 44 & 115 & 633 & nd & nd & 95 & nd & 25 \\
\hline $600 \mathrm{~B}$ & 1037 & 63 & 145 & nd & nd & nd & nd & 247 & 62 \\
\hline $700 \mathrm{~B}$ & 190 & 41 & nd & 1329 & nd & nd & 73 & 206 & 21 \\
\hline $800 \mathrm{~B}$ & 16 & 36 & nd & 2800 & nd & nd & nd & 95 & 17 \\
\hline 900B & 333 & 43 & 46 & 836 & nd & nd & 101 & 288 & 23 \\
\hline 1000B & nd & 28 & 330 & 108 & nd & nd & 86 & 624 & 26 \\
\hline 1100B & 476 & 40 & 339 & 2096 & nd & nd & 226 & 1839 & 49 \\
\hline $1200 \mathrm{~B}$ & 125 & 42 & nd & 2180 & nd & nd & nd & 228 & 31 \\
\hline 2200B & nd & 27 & 232 & 307 & nd & nd & 91 & 841 & 449 \\
\hline $3000 \mathrm{~B}$ & nd & 49 & 1018 & 2096 & nd & nd & nd & 1196 & 198 \\
\hline N $1 A$ & 316 & 56 & 476 & 771 & 435 & nd & 111 & 263 & 61 \\
\hline NE 1A & 104 & 84 & 1103 & 2500 & 389 & nd & nd & nd & nd \\
\hline E 1A & nd & 121 & nd & nd & nd & nd & nd & nd & nd \\
\hline SE 1A & nd & nd & nd & nd & nd & nd & nd & nd & nd \\
\hline S 1A & 52 & 216 & 40 & nd & nd & nd & nd & nd & 13 \\
\hline SW 1A & 137 & 167 & 133 & nd & nd & nd & nd & nd & 34 \\
\hline W 1A & nd & nd & 63 & nd & nd & nd & nd & nd & nd \\
\hline N $3 A$ & nd & nd & nd & nd & nd & nd & nd & nd & nd \\
\hline NE 3A & nd & 37 & 39 & nd & nd & nd & nd & nd & nd \\
\hline E $3 A$ & nd & 11 & nd & 851 & 270 & nd & 69 & nd & nd \\
\hline SE 3A & nd & 16 & 40 & 149 & 165 & nd & 34 & 69 & nd \\
\hline S $3 A$ & nd & 10 & 96 & 92 & 135 & nd & 24 & 57 & nd \\
\hline SW 3A & 32 & 14 & nd & 113 & 127 & nd & 34 & 45 & 28 \\
\hline W 3A & 5 & 10 & 76 & 79 & 113 & nd & 35 & nd & 29 \\
\hline
\end{tabular}


TABELA A7 - Razão $\mathrm{Kp}_{\mathrm{Ca}\left(\mathrm{NO}_{3}\right)_{2}} / \mathrm{Kp}_{\text {EDTA }}$ dos metais nas amostras do solo de Figueira coletadas ao redor da usina termoelétrica, em 1996 e 1997, antes da instalação dos filtros.

\begin{tabular}{|c|c|c|c|c|c|c|c|c|c|}
\hline & As & $\mathrm{Cd}$ & Co & $\mathrm{Cr}$ & $\mathrm{Cu}$ & Mo & $\mathbf{N i}$ & $\mathrm{Pb}$ & $\mathrm{Zn}$ \\
\hline $200 A$ & 1,1 & 2,3 & nd & nd & 7,1 & 7,2 & 1,8 & 10,6 & 1,8 \\
\hline $300 \mathrm{~A}$ & 0,5 & 1,3 & nd & nd & 6,0 & 22,4 & 1,0 & 7,9 & 1,2 \\
\hline 400A & 0,9 & 1,6 & 10,8 & nd & 7,4 & 95,8 & 1,6 & 6,9 & 1,6 \\
\hline $500 \mathrm{~A}$ & 0,7 & 1,5 & 4,7 & nd & 5,0 & nd & 1,7 & 7,6 & 1,5 \\
\hline $600 A$ & 1,4 & 1,8 & nd & nd & 46,1 & nd & 2,0 & 17,6 & 1,6 \\
\hline $700 A$ & 0,5 & 1,3 & nd & nd & 4,2 & nd & 1,3 & 7,3 & 1,3 \\
\hline $800 A$ & 0,2 & 1,0 & nd & nd & 3,4 & nd & 1,1 & 6,1 & 1,2 \\
\hline $900 \mathrm{~A}$ & 0,1 & 1,0 & nd & nd & nd & nd & 1,5 & 5,2 & 1,2 \\
\hline $1000 \mathrm{~A}$ & 1,5 & 1,7 & 6,3 & nd & nd & nd & 2,4 & 15,6 & 1,7 \\
\hline $1100 \mathrm{~A}$ & nd & 1,9 & 6,9 & 1,7 & nd & nd & 2,3 & 19,3 & 1,8 \\
\hline $1200 \mathrm{~A}$ & 1,4 & 1,8 & nd & 3,2 & nd & nd & nd & 18,0 & 1,5 \\
\hline $2200 A$ & nd & 2,3 & 16,0 & 2,4 & nd & nd & 2,9 & 25,3 & 2,3 \\
\hline $3000 \mathrm{~A}$ & nd & 1,6 & 15,0 & nd & nd & nd & nd & 14,0 & 1,8 \\
\hline $200 B$ & nd & 3,2 & nd & nd & nd & nd & nd & nd & 1,5 \\
\hline $300 \mathrm{~B}$ & 0,4 & 1,4 & 3,5 & nd & nd & nd & nd & nd & 1,3 \\
\hline 400B & nd & 2,2 & nd & nd & nd & nd & nd & nd & 1,8 \\
\hline $500 \mathrm{~B}$ & nd & 1,4 & 1,9 & nd & nd & nd & 1,6 & nd & 1,4 \\
\hline $600 \mathrm{~B}$ & 0,7 & 1,3 & 1,3 & nd & nd & nd & nd & 13,7 & 1,2 \\
\hline $700 \mathrm{~B}$ & 0,2 & 1,1 & nd & nd & nd & nd & 1,3 & 10,3 & 1,2 \\
\hline $800 \mathrm{~B}$ & 0,0 & 0,7 & nd & 23,7 & nd & nd & nd & 5,3 & 1,2 \\
\hline $900 \mathrm{~B}$ & 0,3 & 1,0 & 1,5 & 2,5 & nd & nd & 1,4 & 12,0 & 1,1 \\
\hline 1000B & nd & 1,3 & 6,6 & nd & nd & nd & 2,2 & 17,8 & 1,7 \\
\hline 1100B & 0,7 & 1,4 & 3,5 & nd & nd & nd & 1,6 & 16,7 & 1,4 \\
\hline 1200B & 0,4 & 1,3 & nd & nd & nd & nd & nd & 8,8 & 1,3 \\
\hline 2200B & nd & 1,3 & 7,7 & 1,5 & nd & nd & 1,7 & 18,7 & 11 \\
\hline 3000B & nd & 1,1 & 13,6 & nd & nd & nd & nd & 15,0 & nd \\
\hline N 1A & 0,6 & 1,0 & 14,9 & nd & 4,3 & nd & 1,3 & 18,8 & 1,6 \\
\hline NE $1 \mathrm{~A}$ & 0,4 & 1,2 & 30,6 & nd & 4,6 & nd & nd & nd & nd \\
\hline E 1A & nd & nd & nd & nd & nd & nd & nd & nd & nd \\
\hline SE 1A & nd & nd & nd & nd & nd & nd & nd & nd & nd \\
\hline S 1A & 0,3 & 1,0 & 2,9 & nd & nd & nd & nd & nd & 1,2 \\
\hline SW $1 A$ & 0,5 & 2,2 & 3,4 & nd & nd & nd & nd & nd & 1,5 \\
\hline W 1A & nd & nd & 2,4 & nd & nd & nd & nd & nd & nd \\
\hline N $3 A$ & nd & nd & nd & nd & nd & nd & nd & nd & nd \\
\hline NE 3A & nd & nd & 13,0 & nd & nd & nd & nd & nd & nd \\
\hline E 3A & nd & nd & nd & 2,4 & 3,2 & nd & 0,8 & nd & nd \\
\hline SE 3A & nd & nd & 1,7 & nd & 1,5 & nd & 0,5 & 7,7 & nd \\
\hline S 3A & nd & nd & 4,6 & nd & 1,7 & nd & nd & 7,1 & nd \\
\hline SW $3 A$ & 0,1 & nd & nd & 0,7 & 1,1 & nd & 0,4 & 6,4 & 0,6 \\
\hline W 3A & 0,2 & nd & 6,3 & 0,5 & 1,7 & nd & 0,7 & nd & 1,5 \\
\hline
\end{tabular}

nd: não determinado 
TABELA A8 - Razão Kp $p_{\text {CSoil }} / \mathrm{Kp}_{\text {EDTA }}$ dos metais nas amostras do solo de Figueira coletadas ao redor da usina termoelétrica, em 1996 e 1997, antes da instalação dos filtros.

\begin{tabular}{|c|c|c|c|c|c|c|c|c|c|}
\hline & As & Cd & Co & $\mathrm{Cr}$ & $\mathrm{Cu}$ & Mo & $\mathbf{N i}$ & $\mathrm{Pb}$ & $\mathrm{Zn}$ \\
\hline $200 A$ & 0,6 & 2,8 & nd & nd & 4,3 & 0,06 & 8,4 & 29 & 9,6 \\
\hline $300 A$ & 0,6 & 2,6 & nd & nd & 5,1 & 0,004 & 8,8 & 34 & 7,6 \\
\hline $400 A$ & 0,9 & 4,0 & 5,7 & nd & 5,4 & 0,11 & 10,6 & 25 & 9,3 \\
\hline $500 \mathrm{~A}$ & 0,8 & 3,5 & 10,9 & nd & 5,2 & 0,10 & 13,7 & 67 & 10,9 \\
\hline $600 A$ & 1,0 & 4,2 & nd & nd & 11,7 & 0,04 & 10,4 & 44 & 9,6 \\
\hline $700 \mathrm{~A}$ & 1,0 & 4,8 & nd & nd & 3,6 & nd & 10,8 & 41 & 10 \\
\hline $800 A$ & 0,9 & 4,4 & nd & nd & 3,5 & nd & 8,5 & 18 & 10 \\
\hline $900 \mathrm{~A}$ & 0,4 & 1,6 & nd & nd & 2,5 & nd & 8,0 & 51 & 4,5 \\
\hline $1000 \mathrm{~A}$ & 1,0 & 4,3 & 1,4 & nd & 5,0 & 0,06 & 11,7 & 22 & 10,4 \\
\hline $1100 \mathrm{~A}$ & 1,6 & 6,1 & 4,4 & 33,3 & 5,7 & 0,07 & 12,2 & 38 & 11,4 \\
\hline $1200 \mathrm{~A}$ & 1,5 & 6,6 & nd & 59,3 & 5,1 & nd & 14,4 & 160 & 11,4 \\
\hline $2200 A$ & 2,4 & 9,5 & 30,0 & 54,1 & 5,6 & nd & 12,7 & 44 & 9,3 \\
\hline $3000 \mathrm{~A}$ & nd & 2,3 & 3,3 & nd & 4,1 & nd & 3,5 & 28 & 7,6 \\
\hline $200 B$ & 1,6 & 4,0 & nd & nd & 5,9 & nd & 13,7 & nd & 17,9 \\
\hline $300 \mathrm{~B}$ & 1,8 & 5,9 & 3,9 & nd & 7,3 & nd & 11,0 & 71 & 14,7 \\
\hline $400 B$ & 2,0 & 5,1 & 2,0 & nd & 7,7 & nd & 7,8 & 29 & 11,4 \\
\hline $500 B$ & 1,2 & 6,1 & 2,0 & nd & 5,9 & 0,14 & 9,3 & 56 & 13,9 \\
\hline $600 \mathrm{~B}$ & 0,7 & 4,0 & 1,0 & 16,0 & 4,3 & nd & 3,3 & 133 & 5 \\
\hline $700 \mathrm{~B}$ & 1,2 & 5,0 & nd & nd & 6,5 & nd & 9,8 & 120 & 13,9 \\
\hline $800 \mathrm{~B}$ & 2,1 & 3,5 & nd & 122,0 & 8,1 & nd & 9,2 & 133 & 17,9 \\
\hline 900B & 0,8 & 4,2 & 4,0 & 42,2 & 5,1 & 0,10 & 7,7 & 100 & 11,9 \\
\hline $1000 \mathrm{~B}$ & 3,2 & 8,6 & 2,4 & nd & 8,1 & nd & 14,0 & 69 & 16,7 \\
\hline $1100 \mathrm{~B}$ & 1,4 & 6,6 & 1,3 & nd & 3,8 & nd & 4,1 & 22 & 7,1 \\
\hline $1200 \mathrm{~B}$ & 3,2 & 5,9 & nd & nd & 5,0 & nd & 8,9 & 92 & 10,4 \\
\hline $2200 B$ & 5,0 & 9,0 & 4,0 & 71,6 & 6,9 & nd & 10,6 & 53 & 6,1 \\
\hline $3000 B$ & 4,8 & 4,3 & 1,6 & nd & 4,0 & nd & 1,6 & 30 & nd \\
\hline N 1A & 1,8 & 3,5 & 3,8 & nd & 5,3 & nd & 6,7 & 171 & 6,8 \\
\hline NE $1 \mathrm{~A}$ & 4,0 & 2,6 & 3,3 & nd & 6,4 & nd & 12,2 & nd & 4,9 \\
\hline E 1A & nd & nd & nd & nd & 3,4 & nd & nd & nd & nd \\
\hline SE 1A & nd & nd & nd & 62,1 & 6,6 & nd & 7,0 & nd & nd \\
\hline S 1A & 5,3 & 0,8 & 8,6 & nd & 5,9 & nd & 7,9 & nd & 22,7 \\
\hline SW 1A & 3,6 & 2,5 & 3,1 & nd & 3,5 & nd & 3,1 & nd & 11,4 \\
\hline W 1A & nd & nd & 4,6 & nd & 6,7 & nd & 6,7 & 267 & nd \\
\hline N 3A & nd & 17,3 & nd & nd & 2,0 & nd & 7,9 & 267 & nd \\
\hline NE 3A & nd & 10,6 & 40,0 & nd & 3,8 & nd & 9,3 & nd & nd \\
\hline E 3A & nd & nd & nd & 41,0 & 6,4 & nd & 6,4 & nd & nd \\
\hline SE $3 A$ & nd & nd & 5,0 & nd & 4,8 & nd & 7,6 & 267 & nd \\
\hline S $3 A$ & nd & nd & 5,7 & nd & 6,7 & nd & nd & 300 & nd \\
\hline SW 3A & 3,5 & nd & nd & 91,7 & 4,6 & nd & 6,2 & 343 & 5,2 \\
\hline W 3A & 29,7 & 2,4 & 10,0 & 82,8 & 8,3 & nd & 11,4 & nd & 13,2 \\
\hline
\end{tabular}

nd: não determinado 
TABELA A9 - Razão $\mathrm{Kp}_{\mathrm{CS} \text { oil }} / \mathrm{Kp}_{\mathrm{Ca}\left(\mathrm{NO}_{3}\right)_{2}}$ dos metais nas amostras do solo de Figueira coletadas ao redor da usina termoelétrica, em 1996 e 1997, antes da instalação dos filtros.

\begin{tabular}{|c|c|c|c|c|c|c|c|c|c|}
\hline & As & $\mathbf{C d}$ & Co & $\mathrm{Cr}$ & $\mathrm{Cu}$ & Mo & $\mathbf{N i}$ & $\mathrm{Pb}$ & $\mathrm{Zn}$ \\
\hline $200 A$ & 0,5 & 1,2 & nd & 17 & 0,6 & 0,01 & 4,7 & 2,7 & 5,4 \\
\hline $300 \mathrm{~A}$ & 1,1 & 2,0 & nd & 25 & 0,9 & 0,002 & 8,5 & 4,3 & 6,1 \\
\hline $400 \mathrm{~A}$ & 1,0 & 2,5 & 0,5 & 51 & 0,7 & 0,001 & 6,5 & 3,6 & 5,8 \\
\hline $500 \mathrm{~A}$ & 1,2 & 2,4 & 2,3 & 42 & 1,0 & nd & 7,9 & 8,8 & 7,4 \\
\hline $600 \mathrm{~A}$ & 0,7 & 2,4 & nd & 17 & 0,3 & nd & 5,3 & 2,5 & 6,1 \\
\hline $700 \mathrm{~A}$ & 1,8 & 3,7 & nd & 40 & 0,9 & nd & 8,5 & 5,7 & 7,6 \\
\hline $800 \mathrm{~A}$ & 4,0 & 4,4 & nd & 46 & 1,0 & nd & 7,5 & 2,9 & 8,3 \\
\hline $900 \mathrm{~A}$ & 3,8 & 1,6 & nd & 19 & nd & nd & 5,4 & 9,9 & 3,8 \\
\hline $1000 \mathrm{~A}$ & 0,7 & 2,5 & 0,2 & 41 & nd & nd & 5,0 & 1,4 & 6,1 \\
\hline $1100 \mathrm{~A}$ & nd & 3,2 & 0,6 & 20 & nd & nd & 5,2 & 1,9 & 6,4 \\
\hline $1200 \mathrm{~A}$ & 1,1 & 3,6 & nd & 18 & nd & nd & nd & 8,9 & 7,4 \\
\hline $2200 A$ & nd & 4,1 & 1,9 & 23 & nd & nd & 4,3 & 1,7 & 4,1 \\
\hline $3000 \mathrm{~A}$ & nd & 1,4 & 0,2 & 24 & nd & nd & nd & 2,0 & 4,1 \\
\hline $200 B$ & nd & 1,3 & nd & nd & nd & nd & nd & nd & 11,9 \\
\hline $300 \mathrm{~B}$ & 4,4 & 4,3 & 1,1 & nd & nd & nd & nd & nd & 11,4 \\
\hline 400B & nd & 2,3 & nd & 66 & nd & nd & nd & nd & 6,4 \\
\hline $500 \mathrm{~B}$ & nd & 4,3 & 1,0 & 23 & nd & nd & 5,9 & nd & 10 \\
\hline $600 \mathrm{~B}$ & 0,9 & 3,0 & 0,8 & nd & nd & nd & nd & 9,7 & 4 \\
\hline $700 \mathrm{~B}$ & 5,2 & 4,6 & nd & 11 & nd & nd & 7,7 & 11,7 & 11,9 \\
\hline $800 \mathrm{~B}$ & 61,3 & 5,3 & nd & 5 & nd & nd & nd & 25,3 & 14,7 \\
\hline $900 \mathrm{~B}$ & 2,9 & 4,4 & 2,6 & 17 & nd & nd & 5,5 & 8,3 & 10,9 \\
\hline $1000 \mathrm{~B}$ & nd & 6,8 & 0,4 & 133 & nd & nd & 6,5 & 3,8 & 9,6 \\
\hline 1100B & 2,1 & 4,8 & 0,4 & 7 & nd & nd & 2,5 & 1,3 & 5,1 \\
\hline 1200B & 7,8 & 4,5 & nd & 7 & nd & nd & nd & 10,5 & 8,1 \\
\hline 2200B & nd & 7,0 & 0,5 & 47 & nd & nd & 6,2 & 2,9 & 0,6 \\
\hline $3000 \mathrm{~B}$ & nd & 3,9 & 0,1 & 7 & nd & nd & nd & 2,0 & 1,3 \\
\hline N 1A & 3,1 & 3,4 & 0,3 & 19 & 1,2 & nd & 5,0 & 9,1 & 4,1 \\
\hline NE 1A & 9,4 & 2,3 & 0,1 & 6 & 1,4 & nd & nd & nd & nd \\
\hline E 1A & nd & 1,6 & nd & nd & nd & nd & nd & nd & nd \\
\hline SE 1A & nd & nd & nd & nd & nd & nd & nd & nd & nd \\
\hline S1A & 18,8 & 0,9 & 3,0 & nd & nd & nd & nd & nd & 19,2 \\
\hline SW 1A & 7,2 & 1,1 & 0,9 & nd & nd & nd & nd & nd & 7,4 \\
\hline W 1A & nd & nd & 1,9 & nd & nd & nd & nd & nd & nd \\
\hline N 3A & nd & nd & nd & nd & nd & nd & nd & nd & nd \\
\hline NE 3A & nd & 5,1 & 3,1 & nd & nd & nd & nd & nd & nd \\
\hline E $3 A$ & nd & 17,3 & nd & 17 & 2,0 & nd & 8,1 & nd & nd \\
\hline SE 3A & nd & 11,9 & 3,0 & 97 & 3,3 & nd & 16,5 & 34,8 & nd \\
\hline S 3A & nd & 19,0 & 1,3 & 157 & 4,0 & nd & 23,3 & 42,1 & nd \\
\hline SW $3 A$ & 30,6 & 13,6 & nd & 127 & 4,3 & nd & 16,5 & 53,3 & 8,9 \\
\hline W 3A & 196 & 19,0 & 1,6 & 182 & 4,8 & nd & 16,0 & nd & 8,6 \\
\hline
\end{tabular}


TABELA A10 - Valores de Kp $p_{E D T A}$ dos metais das amostras do solo de Figueira coletadas em 2001 depois da instalação dos filtros na usina.

\begin{tabular}{cccccccccc}
\hline $\begin{array}{c}\text { Ponto } \\
\text { de } \\
\text { coleta }\end{array}$ & As & Cd & Co & Cr $\begin{array}{c}\text { Kp } \\
\text { Cu }\end{array}$ & Mo & Ni & Pb & Zn \\
\hline $\begin{array}{c}\text { 400A } \\
1\end{array}$ & 1086 & 43 & nd & nd & 87 & 250 & 92 & 23 & 22 \\
2 & 118 & 42 & 43 & nd & 96 & 214 & 130 & 14 & 34 \\
3 & 1375 & 51 & 57 & nd & 117 & 205 & 123 & 17 & 45 \\
\hline $\mathbf{6 0 0 A}$ & & & & & & & & & \\
1 & 1782 & 55 & 23 & nd & 138 & nd & 148 & 16 & 48 \\
2 & 2076 & 185 & nd & nd & 118 & 128 & 70 & 25 & 39 \\
3 & 217 & 12 & nd & nd & 77 & nd & 47 & 18 & 6 \\
\hline nd não determinado & & & & & & & & \\
\hline
\end{tabular}

nd. não determinado 
TABELA A11 - Características físico-químicas das amostras do solo de Figueira coletadas ao redor da usina termoelétrica, em 1996 e 1997, antes da instalação dos filtros na usina.

\begin{tabular}{|c|c|c|c|c|c|c|c|c|c|}
\hline $\begin{array}{c}\text { Amostras } \\
\text { de solo }\end{array}$ & $\mathrm{pH}_{\mathrm{KCl}}$ & $\begin{array}{l}\text { MO } \\
\text { (\%) }\end{array}$ & $\begin{array}{c}\text { Argila } \\
(\%)\end{array}$ & $\begin{array}{c}\text { Areia } \\
(\%)\end{array}$ & $\begin{array}{l}\text { Silte } \\
(\%)\end{array}$ & $\begin{array}{c}\text { CTC } \\
\left(\mathrm{cmol} \mathrm{kg}^{-1}\right)\end{array}$ & $\begin{array}{l}\text { Al } \\
(\%)\end{array}$ & $\begin{array}{l}\mathrm{Fe} \\
(\%)\end{array}$ & $\begin{array}{c}\mathrm{Mn} \\
\left(\mathrm{mg} \mathrm{kg}^{-1}\right)\end{array}$ \\
\hline $200 A$ & 5,2 & 6,4 & 6 & 57 & 37 & 26 & 6,13 & 11,82 & 94 \\
\hline $300 A$ & 4,7 & 4,9 & 19 & 42 & 38 & 22 & 4,7 & 5,78 & 315 \\
\hline 400A & 5,0 & 3,3 & 14 & 50 & 36 & 16 & 5,87 & 3,447 & 1699 \\
\hline $500 \mathrm{~A}$ & 4,6 & 3,0 & 9 & 61 & 29 & 12 & 3,55 & 2,105 & 910 \\
\hline $600 A$ & 4,7 & 5,5 & 18 & 42 & 40 & 18 & 4,3 & 4,6 & 446 \\
\hline $700 \mathrm{~A}$ & 4,2 & 5,0 & 36 & 25 & 40 & 28 & 4,36 & 2,8 & 480 \\
\hline $800 A$ & 4,0 & 4,4 & 37 & 34 & 29 & 25 & 5,4 & 2,58 & 1046 \\
\hline $900 \mathrm{~A}$ & 3,7 & 2,7 & 41 & 24 & 43 & 24 & 4,36 & 2,21 & 287 \\
\hline $1000 \mathrm{~A}$ & 4,3 & 5,4 & 32 & 32 & 36 & 23 & 10,6 & 1,87 & 4109 \\
\hline $1100 \mathrm{~A}$ & 4,4 & 5,4 & 24 & 35 & 42 & 24 & 6,59 & 2,373 & 1903 \\
\hline $1200 \mathrm{~A}$ & 4,2 & 6,3 & 26 & 34 & 40 & 25 & 4,42 & 1,849 & 964 \\
\hline $2200 A$ & 4,4 & 4,6 & 26 & 32 & 42 & 19 & 6,92 & 1,02 & 3098 \\
\hline $3000 \mathrm{~A}$ & 4,2 & 3,0 & 29 & 27 & 44 & 22 & 7,3 & 1,32 & 2453 \\
\hline 200B & 5,9 & 0,5 & 5 & 84 & 11 & 10 & 1,798 & 0,543 & 576 \\
\hline $300 \mathrm{~B}$ & 3,9 & 1,9 & 29 & 47 & 25 & 19 & 4,5 & 2,022 & 555 \\
\hline 400B & 5,2 & 0,7 & 14 & 66 & 20 & 11 & 6,09 & 0,669 & 2484 \\
\hline 500B & 4,6 & 1,9 & 13 & 64 & 23 & 14 & 4,71 & 1,43 & 1122 \\
\hline $600 B$ & 4,2 & 3,0 & 23 & 44 & 33 & 18 & 4,19 & 2,66 & 406 \\
\hline $700 \mathrm{~B}$ & 3,5 & 3,1 & 40 & 22 & 38 & 24 & 4,4 & 2,18 & 361 \\
\hline $800 B$ & 3,7 & 2,2 & 51 & 24 & 25 & 22 & 4,95 & 2,12 & 238 \\
\hline $900 \mathrm{~B}$ & 3,8 & 2,7 & 41 & 31 & 28 & 24 & 5,6 & 3,48 & 619 \\
\hline $1000 \mathrm{~B}$ & 4,5 & 2,4 & 26 & 46 & 28 & 15 & 12,34 & 0,213 & 5260 \\
\hline 1100B & 4,2 & 2,6 & 31 & 30 & 39 & 16 & 5,96 & 2,03 & 1176 \\
\hline 1200B & 4,1 & 3,0 & 32 & 28 & 40 & 18 & 4,22 & 1,307 & 705 \\
\hline $2200 B$ & 4,3 & 2,4 & 24 & 32 & 44 & 15 & 7,28 & 0,81 & 2973 \\
\hline $3000 \mathrm{~B}$ & 4,5 & 1,9 & 45 & 18 & 37 & 18 & 6,89 & 2,06 & 1250 \\
\hline
\end{tabular}


TABELA A11 - Características físico-químicas das amostras do solo de Figueira coletadas ao redor da usina termoelétrica, em 1996 e 1997, antes da instalação dos filtros.

\begin{tabular}{cccccccccc}
\hline $\begin{array}{c}\text { Amostras } \\
\text { de solo }\end{array}$ & $\mathbf{p H}_{\mathbf{K C l}}$ & $\begin{array}{c}\text { MO } \\
(\%)\end{array}$ & $\begin{array}{c}\text { Argila } \\
(\%)\end{array}$ & $\begin{array}{c}\text { Areia } \\
(\%)\end{array}$ & $\begin{array}{c}\text { Silte } \\
(\%)\end{array}$ & $\begin{array}{c}\text { CTC } \\
\left(\mathbf{c m o l ~ k g}^{-1}\right)\end{array}$ & $\begin{array}{c}\text { Al } \\
(\%)\end{array}$ & $\begin{array}{c}\mathbf{F e} \\
(\%)\end{array}$ & $\begin{array}{c}\text { Mn } \\
(\mathbf{p p m})\end{array}$ \\
\hline N1A & 4,6 & 3,7 & 26 & 36 & 38 & 23 & 4,08 & 2,55 & 3095 \\
NE1A & 5,0 & 2,3 & 28 & 32 & 40 & 19 & 4,46 & 2,43 & 1098 \\
E1A & 4,7 & 1,4 & 3 & 83 & 14 & 5 & 1,97 & 0,809 & 198 \\
SE1A & 3,8 & 2,2 & 24 & 51 & 26 & 16 & 3,75 & 2,01 & 135 \\
S1A & 3,8 & 2,0 & 32 & 43 & 26 & 14 & 4,72 & 2,48 & 1543 \\
SW1A & 3,7 & 2,0 & 38 & 48 & 13 & 18 & 5,52 & 3,11 & 445 \\
W1A & 3,7 & 1,7 & 26 & 48 & 26 & 13 & 4,81 & 2,09 & 1064 \\
N3A & 4,4 & 1,2 & 18 & 55 & 27 & 22 & 3,04 & 1,38 & 208 \\
NE3A & 3,9 & 1,4 & 17 & 55 & 28 & 9 & 2,55 & 1,27 & 826 \\
E3A & 4,3 & 3,9 & 32 & 48 & 21 & 25 & 5,16 & 2,87 & 203 \\
SE3A & 3,9 & 1,2 & 17 & 62 & 20 & 12 & 3,75 & 1,478 & 539 \\
S3A & 4,2 & 0,7 & 26 & 56 & 18 & 8 & 4,15 & 1,83 & 1232 \\
SW3A & 3,4 & 3,6 & 20 & 58 & 22 & 21 & 3,14 & 1,58 & 133 \\
W3A & 4,5 & 2,4 & 26 & 42 & 32 & 11 & 3,7 & 1,77 & 978 \\
\hline MO- material orgânica & & & & & & & & &
\end{tabular}

MO: material orgânica

CTC: capacidade de troca catiônica 
TABELA A12 - Concentração total dos metais $\left(\mathrm{mg} \mathrm{kg}^{-1}\right)$ das amostras do solo de Figueira coletadas ao redor da usina termoelétrica, em 1996 e 1997, antes da instalação dos filtros.

\begin{tabular}{ccccccc}
\hline $\begin{array}{c}\text { Amostras } \\
\text { de solo }\end{array}$ & As & Cr & Cu & Ni & Pb & Zn \\
\hline 200A & $98 \pm 2$ & $111 \pm 7$ & nd & $60 \pm 1$ & $155 \pm 2$ & nd \\
300A & $88 \pm 2$ & $65 \pm 6$ & $40 \pm 1$ & $48 \pm 4$ & $125 \pm 2$ & $360 \pm 8$ \\
400A & $41 \pm 2$ & $37 \pm 4$ & $51 \pm 1$ & $52 \pm 4$ & $91 \pm 2$ & $799 \pm 4$ \\
500A & $21,5 \pm 1,9$ & $20,5 \pm 1,4$ & $41 \pm 1$ & $44 \pm 2$ & $66 \pm 8$ & $750 \pm 5$ \\
600A & $58 \pm 3$ & $46,3 \pm 3,6$ & $69,0 \pm 1,4$ & $46,8 \pm 0,5$ & $107 \pm 3$ & $741 \pm 12$ \\
700A & $28,7 \pm 5,3$ & $27,8 \pm 0,6$ & $37 \pm 3$ & $35 \pm 3$ & $65,5 \pm 1,2$ & $650 \pm 3$ \\
800A & $38,4 \pm 4,4$ & $23,1 \pm 1,5$ & $35 \pm 1$ & $41 \pm 2$ & $107 \pm 2$ & $495 \pm 2$ \\
900A & $3,2 \pm 0,5$ & $20,5 \pm 2,5$ & $29 \pm 1$ & $39 \pm 2$ & $30,5 \pm 2,4$ & $162 \pm 2$ \\
1000A & $32 \pm 2$ & $21,6 \pm 3,8$ & $76 \pm 2$ & $54,5 \pm 5,4$ & $102 \pm 3$ & $889 \pm 3$ \\
1100A & $30 \pm 1$ & $31 \pm 2$ & $51 \pm 1$ & $43,6 \pm 2,2$ & $98,9 \pm 2,5$ & $692 \pm 3$ \\
1200A & $11,1 \pm 0,7$ & $24,5 \pm 5,2$ & $37 \pm 1$ & $39 \pm 3$ & $54,9 \pm 0,4$ & $519 \pm 3$ \\
2200A & $5,6 \pm 1,0$ & $26 \pm 3$ & $51 \pm 2$ & $45,4 \pm 3,4$ & $67,8 \pm 1,6$ & $366 \pm 1$ \\
3000A & $<2$ & $20,6 \pm 2,2$ & $49,8 \pm 3,4$ & $52 \pm 4$ & $36,9 \pm 1,5$ & $51 \pm 1$ \\
200B & $<2$ & $<3$ & $13 \pm 1$ & $44 \pm 3$ & $80,2 \pm 2,0$ & $71 \pm 2$ \\
300B & $6,8 \pm 0,4$ & $27,6 \pm 2,7$ & $26 \pm 2$ & $41 \pm 2$ & $31 \pm 1$ & $285,1 \pm 2,5$ \\
400B & $3,2 \pm 0,5$ & $10,4 \pm 1,1$ & $28,7 \pm 0,9$ & $48,4 \pm 3,6$ & $28,8 \pm 3,0$ & $218,1 \pm 2,8$ \\
500B & $10,4 \pm 1,9$ & $19 \pm 1$ & $35,5 \pm 1,0$ & $42,2 \pm 0,7$ & $40 \pm 2$ & $501 \pm 3$ \\
600B & $25,0 \pm 1,4$ & $30,2 \pm 4,8$ & $34,4 \pm 1,4$ & $39,1 \pm 2,6$ & $55,3 \pm 1,4$ & $514 \pm 2$ \\
700B & $11,3 \pm 0,9$ & $27,8 \pm 0,6$ & $29,5 \pm 1,9$ & $32,8 \pm 2,3$ & $38,2 \pm 1,7$ & $410 \pm 3$ \\
800B & $5,3 \pm 2,2$ & $16,2 \pm 1,3$ & $15,8 \pm 0,9$ & $31 \pm 3$ & $33,8 \pm 0,6$ & $116 \pm 3$ \\
900B & $41,0 \pm 4,2$ & $36,6 \pm 2,5$ & $33 \pm 1$ & $36,5 \pm 1,3$ & $81 \pm 2$ & $553 \pm 2$ \\
1000B & $4,5 \pm 0,7$ & $7,9 \pm 3,1$ & $56,7 \pm 2,2$ & $56,7 \pm 3,4$ & $95,2 \pm 1,3$ & $278 \pm 6$ \\
1100B & $8,5 \pm 0,2$ & $25 \pm 2$ & $28,0 \pm 0,9$ & $37,3 \pm 2,2$ & $53,3 \pm 2,3$ & $326 \pm 2$ \\
1200B & $1,01 \pm 0,55$ & $6,8 \pm 1,7$ & $14,3 \pm 2,1$ & $34 \pm 2$ & $21,9 \pm 1,7$ & $122 \pm 1$ \\
2200B & $4,3 \pm 0,2$ & $12,5 \pm 0,2$ & $26,0 \pm 0,8$ & $42,2 \pm 1,5$ & $46,1 \pm 1,3$ & $104 \pm 1$ \\
3000B & $<2$ & $22,9 \pm 1,4$ & $18,6 \pm 0,3$ & $38,5 \pm 2,5$ & $30,3 \pm 1,1$ & $20 \pm 1$ \\
\hline
\end{tabular}




\title{
GLOSSÁRIO
}

\author{
Antrópico referente às ações dos homens \\ Concentração \\ biodisponível \\ concentração obtida por extração com EDTA \\ Concentração parcial concentração obtida por digestão com $\mathrm{HNO}_{3}$ \\ Concentração total concentração obtida por FRX \\ Concentração concentração obtida por extração com $\mathrm{Ca}\left(\mathrm{NO}_{3}\right)_{2}$ \\ trocável \\ Solo natural \\ solo com pouco impacto antrópico \\ Transect A \\ solos coletados na direção NW com profundidade de 0 a $25 \mathrm{~cm}$ \\ Transect B \\ solos coletados na direção NW com profundidade de 25 a $50 \mathrm{~cm}$ \\ Valor de alerta \\ indica a alteração da qualidade do solo natural com caráter \\ preventivo \\ Valor de intervenção \\ indica o limite de contaminação acima do qual existe risco \\ potencial à saúde humana \\ Valor nominal \\ valor adotado pelo governo holandês \\ Valor de referência indica o limite de qualidade para um solo considerado limpo
}




\section{REFERÊNCIAS BIBLIOGRÁFICAS}

1 AGBENIN, J.O.; OLOJO, L.A. Competitive adsorption of copper and zinc by a $\mathrm{Bt}$ horizon of a savanna Alfisol as affected by $\mathrm{pH}$ and selective removal of hydrous oxides and organic matter. Geoderma, v. 119, p. 85-95, 2004.

2 AGVISELABS. Disponível em: <http://www.agviselabs.com>. Acesso em: 31 ago. 2005.

3 ALLEN, H.E.; CHEN, Y.T.; LI, Y.; HUANG, C.P. Soil partition coefficients for Cd by column desorption and comparison to batch adsorption measurements.

Environ. Sci. Technol., v. 29, p. 1887-1891, 1995.

4 ALLOWAY, B.J. Heavy metals in soils. John Wiley \& Sons, Inc., New York, 1990.

5 ANDERSON, P.R.; CHRISTENSEN, T.H. Distribuition coefficients of Cd, Co, Ni, and Zn in soils. J. Soil Sci., v. 39, p. 15-22, 1988.

6 BAES, C.F.; SHARP, R.D.; SJOREEN, A.L.; SHOR, R.W. A review and analysis of parameters for assessing transport of environmentally released radionuclides through agriculture. Oak Ridge: ORNL, 1984. (ORNL-5786).

7 BASTA, N.; GRADWOHL, R. Estimation of $\mathrm{Cd}, \mathrm{Pb}$, and $\mathrm{Zn}$ bioavailability in smelter-contaminated soils by a sequential extraction procedure. J. Soil Contam., v. 9, n. 2, p. 149-164, 2000.

8 BERG, R. van den; ROELS, J.M. Risk assessment to man and the environment in case of exposure to soil contamination. Integration of different aspects. Netherlands: RIVM, 1991. (report 725201013).

9 BERG, R. van den. Human exposure to soil contamination a qualitative and quantitative analices towards proposals for human toxicological intervention values. Netherlands: RIVM, 1994. (report 725201011).

10 BERGE, W. Ten. SOILRISK. Human exposure assessment to soil contaminants. Gelen: DSM, 1990. (DSM 1527/90).

11 BLUME, H.P. Handbuch des Bodenschutzes., Landsberg: Auflage, 1992.

12 BRADY, N.C.; BUCKMAN, H.O. Natureza e propriedades do solo. $7^{\mathrm{a}}$ ed., Livraria Freitas Bastos S.A.: São Paulo, 1989. 
13 BROUWERE, K.; SMOLDERS, E.; MERCKX, R. Soil properties affecting solidliquid distribution of As (V) in soils. Eur. J. Soil. Sci., v. 55, p. 165-173, 2004.

14 BRUN, L.A.; MAILLET, J.; RICHARTE, J.; HERRMANN, P.; REMY, J.C. Relationships between extractable copper, soil properties and copper uptake by wild plants in vineyard soils. Environ. Pollut., v.102, p. 151-161, 1998.

15 BRUN, L.A.; MAILLET, J.; HINSINGER, P.; PÉPIN, M. Evaluation of copper availability to plants in copper-contaminated vineyard soils. Environ. Pollut., vol.111, p. 293-302, 2001.

16 BUCHTER, B.; DAVIDOFF, B.; AMACHER, M.C.; HINZ, C.; ISKANDAR, I.K.; SELIM, H.M. Correlation of Freundlich $\mathrm{Kd}$ and $\mathrm{n}$ retention parameters with soils and elements. Soil Sci., v. 148, n. 5, p. 370-379, 1989.

17 BUND-LÄNDER-ARBEITSGEMEINSCHAFT BODENSCHUTZ - LABO Disponível em: <http://www.labo-deutschland.de/LABO-HGW-Text.pdf>. Acesso em: 27 out. 2004.

18 CAMARGO, I.M.C.; HAMA, P.; COTRIN, M.B.; FIGUEIREDO F, P.M.; FLUES, M. Avaliação da contaminação biodisponível de metais no solo sob influência da atividade de uma termoelétrica a carvão. In: VIII CONGRESSO BRASILEIRO DE GEOQUÍMICA, 21 a 26 de outubro, 2001, Curitiba, PR.

19 CARLON, C.; NORBIATO, M.; CRITTO, A.; MARCOMINI, A. Risk analysis applied to a contaminated industrial site: determination of risk based remedial targets. Ann. Chim., v. 90, p. 349-358, 2000.

20 CELARDIN, F. Semi-empirical correlations between so-called mobilizable and mobile concentrations of heavy metals in soils. Commun. Soil Sci. Plant Anal., v. 30, n. 5-6, p. 843-854,1999.

21 CHANG, C.M.; WANG, M.K.; CHANG, T.W.; LIN, C.; CHEN, Y.R. Transport modeling of copper and cadmium with linear and nonlinear retardation factors. Chemosphere, v. 43, p. 1133-1139, 2001.

22 COMPANHIA DE TECNOLOGIA DE SANEAMENTO AMBIENTAL Uso das águas subterrâneas para abastecimento público no Estado de São Paulo. São Paulo: CETESB, 1997.

23 COMPANHIA DE TECNOLOGIA DE SANEAMENTO AMBIENTAL Relatório de estabelecimento de valores orientadores para solos e águas subterrâneas no Estado de São Paulo. São Paulo: CETESB, 2001. (R321). 
24 CONDER, J.M.; LANNO, R.P.; BASTA, N.T. Assessment of metal availability in smelter soil using earthworms and chemical extractions. J. Environ. Qual., v. 30, p. 1231-1237, 2001.

25 DEGRYSE, F.; BROOS, K.; SMOLDERS, E.; MERCKX. R. Soil solution concentration of $\mathrm{Cd}$ and $\mathrm{Zn}$ can be predicted with a $\mathrm{CaCl}_{2}$ soil extract. Eur. J. Soil Sci., v. 54, p. 149-157, 2003.

26 DIAS, C.L.; CASARINI, D.C.P. Gerenciamento da qualidade de solos e águas subterrâneas. São Paulo: CETESB, 1996. (Relatório técnico de viagem à Holanda).

27 DUMAT, C.; CHIQUET, A.; GOODDY, D.; AUBRY, E.; MORIN, G.; JUILLOT, F.; BENEDETTI, M.F. Metal ion geochemistry in smelter impacted soil and soil solutions. Bull. Soc. Geol. France, v. 172, n. 5, p. 539-548, 2001.

28 DZOMBAK, D.A.; MOREL, F.M.M., 1990. Surface complexation modeling: hydrous ferric oxide. John Wiley \& Sons, Inc., New York. In: JANSSEN, R.P.T.; PEIJNENBURG, W.J.G.M.; POSTHUMA, L.; VAN DEN HOOP, M.A.G.T., 1997. Equilibrium partitioning of heavy metals in dutch field soils. I Relationship between metal partition coefficients and soil characteristics. Environ. Toxicol. Chem., v. 16, n. 12, p. 2470-2478.

29 ECHEVERRÍA, J.C.; MORERA, M.T.; MAZKIARÁN, C.; GARRIDO, J.J. Competitive sorption of heavy metal by soils. Isotherms and fractional factorial experiments. Environ. Pollut., v. 101, p. 275-284, 1998.

30 ELZINGA, E.J.; VAN GRINSVEN, J.J.M.; SWARTJES, F.A. General purpose Freundlich isotherms for cadmium, copper and zinc in soils. Eur. J. Soil Sci., v. 50, n. 139-149, 1999.

31 EMPRESA BRASILEIRA DE AGROPECUÁRIA, EMBRAPA. Manual de métodos de análise de solo. Centro Nacional de Pesquisas de Solos, Rio de Janeiro, 1997. $2^{a}$. ed., $212 \mathrm{p}$.

32 ENVIRONMENTAL PROTECTION AGENCY Soil Screening Guidance: Technical Background Document. Washington: EPA, 1996 (EPA/540/R95/128).

33 ENVIRONMENTAL PROTECTION AGENCY Understanding variation in partition coefficients, $K d$, values: The $K d$ model, methods of measurements, and application of chemical reactions codes. Washington: EPA, 1999a. (EPA 402-R-99-004A). in surface water, soil and waste. Washington: EPA, 1999b. (draft). 
35 ENVIRONMENTAL PROTECTION AGENCY - EPA. Disponível em: $<$ http://www.epa.gov/SW-846/pdfs/3051.pdf>. Acesso em: 6 jan. 2003.

36 EUROPEAN CHEMICAL INDUSTRY ECOLOGY AND TOXICOLOGY CENTRE. Hazard assessment of chemical contaminants in soil. Bélgica: ECETOC, 1990. (Technical report 40).

37 FAQUIN, V. Nutrição mineral de plantas. Lavras, M.G.: FAEPE da Universidade Federal de Lavras, 1997.

38 FERREIRA, M.M.; JUNIOR, M.S.D. Física do solo. UFLA/FAEPE, Lavras, 1999.

39 FLUES, M.; MORAES, V.; MAZZILI, B.P. The influence of a coal-fired plant activity on the radionuclides concentration in soil (Brazil). J. Environ.

Radioact., v. 63, n. 3, p. 285-294, 2002a.

40 FLUES, M; HAMA, P.; LEMES, M.J.L.; DANTAS, E.S.K.; FORNARO, A. Evaluation of rain water acidity of a rural region due to coal-fired plant in Brazil. Atmos. Environ., v. 36, p. 2397-2404, 2002b.

41 FLUES, M; HAMA, P; FORNARO, A. Avaliação do nível da vulnerabilidade do solo devido à presença de termelétrica a carvão (Figueira, PR - Brasil). Quim. Nova, v. 26, n. 4, p. 479-483, 2003.

42 FONTES, M.P.F. Publicação eletrônica [mensagem pessoal]. Mensagem recebida por<mpfontes@ufv.br> em 6 fev. 2002.

43 GAO, S.; WALKER, W.J.; DAHLGREN, R.A.; BOLD, J. Simultaneous sorption of $\mathrm{Cd}, \mathrm{Cu}, \mathrm{Ni}, \mathrm{Zn}, \mathrm{Pb}$ and $\mathrm{Cr}$ on soils treated with sewages sludge supernatant. Water, Air, Soil Pollut., v. 93, p. 331-345, 1997.

44 GLOBEL, B.; ANDRES, C. Investigations on fly-ash soil samples in the environment of a coal-fired power-plant. Sci. Total Environ., v. 45, p. 63-67, 1985.

45 GOMES, P.C.; FONTES, M.P.F.; SILVA, A.G.; MENDONÇA, E.S.; NETTO, A.R. Selectivity sequence and competitive adsorption of heavy metals by Brazilian soils. Soil Sci. Soc. Am. J., v. 65, p. 1115-1121, 2001.

46 GOODDY, D.C.; SHAND, P.; KINNIBURGH, D.G.; VAN RIEMSKIJK, W.H. Field-based partition coefficients for trace elements in soil solutions. Eur. $J$. Soil Sci., v. 46, p. 265-285, 1995. 
47 GUILHERME, L.R.G. Publicação eletrônica [mensagem pessoal]. Mensagem recebida por <quilherm@ufla.br> em 6 fev. 2002.

48 GUPTA, S.K.; ATEN, C. Comparison and evaluation of extraction media and their suitability in a simple model to predict the biological relevance of heavy metal concentrations in contaminated soils. Intern. J. Environ. Anal. Chem., v. 51, p. 25-46, 1993.

49 HAMA, P. Estudo da influência da chuva ácida na concentração de alumínio em solos próximos a uma termoelétrica a carvão. 2001. Dissertação (Mestrado) - Instituto de Pesquisas Energéticas e Nucleares, São Paulo.

50 HASSAN, S.M.; GARRISON, A.W. Distribution of chromium species between soil and porewater. Chem. Speciation Bioavailability, v. 8, n. 3-4, p. 85-103, 1996.

51 HEIL, D.; HANSON, A.; SAMANI, Z. The competitive binding of lead by EDTA in soils and implications for heap leaching remediation. Radioact. Waste Manage. Environ. Restor., v. 20, n. 2-3, p. 111-127, 1996.

52 HEIL, D.M.; SAMANI, Z.; HANSON, A.T.; RUDD, B. The competitive binding of lead by EDTA in soils and implications for heap leaching remediation. Water, Air, Soil Pollut., v. 113, n. 1-4, p. 77-95, 1999.

53 HOODA, P.S.; McNULTY, D.; ALLOWAY, B.J.; AITKEN, M.N. Plant availability of heavy metals in soils previously amended with heavy application of sewage sludge. J. Sci. Food Agric., vol. 73, p. 446-454, 1997.

54 HORNBURG, V. Untersuchungen zur mobilität und verfügbarkeit von cadmium, zink, mangan, blei und kupfer in böden. 1991. Tese (Doutorado) - Institut für Bodenkunde, Bonn.

55 IBGE - Instituto Brasileiro de Geografia e Estatística. Disponível em: <http//www.ibge.gov.br>. Acesso em: 5 set. 2005.

56 JANSSEN, R.P.T.; PRETORIUS, P.J.; PEIJNENBURG, W.G.J.M.; Van den HOOP, M.A.G.T. Determination of field-based partition coefficients for heavy metals in Dutch soils and the relationships of these coefficients with soil characteristics. Bilthoven: RIVM, 1996. (report 719101023).

57 JANSSEN, R.P.T.; PEIJNENBURG, W.J.G.M.; POSTHUMA, L.; VAN DEN HOOP, M.A.G.T. Equilibrium partitioning of heavy metals in dutch field soils. I Relationship between metal partition coefficients and soil characteristics. Environ. Toxicol. Chem., v. 16, n. 12, p. 2470-2478, 1997. 
58 JOPONY, M.; YOUNG, S.D. The solid-solution equilibria of lead and cadmium in polluted soils. Eur. J. Soil Sci., v. 45, p. 59-70, 1994.

59 JURY, W.A.; SPENCE, W.F.; FARMER, W.J. Behaviour assessment model for trace organics in soil: I. Model description. J. Environ. Qual., n. 12, p. 558564, 1983.

60 KABATA-PENDIAS, A.; PENDIAS, H. Trace elements in soils and plants. Boca Raton, Florida: CRC Press, 1984.

61 KAMINSKI, M.D.; LANDSBERGER, S. Heavy metals in urban soils of East St. Louis, IL, part I: Total concentration of heavy metals in soils. J. Air Waste Manage. Assoc., v. 50, n. 9, p. 1667-1679, 2000.

62 KAPICKA, A.; PETROVSKY, E.; USTJAK, S.; MACHACKOVA, K. Proxy mapping of fly-ash pollution of soils around a coal-burning power plant: a case study in the Czech Republic. J. Geochem. Explor., v. 66, p. 291-297, 1999.

63 KRETZSCHMAR, R. Publicação eletrônica [mensagem pessoal]. Mensagem recebida por <kretzschmar@ito.umnw.ethz.ch> em 6 fev. 2002.

64 KRISHNAMURTI, G.S.R.; NAIDU, R. Solid-solution speciation and phytoavailability of copper and zinc in soils. Environ. Sci. Technol., v. 36, p. 2645-2651, 2002.

65 LACHANCE, G. R. \& CLAISSE, F. Quantitative x-ray Fluorescence Analysis. Theory and Application. John Wiley, London, 1995.

66 LEBOURG, A.; STERCKEMAN, T.; CIESIELSKI, H.; PROIX, N. Trace metal speciation in three unbuffered salt solutions used to assess their bioavailability in soil. J. Environ. Qual., v. 27, p. 584-590, 1998.

67 LEE, S.Z.; ALLEN, H.E.; HUANG, C.P.; SPARKS, D.L.; SANDERS, P.F.; PEIJNENBURG, W.J.G.M. Predicting soil-water partition coefficient for cadmium. Environ. Sci. Technol., v. 30, p. 3418-3424, 1996.

68 LEE, S.Z.; CHANG, L.; YANG, H.H.; CHEN, C.M.; LIU, M.C. Adsorption characteristics of lead onto soils. J. Hazard. Mater. A, v. 63, p. 37-49, 1998.

69 LEGOUX, Y.; BLAIN, G.; GUILLAUMONT, R.; OUZOUNIAN, G.; BRILLARD, L.; HUSSONNOIS, M. Kd measurements of activation, fission and heavy elements in water/solid phase systems. Radiochim. Acta, v. 58/59, p. 211218, 1992. 
70 LIM, T.T.; TAY, J.H.; WANG, J.Y. Chelating-agent-enhanced heavy metal extraction from a contaminated acidic soil. J. Environ. Eng.-ASCE, v. 130, n. 1, p. 59-66, 2004.

71 LIM T.T.; CHUI, P.C.; GOH, K.H. Process evaluation for optimization of EDTA use and recovery for heavy metal removal from a contaminated soil.

Chemosphere, v. 58, n. 8, p. 1031-1040, 2005.

72 LIN, C.; SHACAHR, Y.; BANIN, A. Heavy metal retention and partitioning in a large-scale soil-aquifer treatment (SAT) system used for wastewater reclamation. Chemosphere, v. 57, p. 1047-1058, 2004.

73 LINDERS, J.B.H.J. Risicobeoordelino voor de mens bij blootstelling aan stoffen. Uitgangspunten en veronderstellingen. Bilthoven: RIVM, 1990. (rapport 7252 01003).

74 MARSCHNER, B. Publicação eletrônica [mensagem pessoal]. Mensagem recebida por<marschner@geographie.ruhr-uni-bocum.de> em 6 fev. 2002.

75 McBRIDE, M.B. Environ. Chem. Soils. OXFORD UNIVERSITY PRESS, New York, 1994.

76 McBRIDE, M.B.; MARTINEZ, C.E.; TOPP, E.; EVANS, L. Trace metal solubility and speciation in a calcareous soil 18 years after no-till sludge application. Soil Sci., v. 165, n. 8, p. 646-656, 2000.

77 McGRATH, D. Application of single and sequencial extraction procedures to polluted and unpolluted soils. Sci. Total Environ., v. 178, p. 37-44, 1996.

78 MEHRA, A.; FARAGO, M.E.; BANERJEE, D.K. Impact of fly ash from coal-fired power stations in Delhi, with particular reference to metal contamination.

Environ. Monit. Assess., v. 50, n. 1, p. 15-35, 1998.

79 MENCH, M.; VANGRONSVELD, J; DIDIER, V.; CLIJSTERS, H. Environ. Pollut., v. 86, n. 3, p. 279-286, 1994.

80 MESQUITA, M.E.; SILVA, J.M.V.; BRANCO, M.A.C.; SEQUEIRA, E.M. Copper and zinc competitive adsorption: desorption in calcareous soils. Arid Soil Res. Rehabil., v. 14, p. 27-41, 2000.

81 MORAES, V.R.; FLUES, M.; MAZZILLI, B.P. Avaliação da contaminação por radionuclídeos dos solos próximos a uma termoelétrica a carvão. In: V ENAN, 15 a 20 de outubro, 2000, Rio de Janeiro, RJ. 
82 MORRONE, N.; DAEMON, R.F. Jazida de urânio de Figueira. In: Principais Depósitos Minerais do Brasil. Departamento Nacional da Produção Mineral (DNPM), p. 133-142, 1985.

83 OTTE, J.G.; RÖMKENS, P.F.A.M.; TIKTAK, A.; VRIES, W. Partitie relaties poor $\mathrm{zware}$ metalen $(\mathrm{Cd}, \mathrm{Cu}, \mathrm{Pb}, \mathrm{Zn})$ voor diffuus verontreinigde Nederlandse bodems (in Dutch). Wageningen, 2000. (PGBO 30).

84 OTTE, P.F.; LIJZEN, J.P.A.; OTTE, J.G.; SWARTJES, F.A.; VERSLUIJS, C.W. Evaluation and revision of the $C$-Soil parameter set. Bilthoven: RIVM, 2001. (report 711701021).

85 PINAMONTI, F.; NICOLINI, G.;DALPIAZ, A.; STRINGARI, G; ZORZI, G. Compost use in viticulture: Effect on heavy metal levels in soil and plant. Commun. Soil Sci. Plant Anal., v. 30, n. 9-10, p. 1531-1549, 1999.

86 PODLESÁKOVÁ, E.; NEMECEK, J.; VÁCHA, R. Mobility and bioavailability of trace elements in soils. In: ISKANDAR, I.K.; KIRKHAM Trace Elements in Soil: Bioavailability, Flux, and Transfer. Boca Raton, Florida: CRC Press: 2000.

87 PRADO, H. Solos do Brasil. Piracicaba, SP, 2003.

88 QUINÁGLIA, G.A. Estabelecimento de um protocolo analítico de preparação de amostras de solos para determinação de metais e sua aplicação em um estudo de caso. 2001. Dissertação (Mestrado). Faculdade de Saúde Pública, São Paulo.

89 RHOADES, J.D. Methods of soil analysis. Madison, A.S.A, 1982. part 2, Cation Exchange Capacity. p. 149-157.

90 ROMKENS, P.F.A.M.; SALOMONS, W. Cd, Cu and Zn solubility in arable and forest soils: consequences of land use changes for metal mobility and risk assessment. Soil Sci., v. 163, n. 11, p. 859-871, 1998.

91 SAGER, M. Current interlaboratory precision of exchangeable soil fraction measurements. Accred. Qual. Assur., v. 4, p. 299-306, 1999.

92 SANCHEZ, J.C.D. Emissão de elementos-traços provenientes da combustão do carvão em caldeira de grande porte. 1987. Dissertação (Mestrado). Universidade Federal do Rio Grande do Sul, Porto Alegre.

93 SASTRE, J.; HERNÁNDEZ, E.; RODRÍGUEZ, R.; ALCOBÉ, X.; VIDAL, M.; RAURET, G. Use of sorption and extraction tests to predict the dynamics of the 
interation of trace elements in agricultural soils contaminated by a mine tailing accident. Sci. Total Environ., v. 329, p. 261-281, 2004.

94 SATO, K.; SADA, K. Effects of emissions from a coal-fired power plant on surface soil trace-element concentrations. Atmos. Environ. Part A, v. 26, n. 2 , p. $325-331,1992$.

95 SAUVE, S.; HENDERSHOT, W.; ALLEN, H.E. Solid-solution partitioning of metals in contaminated soils: dependence on $\mathrm{pH}$, total metal burden, and organic matter. Environ. Sci. Technol., v. 34, n. 7, p. 1125-1131, 2000a.

96 SAUVE, S.; NORVELL, W.A.; MCBRIDE, M.; HENDERSHOT, W. Speciation and complexation of cadmium in extracted soil solutions. Environ. Sci. Technol., v. 34, p. 291-296, 2000b.

97 SCHULZE, D.; KRÜGER, A.; KUPSCH, H.; SEGEBADE, C.; GAWLIK, D. Enrichment and distribuition of elements in flood-plain soils of the Bitterfeld industrial area - studied by neutron activation analysis. Sci. Total Environ., v. 206, p. 227-248, 1997.

98 SEUNTJENS, P. Field-scale cadmium transport in a heterogeneous layered soil. Water, Air, Soil Pollut., v. 140, p. 401-423, 2002.

99 SINGH, S.P.; TACK, F.M.G.; VERLOO, M.G. Extractability and bioavailability of heavy metals in surface soils derived from dredged sediments. Chem. Speciation Bioavailability, v. 8, n. 3-4, p. 105-110, 1996.

101 SOARES, M.R. Coeficiente de distribuição $\left(K_{D}\right)$ de metais pesados em solos do estado de São Paulo. 2004. Tese (Doutorado). Escola Superior de Agricultura Luiz Queiroz - USP, Piracicaba, São Paulo.

102 SPARKS, D.L. Environmental Soil Chemistry. Academic Press, Califórnia, 1995.

103 SPOSITO, G. The chemistry of soils. Oxford University Press, New York, 1989.

104 STAUNTON, S. Publicação eletrônica [mensagem pessoal]. Mensagem recebida por <staunton@ensam.inra.fr> em 6 fev. 2002.

105 STAUNTON, S.; BARTHES, M.; CESSAC, E.L.; PINEL, F. Effect of sterilization and experimental conditions on the isotopic exchange of nickel in two contrasting soils. Eur. J. Soil Sci., v. 53, p. 655-661, 2002. 
106 STAUNTON, S. Sensitivity analysis of the distribution coefficient, Kd, of nickel with changing soil chemical properties. Geoderma, v. 122, p. 281-290, 2004.

107 SUN, B.; ZHAO, F.J.; LOMBI, E.; McGRATH, S.P. Leaching of heavy metals from contaminated soils using EDTA. Environ. Pollut., v. 113, n. 2, p. 111120, 2001.

108 SWARTJES, F.A.; BERG, R. van den. Remediation of contaminated soil and groundwater: proposals for criteria and priority setting. In: WORKSHOP ON CONTAMINATED SOIL, Out., 1993, Stocholm, Sweden.

109 TAWINTEUNG, N.; PARKPIAN, P.; DELAUNE, R.D.; JUQSUJINDA, A. Evaluation of extraction procedures for removing lead from contaminated soil. J. Environ. Sci. Health part A, v. 40, n. 2, p. 385-407, 2005.

110 UNITED STATE DEPARTMENT OF AGRICULTURE SOIL STAFF - USDA Soil Taxonomy: a Basic System of Soil Classification for Making and Interpreting Soil Surveys. Washington, 1975, 754p.

111 URE, A.M.; QUEVAUVILLER, P.H.; MUNTAU, H.; GRIEPINK, B. Speciation of heavy metals in soils and sediments. An account of the improvement and harmonization of extraction techniques undertaken under the auspices of the european communities. Inter. J. Environ. Anal. Chem., v. 51, p. 135-151, 1993.

112 URE, A.M. Single extraction schemes for soil analysis and related applications. Sci. Total Environ., v. 178, p. 3-10, 1996.

113 VEERESH, H.; TRIPATHY, S.; CHAUDHURI, D.; HART, B.R.; POWELL, M.A. Competitive adsorption behavior of selected heavy metals in three soil types of India amended with fly ash and sewage sludge. Environ. Geol., v. 44, p. 363-370, 2003a.

114 VEERESH, H.; TRIPATHY, S.; CHAUDHURI, D.; HART, B.R.; POWELL, M.A. Sorption and distribution of adsorbed metals in three soils of India. Appl. Geochem., v. 18, p. 1723-1731, 2003b.

115 WASAY, S.A.; BARRINGTON, S.; TOKUNAGA, S. Retention form of heavy metals in three polluted soils. J. Soil Contam., v. 7, n. 1, p. 103-119, 1998.

116 WEISSENHORN, I.; LEYVAL, C.; BERTHELIN, J. Bioavailability of heavymetals and abundance of arbuscular mycorrhiza in a soil polluted by atmospheric deposition from a smelter. Biol. Fertil. Soils, v. 19, n. 1, p. $22-$ 28, 1995. 
117 WHELLER, B. Chemical analysis of ferrous base allolys utilizing the fundamental parameters technique assisted by standards of similar and dissimilar materials. Rigaku J., v. 15, p. 28-40, 1998.

118 YONG, R.N.; MULLIGAN, C.N. Natural attenuation of contaminants in soils. CRC Press, Boca Raton, Florida, 2003.

119 ZELEWSKI, L.M.; KRABBENHOFT, D.P.; ARMSTRONG, D.E. Trace metal concentrations in shallow ground water. Ground Water, v. 39, n. 4, p. 485491, 2001. 